National Library

ol Canada

Acquisitions and

Bibliographic Services Branch

395 Wellington Sitee!

Otrawa. Ontaro

KiA ONA
Bibliotheque nationale

du Canada

Direction des acquisitions el

des services bibliographiques

395, ne Wellingion

Onawa (Onlaro)
NOTICE

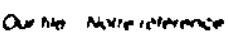

AVIS
The quality of this microform is heavily dependent upon the quality of the original thesis subrinitted for microfilming. Every effort has been made to ensure the highest quality of reproduction possible.

If pages are missing, contact the university which granted the degree.

Some pages may have indistinct print especially if the original pages were typed with a poor typewriter ribbon or if the university sent us an inferior photocopy.

Reproduction in full or in part of this microform is governed by the Canadian Copyright Act, R.S.C. 1970, C. C-30, and subsequent amendments.
La qualité de cette microforme dépend grandement de la qualité de la thèse soumise au microfilmage. Nous avons tout fait pour assurer une qualité supérieure de reproduction.

S'il manque des pages, veuillez communiquer avec l'université qui a conféré le grade.

La qualité d'impression de certaines pages peut laisser à désirer, surtout si les pages originales ont été dactylographiées à l'aide d'un ruban usé ou si l'université nous a fait parvenir une photocopie de qualité inférieure.

La reproduction, même partielle, de cette microforme est soumise à la Loi canadienne sur le droit d'auteur, SRC 1970, c. C-30, et ses ameridements subséquents. 


\title{
COMBINED CONVECTIVE AND MICROWAVE DRYING OF GRAPES
}

\author{
A Thesis submitted to \\ The Faculty of Graduate Studies and Research of \\ McGill University
}

by

Tarikere N. Tulasidas

In Partial Fulfilment of the

Requirements for the Degree of

Doctor of Philosophy

Department of Agricultural Engineering

Macdonald Campus of McGill University

Ste-Anne-de Bellevue, H9X 3V9

Québec, Canada

() October 1994 
National Library

of Canada

Acquisitions and

Bibliographic Services Branch

395 Wellington Street

Orawa. Ontano

KIA ONA
Sibliotheque nationale

du Canada

Direction des acquisitions et

des services bibliographiques

395. ne Wellington

Onzwa (Ontano)

KIA ONA

tow the bovereterence

THE AUTHOR HAS GRANTED AN IRREVOCABLE NON-EXCLUSIVE LICENCE ALLOWING THE NATIONAL LIBRARY OF CANADA TO

REPRODUCE, LOAN, DISTRIBUTE OR SELL COPIES OF HIS/HER THESIS BY ANY MEANS AND IN ANY FORM OR FORMAT, MAKING THIS THESIS AVAILABLE TO INTERESTED PERSONS.
L'AUTEUR A ACCORDE UNE LICENCE IRREVOCABLE ET NON EXCLUSIVE PERMETTANT A LA BIBLIOTHEQUE NATIONALE IUU CANADA DE REPRODUIRE, PRETER, DISTRIBUER OU VENDRE DES COPIES DE SA THESE DE QUELQUE MANIERE ET SOUS QUEIQUE FORME QUE CE SOIT POUR METTRE DES EXEMPLAIRES DE CETTE THESE A LA DISPOSITION DES PERSONNE INTERESSEES.
THE AUTHOR RETANS OWNERSHIP OF THE COPYRIGHT IN HIS/HER THESIS. NEITHIER THE THESIS NOR SUBSTANTIAI EXTRACTS FROM IT MAY BE PRINTED OR OTHERWISE REPRODUCED WITHOUT HIS/HER PERMISSION.
L'AUTEUR CONSERVE LA PROPRIETE DU DROIT D'AUTEUR QUI PROTEGE SA THESE. NI LA THESE NI DES EXTRAITS SUBSTANTIELS DE CELLECI NE DOIVENT ETRE IMPRIMES OU AUTREMENT REPRODUITS SANS SON AUTORISATION. 


\section{Combined convective and microwave drying of grapes}

The potential of dielectric heating with microwaves at $2450 \mathrm{MHz}$ for drying grapes into raisins was studied. Feasibility studies in a conventional microwave oven were successful. A new microwave drying system equipped with specialized instrumentation and data acquisition components and permitting full control of microwave power levels and duration of application was then developed and used for detailed experimental work.

A factorial experiment aimed at determining the relationships between drying kinetics and operating parameters was performed. The drying runs included quality evaluation by both objective and subjective tests. A number of experiments designed to determine the relationships between grape physical and electrical properties and grape moisture content and temperature during drying were executed. These relationships were then used in the development of a model of microwave drying based on Fick's diffusion equation. The model was solved using the method of lines and model simulations were validated against the experimental data.

It was found that when the grapes were dipped in surfactants, as is common practice in the raisin industry, microwave drying was not only faster than convective drying but also had a much lower specific energy requirement. However, it was also possible to obtain raisins of adequate quality without dippings. Good quality light coloured raisins were obtained without sulphur dioxide fumigation. Thus, microwave drying has potential in reducing both the quantity of chemicals entering at this point in the food chain and the energy consumed for food preservation. 
The shrinkage and density of grapes were found to be linearly related to moisture content; initial size and method of drying had no influence. The dielectric constant and loss factor of grapes were measured and described by regression equations in terms of moisture content and temperature. For a given power density the electrical field strength was found to be linearly related to moisture content. All of the above relationships were used in the development of the microwave drying nodel.

Data simulated by the model fitted the kinetics data very well. The experimental data were also used to determine optimum ranges for the operating parameters with respect to quality constraints. 


\section{RÉSUMÉ}

Tarikere N. Tulasidas

Ph.D. (Agric. Eng.)

Production de raisins secs par séchage mixte micro-onde et air chaud

Les avantages du chauffage diélectrique à la fréquence micro-onde de $2450 \mathrm{MHz}$ ont été étudiés pour la production de raisins secs. Des études préliminaires, très concluantes ont d'abord été conduites à l'aide d'un microonde conventionnel. Les succès obtenus ont amené la conceptualisation et la construction d'un système automatisé de séchage au micro-onde fermettant le contrôle de la puissance et la durée de chaque traitement. Ce système a été utilisé pour les études ci-après mentionnées.

Une étude factorielle a été conduite dans le but de déterminer les relations existantes entre le bilan énergétique et les paramètres du procédé de séchage. La qualité d'un échantillon de chaque étude de séchage a été évaluée par différents tests autant subjectifs qu'objectifs. De plus, des expériences ont été conduites afin de déterminer les propriétés mécanique et électrique des raisins et leurs relations avec le taux d'humidité et la température durant le séchage. Une fois établies, ces relations ont permis le développement d'un mod̉̉e, basé sur la loi de Fick, qui résume le procédé de séchage micro-onde. Ce modèle a été résolu numériquement par la méthode des lignes, et les simulations ont été validées à l'aide des résultats expérimentaux.

Les résultats ont démontré que le séchage micro-onde de raisins traités avec un agent tensioactif, comme le veut la pratique industrielle, peut être plus rapide, et plus économe en terme de consommation d'énergie, que le séchage par convection forcée à air chaud. II est également possible d'obtenir des raisins secs de bonne qualité sans le traitement avec surfactant, et de couleur dorée sans la fumigation au dioxyde de souffre. Il est donc envisageable que le séchage au micro-onde puisse réduire l'utilisation de produits chimiques ainsi que la consommation énergétique lors de la production de raisins secs.

La perte de masse et de densité des raisins se trouvent être linéairement 
influencée par le taux d'humidité, et cependant non influencée par la grosseur initiale du raisin et la méthode de séchage. La permittivité diélectrique et l'angle de perte des raisins ont été mesurés et représentés par des régressions en fonction de l'humidité et de la température. Pour chaque puissance employée, une relation linéaire a été trouvée entre le champ électrique et le taux d'humidité. C'est à partir de toutes ces découvertes qu'un modèle fut développé pour le séchage micro-onde du raisin. Les simulations obtenues avec ce modèle rencontrent, de façon très satisfaisante, les résultats empiriques obtenus. 


\section{ACKNOWLEDGMENTS}

I am deeply indebted to Dr. G.S.V. Raghavan who gave me an opportunity to grow and prosper in my academic pursuits. I have benefited immensely under bis guidance and I always cherish his inspiration and encouragement. I express my deepest gratitude to Dr. Raghavan and to his family for their friendship and belp.

I am grateful to the members of my advisory committee, Dr. A.S. Mujumdar, Dept. of Chemical Engineering, Prof. H.S. Ramaswamy, Dept. of Food Science, Dr. E. Norris and Dr. S. F. Barrington, Department of Agricultural Engineering, for their advice and encouragement throughout the variors phases of this research project. Dr. Ramaswamy extended many of his laboratory facilities whenever I needed. I express my gratitude and sincere thanks to him and to his family for their help and friendship.

Dr. T. Kudra, Scientist, CANMET, made valuable contribution in the design and fabrication of the MW drying apparatus. I duly acknowledge his help and assistance and express my sincere thanks to him.

I duly acknowledge the help I received from Mr. Y. Gariepy, Research Associate, Department of Agricultural Engineering during the development of data acquisition system and the instrumentation work. His encouragement and assistance was of immense use and I am very grateful to him for the same.

I am indebted to Dr. C. Ratti, Post Doctoral Fellow, for introducing me to the "Numerical Techniques" and to the Gear software. My sincere thanks to Christina for her time and assistance; I express my gratitude for her help.

I would like to sincerely thank Mr. P. Alvo for his critiques and suggestions throughout the writing stages of this thesis. I am thankful to him for reading the manuscript and providing the editorial commerts. I am indebted for his help and value his friendship.

I thank Dr. R. Gérald, Scientist, Hydro Québec, for his co-operation during my work at Labortoies Technologies Electrical (LTEE), Shawanigan. I also thank Mr. Gonzalo Milet, Graduate student, Dept. of Agricultural Engineering who worked with me for some time at LTEE. I thank LTEE, Hydro Québec, for use of their research facility in the High Frequency Laboratory at Shawanigan. 
My heartfelt appreciation goes to Mr. Samson Sotocinal, a close friend and a colleague. I have benefitted greatly from him both in my personal and professional life. Also my thanks to Mr. R. Nattress for the help he provided me in his Electronics Lab. whenever needed. My sincere thanks to Mrs. Sandra Nagy and Mrs. Roberta Boyle for their help and encouragement.

I take this opportunity to thank Dr. R. Ramaiah, Professor and Head, Department of Agricultural Engineering, U.A.S., Bangalore for his encouragement. Many thanks to my friends Ms. Valerie Orsat, Dr. U.S. Shivhare and his family and Dr. Z. Alikhani and his family. I am grateful for the encouragement and support I received from my friends Mr. B. Ranganna, Mrs. Ratna Ranganna, Mr. Prabhanjan, Mr. Ramachandra, Mrs. Hema Ramachandra, Mr. S. Batagurki, Mrs. S. Batagurki, Mr. D. Ganeshmurthy, Dr. Subramanya, Dr. Javare Gowda, Mr. Ramakumar, Mr. Venkatachalapathy, Dr. M.P. Vaidehi, Dr. M. Chowdegowda, Mr. H. Eswarappa and Mr. T.M. Basavakumar. I am thankful for the encouragement of Mr. K.C. Krishnamurthy. My appreciation to Mr. Shayam Sabalani for his help. My thanks to Ms. C. Abbatemarco for her help while planning the sensory evaluation experiment.

I express my sincere gratitude to CIDA for providing me an opportunity to pursue my $\mathrm{Ph} . \mathrm{D}$ studies. I am greatly obliged for the $\mathrm{Ph} . \mathrm{D}$ fellowship I received from CIDA through BAMPHE project. I also received "Hydro Québec Major Award" for the years 1992-93 and 1993-94. I am grateful to Hydro Québec for this generosity. The funding received from NSERC and FCAR for this research project is duly ackmowiedged. I express my gratitude to the University of Agricultural Sciences, Bangalore, India for granting me the study leave and deputation for my Ph.D studies.

The sacrifice and support given by family is immeasurable. I would like to gratefully and humbly acknowledge the favour and blessings of my mother and the unfailing support of my whole family. I would like to ackmowledge the sacrifice made by my children who had to miss their home and parents for a long time during the course of this work. I thank my sons T.T. Niranjan and T.T. Dheeraj for their consideration, love and affection. My wife, Kamala Das cannot be thanked enough for her patience, understanding and assistance she gave me in all aspects of this dissertation. 


\section{CHAPTER I INTRODUCTION}

1.1 Background 1

1.2 Hypothesis 3

1.3 Objectives 4

\section{CHAPTER II REVIEW OF LITERATURE}

2.1 Quality Factors in Raisins 6

2.2 Methods of Grape Drying 8

1 Sun Drying 8

2 Solar Drying 8

3 Hot Air Drying 9

2.3 Drying Kinetics of Grapes/Raisins 11

1 Pretreatments and Grape Skin Resistance 11

2.4 Drying Models 13

1 Semitheoretical Models 14

2 Diffusion Models 16

3 Solution of the Diffusion Equation 17

4 Effective Diffusivity 20

2.5 Shrinkage 21

2.6 Summary of Hot Air Drying of Grapes 22

2.7 Microwave Heating and Drying 23

1 Dielectric Properties 24

1 Moisture Content 25

2 Temperature 25

2.8 Microwave Applicators $\quad 27$

1 Multimode Cavity Applicators $\quad 27$

2 Single Mode Applicators 28

2.9 Microwave Drying Studies on Agricultural Materials 29 
CHAPTER III PRELIMINARY STUDIES OF MICROWAVE DRIING OF GRAPES'

3.1 Introduction 31

3.2 Materials and Methods 32

3.3 Results and Discussion 36

1 Preliminary Drying Studies $\quad 36$

2 Effect of Pretreatments on MW drying 40

1 Interphase overall mass transfer coeff. 44

3 Washing and Holding Treatments 46

4 Empirical Model to Fit MW Drying Data 48

3.4 Summary 51

3.5 Connecting Statement to Chapter 4

CHAPTER IV DEVELOPMENT OF NEW MHCROWAVE DRYING SETUP

4.1 MW Drying Apparatus 53

4.2 Applicator (Cavity/Resonator) 55

4.3 Instrumentation, Measurements and Controls 59

4.4 Connecting Statement to Chapter $5 \quad 61$

CHAPTER V QUANTIFICATION OF GRAPE PROPERTIES

5.1 Shrinkage of Grapes During Drying 62

1 Materials and Methods for Shrinkage Studies $\quad 62$

2 Results and Discussion for Shrinkage Studies 63

1 Shrinkage in Convective Drying 63

2 Shrinkage in Combined Conv. \& MW Drying 64

5.2 Dielectric Properties of Grapes at $2450 \mathrm{MHz} \quad 67$

1 Materials and Methods for Dielectric Properties 67

2 Predictive Models for Dielectric Properties of Grapes 68

3 Results and Discussion on Dielectric Properties 69

5.3 Electric Field Strength 72

1 Background 72

2 Methodology for Determination of $\mathrm{E}_{\mathrm{rms}} \quad 73$

3 Results of $E_{\mathrm{rms}} \quad 74$ 
$\begin{array}{lll}5.4 & \text { Density } & 77\end{array}$

5.5 Specific Heat 77

5.6 Mass Transfer Coefficients 81

5.7 Connecting Statement to Chapter 6

CHAPTER VI MODELLING OF MICROWAVE DRYING OF GRAPES

6.1 Introduction

6.2 Physical Model, Model Formulation and Procedures

1 Mass Transfer Equation $\quad 85$

2 Energy Equation $\quad 88$

1 The Internal Heat Generation Term $\left(E_{1}\right) \quad 88$

2 The Convective Heat Transfer Term $\left(\mathrm{E}_{2}\right)$

3 The Evaporation Term $\left(E_{3}\right) \quad 89$

3 Effective Diffusivity Parameter 90

6.3 Numerical Procedure 91

1 Simulation 92

6.4 Model Validation Procedure 93

6.5 Discussion of Model Performance 94

6.6 Summary 96

\section{CHAPTER VII DRYING KINETICS OF GRAPES}

7.1 Introduction 99

7.2 Materials and Methods 100

1 Variety of Grapes and other Experimental Procedures 100

2 Convective Drying in the New Drying Apparatus 100

3 Microwave Drying in the New Drying Apparatus 101

1 Experimental Design 102

7.3 Results and Discussion 103

1 Convective Drying 103

1 Grapes without pre-treatment 103

2 Grapes with pre-treatment 104

2 MW Drying Studies 108

1 Effect of Air Temperature 108

2 Effect of MW Power Density 113

3 Effect of Air Velocity 119 
4 Simulation

CHAPTER VIII QUALITY ASPECTS OF MICROWAVE-DRIED GRAPES

8.1 Introduction 127

8.2 Materials and Methods 127

1 Quality Assessment - Objective Tests 129

1 Colour Measurements 129

2 Damage Counts 129

2 Quality Assessment - Subjective Tests 129

3 Data Analysis 130

8.3 Results and Discussion 131

1 Colour (ABYB) 133

2 Damage (DAMAGE) 134

8.4 Process Optimization 135

8.5 Energy Consumption 139

1 Specific Energy Consumption for Drying 139

1 Specific Energy Consumption in Conv. Drying 143

2 Specific Energy Consumption in MW Drying 143

2 Optimization of energy consumption in MW drying 144

$\begin{array}{lll}8.6 \text { Summary } & 147\end{array}$

\section{CHAPTER IX GENERAL DISCUSSIONS AND CONCLUSIONS}

9.1 Summary and Conclusions 148

9.2 Contribution to Knowledge 149

9.3 Recommendations for Further Studies 150

REFERENCES 152

APPENDICES 163

Appendix A 164

Appendix B 165

Appendix C 176 


\section{LIST OF FIGURES}

Figure page

3.1 Schen:atic diagram of the MW drying apparatus 33

3.2 Drying curves of grapes by different methods of drying 38

3.3 Drying rate curves of grapes by different methods of drying 38

3.4 MW drying curves of pretreated grapes at different 41 air temperatures

3.5 Effect of different pretreatments on MW drying of grapes 43

3.6 Effect of washing treatments on MW drying of grapes $\quad 47$

3.7 Comparison of Page's Eq. fitting with the observed MR in 50 grapes drying

4.1a Schematics of the MW drying apparatus

4.1b Photograph of the MW drying apparatus $\quad 54$

4.2 Sectional plan of the single mode applicator (drying chamber) 56 showing the inner details

4.3 Assembled view of the applicator $\quad 57$

4.4 Photograph of the applicator showing the inner details 57

4.5 Photograph showing the details of weighing mechanism 60

5.1 Volume reduction as a function of m.c. 66 in convective and MW drying of grapes

5.2 Variation of dielectric properties of grapes with m.c. 
5.3 Dielectric constant of grapes as a function of temperature at different m.c.

5.4 Dielectric loss factor of grapes as a function of temperature at different m.c.

5.5 Electric field strength of grapes as a function of m.c.

5.6 Density of grapes as a function of m.c.

5.7 Specific heat of grapes as a function of m.c. 80

6.1 General scheme of the numerical model 84

6.2 Predicted average m.c. of grapes by the numerical model 95 compared to experimental observations

6.3 Comparison of observed MR in MW kying of grapes with the MR predicted by the numerical model and the Page's Eq.

6.4 The relative error of approximation for experimental data represented by Page's Eq. compared with numerical model

7.1 Convective drying of grapes (no pretreatment) showing the three different zones of drying

7.2 Convective drying of grapes (pretreated) showing the three different zones of drying

7.3 Effective diffusivity in pretreated grapes as a function of m.c. at different air temperatures

7.4 Effective diffusivity in pretreated grapes as function of air temp. 107

7.5 Effect of air temperature on MW drying of grapes $\left(P=0.1 \mathrm{~W} / \mathrm{g}\right.$ and $V_{s}=1 \mathrm{~m} / \mathrm{s}$ )

7.6 Effect of air temperature on $\mathrm{MW}$ drying of grapes $\left(\mathrm{P}=0.1 \mathrm{~W} / \mathrm{g}\right.$ and $\left.\mathrm{V}_{\mathrm{g}}=2 \mathrm{~m} / \mathrm{s}\right)$

7.7a Effect of air temperature on fruit temperature $\left(T_{m}\right)$ $\left(P=0.1 \mathrm{~W} / \mathrm{g}\right.$ and $\left.V_{8}=2 \mathrm{~m} / \mathrm{s}\right)$ 
7.7b Effect of air temperature on fruit surface temperature $\left(T_{S}\right)$

$\left(\mathrm{P}=0.1 \mathrm{~W} / \mathrm{g}\right.$ and $\left.\mathrm{V}_{\mathrm{s}}=2 \mathrm{~m} / \mathrm{s}\right)$

7.8 MW drying rate of grapes at different air temperatures $\left(\mathrm{P}=0.1 \mathrm{~W} / \mathrm{g}\right.$ and $\left.\mathrm{V}_{\mathrm{g}}=2 \mathrm{~m} / \mathrm{s}\right)$

7.9 Effect of MW power density on drying of grapes $\left(\mathrm{T}_{\mathrm{g}}=30^{\circ} \mathrm{C}\right.$ and $\left.\mathrm{V}_{\mathrm{g}}=2 \mathrm{~m} / \mathrm{s}\right)$

7.10 Effect of $M W$ power density on fruit temperature $\left(T_{m}\right)$ $\left(\mathrm{T}_{\mathrm{g}}=30^{\circ} \mathrm{C}\right.$ and $\left.\mathrm{V}_{\mathrm{g}}=2 \mathrm{~m} / \mathrm{s}\right)$

7.11 MW drying rate of grapes at different power densities $\left(\mathrm{P}=0.1 \mathrm{~W} / \mathrm{g}\right.$ and $\left.\mathrm{V}_{\mathrm{g}}=2 \mathrm{~m} / \mathrm{s}\right)$

7.12 Effect of $M W$ power density on drying of grapes $\left(T_{B}=40^{\circ} \mathrm{C}\right.$ and $\left.V_{B}=2 \mathrm{~m} / \mathrm{s}\right)$

7.13 Effect of MW power density on drying of grapes $\left(T_{g}=50^{\circ} \mathrm{C}\right.$ and $\left.V_{g}=2 \mathrm{~m} / \mathrm{s}\right)$

7.14 Effect of air velocity on $M W$ drying of grapes $\left(\mathrm{T}_{\mathrm{B}}=30^{\circ} \mathrm{C}\right.$ and $\left.\mathrm{P}=0.1 \mathrm{~W} / \mathrm{g}\right)$

7.15 Effect of air velocity on fruit temperature and drying rates in MW drying of grapes $\left(T_{g}=30^{\circ} \mathrm{C}\right.$ and $\left.\mathrm{P}=0.1 \mathrm{~W} / \mathrm{g}\right)$

7.16 Effect of air velocity on outlet air temperature in MW drying of grapes $\left(T_{8}=30^{\circ} \mathrm{C}\right.$ and $\left.\mathrm{P}=0.1 \mathrm{~W} / \mathrm{g}\right)$

7.17 MW drying of grapes at air temperature of $50^{\circ} \mathrm{C}$ at different air velocities $(\mathrm{P}=0.1 \mathrm{~W} / \mathrm{g})$

7.18 Drying rates at air temperature of $50^{\circ} \mathrm{C}$ at different air velocities $(P=0.1 \mathrm{~W} / \mathrm{g})$

7.19 Simulated moisture profiles during $M W$ drying of grapes at different instants of time $\left(P=0.1 \mathrm{~W} / \mathrm{g}, \mathrm{T}_{\mathrm{z}}=50^{\circ} \mathrm{C}, \mathrm{V}_{\mathrm{z}}=2 \mathrm{~m} / \mathrm{s}\right)$

7.20 Simulated moisture profiles during $\mathrm{MW}$ drying of grapes at different instants of time $\left(P=0.1 \mathrm{~W} / \mathrm{g}, \mathrm{T}_{\mathrm{z}}=30^{\circ} \mathrm{C}, \mathrm{V}_{\mathrm{g}}=1 \mathrm{~m} / \mathrm{s}\right)$

8.1 Contour plot of $\mathrm{P} \times \mathrm{T}$ for Damage at $\mathrm{V}=1.0 \mathrm{~m} / \mathrm{s}$ 
8.2 Contour Plot of $\mathrm{P} \times \mathrm{T}$ for $\mathrm{ABYB}$ at $\mathrm{V}=1.0 \mathrm{~m} / \mathrm{s}$

8.3 Contour Plot of $\mathrm{P} \times \mathrm{T}$ for 'Pime at $\mathrm{V}=1.0 \mathrm{~m} / \mathrm{s}$

8.4 Contour Plot of $\mathrm{P} \times \mathrm{T}$ for Damage at $\mathrm{V}=2.0 \mathrm{~m} / \mathrm{s}$

8.5 Contour Plot of $\mathrm{ABYB}$ at $\mathrm{V}=2.0 \mathrm{~m} / \mathrm{s}$

138

8.6 Contour Plot of $P \times T$ for TIME at $V=2.0 \mathrm{~m} / \mathrm{s}$

138

8.7 Contour plot of $\mathrm{P} \times \mathrm{T}$ for DAMAGE with RESTRICTION on DAMAGE at $\leq 10 \%$ and $A B Y B$ at $\leq 0.342 @ \mathrm{~V}=1 \mathrm{~m} / \mathrm{s}$

8.8 Contour plot of $\mathrm{P} \times \mathrm{T}$ for ABYB with RESTRIC.TION on DAMAGE at $\leq 10 \%$ and $A B Y B$ at $\leq 0.342 @ \mathrm{~V}=1.0 \mathrm{~m} / \mathrm{s}$

8.9 Contour plot of $\mathrm{P} \times \mathrm{T}$ for TIME with RESTRICTION on DAMAGE $\leq+10 \%$ and $A B Y B \leq 0.342$ \& $\mathrm{V}=1.0 \mathrm{~m} / \mathrm{s}$

8.10 Contour Plot for DAMAGE with constrained restriction on Damage $\leq 10 \%$ and ABYB $\leq 0.342$ at air velocity of $2 \mathrm{~m} / \mathrm{s}$

8.11 Contour Plot for ABYB with constrained restriction on Damage $\leq 10 \%$ and ABYB $\leq 0.342$ at air velocity of $2 \mathrm{~m} / \mathrm{s}$

8.12 Contour Plot for TIME with constrained restriction on Damage $\leq 10 \%$ and $A B Y B \leq 0.342$ at air velocity of $2 \mathrm{~m} / \mathrm{s}$. 


\section{LIST OF TABLES}

Table

page

$\begin{array}{lll}2.1 & \text { Composition of Thompson seedless grapes } & 7\end{array}$

3.1 Drying time, $h$, under different dipping pretreatments 42

3.2 Drying time, $h$, under washing and holding treatments 48

3.3 Parameters of Page's equation [Eq. 3.3] 49

5.1 Results of linear models (Eq. 5.1) of shrinkage in grapes of 64 different sizes under convective drying

5.2 Results of linear models of shrinisage in grapes of 64 different sizes under MW drying

5.3 Shrinkage Analysis $\quad 65$

$5.4 \quad$ Values of $E_{\mathrm{rm}}$ in $V / m$ for grapes at different m.c. $\quad 75$ and at different MW power densities

5.5 Values of $A_{1}$ and $B_{1}$ of Eq. 5.11 for predicting $E_{\mathrm{rms}} \quad 75$

5.6 Overall mass transfer coefficients of pretreated grapes 81 under convective drying conditions

6.1 Values of coefficients of Eq. 6.17 and 6.18

6.2 Values of $C_{1}, C_{2}$ and $C_{3}$ of Eq. 6.19

6.4 Parameters of the fitting equation and its comparison with 97 the numerical model (global errors) for different MW drying treatments

7.1 Experimental factors and their levels in MW drying of grapes 102

7.2 Effective moisture diffusivities in convective 103 drying of grapes without pretreatment

7.3 Effective moisture diffusivities in convective 106 drying of grapes with pretreatment 
7.4 Values of constants $a$ and $b$ of Eq. ?.2 describing the dependency of effective moisture diffusivity on air temperature under convective drying conditions in pretreated grapes

7.5 Partial vapour pressure difference and the surface temperature for different air temperatures during $M W$ drying of grapes at $P=0.1 \mathrm{~W} / \mathrm{g}$ and $V_{\mathrm{g}}=2 \mathrm{~m} / \mathrm{s}$

8.1 Description of experiments

8.2 Specific energy consumption in convective drying of grapes

8.3 Specific energy consumption in MW drying of grapes $(\mathrm{V}=2.0 \mathrm{~m} / \mathrm{s}$ and $P=0.1 \mathrm{~W} / \mathrm{g})$

8.4. Specific energy consumption in MW drying of grapes $(\mathrm{V}=1.0 \mathrm{~m} / \mathrm{s}$ and $P=0.1 \mathrm{~W} / \mathrm{g})$

8.5 Specific energy consumption of selected MW drying treatments which yielded good quality raisins 


\section{NOTATIONS}

A

surface area of particle, sphere, grape, $\mathrm{m}^{2}$

A

coefficient in Eq. 5.1

$\mathbf{A}_{1}$

coefficient in Eq. 5.11

B

coefficient in Eq. 5.1

$\mathbf{B}_{1}$

coefficient in Eq. 5.11

a.

water activity

C

concentration of species, solids or water, $\mathrm{kg} / \mathrm{m}^{3}$

$C_{1}, C_{2}, C_{3} \quad$ coefficients in Eq. 6.19

CV

coefficient of variation, $\%$

$c_{m}$

sperific heat of material, grapes, J/kg $K$

D

moisture diffusivity, $\mathrm{m}^{2} / \mathrm{s}$

$D^{\prime}$

effective moisture diffusivity, $\mathrm{m}^{2} / \mathrm{s}$

Doff

effective moisture diffusivity parameter, $\mathrm{m}^{2} / \mathrm{s}$

d

diameter, $m$

$d_{1}, d_{2} \quad$ coefficients in Eq. 6.17

$\mathbf{E}_{\mathrm{rma}}$

electric field strength, Volt/m, V/m

$\mathbf{e}_{\mathbf{1}}$

energy demand for heating air, $\mathbf{k W}$

$e_{2}$

energy demand of air blower, $\mathrm{kW}$

$\mathbf{e}_{3}$

energy demand for microwave power generation, $\mathrm{kW}$

e

total energy demand, $\mathbf{k W}$

$\mathbf{e}_{\mathbf{e}}$

specific energy consumption, $\mathrm{MJ} / \mathrm{kg} \mathrm{H}_{2} \mathrm{O}$

$e^{x}$

local relative error of approximation at time $[t]_{0=1}^{N T},(\%)$ 


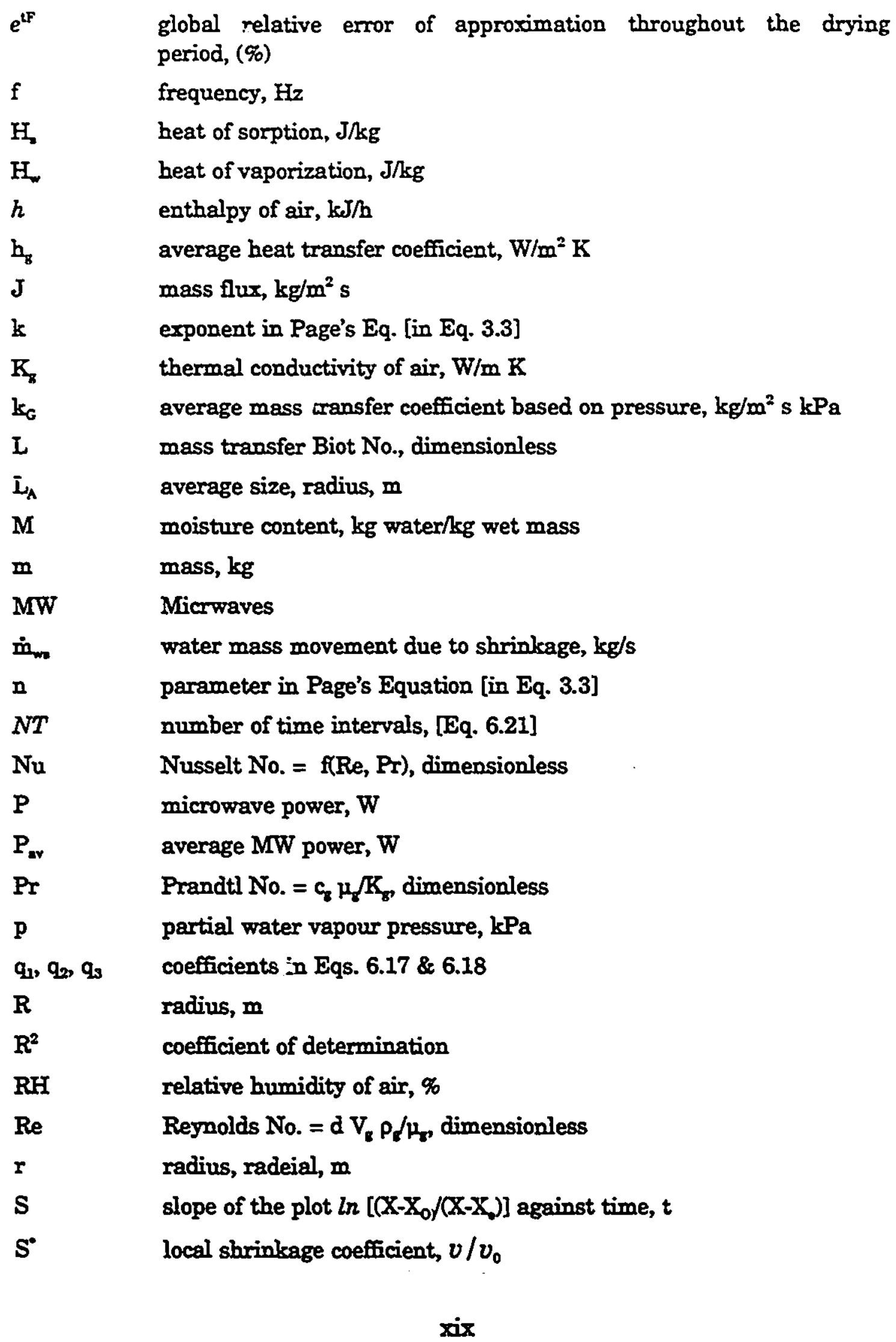




\begin{tabular}{|c|c|}
\hline $\mathbf{T}$ & temperature, ${ }^{\circ} \mathrm{C}$ \\
\hline$T_{R}$ & air temperature, ${ }^{\circ} \mathrm{C}$ \\
\hline T. & solid temperature (raisin) at surface, ${ }^{\circ} \mathrm{C}$ \\
\hline $\mathbf{t}$ & time, $\mathrm{h}$ \\
\hline$[t]_{\tau=1}^{N T}$ & $\begin{array}{l}\text { set of instants bisecting two consecutive time intervals, } \\
\text { (Eq. } 6.20,6.21 \text { ), h }\end{array}$ \\
\hline$v$ & volume, $\mathrm{m}^{3}$ \\
\hline V & velocity, $\mathrm{m} / \mathrm{s}$ \\
\hline $\mathrm{V}_{\mathrm{z}}$ & velocity of air in the drying chamber, $\mathrm{m} / \mathrm{s}$ \\
\hline $\mathbf{X}$ & average moisture content, $\mathrm{kg}$ water/kg dry mass \\
\hline $\mathbf{X}_{\mathbf{\Lambda}}$ & average moisture content, $\mathrm{kg} / \mathrm{kg}$ dry mass \\
\hline $\mathbf{X}_{\mathbf{6}}$ & =quilibrium moisture content of grapes, $\mathrm{kg} / \mathrm{kg}$ dry mass \\
\hline$x^{\circ}$ & local moisture content, kg water/kg dry mass \\
\hline$x$ & spatial coordinate, length \\
\hline & infinity, bullk air stream conditions \\
\hline
\end{tabular}

\section{Subscripts}

$\begin{array}{ll}\text { A } & \text { average } \\ \text { cv } & \text { control volume } \\ \text { e } & \text { equilibrium } \\ \text { eff. } & \text { effective } \\ \text { g } & \text { gas, air } \\ \text { m } & \text { material, grapes } \\ \text { O } & \text { initial } \\ \text { S, s } & \text { dry solid } \\ \text { T } & \text { total } \\ \text { w } & \text { water }\end{array}$

\section{Greel}

$B_{1} \quad$ roots of the Eq. 6.8

$\Delta \quad$ incremental change

$\varepsilon_{0}$ permittivity of free space, $F / m$ 


\begin{tabular}{|c|c|}
\hline$\varepsilon^{\prime}$ & dielectric constant \\
\hline$\varepsilon^{\prime \prime}$ & effective dielectric loss factor \\
\hline \& & velocity of shrinkage, $\mathrm{m} / \mathrm{s}$ \\
\hline$\Lambda^{\bullet}$ & moving coordinate \\
\hline$\Lambda$ & moving coordinate, dimensionless \\
\hline $\mathbf{x}$ & coefficient related to diffusivity, (Appendix B) \\
\hline$\mu$ & chemical potential (Appendix B) \\
\hline$\mu_{8}$ & viscosity of air, $\mathrm{kg} / \mathrm{m} \mathrm{s}$ \\
\hline$\eta$ & mass flux, $\mathrm{kg} / \mathrm{m}^{2} \mathrm{~s}$ \\
\hline$p$ & density, $\mathrm{kg} / \mathrm{m}^{3}$ \\
\hline$P_{\mathbf{m}}$ & density of material, grape, $\mathrm{kg} / \mathrm{m}^{3}$ \\
\hline P. & dry matter concentration (species), grape, $\mathrm{kg} / \mathrm{m}^{3}$ \\
\hline $\boldsymbol{\omega}$ & angular frequency $=2 \pi f$ \\
\hline
\end{tabular}




\title{
CHAPTER I
}

\author{
INTRODUCTION
}

\subsection{Background}

Raisins (dried grapes) are an important product of the grape industry, second only to wine in monetary value (Winkler et al., 1974). The 1990 world production of raisins was nearly one raillion $t$ (FAO, 1990): 396,000 $t$ in Asia, $333,000 \mathrm{t}$ in North America, 136,000 $\mathrm{t}$ in Europe and 61,000 $\mathrm{t}$ in Australia. The main raisin producing and exporting countries are the United States, Greece, Turkey, Iran, Afghanistan, Australia, South Africa, Spain and Italy.

The grape varieties most commonly transformed into raisins are: Thompson seedless, Black Corinth and Muscat of Alexandria. Thompson seedless and similar varieties account for most of the world raisin production. Thompson seedless are also known as "Sultana" in Australia, "White or Oval Kishmish" or "Sultania" in Turkey and some parts of Asia. "Naturals" may include all varieties and refer to sun-dried raisins.

Almost all grapes destined for the raisin markets are sun-dried, an openair process that lasts over a month. High quality raisins are only produced from well mature grapes. A sugar content of $21^{\circ}$ Brix or more is required for better yield and texture (Jacob, 1944; Winkler et al., 1974). Since grapes are highly perishable, timing of operations is critical and an adequate open air drying regime necessary. Weather conditions cannot be depended on to allow harvesting for maximum return after the fruit is naturally dried in the sun (eg., California). Thus, while grapes may be produced in a wide variety of climates, raisin production is restricted to regions where the grape harvest falls in a period when weather conditions are ideal for drying. This situation exists in some south Asian countries and particularly in India. Although the 
per hectare productivity of grape is the highest in India (21.7 tha compared to $16,15.6$ and 5.2 tha in Israel, the U.S and Afghanistan, respectively, the raisin production is limited. Harvest in the north corresponds to the early monsoons and dust storms (CFTRI, 1988) whereas in the south harvest falls in the late southeast monsoon. As a result, sun drying is next to impossible and this country imports over $60,000 \mathrm{t}$ of raisins annually.

The maturity, timing and weather factors involved in obtairing high quality raisins make artificial drying an important alternative to sun drying in many regions. As in other agricultural drying applications, the main limitation of convective drying techniques is that drying time is mainly dependent on flow-through air temperature and cannot be substantially reduced because the product is heat sensitive. In the case of grapes, the main barrier to moisture diffusion is the skin Martin and Stot, 1957; Riva and Peri, 1986). Discolouration of the product due to hot air and long processing time is another important feature of hot air drying (Winkler et al., 1974; Van Arsdel et al., 1973). It is a common practice in the raisin industry to fumigate the fruits prior to drying with sulphur dioxide in order to check browning so as to achieve a good coloured product (Jacob, 1944; Winkler et al., 1974). Some improvements in drying time have been achieved by the application of chemical pre-treatments that modify the skin resistance to diffusion (Ponting and McBean, 1970; Saravacos and Marousis, 1988). However, such reductions in drying time are slight compared to those that can be achieved by dielectric heating methods.

Dielectric heating with microwaves (MW) has been proven to greatly reduce the drying time of many agricultural commodities and, with proper control of the drying regime (dielectric field strength, airflow rate and inlet temperature) a dried product with quality attributes equivalent to those of convection-dried material can be obtained (Otten and St. John, 1988; Gunasekaran, 1990; Caldas, 1992; Shivhare et al., 1992, 1994). However, most 
of the work on MW heating and drying' of agricultural commodities has been done on low-moisture material such as grains. Grapes are a high-moisture commodity and the MW drying of grapes to obtain raisins has not yet been investigated. The development of a commercial-scale microwave drier to produce high quality raisins could make a significant contribution to viticulture industries in India and other nations having similar climates.

In order to achieve the objective of a commercial-scale microwave drier, the following steps were envisioned. First, the feasibility of obtaining marketable raisins by the proposed technology was to be established (Chapter 3). Then, a model which could be used for design and scale-up simulations was to be developed. However this required the development of an appropriate experimental setup (Chapter 4 ) with which to execute studies leading to the required functional relationships between grape properties and the microwave drying environment (Chapters 5 and 7). The model was to be fully described and its performance evaluated against experimental data (Chapter 6). Finally, an optimization was to be performed (Chapter 8).

\subsection{Eypothesis}

The hypothesis entertained in this thesis is that it is possible to produce high quality raisins from grapes using microwaves as the primary source of energy needed for heat and mass transfer within the material to be dried and forced convection as the method of removing moisture from the immediate environment of the drying grapes.

\footnotetext{
From here on, it is implicit that $\mathrm{MW}$ drying involves dielectric heating in a forced-air environment since an airflow is needed to clear moisture away from the immediate environment of the material that is being dried. Thus $\mathrm{MW}$ drying is actually a combination of $\mathrm{MW}$ and convection drying.
} 


\subsection{Objectives}

The primary objective or overall goal of this study was to determine the operating conditions under which high quality raisins could be obtained in a short drying time by applying microwave energy in combination with forced air convection.

In pursuit of this overall goal, the specific objectives of this study were:

i) To examine the feasibility of the concept of microwave drying of grapes.

ii) To quantify the effect of chemical pretreatments on microwave drying of grapes.

iii) To design and develop a laboratory microwave drying apparatus consisting of Single Mode Applicator, associated instrumentation and a data acquisition system.

iv) To conduct systematic microwave drying studies with continuous power at different levels of inlet air temperature, power density and inlet air velocity.

v) To quantify changing physical and electro magnetic properties of grapes as functions of moisture content. The properties include: a) Shrinkage, b) Density, c) Specific heat, d) Dielectric constant, e) Dielectric loss factor, f) Electric filed strength and f) Mass transfer coefficient. 
vi) To develop a thin-layer microwave drying model that accounts for shrinkage and changes in material properties.

vii) To optimize the operating microwave drying parameters microwave power density, inlet air velocity and inlet air temperature - relative to drying time, energy consumption and raisin quality. 


\section{CHAPTER II}

\section{REVIEW OF LITERATURE}

\subsection{Quality Factors in Raisins}

In his monumental work on raisins, Jacob (1944) studied many aspects of raisin processing and production and provided a rich treasure of information including an excellent coverage of the different terms used in the raisin industry, terms which are still relevant. Raisins are known in international trade by names such as " naturals, "soda dipped", "golden bleached", etc., depending on the method used in processing. The following definitions and specifications are given in the United States Department of Agriculture (USDA), Agricultural Marketing Administration, Publication on Grades for Processed Raisins (Aug., 26, 1955; cited in Cruess, 1958). Although the size of Thompson Seedless raisins is not incorporated in the grade specifications as a factor in determining quality, the common size designations are given. "Select" size means that not less than $35 \%$ by mass of the raisins and not more than $85 \%$ will pass through round perforations $24 / 64$ inch $(0.953 \mathrm{~cm})$ in diameter, but not more than 5\% may pass through round perforations 20/64 inch $(0.794 \mathrm{~cm})$ in diameter. "Small" or "Midget" raisins are of such size that all will pass through circular perforations $20 / 64$ inch $(0.794 \mathrm{~cm})$ in diameter.

"U.S. Grade A" or "U.S. Fancy" Thompson Seedless raisins must possess similar varietal characteristics, colour and flavour characteristics of raisins prepared from well-ripened grapes, contain not more than $18 \%$ of moisture by mass, and meet the following additional requirements: the raisins must not contain more than one piece of stem per $32 \mathrm{oz}$.(995 g); not more than 15 cap stems per 16 oz.(498 g); not more than $1 \%$ by mass of immature raisin; not more than $2 \%$ of damaged raisins; not more than $5 \%$ of sugared raisins; not more than $2 \%$ by mass of mouldy raisins; no damage by fermentation; no 
sand or grit of any consequence that would affect appearance or edibility.

"U.S. Grade B" or "U.S. Choice" Thompson Seedless raisins possess similar varietal characteristics, reasonably good typical colour, and good characteristic flavour, they must be prepared from reasonably well-matured grapes and contain not more than $18 \%$ moisture. The additional requirements are somewhat less severe than for U.S. Grade A. The requirements for "Grade C or "U.S. Standard" are less rigorous than for the U.S. Choice, but the raisins must not have more than $18 \%$ moisture, and they must possess a fairly good colour. Substandard raisins are those that do not meet the requirements for the U.S. Grade C. The other quality aspects that are mentioned in the literature are colour, hue, condition of the berry surface and texture of the skin and pulp. These attributes are not defined quantitatively.

Moisture and sugar are the major constituents of grapes and there are minor quantities of mineral salts. On drying, grapes lose moisture and the resulting raisins essentially consist of nearly $80 \%$ sugar, the moisture content being about 15 - 16\% wet basis. The composition and characteristics of fresh grapes are shown in Table 2.1.

Table 2.1. Composition of Thompson seedless grapes

(CFTRI, 1988)

\begin{tabular}{lc}
\multicolumn{1}{c}{ Description } & composition \\
\hline TSS, ${ }^{\circ}$ Brix & 17.60 \\
Acidity, (\%), g tartarid100 g berries & 0.64 \\
pH & 3.6 \\
Dry Matter, (\%) & 23.28 \\
Nitrogen, (\%) & 0.152 \\
Total Sugar, (\%) & 12.83 \\
Reducing Sugar, (\%) & 11.55 \\
Sucrose,(\%) & 1.22 \\
Glucose,(\%) & 6.38 \\
Fructose,(\%) & 7.10 \\
Gluco-Fructose, (\%) & 0.58 \\
Total Sugar/Acid ratio & 17.9 \\
\hline
\end{tabular}




\subsection{Methods of Grape Drving}

\subsubsection{Sun Drying}

Naturals are essentially sun-dried raisins. The most popular method of drying grapes in the Californian valley is to spread the grape clusters on paper trays between the rows of grape vines in the orchard. When the moisture loss is about 33\% the clusters are turned for uniform drying. After three weeks, or when the moisture reaches $15-16 \%$, the raisins are rolled in paper trays into 'biscuits' and stored (Winkler et al., 1974). These cured or sweated raisins are washed, graded and packed. Struder and Olmo (1973) described raisin drying by the 'severed-cane technique'. Canes carrying mature grapes are severed from the plant and allowed to dry in the sun. The moisture drops to 25-35 \% in about 6-9 weeks and the vines are then shaken to separate out the raisins. These are then finish-dried to $15 \%$ moisture content in a tunnel dryer. It is claimed that this method involves less labour, consumes less energy for drying and results in a quality product. Fuller et al. (1990) have reported a method of improving traditional grape drying using solar energy in Australia. The method adopts polyethylene curtains and a solar heating system in the traditional rack drying. The study has indicated a good customer acceptance.

Sun drying is the popular method but the associated long drying time requirement and favourable weather restrict its application to many grape regions of the world. Though this is a popular method of drying heavy losses are reported because of occasional rains and unfavourable weather during the grape harvest season. Miller and Fischer (1959) have reported a crop loss of $32 \%$ and concluded that production of sun dried raisins in California is a high risk business.

\subsubsection{Solar Drying}

Solar driers have also been used to dry grapes. Eissen (1984) compared floor drying of raisins under transparent plastic sheets to drying in a solar bed drier fitted with a plastic tunnel. He obtained superior product quality and 
reduced drying time in the solar dryer. Eissen et al. (1985) studied the influence of drying air temperature, air velocity and characteristics of pretreatments in a laboratory-scale solar drier. These experiments showed that an air temperature of $60^{\circ} \mathrm{C}$ and an air velocity of $0.25-0.5 \mathrm{~m} / \mathrm{s}$ were optimum for drying grapes. The drying of seedless grapes was investigated under intermittent and continuous operating conditions in a laboratory-scale solar installation which consisted of a thermal bed and an auxiliary heater (Raouzeos and Saravacos, 1986). Drying was accomplished in times varying from 24 to $66 \mathrm{~h}$ depending on the operating mode, continuous or intermittent, and pretreatment used. Information on commercial application of solar driers for raisins is generally scarce in the literature.

\subsubsection{Hot Air Drying}

A recirculating electrically heated tunnel dryer was used by Jacob (1944). Grapes subjected to different treatments were dried at $55-65^{\circ} \mathrm{C}$. Pretreated grapes took about $19 \mathrm{~h}$ to dry whereas untreated grapes took as long as $41 \mathrm{~h}$. The yield and quality of the raisins obtained by mechanical drying were comparable to those of naturally dried raisins. Van Arsdel (1973) discussed the difficulties experienced by raisin processors in getting uniform quality of golden bleached raisins under hot-air drying conditions. The experiments revealed several factors responsible for poor quality. These were: variation in total time, non-uniform tray loading and non-uniform air distribution in the dehydrator. The amount of checking from the alkali dip had some influence but the method of sulphuring had no effect on quality. The total drying time was $24-45 \mathrm{~h}$ and the final moisture content ranged from 10 to $14 \%$. It was noted that the brightness of the product was directly related to sulphur dioxide content of the fruits. Experimental samples that were dehydrated to $11.5-14 \%$ moisture content contained over 2000 ppm sulphur dioxide and had very good colour, however products dehydrated to less than 11\% moisture contained 1500 ppm sulphur dioxide and were of poor quality. 
This indicated that sulphur dioxide was lost at moisture contents below $11 \%$. This study clearly indicates the importance of maintaining adequate sulphur dioxide concentrations to check browning in hot air drying of grapes.

Bolin et al. (1975) reported that methyl and ethyl emulsions could be used to accelerate drying of grapes and pointed out that the FDA (US Food and Drug Administration) permits the use of ethyl esters but not of methyl esters. The author operated a tunnel type dryer at air temperatures of $65-71^{\circ} \mathrm{C}$ to produce golden bleached raisins. Colour measurements were made with a Gardner automatic colour difference meter and the texture was measured using an Instron tensile tester. He observed that residues of oleates at levels of less than $140 \mathrm{ppm}$ did not create any flavour defects even after storage at elevated temperatures. Riva et al. (1986) used a cabinet dryer with trays arranged in parallel under forced convection tangent flow conditions to evaluate the effects of pre-treatments on drying characteristics of grapes. They used air at $50^{\circ} \mathrm{C}, 15 \%$ R.H. and $70^{\circ} \mathrm{C}, 10 \%$ R.H. in their studies and a high airflow rate so as to maintain constant drying conditions. Saravacos and Raouzeos (1986) conducted studies on drying of grapes in a laboratory dryer operating at controlled air temperature and velocity. They reasoned that low diffusivity of moisture in the grapes to be the main factor for low drying rates at relatively low temperatures. In their work on hot air drying of seedless grapes, Berna et al. (1991) used a laboratory drier and investigated the effects of air flow rate and temperature over wide ranges of air velocity $(0.5 \mathrm{~m} / \mathrm{s}$ to 5.0 $\mathrm{m} / \mathrm{s}$ ) and temperature $\left(27\right.$ to $65^{\circ} \mathrm{C}$ ). The advantage of higher air velocities in mechanical drying has been recognised (Saravacos and Raouzeos, 1986; Berna et al., 1991).

It is evident from the literature cited that hot air drying of grapes is a feasible alternative to sun drying both in terms of shorter drying times and light coloured good quality raisins. Inlet air temperature and air velocity were reported to have influence on drying rates. But evaluation of quality of the product in relation to these drying parameters is generally lacking. 


\subsection{Drying Kinetics of Grapes/Raisins}

\subsubsection{Pretreatments and Grape Skin Resistance}

Martin and Stott (1957) conducted studies on some of the physical factors involved in the drying of Sultana grapes. This is perhaps the earliest report of a study on the drying kinetics of grapes. In describing the process of grape drying, they postulated a number of possible processes involved in water movement: a) transfer through the parenchymal cells to the inside of the skin, b) diffusion through the skin, c) evaporation from the outside surface or vapour diffusion through the stationary layer at the surface, and d) removal of the water-laden atmosphere. Their results indicated that drying occurred in three distinct stages: i) the grape retains its regular ellipsoidal shape by an elastic contraction of the skin; ii) the skin starts to wrinkle in the range of 20-50\% moisture loss and, iii) the drying rate decreases markedly thereafter. For each of these stages they found a logarithmic relationship between mass loss ratio and time. A drying constant was calculated from the above relationship for the initial part of each of the stages and was used to compare the drying rates:

$$
k=\left(\frac{1}{t}\right) \log \left[\frac{c}{(c-w)}\right]
$$

where, $c=$ total loss in mass when any further changes in mass are very small for additional drying,

$w=$ loss in mass at any time $t$,

The slope of the plot of $\log [c /(c-w)]$ versus time, yielded the value of $k$. They observed two distinct drying rates; one in the beginning up to 20-50\% moisture loss and the other for the remaining drying period. The initial drying rate was constant for different grapes and they used this factor to compare the drying behaviour of different pretreatments and to find the skin resistance to moisture diffusion. They observed that water movements through the parenchymal cells are faster than through skin. Since various dip treatments gave different drying rates, it was inferred that the drying rate is controlled 
by diffusion of water through the waxy cuticle, and is inversely proportional to the amount of cuticle present. They reasoned that the elastic contraction of the skin causes an increase in the thickness of the cuticle which reduces the permeability.

Dudman and Grncarevic (1962) compared two methods of determining waxy substances on surface of grapes. They deterrined the concentration of waxy material on the grape surfaces before and after the pretreatments to quantify the effect of dipping. According to their results, dipping does not remove the waxy material but only modifies the surface probably from hydrophobic to hydrophillic, thus enabling wetting. Chambers and Possingham (1963) studied the surface waxy bloom of Sultana grapes using the carbon replica technique in combination with electron microscopy. According to their observations this layer consists of a series of tiny wax platelets of about $0.1 \mathrm{\mu m}$ wide. When grapes are dipped in commercial emulsions the air spaces between platelets become filled with the liquid and wet the surface. They reasoned that the surface of the fruit gets modified from hydrophobic to hydrophillic because of the dip treatment, and that the amount of wax material on the surface does not change.

Saravacos and Raouzeos (1986) and Raouzeos and Saravacos (1986) pretreated Sultana grapes in an alkali solution of ethyloleate and conducted drying studies in a cabinet type air dryer at $60^{\circ} \mathrm{C}$ and $2 \mathrm{~m} / \mathrm{s}$ air velocity. They observed a decrease of the mean equivalent diameter from 1.9 to $1.2 \mathrm{~cm}$ with a corresponding moisture decrease from 3.2 to $0.2 \mathrm{~kg}$ water $/ \mathrm{kg}$ dry solids. The effective moisture diffusivity $\left(D_{\odot}\right)$ was determined from the drying curves. $D_{\text {. }}$ was found to decrease from $2.5 \times 10^{-10}$ to $0.5 \times 10^{-20} \mathrm{~m}^{2} / \mathrm{s}$, as the moisture content decreased. Riva and Peri (1986) conducted a study on drying kinetics and evaluated five different grape varieties with chemical pre-treatments. The procedure they adopted to analyze the data of kinetic studies was similar to that of Raouzeos and Saravacos (1986). They correlated the drying rate to a geometrical parameter which accounts for both the radius of the berry and the 
thickness of the fruit skin:

$\begin{array}{ll}\text { (a) Sun drying: } & \mathbf{k}=0.05-12.8 \times \mathrm{R}^{2} \times \mathrm{T}_{\mathrm{h}} \\ \text { (b) Air drying: } & \mathrm{k}=0.42-87.8 \times \mathrm{R}^{2} \times \mathrm{T}_{\mathrm{b}}\end{array}$

where, $\mathrm{k}=$ rate constant, per $\mathrm{h}$

$\mathrm{R}$ = average radius of berry, $\mathrm{cm}$

$T_{b}=$ average skin thickness, $\operatorname{com} 10^{-3}$

The results showed that Ruby grapes dried faster than the other varieties considered. Composition and colour data showed that experimental samples compared well with commercial raisin samples. Riva and Peri (1986) investigated the effects of chemical pre-treatments on the kinetics of grape drying at temperatures of $50^{\circ} \mathrm{C}$ and $70^{\circ} \mathrm{C}$ with an exceedingly high air-flow rate in a tangential flow cabinet dryer. They used a Hunterlab Colorimeter to evaluate quality in terms of colour measured as lightness $(\mathrm{L})$, yellowness $(\mathrm{b})$, and redness (a) and transformed to C.I.E. parameters. The authors reported that the effect of chemical pre-treatment is only significant at intermediate temperatures $\left(50^{\circ} \mathrm{C}\right)$. They reasoned that water diffusivity is higher at higher temperatures making the chemical pre-treatment ineffective. In a similar study, Saravacos and Marousis (1988) reported a method of estimating interphase mass transfer coefficients by making use of drying data. They assumed a wet bulb temperature for the solid during the constant drying rate period in order to predict the solid surface temperature. Berna et al. (1991) interpreted the drying kinetics of seedless grapes in terms of activation energy and reported that air velocities beyond $2-3 \mathrm{~m} / \mathrm{s}$ do not increase the drying rates.

\subsection{Drying Models}

Various mathematical models have been proposed for describing the thin layer drying behaviuur of agricultural materials. These models can be grouped and classified as (Sharaf-Eldeen, et al., 1979; Jayas, et al., 1991):

a) Semitheoretical and empirical models, 
b) Diffusion models,

c) Simultaneous heat and mass transfer models

\subsubsection{Semitheoretical Models}

The most commonly used relationship is a semi- theoretical equation analogous to Newton's law of cooling. Assuming that the rate of moisture evaporation during drying is directly proportional to the difference in moisture content between the material to be dried and its equilibrium moisture conditions;

$$
\frac{d X}{d T}=-k\left(X-X_{e}\right)
$$

where, $\mathrm{X}=$ moisture content at any time $\mathrm{t}, \mathrm{kg} / \mathrm{kg}$ dry mass

$t=$ drying time, $h$

$\mathrm{k}=$ rate constant, $\mathbf{h}^{-1}$

$X_{0}=$ equilibrium moisture content corresponding to drying air conditions, $\mathrm{kg} / \mathrm{kg}$ dry mass.

The solution of the above equation is,

$$
M R=a \exp (-k t)
$$

where, $M R=$ Moisture Ratio, $\left(X-X_{0}\right) /\left(X_{0}-X_{0}\right)$,

dimensionless, decimal

a $=$ a constant, dimensionless

$\mathrm{X}_{0}=$ initial moisture content, $\mathrm{kg} / \mathrm{kg}$ dry mass

This describes the drying rate of a thin layer of material under constant drying conditions. In the development of this model the assumption made is that the resistance to moisture flow is concentrated in a layer at the surface of the product and is therefore iridependent of the geometry of the product. $X$ used here is the asymptotic value of the drying curve. It appears to give good results and has been used ty other researchers (Sharaf-Eldeen, 1979; Hansen 
et al., 1993; Patil et al., 1993). The rate constant was found to depend on the temperature for a particular material and was described by an Arrhenius type of equation (Pabis and Henderson, 1962):

$$
k=a \exp \left(-\frac{b}{T_{a b s}}\right)
$$

where, $a=$ material constant $/ \mathrm{h}$

b $=$ material constant $/ h$

$\mathrm{T}_{\mathrm{ab}}=$ absolute temperature, $\mathrm{K}$

Several investigators have applied Eq. 2.7 to describe the drying behaviour of agricultural materials (Berna et al., 1991). Experimental evidence showed that a single temperature-dependent drying parameter underestimates the drying rate in the initial stages and overestimates it in the final stages of drying (Byler, 1983). A simplified form of the Fick's equation applicable to longer drying times is very similar to Eq. 2.5;

$$
\frac{X-X_{c}}{X_{0}-X_{e}}=a \exp \left(-\frac{k t}{L^{2}}\right)
$$

where, $\mathrm{L}=$ sample thickness, $m$

Eq. 2.8 has been one of the most widely used equations in modelling drying data. The diffusion-based modelling approach involves the use of a finite number of terms of the infinite series solution to the diffusion equation (Eq. 2.9):

$$
M R=a_{0} \exp \left(-k_{0} t\right)+a_{1} \exp \left(-k_{1} t\right)+\ldots
$$

Otten and St. John (1988) applied a two term exponential equation to describe thin layer MW drying of peanuts and Patil et al. (1993) used the model to describe drying of chopped alfalfa. The other model which has been frequently used to fit thin-layer drying data $\left(\mathrm{L}_{i}\right.$ and Morey, 1987; Kalwar, 1991) is a purely empirical one which was first proposed by Page (1949). 
Page (1949) added an empirical exponent to time t, in the Eq. 2.5, to overcome the shortcomings of logarithmic model and the modified equation is:

$$
M R=\frac{X-X_{c}}{X_{0}-X_{0}}=\exp \left(-k t^{n}\right)
$$

where, $\mathrm{n}=$ empirical drying exponent.

This modified exponential equation (Eq. 2.10) gave better results in describing fully exposed drying of grains and has been used by many researchers (SharafEldeen, 1979; Otten et al., 1989, Tulasidas et al., 1993). Comparing Page's equation with the logarithmic equation, Page's equation should be able to fit the data better because the exponent of time can cause the exponential decay to curve slightly, giving a greater slope at the initial stages of drying and a gentler one at the end. If the MR could be measured over time, then Page's equation could be linearized and the regression required to evaluate the parameters is simpler (Byler, 1983; Tulasidas et al., 1993). The drying constants $k$ and $n$ of Eq. 2.10 have been correlated to various functions of temperature, humidity, air velocity and initial moisture content. Eq. 2.10 may be modified to include the sample thickness $L$, as the Fick's equation, to give the modified Page Equation:

$$
\frac{X-X_{e}}{X_{0}-X_{e}}=\exp \left(-k\left[\frac{t}{L^{2}}\right]^{n}\right)
$$

Diamante and Munro (1991) used this equation to fit drying data of sweet potato slices. They reported this equation to be better than Eq. 2.5 to fit the data.

\subsubsection{Diffusion Models}

Drying takes place in the falling rate period, during which water is transported by diffusion from the interior to the surface. The falling rate period is best described by Fick's transient diffusion model. For a spherical object of 
radius $R$, the diffusion of moisture $(X)$ with time is described as (Crank, 1975):

$$
\frac{\partial X}{\partial t}=\frac{1}{r^{2}} \frac{\partial}{\partial r}\left[r^{2} D(X) \frac{\partial X}{\partial r}\right]
$$

In Eq. 2.12, $\mathrm{r}$ represents the radius of an elemental sphere in one dimensional spherical coordinate system that determines the size (the radial length from centre to the periphery and the surface area). In solving the above equation, it can be assumed that the spherical object has an initially uniform moisture content (throughout its volume) and that there is no moisture gradient at the centre of the fruit, ie. at the centre of the sphere. These assumptions lead to the following initial and boundary condition:

$$
\begin{array}{lll}
t=0 & X=X_{0} & r \geq 0 \\
t \geq 0 & \partial X / \partial=0 & r=0
\end{array}
$$

From Eq. 2.12, it is inferred that;

i) the diffusion coefficient $D$ is not a constant since it may be a function of moisture content which varies as drying progresses.

ii) the size and shape of the object change in time due to shrinkage and hence the characteristic length, $R$, diminishes with time.

The surface water concentration at the boundary is assumed to be at the corresponding conditions of drying air, which is equivalent to $X_{0}$ i.e,

$$
t \geq 0 \quad \mathrm{X}=\mathrm{X}, \quad \mathrm{r}=\mathrm{R}
$$

\subsubsection{Solution of the Diffusion Equation}

In the absence of a constant drying rate, it is assumed that drying starts in the falling rate period. It is further assumed that the material is dried as a single layer in a high velocity air stream and that the resistance to mass transfer at the interphase is therefore negligible compared to the internal resistance to diffusion of moisture within the object to the surface. Such an assumption justifies the boundary conditions assumed. For a sphere of radius $\mathrm{R}$, the solution of Fick's equation (Eq. 2.12) for the case of constant diffusivity 
satisfying the above boundary conditions is (Crank, 1975):

$$
M R=\frac{X-X_{e}}{X_{0}-X_{e}}=\frac{6}{\pi^{2}} \sum_{n=1}^{-} \frac{1}{n^{2}} \exp \frac{\left(-n^{2} \pi^{2} D t\right)}{r^{2}}
$$

Eq. 2.16 has been used by many researchers to describe the diffusion controlled drying mechanism in many foods and grains (Becker and Sallans, 1955; Chittenden and Hustrulid, 1966; Whitaker and Young, 1972; Steffe and Singh, 1980, 1982). Becker and Salians (1955) used Eq. 2.16 to analyze data from their wheat drying experiments and reported that the diffusion coefficient is independent of moisture content. They used the Arrhenius equation to relate the diffusion coefficient to the temperature of the drying air. In their study on rice drying, Steffe and Singh (1980) reported that the total resistance to moisture movement is the combined effect of various resistances of different constituents of the grain. The rice hull provided greater resistance than the bran. The starchy endosperm provided the least resistance. They also used an Arrehenius type of equation to describe the temperature dependency of diffusion coefficient. In a similar study, it was reported that the diffusion coefficient was lower in rough rice than in shelled brown rice, thus indicating a greater resistance of the rice hull to moisture transport (Steffe and Singh, 1982). In the case of corn, the diffusion coefficient of the grem was much higher than that of the endosperm and the pericarp (Syarief et al., 1987).

Eq. 2.16 does not take into account the continuously varying moisture content as the drying progresses and also the assumption of uniform equilibrium moisture content at the surface corresponding to drying air conditions is far from reality. It therefore fails to fit the data adequately over the entire range of drying. Realising these limitations many researchers tried to correlate diffusion coefficient with the temperature and changing moisture content (Pabis and Henderson, 1962; Chittenden and Hustrulid, 1966; Chu, 1966; Chu and Hustrulid, 1968; Hussain et al., 1973; Bruce, 1985; Syarief et 
al., 1987; Haghighi et al., 1990; Parti and Dughmanics, 1990; Karthanos et al., 1990; Jayas et al., 1991; Jaros et al., 1992). Shivhare et al. (1994) considered a varying surface moisture content with time and obtained an exponential drying coefficient to account for varying conditions at the surface. The equation based on corrected moisture ratios that account for the varying conditions at the surface, combined with a drying coefficient, fit the microwave drying data of corn adequately. This approach also gave a good fit to data obtained in drying other grains such as wheat and rice.

For a solid sphere with a finite rate of evaporation under non-steady state has been described as follows (Crank, 1975; Vergnaud, 1992):

"The sphere is assumed to be initially at uniform moisture concentration $\mathrm{C}_{i}$. It is placed in a surrounding atmosphere of infinite volume and it is assumed that the concentration of water vapour remains constant as evaporation proceeds. It is also assumed that on the surface of the sphere, the rate of evaporation of moisture is always equal to the rate at which moisture arrives at the surface by internal diffusion. With these assumptions the initial and final boundary conditions are:

$$
\begin{array}{lll}
t=0, & r<R, & C_{i} \text { (sphere) } \\
t>0, & -D(\partial C / \partial r)_{R}= & F_{0}\left(C_{R t}-C_{0}\right)
\end{array}
$$

where, $C_{R t}$ is the concentration of moisture on the surface at time $t$, and $\mathrm{C}_{0}$ is the concentration required at the surface to maintain equilibrium with the constant vapour pressure in the surrounding atmosphere. $F_{0}$ is the rate of evaporation of water when the concentration is unity at the surface".

For these conditions Crank (1975) has provided the following analytical solution for Eq. 2.12.

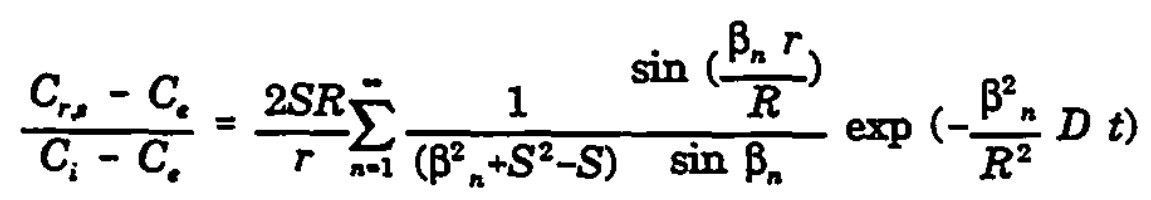


where, the $\beta_{n}$ 's are the roots of the following equation:

$$
\beta_{n} \cot \beta_{n}+S-1=0
$$

and the dimensionless number $S=F_{0}(R / D)$.

The amount of diffusing moisture $Q_{t}$ which has evaporated after time $t$, as a fraction of the corresponding quantity which has evaporated after infinite time, is expressed in terms of $t, \beta_{a}$ and $S$ as:

$$
\frac{Q_{\infty}-Q_{t}}{Q_{\infty}}=\sum_{n=1}^{-} \frac{6 S^{2}}{\left(\beta_{n}^{2}+S^{2}-S\right)} \exp \left(-\frac{\beta^{2}}{R^{2}} D t\right)
$$

\subsubsection{Effective Diffusivity}

The diffusivity coefficient (Eqs. 2.16, 2.18) varies considerably with moisture and could be estimated by an analysis of the drying data. In the case of non-linear drying curves, the effective diffusivity $D_{0}$, at a given moisture content can be estimated by the method of slopes (Perry and Green, 1984). The method of slopes estimates the effective moisture diffusivity at each moisture ratio $M R(t)$, essentially by repeatedly applying the diffusion equation solution, Eq. 2.16 from $M R=1$ to $M R=M R$ at any time $t$, ie, from $X=X_{0}$ to $X=X(t)$. Since the slope of the drying curve and the dimensions of the sample change during drying, the estimated value of $D_{0}$ will vary with the moisture content of the sample. The method of slopes assumes a $D_{0}$ that represents mass transfer by diffusion inside a sample. This is very close to liquid diffusivity in the case of low-porosity solids and Fick's second law can therefore be successfully applied to such solids (Karthanos, et al., 1990).

Jaros et al. (1992) reported a method for determining $D_{e}$ based on kernel moisture content and its temperature utilizing mathematical analysis of convection drying in the falling rate period. They adopted the mass diffusion equation and its series solution for a single wheat kernel, assuming that it can be represented by a sphere as a model system. 


\subsection{Shrinkage}

Fick's equation (Eq. 2.12) cannot be solved analytically if there is a large change in volume due to shrinkage because $R$, the characteristic length in the solution equation (Eq. 2.16) changes during drying. To overcome this problem Crank (1975) has given a procedure which is summarized by Gekas (1992) as follows:

a) Introduce a moving frame of reference in which $r$ remains consiant. Then, Eq. 2.12 determines a kind of diffusion coefficient of reference. Crank uses the terms constant-mass $\left(D_{A}{ }^{M}\right)$ and constant-basic-volume-of $\mathrm{B}\left(\mathrm{D}_{\mathrm{A}}^{\mathrm{B}}\right)$ coefficients.

b) Derive a relationship between the constant-volume diffusion coefficient and the diffusion coefficient of reference.

c) Combine steps $a$ and $b$ to determine the constant volume (or the proper) diffusion coefficient.

To overcome the drawbacks of one-dimensional volume change and onedimensional diffusion in Crank's approach, Gekas (1992) proposed the following modification to cover cases of real volume change - based on experiments, the author considers that the volume change has a fractional or power-law relationship with the change of thickness.

Crapiste et al. (1988a, 1988b) presented a series of papers on the theoretical analysis of moisture transfer in cellular materials based on chemical potential. They used the method of volume averaging to present a general theoretical analysis of the problem of mass transfer during drying of shrinking multiphase system. Constitutive equations for the diffusive flux of water in each phase of the system were used to obtain the one-equation model for water transport.

To account for shrinkage, many researchers have developed relations describing change in volume as a function of average moisture content to be used in numerical solutions. Lozano et al. (1983) reported shrinkage and̄ bulk density of foodstuffs at changing moisture contents. Bala (1992) proposed a 
nonlinear exponential type of equation for shrinkage as a function of moisture content for drying a malt bed. Ratti (1994) conducted studies on shrinkage of many food materials like potatoes, apples and carrots of different geometry and drying conditions; a simple model in which volumetric ratio represented by one or two line segments was developed. Saravacos and Raouzeos (1986) and Masi and Riva (1988) have used similar techniques to account for shrinkage of grapes during drying.

\subsection{Summary of Hot Air Drving of Grapes}

The main points from the studies of convection drying of grapes can be summarized as follows:

(a) In convection drying, the drying time may be reduced by increasing the air temperature. However, there is a quality-related upper temperature limit (about $80^{\circ} \mathrm{C}$ ), beyond which browning and other quality defects occur.

(b) Research has shown that the grape skin is the main barrier to mass transfer. This finding led to application of the method of dipping the grapes in a hot emulsion of ethyl oleate so as to reduce the skin resistance and further increase the drying rate (Martin and Stot, 1957; Dudman and Grncarevic, 1962; Chambers and Passinham, 1963; Ponting and McBean,1970; Riva and Peri, 1986; Raouzeos and Saravacos, 1986; Saravacos and Marousis, 1988). Grapes pretreated with $2 \%$ ethyl oleate took $100 \mathrm{~h}, 29 \mathrm{~h}, 13 \mathrm{~h}, 9 \mathrm{~h}$, and $5 \mathrm{~h}$ to reach $50 \%$ mass loss when dried at temperatures of $38,49,65,80$ and $93^{\circ} \mathrm{C}$, respectively (Ponting and McBean, 1970).

(c) Before treatment, grapes are generally fumigated with sulphur dioxide for about $6 \mathrm{~h}$, corresponding to about 900 ppm concentration (Jacob, 1944; Bolin et al., 1975; Riva and Peri, 1986; Masi and Riva, 1988). This appears to be a standard accepted procedure in the raisin industry to check discoloration. However, the use of sulphur dioxide in food products is always questionable from the standpoint of human health and it would help if this procedure could be eliminated. 
(d) Higher airflow rates are generally adopted in grape drying experiments. Most of the investigators have used a velocity of about $2 \mathrm{~m} / \mathrm{s}$ (Riva and Peri, 1986; Masi and Riva, 1988; Saravacos and Raouzeos, 1986; Saravacos and Marousis, 1988). The reason for higher airflow rates used in experimental work may be to permit the assumption of uniform drying conditions and therefore facilitate analysis of drying data (Riva and Peri, 1986). However, Chambers and Passingham (1963) used low air flow rates and still obtained comparable drying results. The threshold air velocity, over which no increase in the drying rate was observed, was found to be $2-3 \mathrm{~m} / \mathrm{s}$ (Berna et al., 1991). From an optimization point of view, it is necessary to establish an optimum air flow in combination with other drying parameters.

\subsection{Microwave Heating and Drying}

Heating and drying with microwaves or other dielectric energy are distinctly different from so-called convection drying. Convection drying depends on convective heat transfer from the medium to the surface and then conductive transfer to the interior, which is slow. Heating with microwave or dielectric energy is a volumetric process in which the electro magnetic field interacts with the material as a whole and causes nearly an instantaneous heating. The governing factors for heating are the mass and geometry of the material, its specific heat, its dielectric properties, the heat loss mechanisms, the output power level of the microwave source and the coupling efficiency. The topic of microwave heating of food materials is extensively covered in the following literature: Metaxas and Meredith, 1983; Decareau and Peterson, 1986 and Mudgett, 1990. The fundamental dielectric properties that are responsible for dielectric heating in a material are: 1) the dielectric constant $\left(\varepsilon^{\prime}\right)$ and the dielectric loss factor $\left(\varepsilon^{\prime \prime}\right)$. At a given frequency these properties are both influenced by the moisture content and temperature of the material. 


\subsubsection{Dielectric Properties}

Dielectric properties are very important in MW heating and processing design and applications. They provide an intangible link between the electromagnetic waves and the material being processed and a clear understanding of the dielectric properties of a material can lead to a better understanding of the internal heating mechanisms. Electrical and dielectric properties of many food materials have been reported (Nelson, 1990; Mudgett, 1990; Kudra et al., 1992), but information on grapes is not available.

Dielectric properties are defined in terms of the dielectric constant $\left(\varepsilon^{\prime}\right)$ and loss factor $\left(\varepsilon^{\prime \prime}\right)$. Dielectric constant is a measure of the ability of a material to couple with MW. Loss factor is the measure of the ability of a material to heat by absorbing MW. Loss factor actually refers to the effective loss factor which also includes a direct current (d.c.) conductivity effect. The power dissipated inside a material is proportional to $\varepsilon^{\prime \prime}$, the effective loss factor. Their ratio, $\varepsilon^{\prime \prime} / \varepsilon^{\prime}$, called the loss tangent, is a measure of the material's ability to generate heat (Mudgett, 1990). Two factors that affect food material's dielectric properties are the charge due to ionic concentrations and the water content. Microwave heating is greatly affected by presence of water in foods (von Hippel, 1954; Mudgett, 1990; Nelson, 1990). Water is the major absorber of $\mathrm{MW}$ in the foods and, consequently, the higher the moisture content, the better the heating. The organic constituents of food are dielectrically inert ( $\varepsilon^{\prime}<$ 3 and $\varepsilon^{\prime \prime}<0.1$ ) and, compared to aqueous ionic fluids or water, may be considered transparent to MW (Mudgett, 1990). Only at very low moisture levels, when the remaining traces of water are bound and unaffected by the rapidly changing $M W$ field, do the components of low specific heat become the major factors in heating. In high carbohydrate foods and syrups the dissolved sugars are the main MW absorbers (Mudgett, 1990). Grapes, being essentially a high sugar material have a complex $\mathrm{MW}$ heating mechanism due to the interaction with other constituents. As the grape undergoes drying its heating pattern also changes with its composition. 


\subsubsection{Moisture Content}

The amount of free moisture in a substance greatly affects its high frequency heating as governed by its dielectric properties. Water has a very high dielectric constant, approximately 78 at room temperature; whereas that of the base materials is of the order of 2 . Tinus, with a large percentage of water the dielectric constant of a material increases proportionately. But when different dielectrics are mixed, different phenomena may manifest. In general:

a. The higher the moisture content, the higher is $\varepsilon^{\prime}$.

b. $\quad \varepsilon^{\prime \prime}$ increases with the moisture content, but levels off at higher moisture contents and nnay start decreasing at very high moisture contents.

c. The $\varepsilon^{\prime}$ of a mixture usually lies between that of its components.

In grains, at various microwave frequencies both $\varepsilon^{\prime}$ and $\varepsilon^{\prime \prime}$ increased with moisture content (Nelson, 1978). The dielectric loss factor depended little on frequency, but tended to increase with frequency at the higher end of the moisture content range studied ( 6 to $21 \%$, w.b.). The behaviour of the dielectric constant was regular in that it decreased as frequency increased and also decreased as moisture content decreased. The loss tangent and loss factor behaved irregularly, most likely because of dielectric relaxation and dispersion phenomena. Similar patterns were noted in a study on corn over a moisture range of 10 to 50 percent, over the frequency range of $1 \mathrm{GHz}$ to 11 $\mathrm{GHz}$ (Nelson, 1978).

\subsubsection{Temperature}

In the case of distilled water, both the dielectric constant and the loss factor decrease with increasing temperature (von Hippel, 1954). But in the case of foods at low moisture contents the dielectric constant and loss factor increase with temperature since physical binding reduces and dipoles are freer to re-orientate. At hydrations above $25 \%$, the loss factor decreases with increasing temperature because of its influence on ionic conductivity (Metaxas 
and Meredith, 1983). The influence of temperature and frequency have been investigated in the temperature range of -20 to $+60^{\circ} \mathrm{C}$ (Bengtsson and Risman, 1971). The investigation clearly showed the large differences of dielectric constant and effective loss factor between ice and liquid water. Since most foodstuffs contain an appreciable amount of water, their dielectric properties follow a similar pattern to those of water in bulk when plotted as a function of temperature. Both $\varepsilon^{\prime}$ and $\varepsilon^{\prime \prime}$ show large increases with temperature as the material thaws, after which the values again decrease with increasing temperature except for salted foods which show a continuing increase. After thawing, the decrease in dipolar losses with increasing temperature at $2.8 \mathrm{GHz}$ is balanced by an increase in conductivity losses resulting in a practically constant dielectric loss factor. In the case of both milk and whey powders (Rzepecka and Pereria, 1974), the loss factor increases gradually between $10^{\circ} \mathrm{C}$ and $+70^{\circ} \mathrm{C}$ since these materials contain small amounts of water. But in the case of frozen butter (m.c. $=16.5 \%$ ), the effective loss factor undergoes large changes since the dielectric properties of frozen moisture, (ie, ice) are significantly lower than those of liquid water. The volumetric heat source permits the rapid transfer of energy throughout the body of the wet solid and completely alters the physical characteristics of the drying process. Perkin (1979) described three categories of microwave drying as follows: (1) The wet solid is rapidly heated to its boiling point and then $\partial \mathrm{T} / \partial \mathrm{t}=0$; such a method is only suitable for materials which are not heat sensitive; (2) Temperature increases throughout the drying operation; such heating may occur when the throughput of the material is fast and the boiling point of the liquid is not attained; (3) The solid is heated to a critical temperature below the boiling point and the material is force cooled; this method is applicable to heat sensitive materials. In high frequency drying, the temperature of the solid is not limited to the wet bulb temperature of the drying air. The temperature of the wet solid approaches the boiling point of liquid leading to an internal evaporation and increase in total pressure within the pores. Mass transfer is 
primarily governed by the total pressure gradients due to rapid establishment of a vapour phase within the material (Metaxas and Meredith, 1983). This phase of drying precedes the constant drying rate period and is termed the "liquid movement period" (Lyons et al., 1972). As a result, the rate of moisture removal increases beyond the constant drying rate limit. Metaxas and Meredith (1983) compared the rate of evaporation in porous media with that of a dielectric material. They reported that in a web of porous medium the evaporation rate is constant until the critical moisture content is reached and below which the evaporative efficiency starts to fall and the corresponding loss factors are relatively flat. They attributed bound water absorption effects to uniform values of the loss factor in this region of low moisture.

\subsection{Microwave Applicators}

The applicator is that component of a microwave system that couples energy with the product. The unique characteristic of microwave penetration coupled with the characteristics of absorption, transmission and reflection permits the application of energy where it is needed. A wide variety of applicators is available for various types of processes including drying. The important types are: cavity applicators, waveguide applicators and antenna applicators. The most popular applicator for heating is the cavity type; a consumer microwave oven belongs to this group. An industrial cavity microwave applicator uses technology similar to commercial and consumer microwave ovens, i.e, door seals, waveguides, mode stirrer, etc. Multimode oven applicators are mechanically simple, and versatile in accepting a wide range of heating loads (Metaxas and Meredith, 1983).

\subsubsection{Multimode Cavity Applicators}

In principle, the multimode applicator is a closed metal box with some means of coupling in power from a generator. The dimensions of the box should be several wave lengths long in at least two dimensions; such a box will 
support a large number of resonant modes in a given frequency range (Metaxas and Meredith, 1983). In this type of applicator, the load usually represents only a small fraction of the volume of the applicator and is subjected to the microwave field from all sides. This causes a three-dimensional bulk heating effect which is unique to cavity applicators. The major problem with cavity applicators is non-uniformity of the microwave field in the load (Schiffmann, 1987). This problem can be prevented by providing a mode stirrer (rotating metal bladed fan) in the cavity or by turning the load on turntables, which causes reflective scattering of energy and thus the absorption becomes more uniform. In the case of resonant multimode cavities the dimensions are fixed so as to support the maximum number of modes (Schiffmann, 1987).

\subsubsection{Single Mode Applicators}

A single mode resonant cavity, or heater in the present context, consists of a metallic enclosure into which $\mathrm{MW}$ signals of correct electro magnetic polarization are applied (Metaxas and Meredith, 1983). The applied field suffers multiple reflections between the preferred directions and the geometry of the cavity determines this configuration. The superposition of the incident and reflected waves gives rise to standing wave pattern which is very well defined in space for simple structures. The precise knowledge of the electromagnetic field configurations enables dielectric material under treatment to be placed in the position of maximum electric field for optimum transfer of energy. High absorption of the incident energy is a feature of these cavities (Metaxas and Meredith, 1983; Pozar, 1990). However, operation must be within narrow frequency bands in order to maintain high coupling efficiencies.

In general, for the same power applied, a single mode resonant heater will establish much higher electric field strengths than the multimode or the travelling wave applicator. Development of associated microwave circulators and systems for proper tuning and matching to make them workable are the 
essential features of these devices (Metaxas and Meredith, 1983).

\subsection{Microwave Drving Studies on Agricultural Materials}

The effect of microwave power on the drying characteristics of seed grade corn was investigated at different temperatures and inlet air flow rates (Shivhare et al., 1991, 1992). It was observed that the drying time was reduced from 5.0 to 3.5 and 2.5 hours, respectively, when absorbed microwave power was increased from 0.25 to 0.5 and $0.75 \mathrm{~W} / \mathrm{g}$, of wet grain. Product quality was assessed in terms of germination and bulk density and was observed to decrease with increasing microwave power, increase with inlet air flow rate, and remain largely unaffected by inlet air temperatures in the range studied $\left(30^{\circ} \mathrm{C}-40^{\circ} \mathrm{C}\right)$. A response surface analysis of the data indicated that it is possible to obtain germination rates of over $90 \%$ if the microwave power level and inlet air velocity are jointly adjusted to prevent overheating of the kernels (Shivhare et al., 1992).

Otten and St. John (1988) studied the drying behaviour of a single layer of peanut pods and kernels fully exposed to different levels of microwave energy at $2450 \mathrm{MHz}$ in an experimental thin layer drying apparatus. They reported that drying rates from 10 to 94 times the normal rate for convection drying were achieved for pods and 8 to 32 times for kernels. The final seed temperature ranged from 41 to $58^{\circ} \mathrm{C}$. They described microwave drying behaviour of peanuts by a two-term exponential model. Gunasekaran (1990) dried corn in both pulsed and continuous modes in a commercial microwave oven at power levels of 10 and $20 \mathrm{~W} / \mathrm{g}$ and reported faster rate of drying with good product quality as judged by visual observations. In line with the work of Shivhare (1991), the pulsed mode of application of microwave power was more energy efficient than the continuous one. The pulsed mode provided an intermittent MW power thus the energy applied on the material was smaller than in continuous mode. The power levels used here are much higher than the ones used by Shivhare (1991). Verma et al. (1991) investigated heat and 
mass transfer processes during rice parboiling with respect to microwave power level and absolute pressure. Caldas (1992) reported experimental results of radio frequency drying of granular materials like rice, maize, wheat, soya and coffee; rice was the fastest drying product followed by maize and wheat. According to the author the presence of oil in soya and coffee which hindered the moisture diffusion and hence slower drying rates in these materials.

In drying of agricultural materials, control of internal temperature of the product is very important so as not to burn the product. The internal heat generated due to microwave energy absorption directly depends up on the moisture content which is progressively decreasing with time. The temperature rise as a result of internal heating also affects the dielectric properties. Air, which is used as a moisture carrying medium also plays an important role in the control of temperature of the product. A delicate balance is to be achieved between these variables so as to establish an optimum drying condition. The literature review revealed no work done on microwave drying of grapes.

Grapes could lend themselves to microwave drying for two reasons; they are rich in moisture and have high ionic conductivity (pH 3.6), both of which favour higher microwave power absorption. As demonstrated in the earlier studies, convective drying of grapes is a time consuming process that makes it inefficient. On application of snall amounts of microwave energy, the drying rates of many agricultural materials could be accelerated as shown in earlier studies (Otten and St. John., 1988; Shivhare, 1991; Al-Duri and McIntyre, 1992). With this proposition some feasibility studies were planned for drying grapes with microwave energy. The work that was carried out is outlined and discussed in the chapters to follow. 


\section{CHAPTER III}

\section{PRELIMINARY STUDIES OF MICROWAVE DRYING OF GRAPES}

\subsection{Introduction}

The primary objective of this work was to determine whether grapes could be dried into quality raisins in a microwave field, an application which had not been previousiy reported in the literature. The approach to this work included comparisons of microwave-dried grapes with convectively-dried grapes with and without the various pre-treatments used in commercial raisin production. The pre-treatments used in industry include: a) fumigation with sulphur dioxide to ensure a light coloured raisin; a) dipping pretreatments in surfactant emulsions, such as ethyl oleate solutions, to reduce drying time, and c) holding grapes for some time after the pretreatment and washing them to remove residual chemicals from the surface (Riva et al.,1986). In commerical raisin production the fruits are fumigated to an $\mathrm{SO}_{2}$ concentration of $900 \mathrm{ppm}$ and are then dipped in hot alkaline solutions to make the outer skin more permeable to water transport such that drying is more rapid. The effects and effectiveness of these pretreatments on hot air drying of grapes are reported in literature (Ponting and McBean, 1970; Riva et al., 1986; Saravacos and Marousis, 1988).

As a starting point, uniform batches of Thompson seedless grapes were dried in a microwave oven modified to permit control of inlet air temperature and inlet air velocity. Some batches were dried without applying microwave energy so as to simulate the forced convection situation, while others were dried at particular microwave power settings combined with various inlet air temperatures. The inlet air velocity was held constant in these preliminary studies. 


\subsection{Materials and Methods}

A domestic MW oven of rated capacity $600 \mathrm{~W}$ (output power) was modified for use as a dryer in the present study (Fig. 3.1). The microwave oven operated at $2450 \mathrm{MHz}$ and the duty cycle was adjustable in increments of $10 \%$ ranging from a power level of 1 ( $10 \%$ duty cycle) to 10 ( $100 \%$ duty cycle) as provided on the control panel of the MW oven. Power level 1 corresponded to full power for 2 seconds in every 30 second interval. A circular hole of 0.1 m diameter was cut at the base of the microwave oven chamber and was covered with a fine metal wire mesh. A cylindrical tray made of clear acrylic with a perforated bottom fixed at the air inlet served as a tray to hold the test material for drying. Since spatial variation of electric field amplitudes can result in hot spots in the cavity and cause uneven heating (Metaxas and Meredith, 1983; Buffler, 1993), a mode stirrer was added to the oven. The stirrer was $0.22 \mathrm{~m}$ dia., made of aluminum metal sheet and driven by a small motor. It was placed in the cavity at the top of the oven. The stirrer rotated at 90 r.p.m. The blades of the stirrer were bent to an angle of $45^{\circ}$, since this configuration was reported to be suitable for highly absorptive materials (Metaxas and Meredith, 1983). A $0.25 \mathrm{~kW}$ blower supplied forced air; the ambient air was conditioned and was supplied at about $24^{\circ} \mathrm{C}$ and $50 \%$ relative humidity. A control valve varied the draft of air to the desired level and the air was then passed over a bank of controllable electrical heaters. A small hole drilled on the wall of the oven chamber served as an air vent. The inlet and outlet air temperatures were continuously monitored by $\mathrm{K}$ - type thermocouples located outside the microwave oven at the gas entry and exit slots and were recorded by a temperature logger (OM-2, Omega Engineering, Inc., Stanford, CT) with a precession of $\pm 0.5^{\circ} \mathrm{C}$. Air velocity was measured by a thermal anemometer which had a precession of $\pm 3 \%$ of full scale (Dwyer 5106, Dwyer Instruments Inc., Mich., MI). The mass of the test material was measured on a digital electronic balance which had a resolution of $0.01 \mathrm{~g}$ (PE 600, Mettler Instruments AG, Greifensee-Zurich, Switzerland) by taking out the tray along 


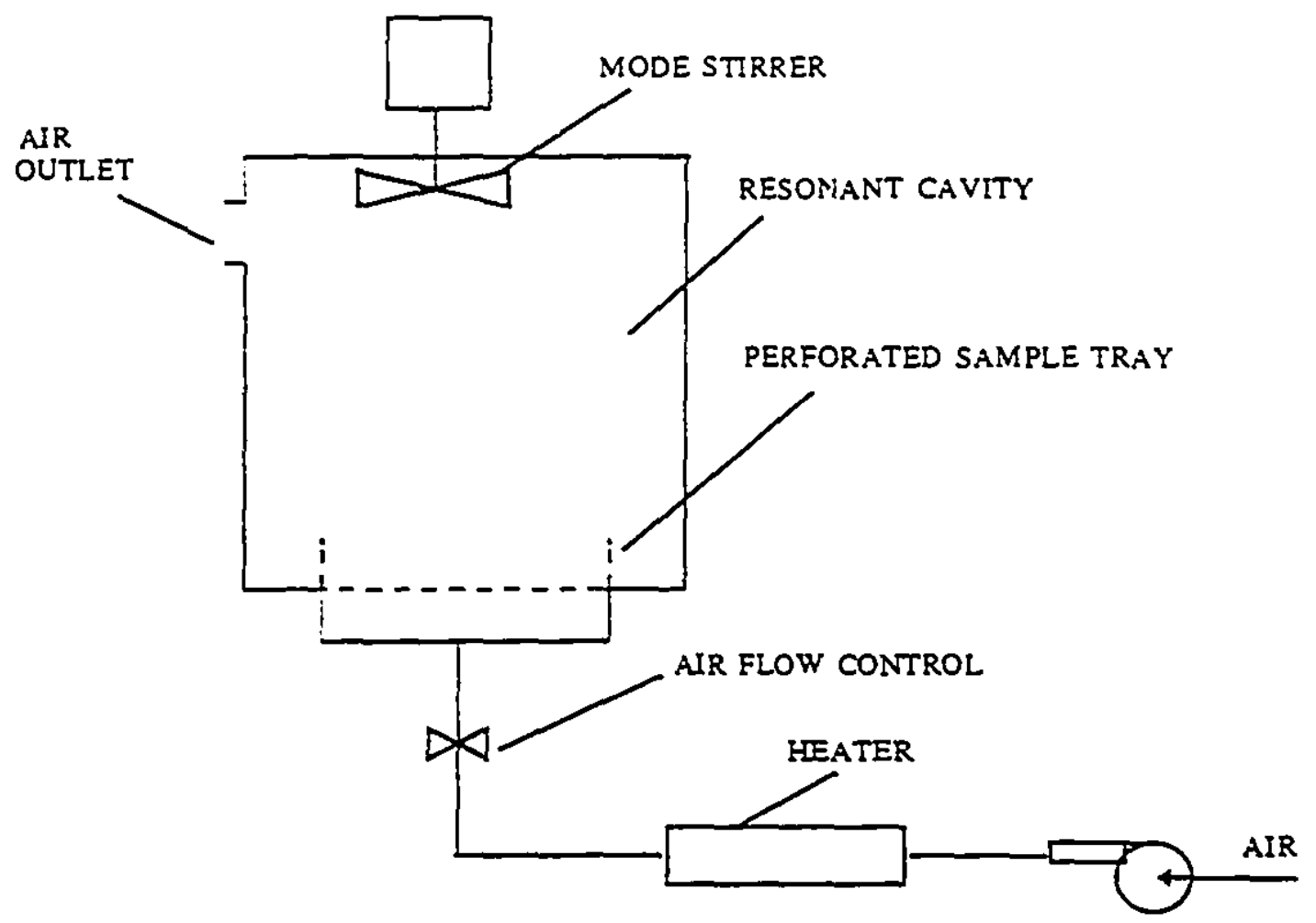

Fig. 3.1. Schematic diagram of the $M W$ drying apparatus (modified MW oven). 
with the sample at pre-determined intervals of time. When the microwave was off, the setup could be used as a conventional convective dryer; and when the microwave was on it could be used as a combined convective and microwave dryer. The preliminary studies indicated that a $10 \%$ duty cycle (Power level 1) was suitable for grapes in this set-up; longer cycles resulted in overheating and burning of the product.

Thompson seedless grapes procured from a local market were used for the studies and were stored in a refrigerated room at $4^{\circ} \mathrm{C}\left( \pm 1^{\circ} \mathrm{C}\right)$. Before the drying trials, fruits were removed from the cold room and allowed to stand for about $2 \mathrm{~h}$ to come to ambient conditions. During this time, the stems were removed manually. The initial moisture content of the fruit was determined for each run and was found to vary from 0.818 to $0.795 \mathrm{~kg} / \mathrm{kg}$ (w.b). In most cases, the moisture content was close to $0.810 \mathrm{~kg} / \mathrm{kg}$ (w.b.). The initial moisture content for each treatment was expressed as the mean of three replicates within that treatment. The analysis of initial moisture contents showed that the computed means were within tine 95\% confidence interval (CV $=0.91 \%$ ). Since the size of the grapes was not uniform, only berries having a diameter of $0.0175 \pm 0.001 \mathrm{~m}$, which represented the average size, were selected. It was important to choose uniformly sized berries for this study since this factor would otherwise influence the drying kinetics. However for a normal commercial application, such a classification would not be necessary. The selected fruits were uniformly spread on the bottom of the tray and dried in a single layer. The sample size for each test was about $50.0( \pm 1.5) \mathrm{g}$. Moisture loss due to drying was measured at $0.5 \mathrm{~h}$ intervals. The grapes were dried till they reached a final moisture content of about $0.15 \mathrm{~kg} / \mathrm{kg}$, wet basis $(0.18 \mathrm{~kg} / \mathrm{kg}$, dry basis), which represented the level of moisture in raisins for safe storage (Jacob, 1944; Winkler et al., 1974). The moisture content of samples was determined using a vacuum oven method at $70^{\circ} \mathrm{C}$ till a constant weight was achieved (Boland, 1984; Canellas et al., 1993).

Convective and microwave drying runs were executed at inlet air 
temperatures of $30,45,50$ and $55^{\circ} \mathrm{C}$. The inlet airflow rate for all experiments was kept at $2 \mathrm{~m} / \mathrm{s}$ to ensure adequate removal of moisture from the fruit laver in the tray. The effect of pretreating fruits with an emulsion of $2 \%$ ethyl oleate in $0.5 \%$ sodium hydroxide was also investigated for each of the drying experiments. The pretreatment consisted of dipping the grapes for $30 \mathrm{~s}$ in the alkaline mixture maintained at $80^{\circ} \mathrm{C}$ (Ponting and McBean, 1970, Riva and Peri, 1986, and Saravacos and Marousis, 1988). The fruits were then removed, rinsed with water, free drained and used for studies. All the experiments were replicated thrice, and the mean moisture content from each set of replicates was used for data interpretation.

A second set of experiments based on the results of the above and aimed at evaluating the following chemical pretreatments was run using the same apparatus:

$\mathrm{C}_{1}$ - Dipping for $30 \mathrm{~s}$ at $80^{\circ} \mathrm{C}$ in $0.5 \%$ sodium hydroxide $(\mathrm{NaOH})$ solution, ( $0.5 \% \mathrm{NaOH}$ only).

$\mathrm{C}_{2}$ - Dipping for $30 \mathrm{~s}$ at $80^{\circ} \mathrm{C}$ in $2.0 \%$ ethyl oleate (EO) in $0.5 \% \mathrm{NaOH}$ solution, $(2 \% \mathrm{EO}+0.5 \% \mathrm{NaOH})$.

$\mathrm{C}_{3}$ - Dipping for $30 \mathrm{~s}$ at $80^{\circ} \mathrm{C}$ in $3.0 \% \mathrm{EO}$ in $0.5 \% \mathrm{NaOH}$ solution, $(3 \% \mathrm{EO}+0.5 \% \mathrm{NaOH})$.

$\mathrm{C}_{4}$ - Dipping for $3 \mathrm{~min}$. at $40^{\circ} \mathrm{C}$ in $3.0 \% \mathrm{EO}$ in $2.5 \%$ potassium carbonate $\left(\mathrm{K}_{2} \mathrm{CO}_{3}\right)$ solution, $\left(3 \% \mathrm{EO}+2.5 \% \mathrm{~K}_{2} \mathrm{CO}_{3}\right)$.

Groups of berries were subjected to different dipping pretreatments and then dried in single layers in the sample holder. The experimental setup was as described above and illustrated in Fig. 3.1. After each pretreatment, the grapes were washed twice in tap water, drained and immediately taken for drying tests.

Finally the possible effects of washing of grapes and time of holding on drying was tested using the best of the treatment combinations from the above tests (which was $\mathrm{C}_{2}$ ). These washing treatments were:

$T_{1}$ - Pre-treated grapes washed twice in tap water, free gravity 
drained and immediately taken for drying with no holding time, (wash, $0 \mathrm{~h}$ ).

$\mathrm{T}_{2}$ - Pre-treated grapes not washed, free gravity drained and were immediately taken for drying with no holding time (no wash, $0 \mathrm{~h}$ ).

$\mathrm{T}_{3}$ - Pre-treated grapes not washed and were kept for $1 \mathrm{~h}$ holding time before drying, (no wash, $1 \mathrm{~h}$ ).

To quantify the importance of the outer skin to the drying kinetics, a few tests were also conducted on de-skinned grapes. In one of the tests, the $\mathrm{C}_{2}$ pretreatment was applied to peeled grapes $\left(\mathrm{PC}_{2}\right)$. In another test, no chemical pretreatment was applied $\left(\mathrm{PC}_{0}\right)$. Care was taken not to disturb the contents of the fruit while peeling. An experiment was also conducted under forced hot air convective conditions with pretreatment $\mathrm{C}_{2}\left(\mathrm{CC}_{2}\right)$. These tests were carried out for the sake of comparison and were conducted under the same drying conditions as mentioned earlier.

The experiments were performed in a randomized complete block design (RCBD) with three replicates to study the effect of different treatments as discussed. The response parameter, drying time, was the time required to dry grapes to a final moisture content of about $0.18 \mathrm{~kg} / \mathrm{kg}$ dry mass. Analysis of variance was conducted to determine whether significant differences existed between different samples and pretreatments. Treatment differences were determined using Tukey's test (Steel and Torrie, 1980; SAS, 1989).

\subsection{Results and Discussion}

\subsubsection{Preliminary Drying Studies}

The three methods of drying studied here were i) Convective drying with pretreatment $\left(\mathrm{CT}_{1}\right)$, ii) Microwave drying without pretreatment $\left(\mathrm{MT}_{\mathrm{o}}\right)$, and iii) Microwave drying with pretreatment $\left(\mathrm{MT}_{1}\right)$; drying air temperature $\left(\mathrm{T}_{z}\right)$ was kept constant at $45^{\circ} \mathrm{C}$ and the air velocity $\left(\mathrm{V}_{z}\right)$ was $2 \mathrm{~m} / \mathrm{s}$ at the drying layer. Under each of these treatments, drying was continued until the desired final moisture content of $0.18 \mathrm{~kg} / \mathrm{kg}$ (dry basis) was reached. The resulting mean 
drying times (i.e. mean of three replicates in a treatment) for $\mathrm{CT}_{1}, \mathrm{MT}_{0}$ and $\mathrm{MT}_{1}$ were $31.33,19.17$ and $13.00 \mathrm{~h}$, respectively. The variation in drying time within the replicates of any given treatment was found to be small. The final drying times for all the runs were analyzed using a completely randomized design model. It was found that the treatments differed significantly at the 0.01 level. The mean moisture content of grapes was plotted against $t$ for the different drying methods as shown in Fig. 3.2. The corresponding drying rate curves are shown in Fig. 3.3; drying rates were derived by numerical differentiation of drying curves (Fig. 3.2) using three-point formula (Pachner, 1984). The drying rates were plotted against corresponding moisture contents to illustrate their dependency (Fig. 3.3). The grape berries were found to shrink continuously during drying leading to characteristic wrinkles of the dried raisins in all the three methods of drying. The drying curves were typical of materials with internally controlled mass transfer. Conventional drying is a slow process relying on heat conduction from the outer surface towards the interior and took as much as $32 \mathrm{~h}$ to reach the desired final moisture content of about $0.18 \mathrm{~kg} / \mathrm{kg}$, dry basis.

The results of the convective drying ( $\left.\mathrm{CT}_{1}\right)$ trials (Figs. 3.2 and 3.3), agree with earlier reports of the absence of a constant rate drying period and following the trend of a falling rate period (Raouzeos and Sarvacos, 1986, and Riva et al., 1986). The microwave drying behaviour ( $\left(\mathrm{MT}_{0}\right.$ and $\left.M \mathrm{M}_{1}\right)$, was entirely different from that of $\mathrm{CT}_{1}$ as seen in Figs. 3.2 and 3.3. Pretreated grapes $\left(\mathrm{MT}_{1}\right)$ and grapes without pretreatment $\left(\mathrm{MT}_{0}\right)$ took about 13 and $19 \mathrm{~h}$, respectively, to dry to the desired final moisture content of $0.18 \mathrm{~kg} / \mathrm{kg}$ (Fig. 3.2). The drying rates were initially higher corresponding to a moisture content up to about 1.75 $\mathrm{kg} / \mathrm{kg}$ (Fig. 3.3) and the time to reach this moisture content was roughly $2.5 \mathrm{~h}$ in the microwave situation as compared to about $7 \mathrm{~h}$ in convective drying (Fig. 3.2). The moisture content of the grapes was high during the initial part of drying and this high moisture content was responsible for higher microwave power absorption, which must have led to higher product temperature and a 


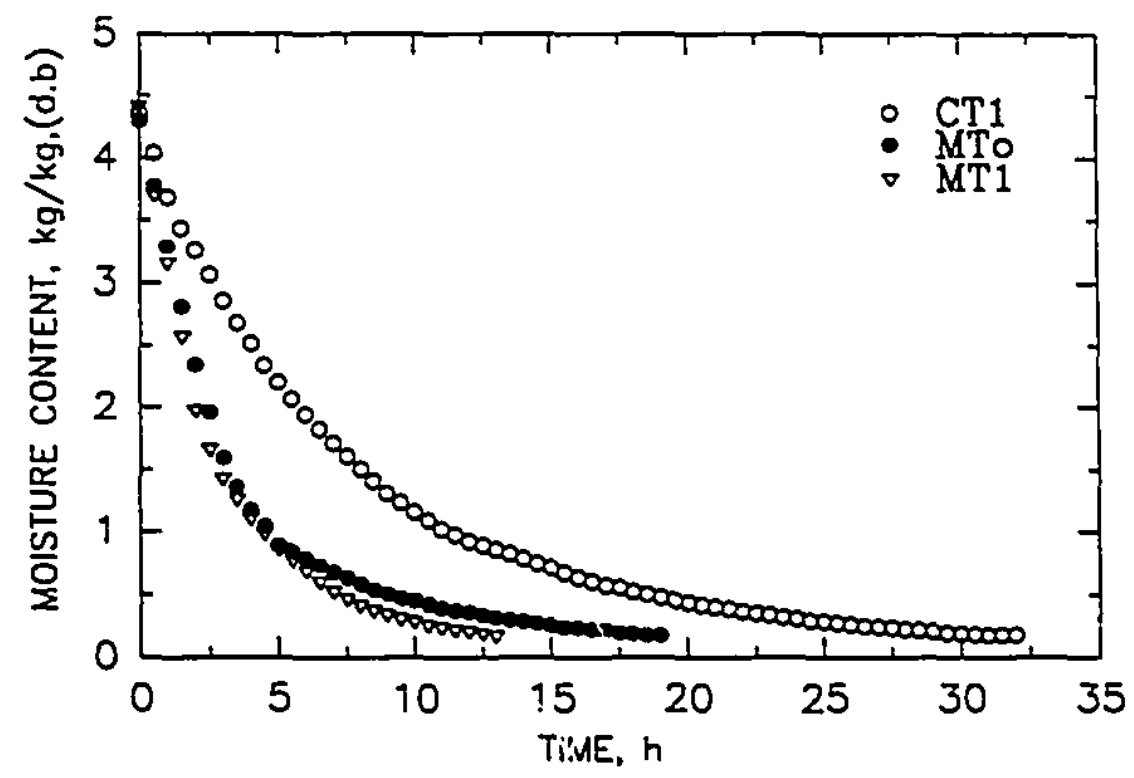

Fig. 3.2. Drying curves for grapes by different methods of drying $\left(T_{g}=45^{\circ} \mathrm{C}\right.$. $M W$ Power level $\left.1, V_{B}=2 \mathrm{~m} / \mathrm{s}\right)$.

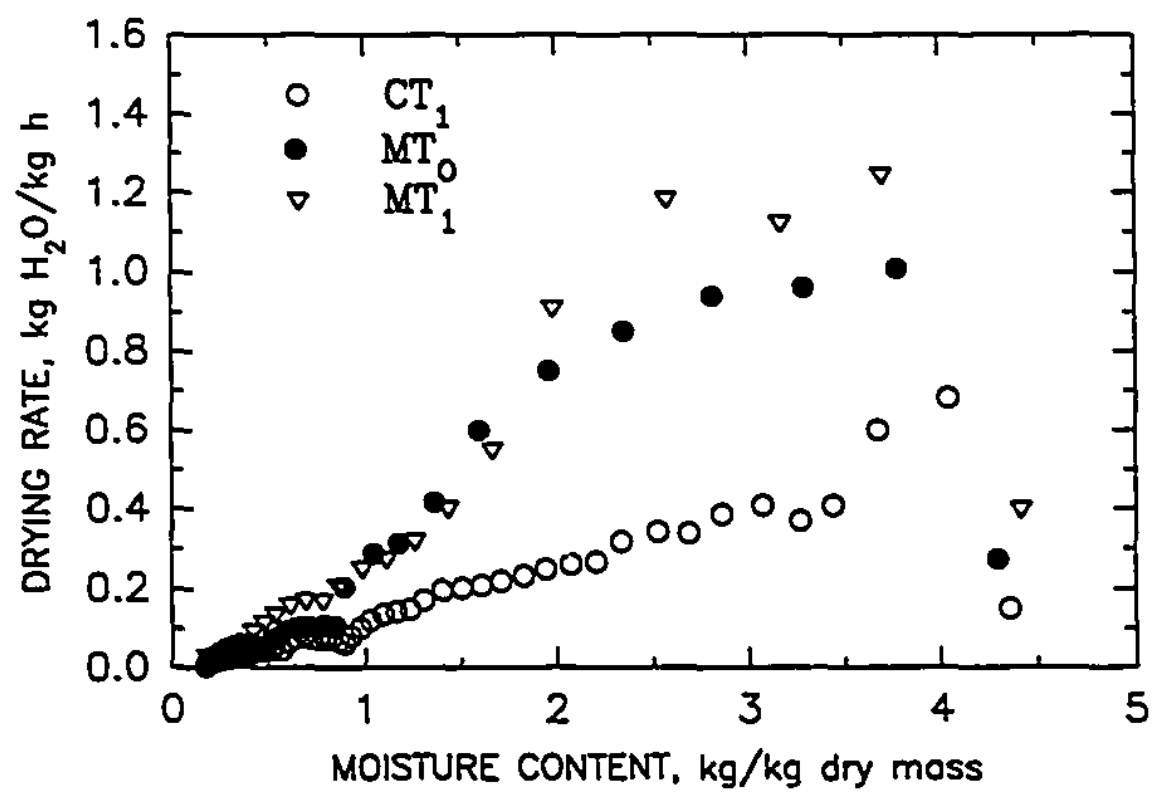

Fig. 3.3. Drying rate curves for grapes by different methods of drying $\left(T_{g}=45^{\circ} \mathrm{C}, \mathrm{MW}\right.$ Power level $\left.1, \mathrm{v}_{\mathrm{g}}=2 \mathrm{~m} / \mathrm{s}\right)$. 
higher diffusion rate. It was reported that the rate of moisture removal during this period increased even beyond the constant drying rate limit in case of porous materials (Perkin, 1990; Turner and Jolly, 1991). This phenomenon was clearly exhibited in Fig. 3.3. However, the exact mechanism of moisture movement in grapes under microwave drying is yet to be understood.

The drying rate curves (Fig. 3.3) indicated the absence of a constant rate drying period. After reaching an early maximum, the drying rate dropped rapidly, signifying a falling rate period. The moisture transfer outwards lagged behind the evaporation rate at the surface. Microwave power absorption largely depends on the moisture content of the material. As the product loses moisture, the microwave power absorption decreases progressively. This could explain the decreased drying rate during the latter part of drying, as well as the fact that the $M W$ drying rate tends to approach the convection drying rate during the final stages of drying. When the product attained a moisture content of about $0.7 \mathrm{~kg} / \mathrm{kg}$ (d.b.), the drying rates were similar to that of $\mathrm{CT}_{1}$. The drying curves of $\mathrm{MT}_{0}$ and $\mathrm{MT}_{1}$ (Fig. 3.2) indicate that the effect of the pretreatment on drying was not very dominant since they followed more or less a similar path throughout the course of drying. The pretreated grapes took about $6 \mathrm{~h}$ less to dry to the same final moisture content than those which were not pretreated. $\mathrm{MT}_{0}$ not only dried frster than $\mathrm{CT}_{1}$ (savings in drying time of as much as $63 \%$ ), but no chemirals were used to pretreat the grapes. The quality of microwave dried raisirss, as evaluated by visual observation of colour and appearance, was found to se comparable to that of conventionally dried raisins with pretreatment. An important point to be noted here is that fumigation of fruits with sulphur dioxide is necessary to get a product of acceptable quality (Winkler et al., 1974) by convective drying and that it may not be necessary when microwaves are used, as observed in this study.

Since the moisture transfer rate was high during the initial part of microwave drying, as indicated by the accelerated drying rate, it was 
important to pass air through the dryer at a proper temperature to ensure rapid evaporation of available free moisture present on the surface. Tests were conducted at air temperatures of $30^{\circ} \mathrm{C}\left(\mathrm{MT}_{1} 30\right), 45^{\circ} \mathrm{C}\left(\mathrm{MT}_{1} 45\right), 50^{\circ} \mathrm{C}\left(\mathrm{MT}_{1} 50\right)$ and $55^{\circ} \mathrm{C}\left(\mathrm{MT}_{1} 55\right)$ to optimize the air temperature needed for microwave drying. A high air velocity of $2 \mathrm{~m} / \mathrm{s}$ was used in all these tests. Microwave drying of pretreated grapes at different air temperatures are summarised in Fig. 3.4. The drying curves (Fig. 3.4) clearly indicated the strong effect of temperature; the drying times required to reach a final moisture content of about $0.18 \mathrm{~kg} / \mathrm{kg}$, (d.b), for $\mathrm{MT}_{1} 30, \mathrm{MT}_{1} 45, \mathrm{MT}_{1} 50$ and $\mathrm{MT}_{1} 55$ were 43.6, 13.0, 8.7 and $6.8 \mathrm{~h}$, respectively. These drying times were the means of three replications and the variation amongst the replicates was observed to be small (CV for $M T_{1} 30, M \Gamma_{1} 45, M T_{1} 50$ were $1.75,3.84,3.33$ and $4.23 \%$, respectively). These treatment means of drying times were found to be significantly different (Duncan's multiple- range test at 0.01 level). Since the applied microwave power was the same in all these cases, the microwave absorption at a particular moisture content must also have been the same. It is therefore, the difference in air temperature which was responsible for the changes in drying rates. An air temperature of $30^{\circ} \mathrm{C}$ was definitely inadequate to evaporate the surface moisture as was evidenced by slow drying (Fig. 3.4). The fastest drying occurred at $55^{\circ} \mathrm{C}$; however, heat damage of the raisin was visible (darker colour). The best temperature seemed to be $50^{\circ} \mathrm{C}$, since this temperature resulted in faster drying and good product quality.

\subsubsection{Effect of Chemical Pretreatments on Microwave Drying}

The times required to dry grapes under different pretreatments to a final m.c of about $0.18 \mathrm{~kg} / \mathrm{kg}$ in the $\mathrm{MW}$ dryer with a $10 \%$ duty cycle mode (power level 1) and an air temperature of $50^{\circ} \mathrm{C}$, are given in Table 3.1, along with the results from Tukey's means separation test (SAS, 1989). 


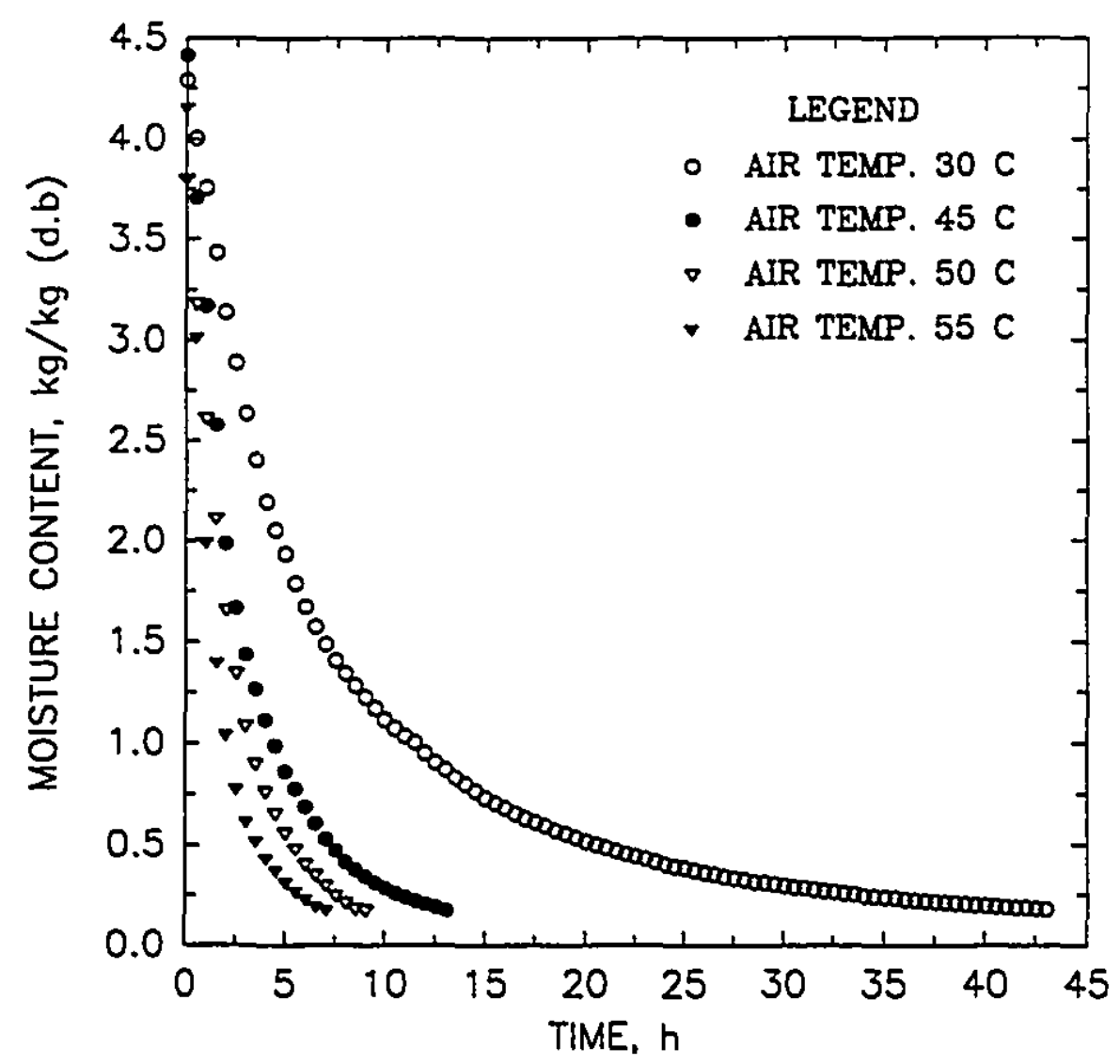

Fig. 3.4. MW drying curves of pretreated grapes at air temperatures: $30^{\circ} \mathrm{C}, 45^{\circ} \mathrm{C}, 50^{\circ} \mathrm{C}$ and $55^{\circ} \mathrm{C}$ (air flow $2.0 \mathrm{~m} / \mathrm{s}$. MW Power level 1). 
Table 3.1. Drying time, $h$, under different dipping pretreatments.

\begin{tabular}{|c|c|c|c|c|}
\hline Blocks(R) & $\begin{array}{c}\mathrm{C}_{1} \\
0.5 \% \mathrm{NaOH}\end{array}$ & $\begin{array}{c}\mathrm{C}_{2} \\
2 \% \mathrm{EO}^{+} \\
0.5 \% \mathrm{NaOH}\end{array}$ & $\begin{array}{c}\mathrm{C}_{3} \\
3 \% \mathrm{EO}+ \\
0.5 \% \mathrm{NaOH}\end{array}$ & $\begin{array}{c}\mathrm{C}_{4} \\
3 \% \mathrm{EO}+ \\
2.5 \% \mathrm{~K}_{2} \mathrm{CO}_{3}\end{array}$ \\
\hline 1 & 12.0 & 8.5 & 8.0 & 11.0 \\
\hline 2 & 11.5 & 9.0 & 8.5 & 10.5 \\
\hline 3 & 11.5 & 8.5 & 8.5 & 11.5 \\
\hline Mean & $11.7^{\circ}$ & $8.7^{\circ}$ & $8.3^{b}$ & $11.0^{\circ}$ \\
\hline
\end{tabular}

Note: Means with a common letter are not significantly different.

The analysis of variance indicated that the drying time was significantly different among treatments ( $F$ value $=52$; d.f. $=3 ; P<0.001$ ). Two pairs of treatments emerged as not having significantly different drying times: $C_{1}$ and $\mathrm{C}_{4}$, and $\mathrm{C}_{3}$ and $\mathrm{C}_{2}$. The quality of raisins obtained was similar for all the treatments except $C_{1}$ which resulted in pale and dull coloured raisins rather than bright ones. The effects of chemical pretreatments on drying kinetics, was similar to those reported for pure convective drying (Riva et al., 1986), even though the drying times observed here were much shorter due to application of MW energy. Fig. 3.5 show the drying curves for grapes under these pretreatments. The tests conducted on de-skinned grapes showed that they dried the fastest $(4.5 \mathrm{~h})$ after the $\mathrm{C}_{2}$ pretreatment $\left(\mathrm{PC}_{2}\right)$, while unpeeled grapes $\left(\mathrm{C}_{2}\right)$ dried in $8.7 \mathrm{~h}$. The drying time for de-skinned fruits $\left(\mathrm{PC}_{0}\right)$ without $\mathrm{C}_{2}$ pretreatment was $5.5 \mathrm{~h}$. Further, the grapes with skin intact and treated with $\mathrm{C}_{2}\left(\mathrm{CC}_{2}\right)$ dried by forced convection (without $\mathrm{MW}$ power) in about $20 \mathrm{~h}$.

It is interesting to note that the peeled fruit that was not pretreated $\left(\mathrm{PC}_{0}\right)$ dried rnore slowly than the peeled fruit treated with ethyl oleate $\left(\mathrm{PC}_{2}\right)$. This confirms earlier claims that ethyl oleate not only decreases skin resistance to diffusion but also enhances the internal moisture diffusion process (Saravacos and Marousis 1988; Riva et al. 1986). 


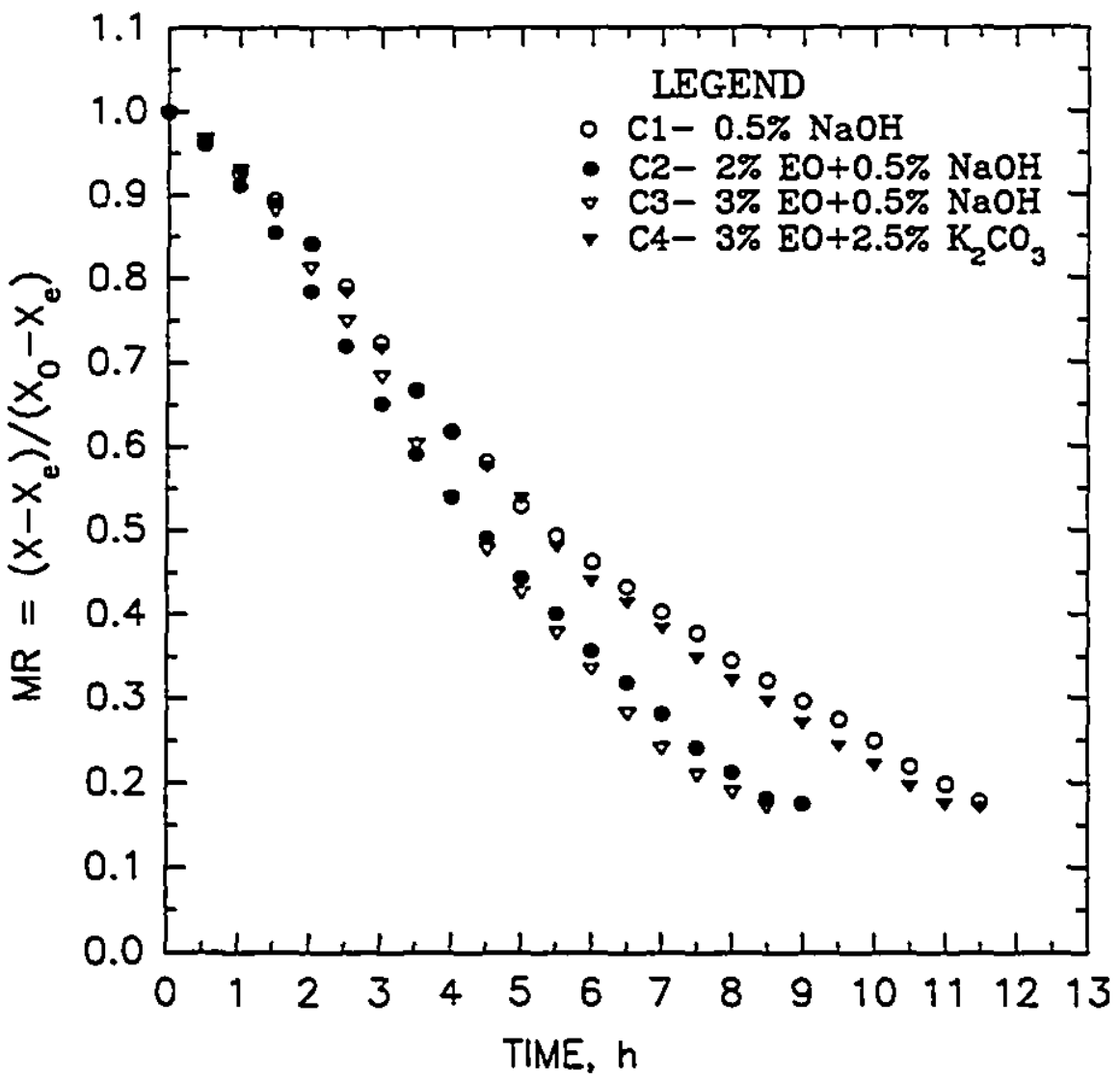

Fig. 3.5. Effect of different pretreatments on $\mathrm{MW}$ drying of grapes; $\mathrm{MW}$ Power Level $1, \mathrm{~T}_{\mathrm{g}}=50^{\circ} \mathrm{C}, \mathrm{V}_{\mathrm{g}}=2.0 \mathrm{~m} / \mathrm{s}$. 


\subsubsection{Interphase Over-all Mass Transfer Coefficients}

As the grapes were exposed to MW radiation, they absorbed energy and heat was generated within the fruit. In consequence, the temperature of the fruit rose above that of the surrounding air which was at $50^{\circ} \mathrm{C}$. Due to application of $\mathrm{MW}$ power with a $10 \%$ duty cycle, the power absorbed by the fruit was not steady and therefore the heat generated within the fruit was obviously not uniform. The power absorbed by a material depends on its dielectric properties, and these are dependent on moisture content (Metaxas and Meredith 1983; Decareau and Peterson 1986). In the case of grape drying, the amount of power absorbed must have changed with time according to the time-dependent change in moisture content. These factors lead to highly complex and transient heat conditions inside the fruit. The temperature measured inside a grape berry was found to range from $56-64^{\circ} \mathrm{C}$. A mean temperature of $60^{\circ} \mathrm{C}$ was assumed to represent the average temperature inside the fruit. MW power absorption was assumed to be uniform throughout the fruit at any given instant of time.

An expression for rate transfer, as given by Geankoplis (1993), is:

$$
J=k_{c} \Delta C=k_{c} \frac{\Delta p}{R T}
$$

where,

$$
\begin{aligned}
& \mathrm{J} \\
& \mathrm{k}_{\mathrm{c}} \quad=\text { mass flux of water, } \mathrm{kg} / \mathrm{m}^{2} \mathrm{~s} \\
& \Delta \mathrm{C}=\text { over-all inter phase mass transfer coefficient, } \mathrm{m} / \mathrm{s} \\
& \Delta \mathrm{p}=\text { partial water vapour difference, } \mathrm{kPa} \\
& \mathrm{R}=\text { gas constant for water vapour, } 461.5 \mathrm{~J} / \mathrm{kg} \mathrm{K} \text { and } \\
& \mathrm{T} \quad=\text { absolute temperature at the mass transfer surface, } \mathrm{K}
\end{aligned}
$$

In order to apply Eq. 3.1 it was assumed that the fruit surface attained the same temperature as that of its interior. This represented a situation of a spherical object with its wet surface at $60^{\circ} \mathrm{C}$ subjected to forced convection in a stream of drying air. The driving force term $\Delta$ p in Eq. 3.1 is the vapour 
pressure difference between saturation vapour pressure at $60^{\circ} \mathrm{C}$ at the surface and partial water vapour pressure of drying air at $50^{\circ} \mathrm{C}$ and $12 \% \mathrm{RH}$. The over-all inter phase mass transfer coefficient $k_{c}$ between the wet grape surface and the bulk air stream is given by a Sherwood relation of the type (Geankoplis, 1993):

$$
S_{h}=2+0.6 R e^{\frac{1}{2}} S c^{\frac{1}{3}}
$$

where,

$$
\begin{array}{ll}
\mathrm{S}_{\mathrm{h}} & =\text { Sherwood No. }=\mathrm{k}_{\mathrm{c}} \mathrm{d} / \mathrm{D} \\
\mathrm{R}_{0} & =\text { Reynolds No. }=\mathrm{dV} \rho / \mathrm{p} \\
\mathrm{S}_{\mathrm{c}} & =\text { Schmidt No. }=\mathrm{p} / \mathrm{pD}_{\mathrm{o}} \\
\mathrm{\rho} & =\text { density of air }=\mathrm{kg} / \mathrm{m}^{3} \\
\mathrm{~V} & =\text { velocity of air, } \mathrm{m} / \mathrm{s} \\
\mu & =\text { viscosity of air, } \mathrm{Pa} \mathrm{s} \\
\mathrm{D}_{0} & =\text { effective diffusion coefficient, } \mathrm{m}^{2} / \mathrm{s} \\
\mathrm{d} & =\text { characteristic length, equivalent diameter of grape, } \mathrm{m}
\end{array}
$$

For moisture diffusion in a sphere of $2.1 \mathrm{~cm}$ diameter evaporating into an air stream at $60^{\circ} \mathrm{C}$ at $2 \mathrm{~m} / \mathrm{s}$, Saravacos and Marousis (1988) estimated the mass transfer coefficient (using Eq. 3.2) and this value was found to be close to their experimentally determined value using Eq. 3.1 under similar drying conditions, thus indicating the validity of the procedure applied. This technique was extended to compute the mass transfer coefficient $\left(k_{c}\right)$ at the grape skin-air interphase. With all other drying conditions being similar, the difference in drying rates between treatments was mainly due to the skin surfaces as modified by particular pretreatments. The interphase mass transfer coefficients reflect the extent of the change in skin surface resistance to moisture transport. The overall mass transfer coefficients at the interphase, were thus computed using Eq. 3.1 to illustrate the effect of different pretreatments under MW drying conditions.

In the MW drying process the initial mnisture transport is higher than in convective drying (Lyons et al. 1972; Turner and Jolly 1991). This 
phenomenon was observed for MW drying of grapes (section 3.3.1) and should essentially keep the evaporating surface wet for some time. Thus, application of Eq. 3.1 was justified for the initial drying period. The over-all mass transfer coefficients at the interphase, as calculated through Eq. 3.1 for the first hour of drying, were $0.00152,0.00205,0.00164$ and $0.00154 \mathrm{~m} / \mathrm{s}$ for treatments $C_{1}, C_{2}, C_{3}$ and $C_{4}$, respectively. The difference in the observed values reflected the effect of pretreatments they received since all other drying conditions were similar. The highest value of $k_{c}$ was observed in the case of pretreatment $\mathrm{C}_{2}$ which indicated that it offered a minimum resistance. This was followed by pretreatments $\mathrm{C}_{3}, \mathrm{C}_{4}$ and $\mathrm{C}_{1}$. Comparison of these values and results (Tables 3.1 ) showed that the pretreatments influenced the drying rate of raisins under microwaves. Although pretreatment $\mathrm{C}_{3}$ resulted in a slightly shorter mean drying time $(8.33 \mathrm{~h})$ than $\mathrm{C}_{2}(8.67 \mathrm{~h})$, the difference was not significant and the quality was the same. It is therefore concluded that there is no advantage in using $3 \% \mathrm{EO}$ rather than $2 \% \mathrm{EO}$ in terms of reducirg the drying time and that treatment $C_{2}$ is the best since less chemical is used. The other treatments considered resulted in significantly longer drying times and are therefore not effective in reducing the time required for $M W$ drying.

\subsubsection{Washing and Holding Treatments}

The drying time in hours required to dry grapes after pretreatment $\mathrm{C}_{2}$ combined with washing of fruits and holding for various times are given in Table 3.2. Since none of these treatments was significantly different from the others (Tukey's test, hsd @ 1\%, SAS 1989), neither washing or holding after a chemical pretreatment significantly affects the drying time. The drying behaviour under these washing treatments was found to be identical (Fig. 3.6). Washing of the fruits immediately after a chemical pretreatment is always preferred from the stand point of removal of residual chemicals left on the fruit surfaces. However, no chemical analysis was done in this study to measure the residual chemicals. Holding the fruits for some time after a chemical 


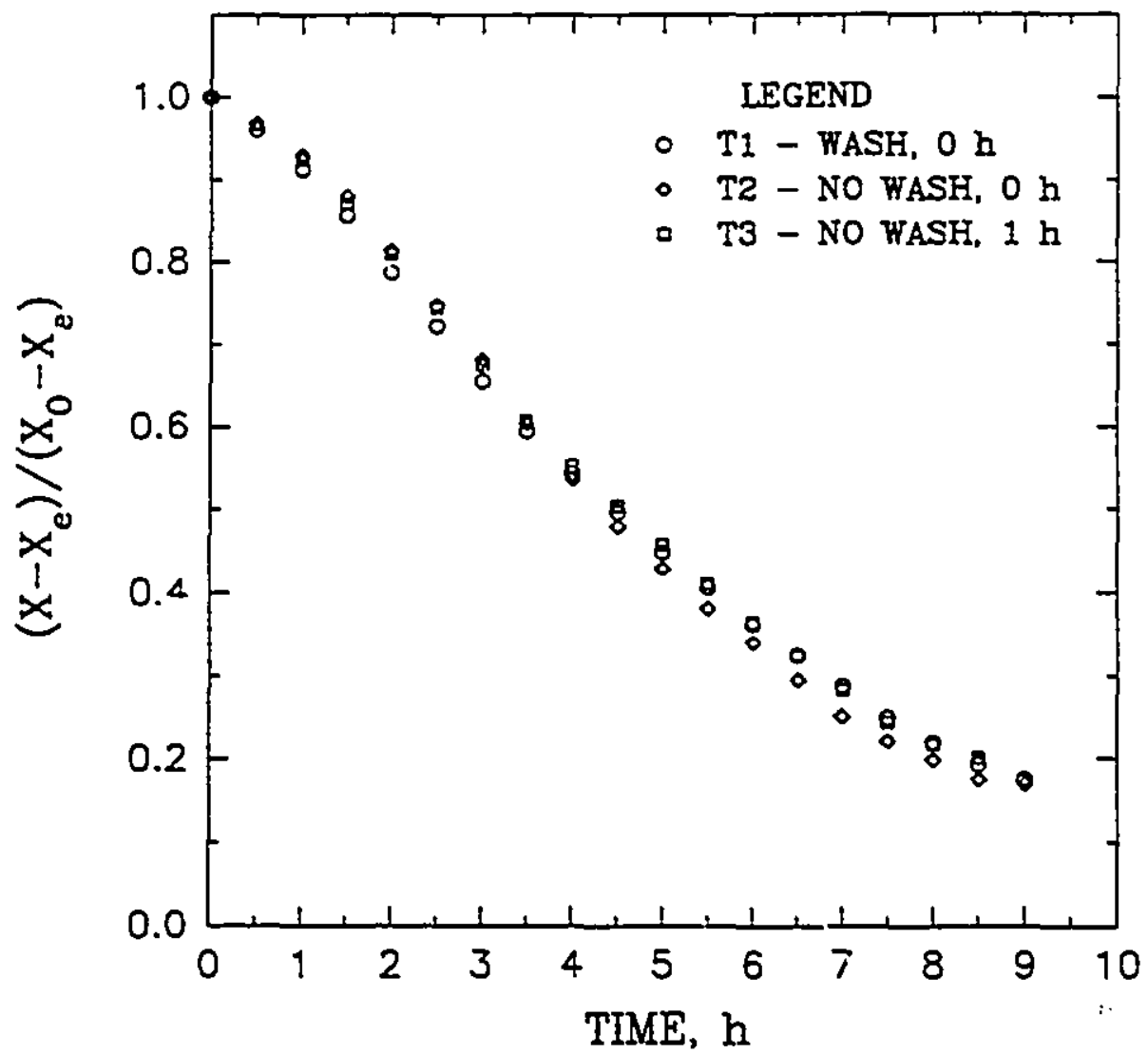

Fig. 3.6. Effect of washing treatments on $\mathrm{MWW}$ drying of grapes, $M W$ Power Level $1, T_{B}=50 \mathrm{C}, V=2.0 \mathrm{~m} / \mathrm{s}$. 
pretreatment necessitates extra equipment, space and time in the processing plant. Since the study indicated that there was no advantage derived from such a holding, the grapes could be washed, drained and immediately taken for drying.

Table 3.2. Drying time, $h$, under washing and holding treatments.

\begin{tabular}{|l|l|l|l|}
\hline Blocks & $\begin{array}{c}\mathrm{T}_{1} \\
\text { wash, 0 h }\end{array}$ & $\begin{array}{c}\mathrm{T}_{2} \\
\text { no wash, 0 h }\end{array}$ & $\begin{array}{c}\mathrm{T}_{3} \\
\text { no wash, 1 h }\end{array}$ \\
\hline 1 & 8.5 & 8.5 & 9.5 \\
\hline 2 & 9.5 & 9.0 & 8.0 \\
\hline 3 & 9.0 & 8.5 & 8.5 \\
\hline Mear & $9.0^{\circ}$ & $8.7^{\circ}$ & $8.7^{\circ}$ \\
\hline
\end{tabular}

NOTE: Means with the same letter are not significantly different at the 0.01 level

\subsubsection{Empirical Model to Fit Microwave Drying Data}

Methods of describing the drying process with thin layer drying models are widely reported in the literature for the purposes of simulation and scaleup. Drying kinetics of grains and other agricultural materials have been described by empirical equations such as modified logarithmic equation or the Page's equation given in Eq. 3.3 (Page, 1949):

$$
M R=\frac{X-X_{c}}{X_{0}-X_{e}}=\exp \left(-k t^{n}\right)
$$

where $\mathrm{n}=$ empirical drying exponent. Data from microwave drying studies conducted at different air temperatures (Fig.3.4) were used to test the applicability of Eq. 3.3. Equilibrium moisture content values for raisins $\left(X_{0}\right)$ were computed using the GAB equation (Maroulis et al., 1988). The coefficients of the equation for different air temperatures and humidities corresponding to air conditions applicable to the present study were evaluated using relations presented by Maroulis et al. (1988). The rate constant $k$ and 
parameter n of Eq. 3.3 were evaluated using non-linear regression (SAS, 1989); the results are presented in Table 3.3.

Table 3.3. Parameters of Page's equation [Eq. 3.3].

\begin{tabular}{|c|c|c|}
\hline Air Temp., ${ }^{\circ} \mathrm{C}$ & $\mathrm{k} \times 10^{2}, \mathrm{~h}^{-1}$ & $\mathrm{n}$ \\
\hline 30 & 4.36 & 1.03 \\
\hline 45 & 8.65 & 1.19 \\
\hline 50 & 9.91 & 1.31 \\
\hline 55 & 22.16 & 1.08 \\
\hline
\end{tabular}

The analysis yielded low values of residual mean squares and high values of $\mathrm{R}^{2}\left(\mathrm{R}^{2}>0.99\right)$ which indicated a good fit cf the data. The fitness is illustrated in Fig. 3.7 for drying of pre-treated grapes with and without $M W$ power $\left(\mathrm{MT}_{1} 45 \& \mathrm{CT}_{2} 45\right)$ at an air temperature of $45^{\circ} \mathrm{C}$ and air velocity of $2 \mathrm{~m} / \mathrm{s}$. In the case of MW drying, the model deviated slightly from the observed values initially since the mechanism of moisture migration during this period was different.

As could be expected, the rate constant $k$ increased with increasing air temperatures (Table 3.3) resulting in higher drying rates. Although $M W$ power was the same in all these cases there was a significant effect of air temperature on the drying times. The conditions at the interface played an important role in determining the heat and mass transfer rates in spite of uniformly applied MW power. Two possible explanations for such behaviour could be: (a) Air at lower temperature must have caused a reduction in sample temperature and hence reduced the drying zate and/or (b) Lower air temperature resulted in a lower wet bulb temperature at the surface, thereby reducing the partial vapour pressure gradient, the main driving force for evaporation of moisture from the surface into the gas stream. Conversely, higher air temperature resulted in higher product temperature and a higher vapour pressure gradient that was reflected in increased drying rates. This hypothesis of dependence of 


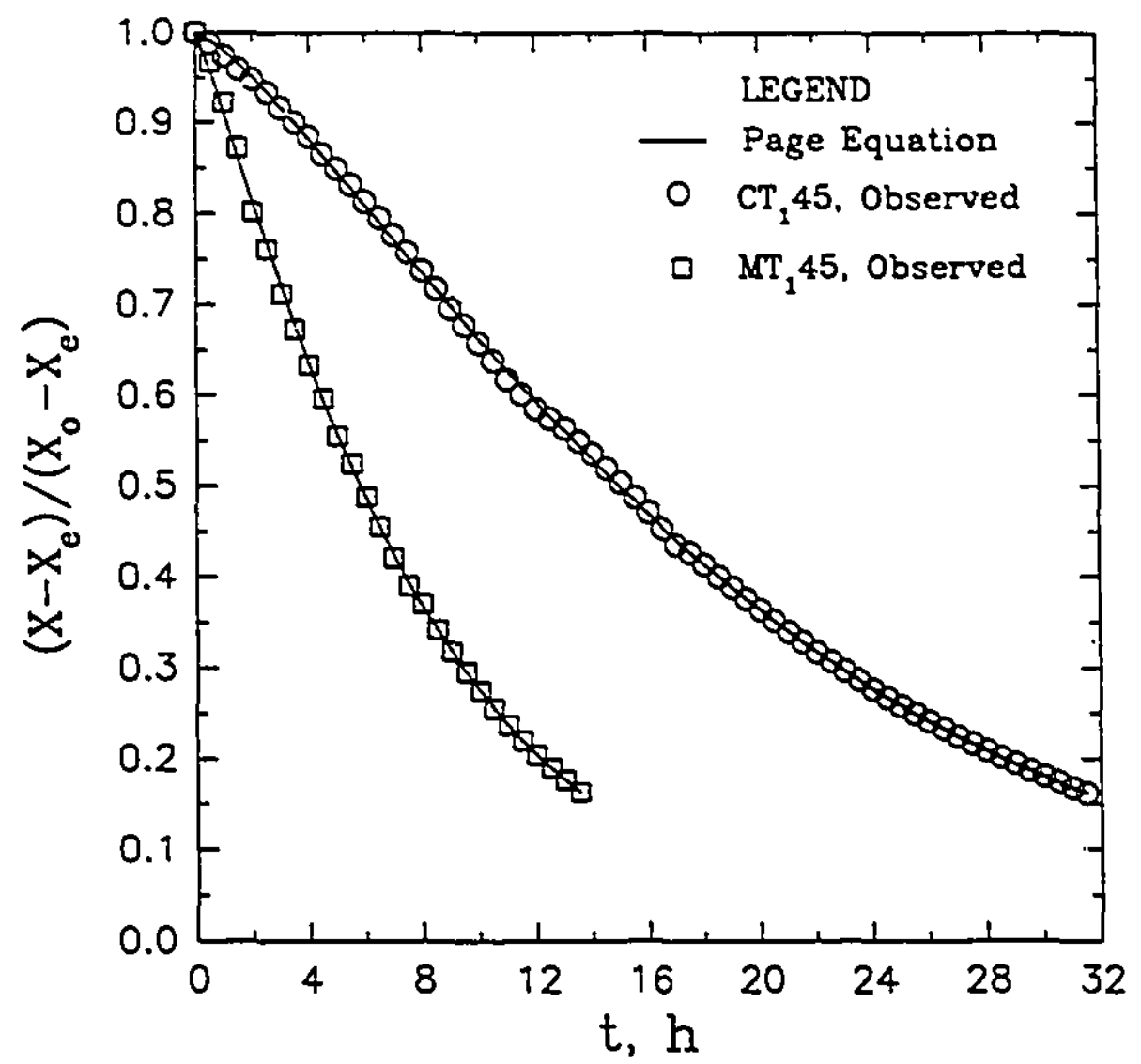

Fig. 3.7. Comparison of Page's Eq. fitting with the observed MR. 
$\mathbf{k}$ on air temperature was venfied as follows: $\mathbf{k}$ was plotted against air temperature and an Arrhenius type of relationship was found to exist between the two $\left(\mathrm{R}^{2}=0.88\right)$; Eq. 3.4 described this relationship:

$$
k=A e^{\left(\frac{\dot{z}}{T}\right)}
$$

where $T=$ the absolute air- temperature $(K)$, the values of constant $A$ and coefficient $z$ were found to be $5.125 \times 10^{6}$ and $-5.657 \times 10^{3}$, respectively. With the help of Eq. 3.4 it would be possible to predict the values of rate constant k of Eq. 3.3 for different air temperatures and hence the drying times. As the relationship is purely empirical it would hold good only for a similar drying condition and for the range of air temperatures considered in this study. There is no possible explanation for the variation of parameter $n$ in Eq. 3.3 and also there is no quantitative term in the relationship to describe the relative contribution of $\mathrm{MW}$ power to drying which gives scope for development of a better model to describe the MW drying behaviour of grapes.

\subsection{Summary}

MW assisted convective drying can be used to dry grapes into raisins more rapidly than by convection drying. The need for either alkaline pretreatment or sulphur-dioxide fumigation in raisin production is not necessary to ensure quality if the grapes are dried by MW. Good quality raisins may be obtained in a short time by drying grapes in a $2450 \mathrm{MHz} \mathrm{MW}$ oven at a 10 percent duty cycle, and at inlet air flow of $2 \mathrm{~m} / \mathrm{s}$ and $50^{\circ} \mathrm{C}$. Even shorter drying times may be obtained if the grapes are pretreated with $2 \%$ ethyl-oleate in $0.5 \% \mathrm{NaOH}$. Interphase mass transfer coefficients also described the effect of these chemical pretreatments. Studies conducted on the effect of washing and time of holding after a pretreatment indicated that neither factor influences drying time. 
Page's equation (Eq. 3.3) described the microwave drying data of grapes adequately and the parametric values of the equation were determined for different drying air temperatures. However, the parameters are purely empirical with no relationship linking the Page parameters to the process control variables. This type of model can therefore not be used for purposes of scale-up or optimization.

\subsection{Connecting Statement to Chapter 4}

The preliminary studies showed that it is possible to obtain good quality raisins in a short time. However, there were several limitations to the setup, some of which were related to the duty cycle mode of operation. First, we observed that the piviuct temperature reaches a maximum during the pulse of power and then decreases. These fluctuations of temperature are such that optimum temperature with respect to drying and product quality are never maintained. Second, since $100 \%$ of the rated power is applied during the pulse, the product is not able io absorb it all without damage, and we are therefore restricted io power level 1. Finally, as drying progresses and the moisture load decreases, less and less of the generated power is absorbed and more may be reflected. This leads to poor energy efficiency.

Evidently, it would be much more convenient, both for experimental work and for drying practice, to modify the equipment such that full control over the energy generated and the time of application could be had. In the limit, one would want to be able to apply low energy levels continuously or for a longer duty cycle, or even be able to adjust the energy level continuously during the process to match the changing absorption capacity (moisture content and dielectric properties) of the product.

In the next chapter, an improved experimental setup is described. 


\section{CHAPTER IV}

\section{DEVELOPIFENT OF NEW MICROWAVE DRYING SETUP}

\subsection{Microwave Drying Apparatus}

A schematic diagram of the microwave drying apparatus and its pictorial view is shown in Fig. 4.1a and Fig. 4.1b, respectively. The important components of the MW drying system are: (1) variable power high frequency generator, (2) waveguide, (3) microwave applicator and (4) variable hot air supply (Fig. 4.1a).

The $750 \mathrm{~W}$ microwave generator produced $\mathrm{MW}$ at a single frequency, $2450 \mathrm{MHz}$. A 15 A VARIAC was located in the generator circuit to provide a variable power output. A rectangular wave guide (WR 284) conveyed $M W$ from the magnetron of the high frequency generator to the applicator via a three port cirsulator. The energy introduced at the inlet or first port of the circulator is forwardly conveyed to the second port while energy introduced at the second port due to reflection is circulated to the third port, thus by-passing the reflected power reaching the magnetron. The third port was connected to a carbon load for dissipation of reflected power. A rectangular and horn type combination wave guide conveyed MW from the second port to the applicator. Power detectors were located on the wave guide next to the circulator as shown in the Fig. 4.1a. These meters were calibrated to read the forward incident power or the backward reflected power in watts. Three tuning stubs in the form of threaded screws were located next to the power detectors and these can be seen in the Fig. 4.1a. These were essentially E-H plane tuner matching devices intended to provide exact local impedance match between the dielectric load being processed in the applicator and the characteristic impedance of the connecting wave guide (Metaxas and Meredith, 1983; Pozar, 1990). 


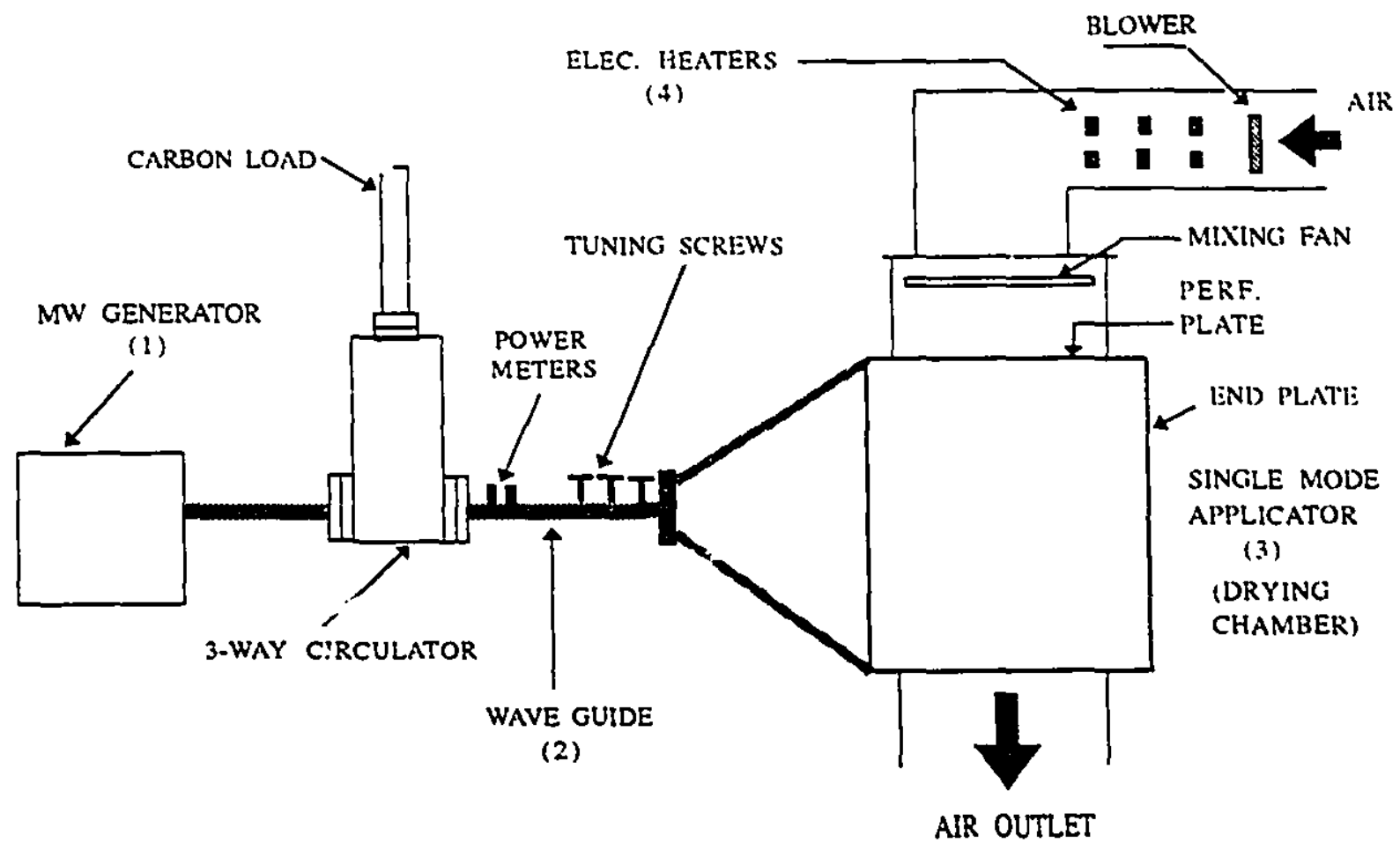

Fig. 4.1a. Schematics of the MW drying apparatus.

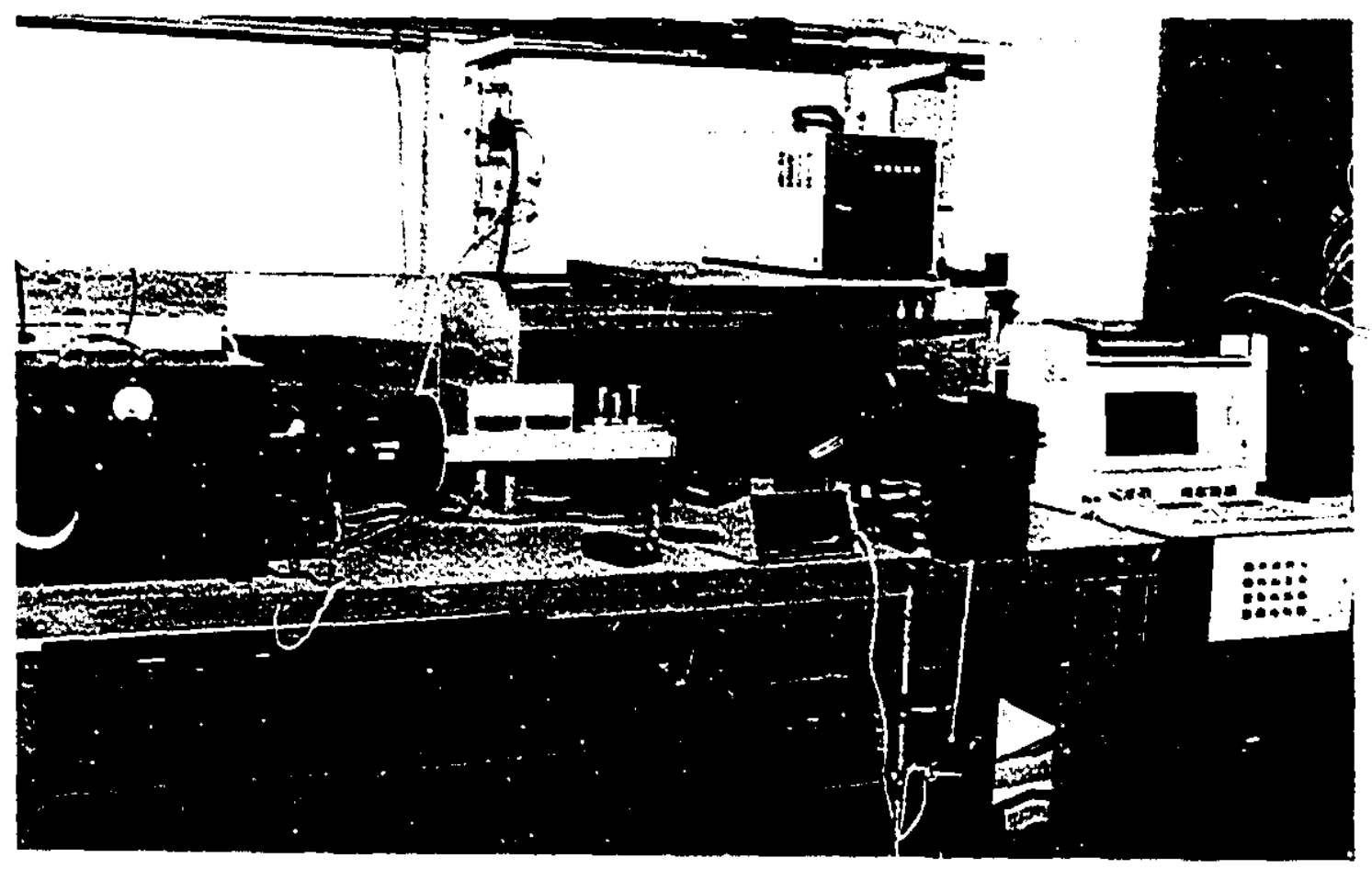

Fig. 4.1b. Photograph of the MW drying apparatus. 


\subsection{Applicator (Cavity/ Resonator)}

A single mode cavity type of applicator was developed for MW drying studies. The applicator was made of rolled brass strips. The applicator (cavity/ resonator) was rectangular in crossection (internal size a x b x d $=140$ $\times 65 \times 150 \mathrm{~mm}$ ). Since $\mathrm{b}<\mathrm{a}<\mathrm{d}$, the resonator essentially operated on a $\mathrm{TE}_{10}$ mode (Pozar, 1990). Internal details of the applicator are shown in a sectional plan in Fig. 4.2. Photographs given in Figs. 4.3 and 4.4 show the details of the applicator. The applicator, provided with the variable air flow supply, was the actual drying chamber where the sample was subjected to simultaneous $\mathrm{MW}$ heating and drying. The air inlet and outlet ends of the applicator are fixed with perforated brass plates (perforations of dia. $4 \mathrm{~mm}$ ). These perforated end plates permitted easy flow of air but shielded the propagation of MW. The wave-guide side of the applicator was covered with a solid plate made of $\mathrm{MW}$ transparent plastic material, which transmitted $M W$ energy into the applicator but shielded the flow of air. This plastic plate can be seen in white colour in the Photograph given in Fig. 4.4; the perforated brass plate seen on the right side is the air inlet from heater. The other open end of the applicator had a removable brass end plate (cover plate) which could be closed or opened with the help of connecting bolts. During the experimental run this end plate stayed in its place and covered the chamber to short circuit the MW transmission line facilitating the test material to absorb $M W$ energy. For inspection, loading \& unloading of the sample tray the end plate was removed. The top and bottom ends of the applicator were permanently closed with solid brass plates. The inner walls of the applicator were always kept clean and shining for good reflection.

During test runs it was observed that power absorption was not uniform in the material. This was evidenced by nonuniform drying and localised burning in certain locations. Also fine tuning with the three screw tuners was difficult particularly with low m.c. samples. An improvement of the applicator design was required. It was identified that matching of the impedance with 


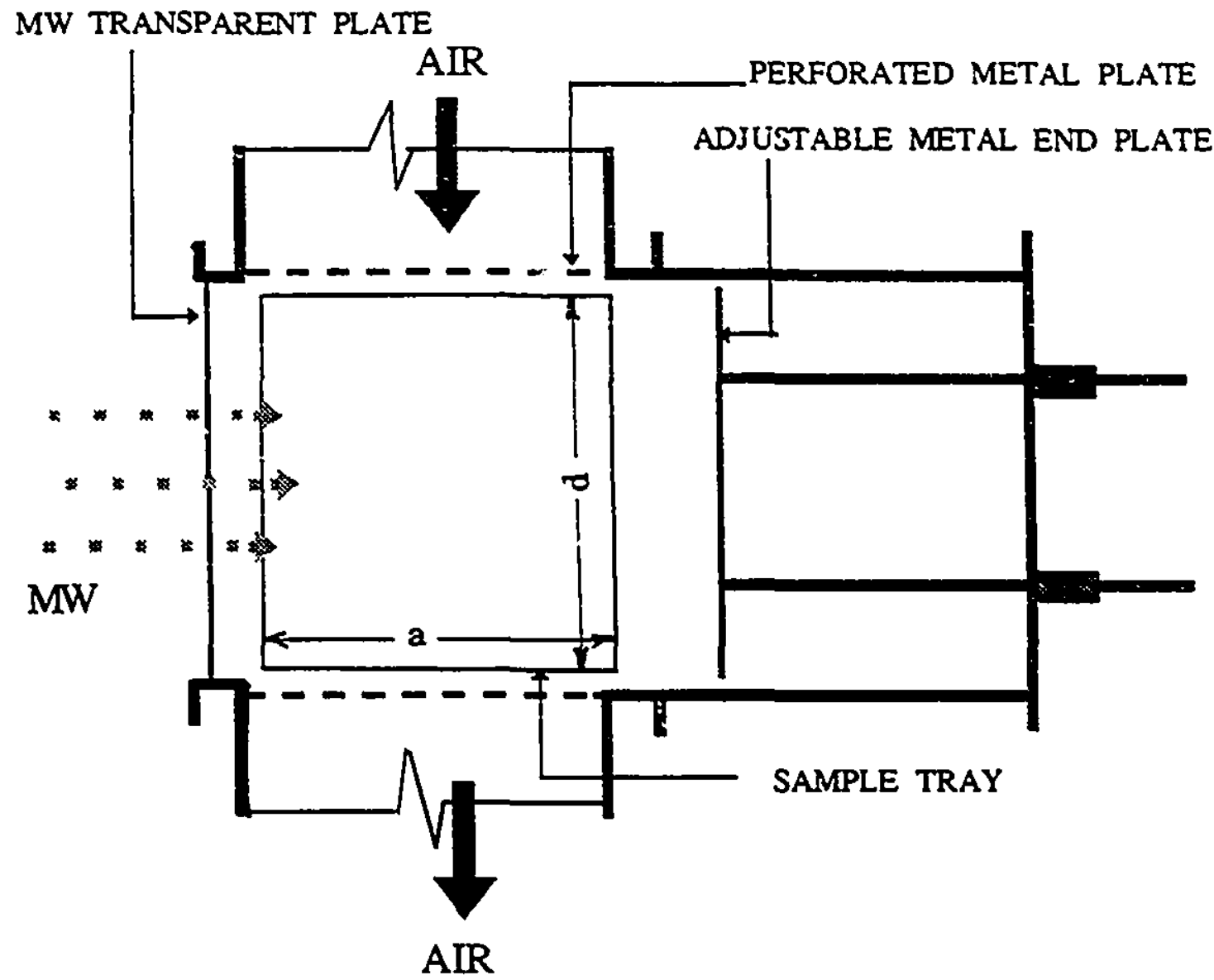

Fig. 4.2. Sectional plan of the single mode applicator (drying chamber) showing the inner details. 


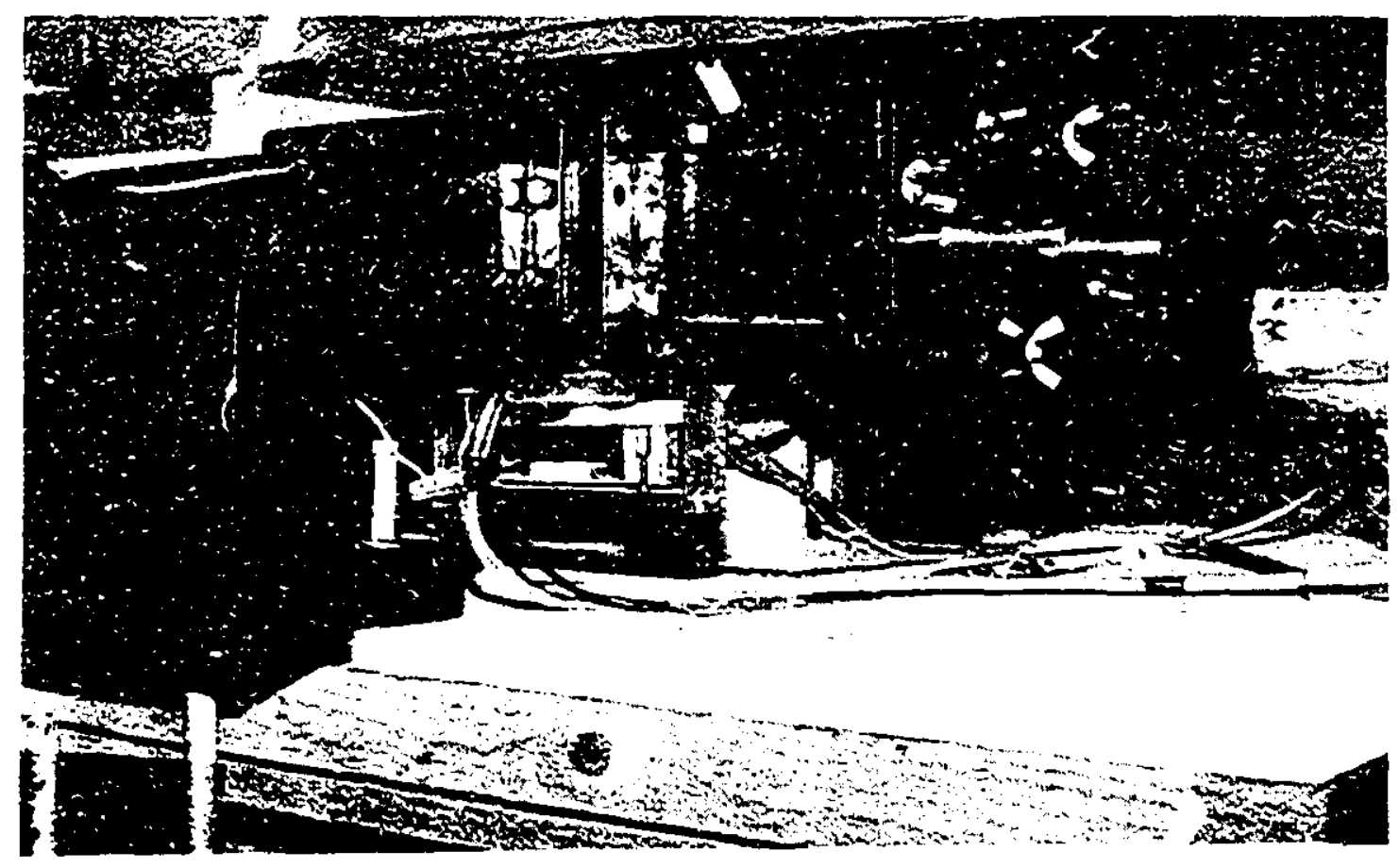

Fig. 4.3. Assembled view of the applicator

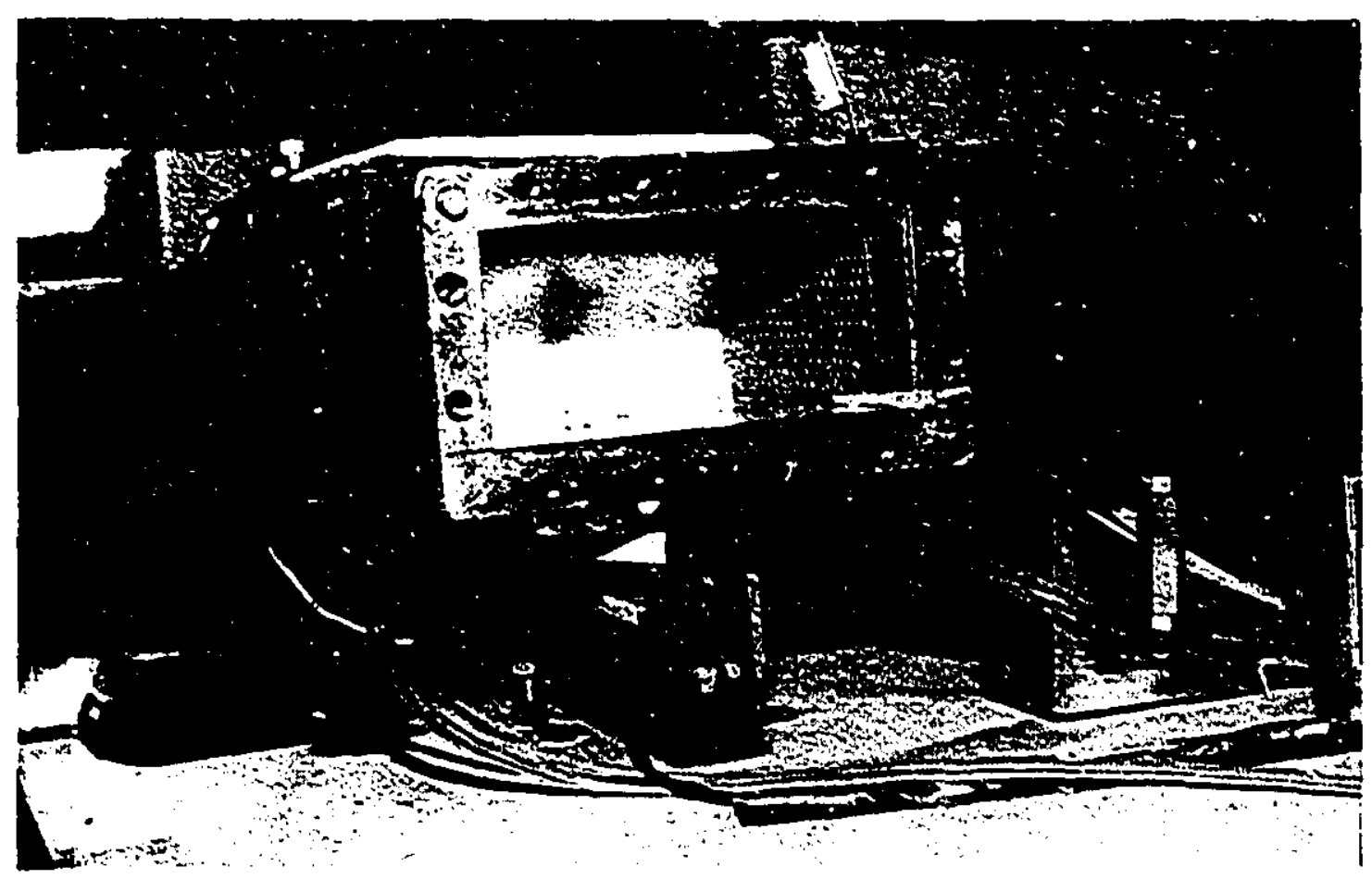

Fig. 4.4. Photograph of the applicator showing the inner details. 
the help of three screw tuners was inadequate. Then the short circuited end plate (open end) was made movable to allow the position to be adjusted. The exact location of the end plate could be selected to suit to the requirements of the material being processed. A rectangular brass box that matched its dimensions with that of the applicator was fabricated (this part can be seen at the right end in Fig. 4.3). This box had a adjustable metal end plate as shown in Fig.4.2. For grapes a distance of about $40 \mathrm{~mm}$ from the open end of the applicator was found to be suitable. With this adjustment MW absorption and drying of samples was found to be more uniform inside the applicator.

Air blown through the applicator was heated by a bank of electrical heaters and temperature of air was adjustable according to the requirement. A fan was provided in the air duct located between the heater section and the applicator) to mix air for uniform temperature before it enters the drying chamber; this fan ran on the draft of the forced air. The perforated wall of the applicator provided further air mixing and even air distribution inside the chamber.

The sample holder was made of perforated rectangular teflon plate of 1.6 $\mathrm{mm}$ thick and $130 \times 130 \mathrm{~mm}$ in size. Rectangular perforations of size $11 \times 17.5$ mm were cut on the plate to hold the grape berries. The perforated tray was supported on a $6 \mathrm{~mm}$ thick teflon plate and which was mounted on three teflon pins of dia. $4.6 \mathrm{~mm}$. Three holes of dia $6.0 \mathrm{~mm}$ were drilled at the bottom side of the applicator. The three teflon pins pass through these matching holes without touching the bottom side of the applicator (Fig. 4.4). At the exterior of the bottom side of the applicator the pins were attached to a circular teflon disc which formed an integral part of the weighing mechanism. The sample tray' inside the cavity was freely supported on the weighing mechanism with the help of these teflon pins. A strain gauge in the weighing mechanism sensed the mass changes and translated them into electrical signals which were received and recorded by the data acquisition system. The details of the weighing mechanism are well demonstrated in the Figs. 4.4 and 4.5. The three 
teflon pins seen in white colour in Fig. 4.4 show their location inside the drying chamber. The strain gauge and its mounting is clearly seen in the Fig. 4.5.

\subsection{Instrumentation, Measuremeuts and Controls}

Inlet and outlet air temperatures were monitored by T-type thermocouples located in the air streams outside the applicator. At each location the temperature was the average of three measurements. Air velocity was measured by a thermal anemometer (Jwyer 5106, Dwve: Instruments Inc., Michigan, IN) positioned in the air stream. Humidity of the outlet air was measured by a humidity meter (HMI - 32, VAIS.ALA, Finland) which had an accuracy of about $\pm 1.5 \%$. The electrical output from the strain gauge indicated the mass measurements. The two power detectors located on the wave guide read the incident power and the reflected power in watts. These meters were calibrated using distilled water as the load inside the cavity and power was determined by calorimetric measurements (Metaxas and Meredith, 1983); the resulting calibration curve is given in the Appendix A (Fig. A1). The data from various sensors were received and resorded by a computer through the data acquisition system (3497 A - Data Acquisition/Control Unit, HewlettPackard, USA). A computer program written in HP-QBASIC monitored the process, collected and recorded the data in sequence. The program utilised the algorithms for sensors in case of mass, relative humidity, incident power and reflected power. The calibration equations were provided in the program to convert various electrical signals into appropriate quantities. In the case power measurements, the program recorded a mean value of power over the measurement time interval. The program had the capability of turning the MW power ON or OFF at any desired time interval, and also fin turning ine system OSF when the desired final mass was reached on completion of drying. Features like turning OFF of heaters and/or MW generator was provided in the program in case if the pre-set safety conditions were exceeded. The designated safety parameters were: 1) maximum air temperature in the 


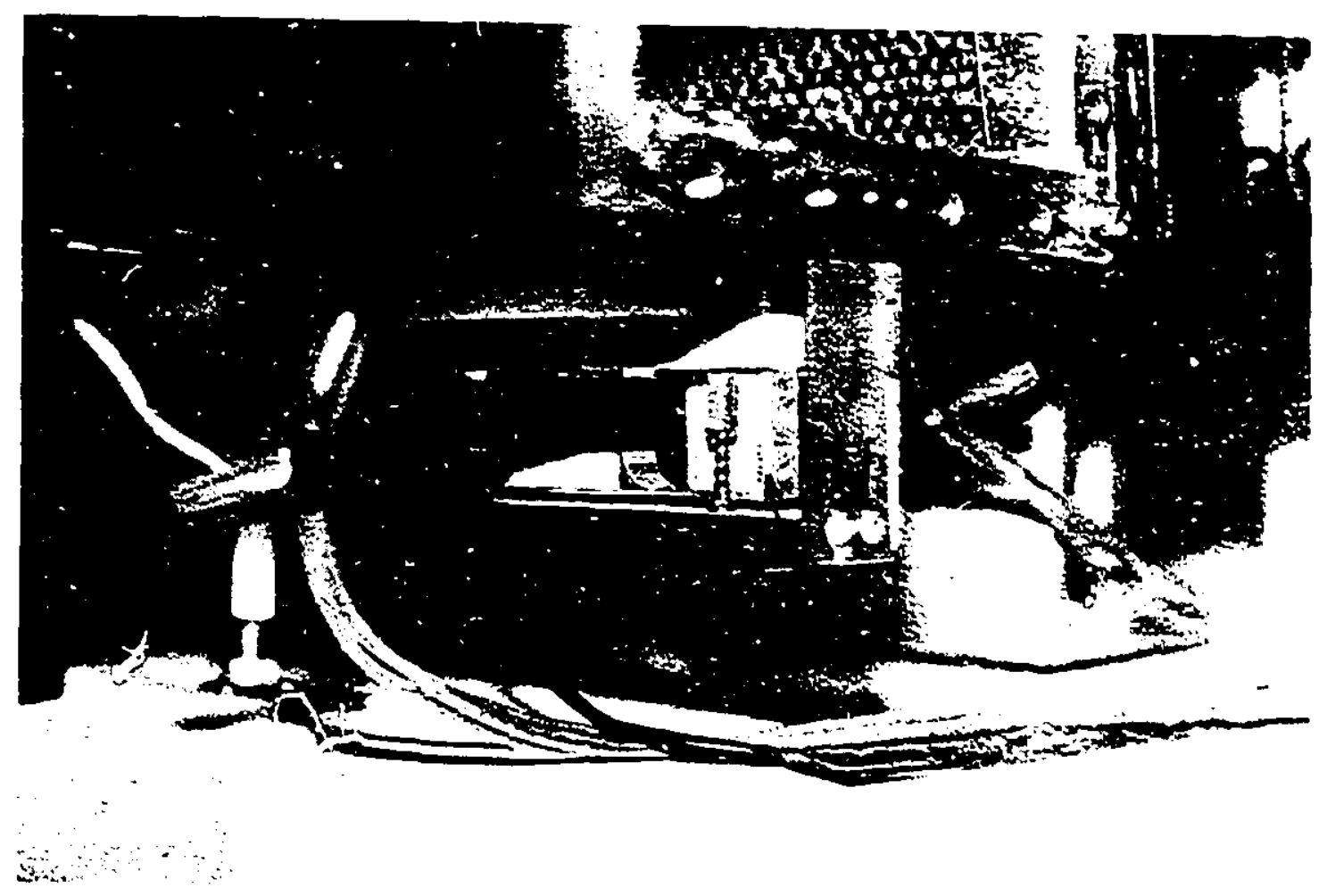

Fig. 4.5. Photograph showing the details of the weighing mechanism; the three teflon pins are supported by a flat teflon plate at the bottom of the applicator which is mounted on a strain gauge. 
applicator and 2) the maximum reflected power. The program collected and recorded the data at desired time intervals. In the present drying studies, data was collected at 5 minute intervals. Later the data was transformed from HP_QBASIC format into DOS format.

Provision was also made in the applicator to insert fibre optic temperature sensors for measurernent of fruit temperature inside the cavity. A Luxtron multichannel fluroptic thermometer (Model 755, Luxtron, Cary, NY) was used to read the temperatures in MW environment. This instrument was directly read as there was no provision to hook it to the data acquisition system.

\subsection{Connecting Statement to Chapter 5}

For the development of the model to describe $M W$ drying of grapes, it was necessiary to establish the relationships among some physical and electrical properties of grapes. Some of these relationships (electric field strengch, the effective diffusivity parametax, and mass transfer coefficients) could only be studied with the developed setup described above.

In the next chapter, the procedures used to establish all of the above relationships are described. 


\section{CHAPTER V}

\section{QUANTIFICATION OF GRAPE PROPERTIES}

\subsection{Shrinkage of Grapes During Drving}

One of the research objectives was to develop a moisture diffusion model that could, among other things, take into account the drastic shrinkage that takes place during the drying of high moisture materials such as grapes. The approach taken was to determine the relationship between volume and moisture content of grapes. The relationship was studied for two methods of drying; convective drying and combined convective and MW drying. Possible effects of initial size on shrinkage were also considered in the experimental procedure described in this section.

\subsubsection{Materials and Methods for Shrinkage Studies}

The volume of grape/raisin ${ }^{2}$ was determined by the liquid displacement technique using toluene at room temperature (Mohsenin, 1986; Sravacos and Raouzeos, 1986). A sample of ten grapes/raisins was used to determine the average volume. The volume of fresh grapes was taken as $v_{0}$ corresponding to the grape at its initial moisture content $\mathrm{X}_{0}(\mathrm{~kg} / \mathrm{kg}$ dry mass) before drying. The grape (treated with $2 \%$ ethyl oleate in $0.5 \% \mathrm{NaOH}$ ) were dried by two methods: a) Convective drying at $60^{\circ} \mathrm{C}$, air flow $2.0 \mathrm{~m} / \mathrm{s}$ and b) MW drying, MW power level 1, air temperature $50^{\circ} \mathrm{C}$ and air flow $2.0 \mathrm{~m} / \mathrm{s}$. At difierent stages of drying, samples of 10 berries/raisins of uniform size and appearance were taken out and their average volume $(v)$ was determined as explained above along with their moisture content $(X)$.

\footnotetext{
2 The terms grapes/raisins and berries/raisins refer to a grape at an undefined stage of drying, as opposed to grape or berry (before drying) and raisin (at final dried moisture content).
} 
Shrinkage studies were conducted using grape of different initial size, but of uniform size within a batch. The initial sizes corresponded to three initial volumes: $3.1 \mathrm{~mL}(3.0 \pm 0.1 \mathrm{~g}), 4.0 \mathrm{~mL}(4.0 \pm 0.1 \mathrm{~g})$ and $4.88 \mathrm{~mL}(5.0 \pm 0.1 \mathrm{~g})$. All the experiments were conducted on a single lot of Thompson seedless grapes.

\subsubsection{Results and Discussion for Shrinkage Studies}

The relationship between $v / v_{0}$ and $\mathrm{X} / \mathrm{x}_{0}$ was represented by a linear equation (Lozano et al., 1983):

$$
\frac{v}{v_{0}}=A+B\left(\frac{X}{X_{0}}\right)
$$

where $v_{0}$ is the initial volume of the grape in $\mathrm{mL}$ and $\mathrm{X}_{0}$ is the initial moisture content of grape corresponding to the initial volume $v_{0}$ in $\mathrm{kg} / \mathrm{kg} d r y$ matter. The constants $A$ and $B$ were obtained through linear regression analysis for different size groups and drying methods.

\subsubsection{Shrinkage in Convective Drying}

The results of the linear regression analysis (Eq. 5.1) of duplicated experiments are given in the Table 5.1. The linear relationship between $v / v_{0}$ and $\mathrm{X} / \mathrm{X}_{0}$ was significant and described the data well as evidenced by the high $\mathrm{R}^{2}$ values for all the sizes considered (Table 5.1). The coefficients $(B)$ of the regression (i.e. the shrinkage rates) were independent of the initial size of the grapes (Duncan's Test, 0.05 level). The data were therefore pooled and a new regression equation generated for convective drying condiäons. The procedure yielded an equation with intercept $A=0.159$ and slope $B=0.1354\left(\mathrm{R}^{2}=0.975\right)$. This equation compares well wiin that of Masi and Riva (1988) which was derived from similar work on six varieties of grapes $(A=0.167$ and $B=0.833$ ). 
Table: 5.1. Results of linear models (Eq. 5.1) of sbrinkage in grapes of different sizes under convective drying.

\begin{tabular}{||c|c|c|c||}
\hline \hline size & $\begin{array}{c}\text { constant } \\
(A)\end{array}$ & $\begin{array}{c}\text { coeff. } \\
(B)\end{array}$ & $\mathrm{R}^{2}$ value \\
\hline$v_{0} 3.1 \mathrm{~mL}$ & 0.129 & 0.326 & 0.993 \\
$(3.0 \pm 0.1 \mathrm{~g})$ & 0.128 & 0.820 & 0.995 \\
\hline$v_{0} 4.0 \mathrm{~mL}$ & 0.166 & 0.870 & 0.995 \\
$(4.0 \pm 0.1 \mathrm{~g})$ & 0.180 & 0.843 & 0.992 \\
\hline$v_{0} 4.8 \mathrm{~mL}$ & 0.169 & 0.903 & 0.984 \\
$(5.0 \pm 0.1 \mathrm{~g})$ & 0.147 & 0.824 & 0.964 \\
\hline
\end{tabular}

\subsubsection{Shrinkage in Combintd Convective and MW Drying}

The same procedure as described above was performed to study grape shrinkage under MW drying conditions. The results are given in Table 5.2. There were three replicates in the case of size $4.0 \mathrm{~g}$ and two each in the remaining two treatments. Again, the coefficients $(B)$ (Table 5.2), were found not significantly different among sizes (Duncan's Test, 0.05 level).

Table: 5.2. Results of linear models of shririage in grapes of different sizes under MW Drying.

\begin{tabular}{|c|c|c|c||}
\hline size & $\begin{array}{c}\text { constant } \\
(\mathrm{A})\end{array}$ & $\begin{array}{c}\text { coeff. } \\
(B)\end{array}$ & $\mathrm{R}^{2}$ value \\
\hline$v_{0} 3.1 \mathrm{~mL}$ & 0.149 & 0.818 & 0.988 \\
$(3.0 \pm 0.1 \mathrm{~g})$ & 0.144 & 0.807 & 0.986 \\
\hline$v_{0} 4.0 \mathrm{~mL}$ & 0.090 & 0.918 & 0.950 \\
$(4.0 \pm 0.1 \mathrm{~g})$ & 0.194 & 0.747 & 0.964 \\
& 0.127 & 0.865 & 0.986 \\
\hline$v_{0} 4.88 \mathrm{~mL}$ & 0.154 & 0.779 & 0.988 \\
$(5.0 \pm 0.1 \mathrm{~g})$ & 0.122 & 0.810 & 0.973 \\
\hline
\end{tabular}


Finally, the coefficients $(B)$ from both sets (ie. convective and microwave) were tested for differences due to drying method. None were found (PROC GLM; SAS, 1989). Therefore, the below final regression equation based on all the results (Fig. 5.1) and applicable to shrinkage under convective and microwse drying was generated:

$$
\frac{v}{v_{0}}=0.147+0.839 \frac{X}{X_{0}}
$$

The results of the linear regression analysis are shown in Table 5.3 (SAS, 1989). For a known initial size of grape (volume) the above equation predicts the actual size (volume) of grape at a given moisture content. Eq. 5.2 has been retained for the modelling work.

\section{Table 5.3. Shrinkage Analysis}

(Number of observations in data set $=167$ ) (General Linear Models Procedure, SAS, 1989)

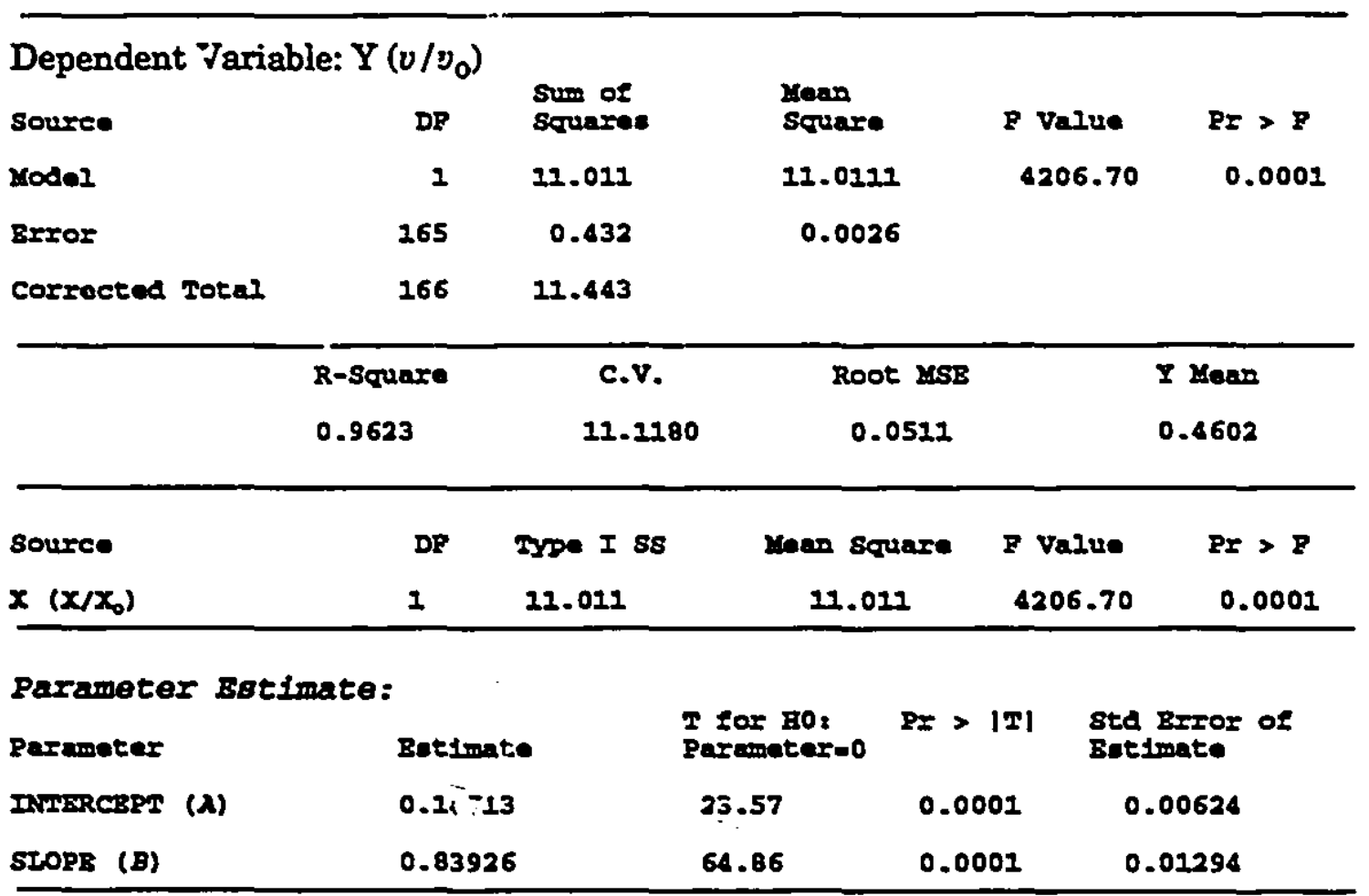




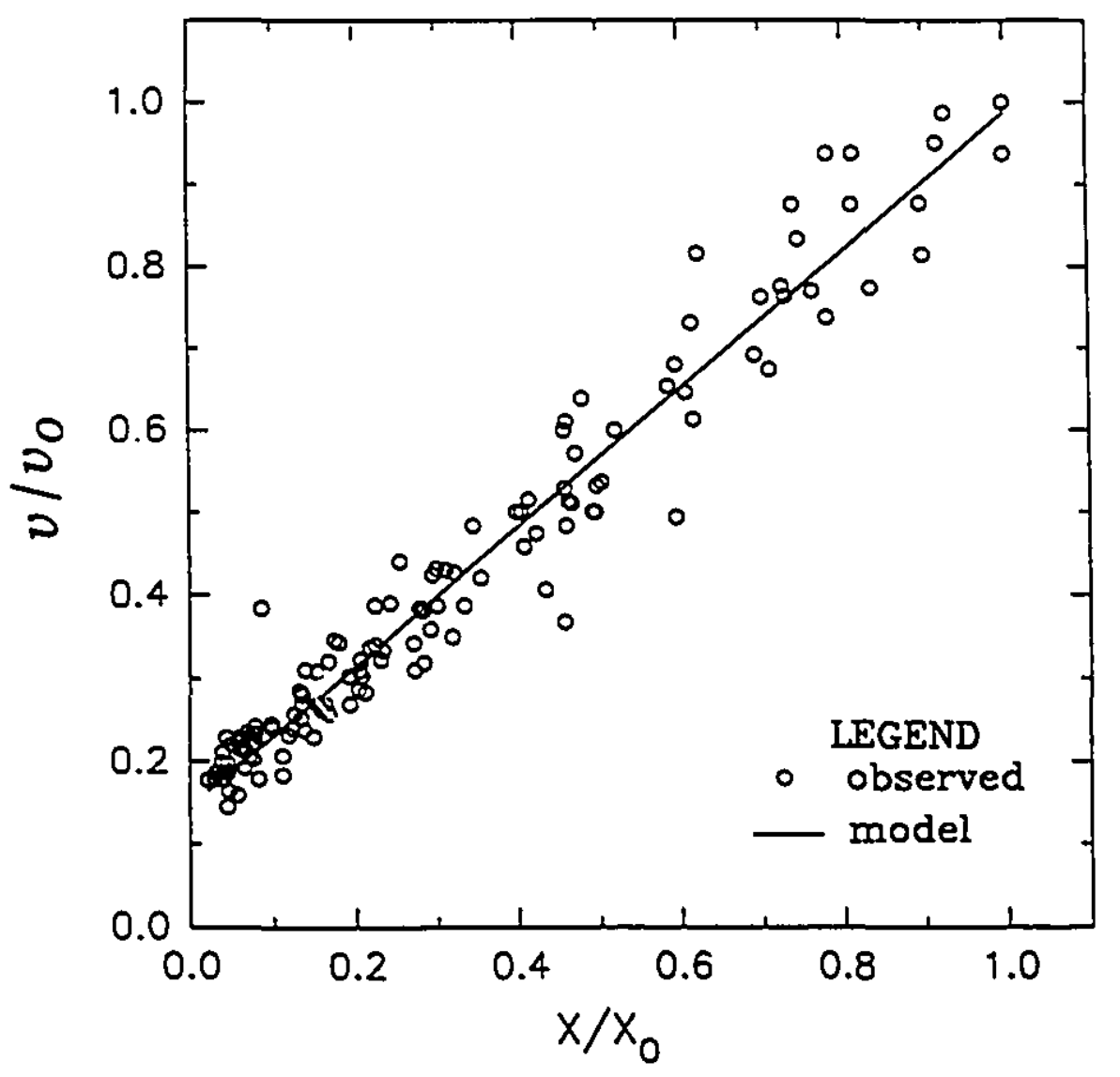

Fig. 5.1. Volume reduction as a function of m.c. in convective and $\mathrm{MW}$ drying of grapes $\left(\mathrm{T}_{\mathrm{g}}=50^{\circ} \mathrm{C}, \mathrm{V}_{\mathrm{g}}=2 \mathrm{~m} / \mathrm{s}\right.$, MW Power level 1$)$. 


\subsection{Dielectric Properties of Grapes at $2450 \mathrm{MHz}$}

An understanding of the dielectric properties of a material is very important to microwave (MW) heating/processing design. The dielectric constant and loss factors of a material are essentially measures of the extent to which a material is stimulated by an electromagnetic field. Although the electrical and dielectric properties of many food materials have been reported (Nelson, 1990; Mudget, 1990) information on grapes has not been previously documented.

As the grape dries, its composition changes and the resulting MW heating pattern also changes. The study of the changes in dielectric properties with respect to moisture content (m.c.) and temperature ( $T$ ) is essential to the understanding of MW heating which leads to proper process control and design. It is the objective of this work to obtain the dielectric properties of grapes measured at different moisture contents (i.e. at various stages of drying) and temperatures.

\subsubsection{Materials and Methods for Dielectric Properties}

Thompson seedless grapes of about $20-21^{\circ}$ brix and of uniform size were selected for the study. Samples of different moisture contents were prepared by air drying at $50^{\circ} \mathrm{C}$ to achieve moisture contents of 0.8 (fresh grapes), $0.6,0.4$ and $0.15 \mathrm{~kg} / \mathrm{kg}$ (wet basis). For each of these moisture contents, two grapes/raisins were taken, cut in half and the dielectric properties were then measured (the equipment used to determine the dielectric properties is described in the next section).

Each grape half was wrapped with polystyrene foam film and a fine thermocouple sensor was inserted into the fruit. The sample was then quickly heated in an oven. As soon as the fruit reached a temperature of $82-83^{\circ} \mathrm{C}$ the fruit was removed from the oven and transferred to a pre-warmed sample holder for measurements. The cut face of the fruit was exposed to the measuring probe and the remaining surface was still covered with the plastic 
foam film which provided good insulation and maintained a minimum temperature gradient at the measurement site. The thermocouple indicated the fruit temperature at the holder. As soor as the temperature reached $80^{\circ} \mathrm{C}$, the thermocouple sensor was withdrawn from the fruit and the first measurement of dielectric properties was made. The thermocouple was again introduced and the fruit was allowed to cool to $70^{\circ} \mathrm{C}$. On attaining this temperature the thermocouple was withdrawn and a second measurement of dielectric properties was made. This procedure was repeated for temperatures of $60,50,40$ and $25^{\circ} \mathrm{C}$. The same procedure was used for the other moisture contents. Care was taken to ensure proper contact between the test probe and the sample. Three replicates were performed for each moisture content and the moisture content/replicate combinations were completely randomized.

Dielectric properties were determined at $2450 \mathrm{MHz}$ using an OpenEnded Co-Axial Probe system HP 85070B. The software calculated the dielectric parameters from the phase and amplitude of the reflected signal at the interface between an open-ended coaxial line and the sample to be analyzed. The properties were determined by a Hewlett-Packard $8753 \mathrm{C}$ Network Analyzer/ 85047A, $300 \mathrm{kHz}$ to $6.0 \mathrm{GHz}$, S Parameter test set (Hewlett-Packard Corp., Santa Clara, CA). The instrument was first calibrated using three different loads: 1) a short circuit with mercury, 2) air and 3) pure water at room temperature. After calibrations the instrument was tested by taking a measurement on a standard liquid of known dielectric properties in order to confirm the accuracy.

\subsubsection{Predictive Models for Dielectric Properties of Grapes}

Response Surface Methodology (RSM) was used as a basis for expressing the dependent variable as a function of independent variables (Box et al, 1978). The method consists of generating regression models of the response variables ( $\varepsilon^{\prime}$ and $\varepsilon^{\prime \prime}$ ) in terms of the operating variables (m.c. and T) such that the terms in the model are orthogjnal. Orthogonality is ensured first by 
coding the predictor variables ( $\varepsilon^{\prime}$ and $\varepsilon^{\prime \prime}$, in this case). The transformation consists of subtracting the mean level from each predictor and dividing by the interval between levels (assumed to be equal from one level to the next). The terms in the model consist of linear, squared and interaction terms of all the operating parameters. In this study, the general model used was:

$$
\text { Response }=a_{0}+a_{1} M_{c}+a_{2} T_{c}+a_{3} M_{c}^{2}+a_{4} T_{c}^{2}+a_{5} M_{c} T_{c}+e
$$

Where the $a_{j}$ are the regression coefficients, the subscript $\mathrm{a}$ indicates that the original term has been coded; $\mathrm{M}$ is the moisture content ( $\mathrm{kg} / \mathrm{kg}$ wet mass); $\mathrm{T}$ is the temperature $\left({ }^{\circ} \mathrm{C}\right)$ and $\varepsilon$ is the error. PROC RSREG (SAS, 1989) was used to perform the analysis on the response variables $-\varepsilon^{\prime}$ and $\varepsilon^{\prime \prime}$.

\subsubsection{Results and Discussion on Dielectric Properties}

The dielectric constant and loss factor of grapes/raisins at ambient temperature $\left(25^{\circ} \mathrm{C}\right)$ as functions of m.c. are shown in Fig. 5.2. This range of moisture covers m.c. from fresh grapes at $0.8 \mathrm{~kg} / \mathrm{kg}$ wet mass to final raisins at $0.15 \mathrm{~kg} / \mathrm{kg}$ wet mass. Within this range, large variations in both $\varepsilon^{\prime}$ and $\varepsilon^{\prime \prime}$ were observed. For fresh grapes, the values of $\varepsilon^{\prime}$ and $\varepsilon^{\prime \prime}$ were 69.81 and 17.5, respectively. For final raisins $(0.15 \mathrm{~kg} / \mathrm{kg}$ wet ma' ' these parameters dropped to 7.47 and 2.19, respectively, as would be expectea due to the drop in moisture content (Nelson, 1990; Metaxas and Meredith, 1983).

The effect of temperature on the dielectric constant at different moisture contents is shown in Fig. 5.3. Two types of behaviour were observed for $\varepsilon^{\prime}$. At high moisture, $\varepsilon^{\prime}$ decreases as temperature increases whereas at intermediate and low moisture ( $0.4 \mathrm{~kg} / \mathrm{kg}$ wet mass and below) the trend was opposite. In the case of the loss factor (Fig. 5.4), at m.c. $0.4 \mathrm{~kg} / \mathrm{kg}$ and above, $\varepsilon^{\prime \prime}$ decreased with an increase in temperature whereas the opposite was true at m.c. 0.15 $\mathrm{kg} / \mathrm{kg}$ wet mass.

The response surface equations for $\varepsilon^{\prime}$ and $\varepsilon^{\prime \prime}$ in coded terms of the predictors are: 


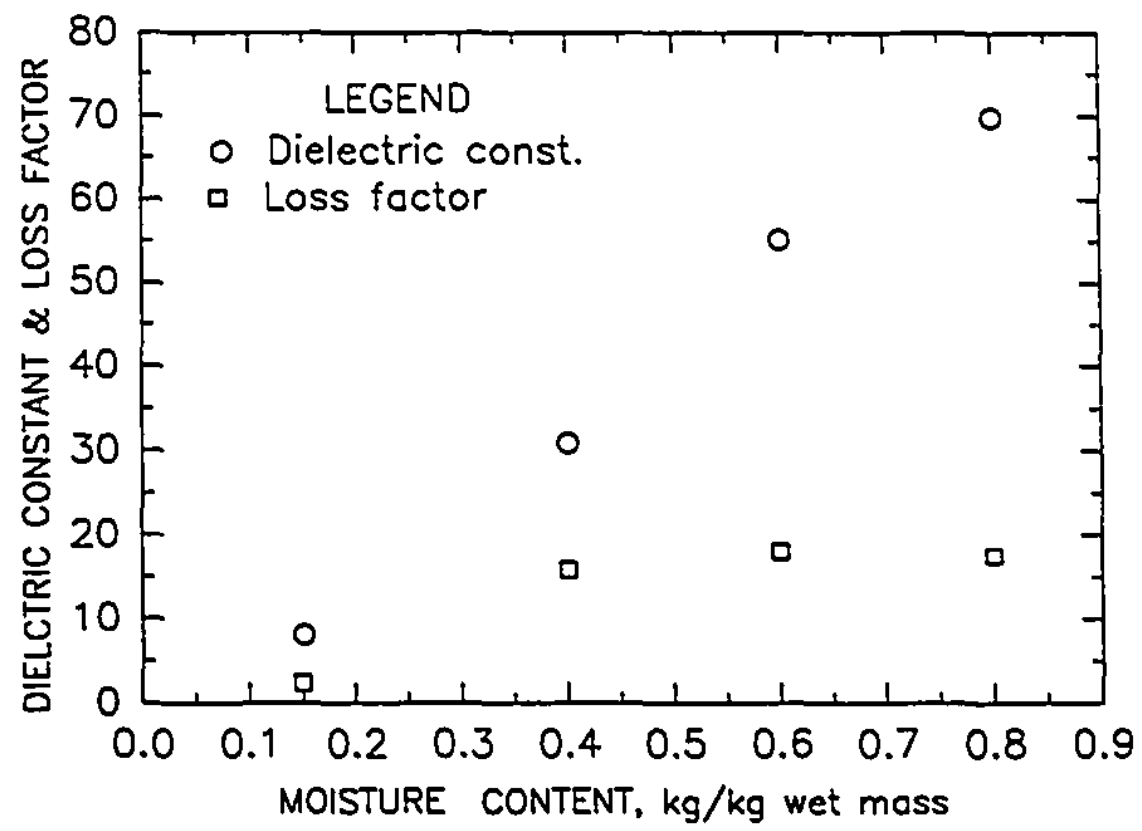

Fig. 5.2. Variation of dielectric properties of grapes with moisture content $\left(25^{\circ} \mathrm{C}, 2450 \mathrm{MHz}\right.$ ).

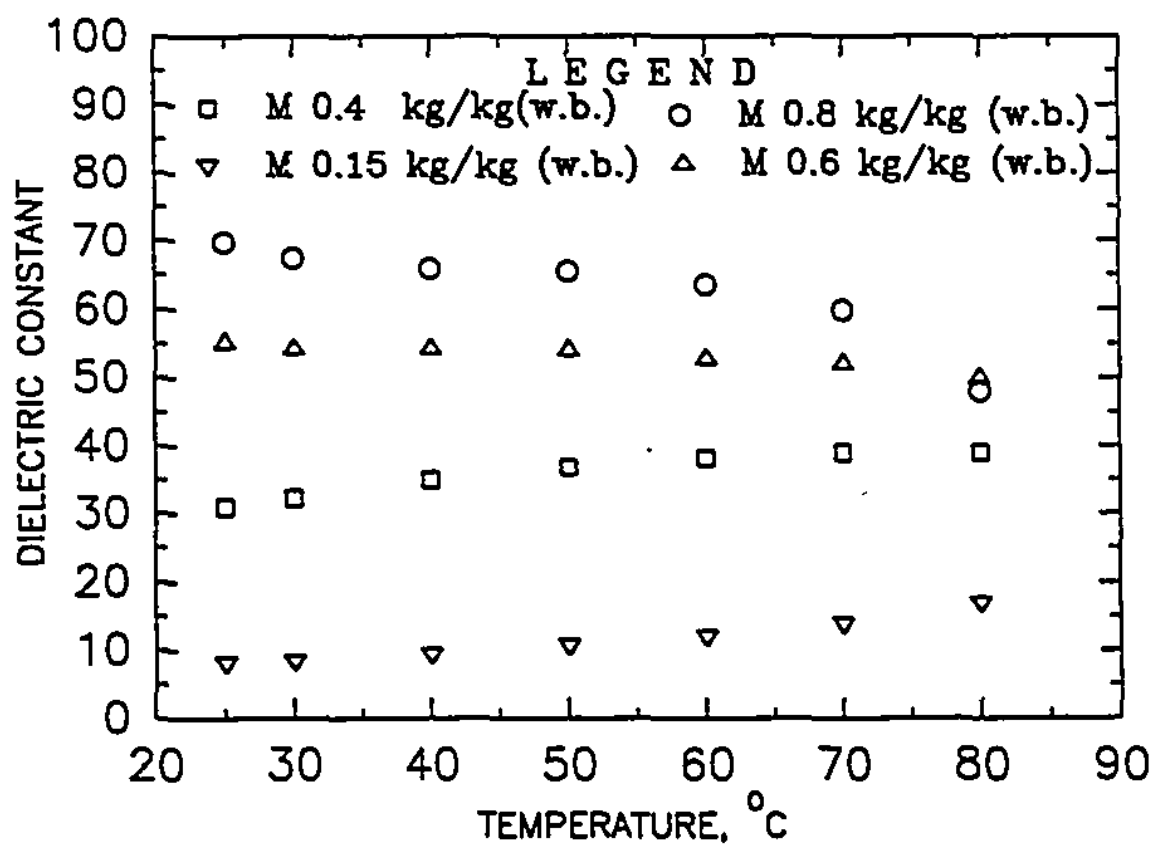

Fig. 5.3. Dielectric constant of grapes as a function of temperature at different m.c., $2450 \mathrm{MHz}$. 


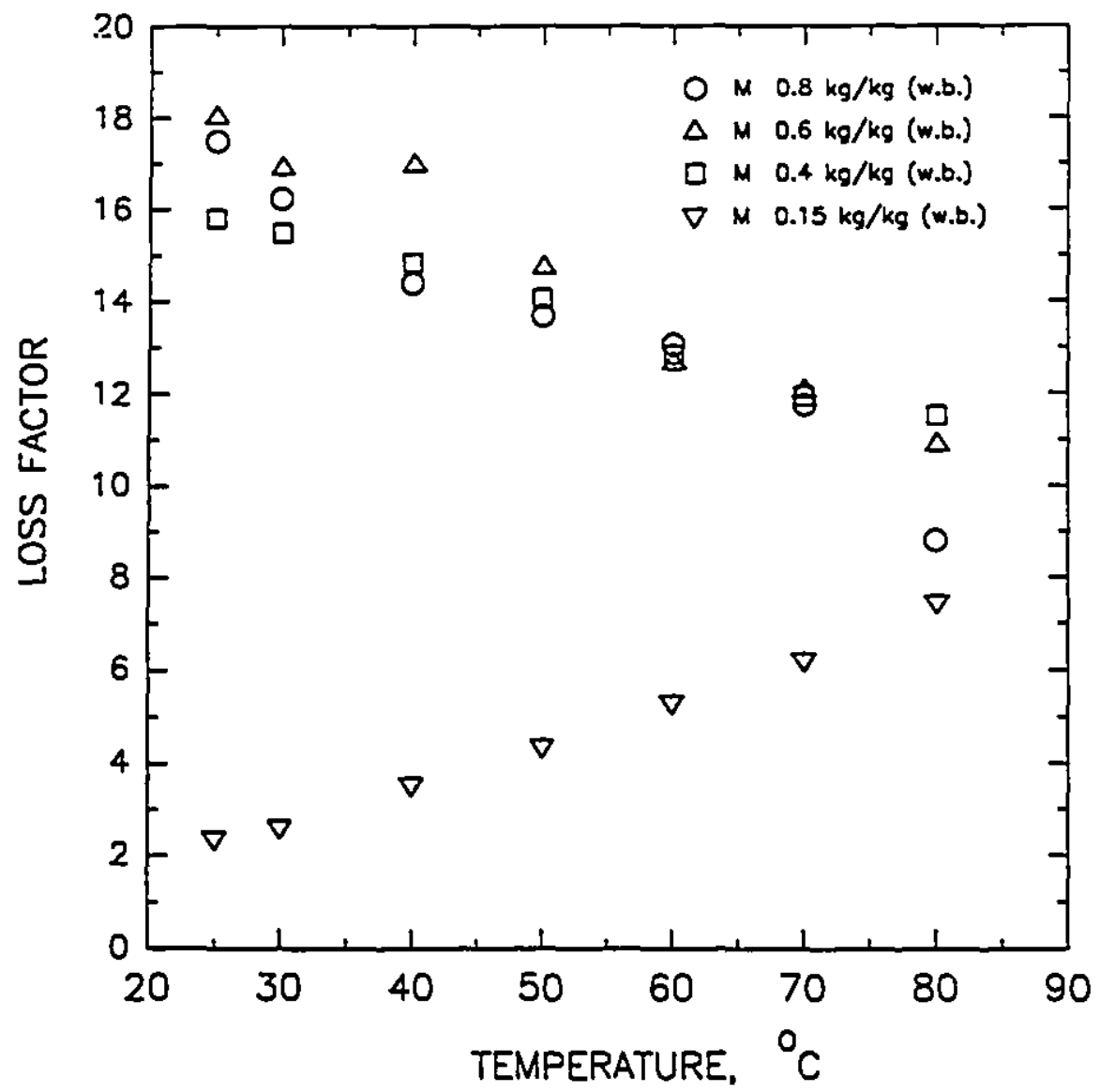

Fig. 5.4. Dielectric loss factor of grapes as a function of temperature at different m.c.(2450 MHz.). 
$\varepsilon^{\prime}=44.322+25.63 \mathrm{M}-0.497 \mathrm{~T}-6.18 \mathrm{M}^{2}+6.668 \mathrm{M} \mathrm{T}-2.07 \mathrm{~T}^{2}$

$\varepsilon^{\prime \prime}=14.358+4.13 \mathrm{M}-1.689 \mathrm{~T}-5.40 \mathrm{M}^{2}-3.131 \mathrm{M} \mathrm{T}-0.01682 \mathrm{~T}^{2}$

where, $\mathrm{T}=$ temperature ${ }^{\circ} \mathrm{C}$ and

$\mathrm{M}=$ m.c. on wet basis, $\mathrm{kg} / \mathrm{kg}$ wet material.

The model for $\varepsilon^{\prime}$ (Eq. 5.4) yielded an $R^{2}$ value of 0.988 with a $C V$ of $5.45 \%$ and the model for $\varepsilon^{\prime \prime}$ (Eq. 5.5) resulted a $R^{2}$ value of 0.953 and a $C V$ of 9.02\%. Both models were significant at the 0.01 level. All the coefficients were significantly different from 0 .

The predictive models in actual terms (uncoded) are also given below. These could be directly used to compute the values of the dielectric properties of grapes at any given m.c. and temperature:

$\varepsilon^{\prime}=-31.345+172.17 \mathrm{M}+0.623 \mathrm{~T}-57.63 \mathrm{M}^{2}-0.74 \mathrm{M} \mathrm{T}-0.0027 \mathrm{~T}^{2}$

$\varepsilon^{\prime \prime}=-8.696+78.95 \mathrm{M}+0.1069 \mathrm{~T}-50.344 \mathrm{M}^{2}-0.347 \mathrm{M} \mathrm{T}-0.00002 \mathrm{~T}^{2}$

where, $\mathrm{T}=$ temperature ${ }^{\circ} \mathrm{C}, 25<\mathrm{T}<80$ and

$\mathrm{M}=$ m.c. on wet basis, $\mathrm{kg} / \mathrm{kg}$ wet mass, $0.15<\mathrm{M}<0.80$.

\subsection{Electric Field Strength}

\subsubsection{Background}

Average MW power dissipated in a material could be derived from Maxwell's equations and on the assumption of a constant electric field in the material, the familiar equation for $P_{a v}$ is (Metaxas and Meredith, 1983):

$$
\mathbf{P}_{\mathrm{ar}}=\omega \varepsilon_{\mathrm{o}} \varepsilon^{\prime \prime} \mathbf{E}_{\mathrm{rms}} \boldsymbol{v}
$$

where,

$P_{\mathrm{av}}=$ power, $\mathrm{W} / \mathrm{m}^{3}$

$\varepsilon_{0}=$ permittivity of free space, $\mathrm{F} / \mathrm{m}$

$\mathrm{E}_{\mathrm{rme}}=$ electric field strength, $V / \mathrm{m}$

$v=$ volume, $\mathrm{m}^{3}$

$\omega=2 \pi f$, frequency, $\mathrm{Hz}$ 
As the MW energy is absorbed, the material's temperature rises at a rate depending on a number of distinct parameters. Substituting $\varepsilon_{0}=8.8 \times 10^{-12} \mathrm{~F} / \mathrm{m}$ for free space and $\mathrm{f}=2450 \mathrm{MHz}$ in Eq. 5.8; the power required to raise the temperature of a mass of a material over a time period is given by (Metaxas and Meredith, 1983):

$$
P_{\mathrm{ev}}=\frac{0.13622 \varepsilon^{\prime \prime} E_{\mathrm{mm}}^{2}}{P_{\mathrm{m} \text { m }} c_{\mathrm{m}}}
$$

Eq. 5.9 was adopted to calculate the energy absorbed by the material due to microwave radiation. Use of Eq. 5.9 needed $\mathrm{E}_{\mathrm{rms}}$ for grapes/raisins and the procedure that was followed in its establishment is given below.

\subsubsection{Methodology for Determination of $\mathbf{E}_{\mathrm{rms}}$}

$E_{\mathrm{rms}}$ for grapes/raisins of different m.c. corresponding to various power densities were experimentally determined. The dielectric loss factor $\left(\varepsilon^{\prime \prime}\right)$ as a function of moisture and temperature was computed using Eq. 5.7.

The electric field strength is the prime parameter in MW heating; it is the intangible link between the electromagnetic energy and the material to be treated. The complex interaction of electro-physical properties of the material under electromagnetic radiation makes prediction of the electric field extremely difficult. One way to determine the absolute value of the electric field strength is through calorimetry and is given by (Metaxas and Meredith, 1983):

$$
E_{m=}=\left[\frac{\rho_{m} c_{m}\left(T_{m}-T_{m o}\right) / t}{0.556 \times 10^{-10} f e_{d f}^{d}}\right]
$$

where,

$\begin{array}{ll}\Phi_{\mathrm{ms}} & =\text { Electric field strength, volt } / \mathrm{m} \\ \rho_{\mathrm{m}} & =\text { density of raisins at a given m.c., } \mathrm{kg} / \mathrm{m}^{3} \\ c_{\mathrm{m}} & =\text { heat capacity of raisins at a given m.c., } \mathrm{J} / \mathrm{kg}{ }^{\circ} \mathrm{C}\end{array}$




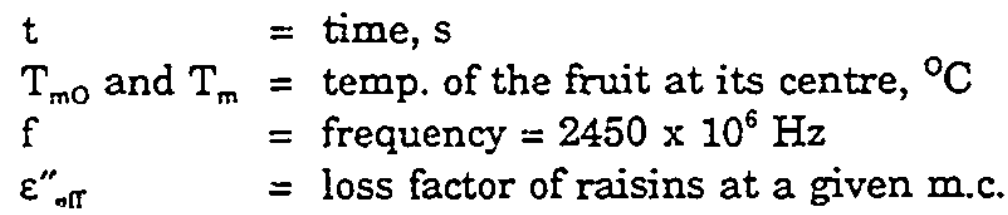

Eq. 5.10 was used to calculate the value of $E_{\mathrm{rms}}$ based on experimental measurements of the temperature rise $\left(T_{m}-T_{m 0}\right)$ in the particle (grape/raisin) for a known interval of time ( $t$ ). The size of the sample consisted of 24 particles. The sample was spread in a single layer in the tray and subjected to MW radiation. These conditions were identical to the conditions existing during the $M W$ drying experiments. Since the determination of $M W$ heating is the point of interest, these expeximents were corducted with no air flow through the cavity (drying chamber). A fluoroptic sensor inserted at the centre of a grape berry indicated the temperature rise in the particle due to $\mathrm{MW}$ radiation. In the absence of air flow the temperature rise in the particle was rapid. The experiments were concluded as soon as mass loss was noticed as Eq. 5.10 is valid for a constant mass. Continuous monitoring of the experiment through the data acquisition system permitted accurate control; the observations were recorded at every $5 \mathrm{~s}$. The temperature rise in the fruit during this time interval was recorded as $\left(T_{m}-T_{m 0}\right)$. $E_{m m}$ was calculated using Eq. 5.10 for each step interval and the average of all the steps represented the actual $E_{\mathrm{zms}}$ for a particular run.

These experiments were conducted with grapes of different moisture content, viz., $80 \%$ (fresh grapes), $60 \%$ m.c., $40 \%$ m.c., $25 \%$ m.c. and $15 \%$ m.c. The experiments were conducted at three power densities, viz., $0.1 \mathrm{~W} / \mathrm{g}$, $0.2 \mathrm{~W} / \mathrm{g}$ and $0.3 \mathrm{~W} / \mathrm{g}$. These power densities were similar to the ones used in drying studies. All experiments were replicated three times and the averaged values of $E_{\text {rms }}$ were used for further analysis.

\subsubsection{Results of $\mathbf{E}_{\text {m.m. }}$}

The results of the average values of $\mathrm{E}_{\mathrm{rms}}$ (Eq. 5.10) of grapes at different water content are given for each of the power densities in Table 5.4. 
Table 5.4. Values of $\mathrm{E}_{\mathrm{rme}}$ in $\mathrm{V} / \mathrm{m}$ for grapes at different $m . c$. and at different $M W$ power densities.

\begin{tabular}{||l|l|l|c|}
\hline m.c. (w.b) (M) & Power 0.1 W/g & Power 0.2 W/g & Power 0.3 W/g \\
\hline 0.81 & 332.1 & 437.9 & 562.6 \\
\hline 0.60 & 406.7 & 476.2 & 595.8 \\
\hline 0.40 & 440.1 & 546.1 & 618.0 \\
\hline 0.25 & 499.2 & 646.1 & 704.2 \\
\hline 0.15 & 529.9 & 725.8 & 773.1 \\
\hline
\end{tabular}

A linear relationship between $E_{r m a}$ and m.c. (M) was observed for each power density:

$$
E_{\mathrm{rms}}=A_{1}+B_{1} M
$$

where, $E_{\mathrm{rms}}=$ electric field strength in $V / m$ and $M=m . c ., \mathrm{kg} / \mathrm{kg}$ wet mass. The linear models were found to be significant at the 0.05 level (Steel and Torrie, 1980). The resulting values of $A_{1}$ and $B_{1}$ obtained from linear regressions are given in Table 5.5.

Table 5.5. Values of $A_{1}$ and $B_{1}$ of Eq. 5.11 for predicting $E_{r m s}$.

\begin{tabular}{|l|l|l|l|}
\hline Power density & Intercept $\left(\mathrm{A}_{1}\right)$ & slope $\left(\mathrm{B}_{1}\right)$ & $\mathrm{R}^{2}$ \\
\hline $0.1 \mathrm{~W} / \mathrm{g}$ & 570.57 & -292.41 & 0.99 \\
\hline $0.2 \mathrm{~W} / \mathrm{g}$ & 757.99 & -434.39 & 0.93 \\
\hline $0.3 \mathrm{~W} / \mathrm{g}$ & 784.74 & -784.74 & 0.87 \\
\hline
\end{tabular}

Fig. 5.5 show the fitness of the linear model for a case of $\mathrm{MW}$ power density of $0.1 \mathrm{~W} / \mathrm{g} ; 95 \%$ confidence interval bands are also drawn. $\mathrm{E}_{\mathrm{rma}}$ values generally increased as moisture content decreased. This behaviour is obvious as a higher field strength would be required for a lower m.c. material so as to enable coupling of the electromagnetic field with the material. The decreasing 


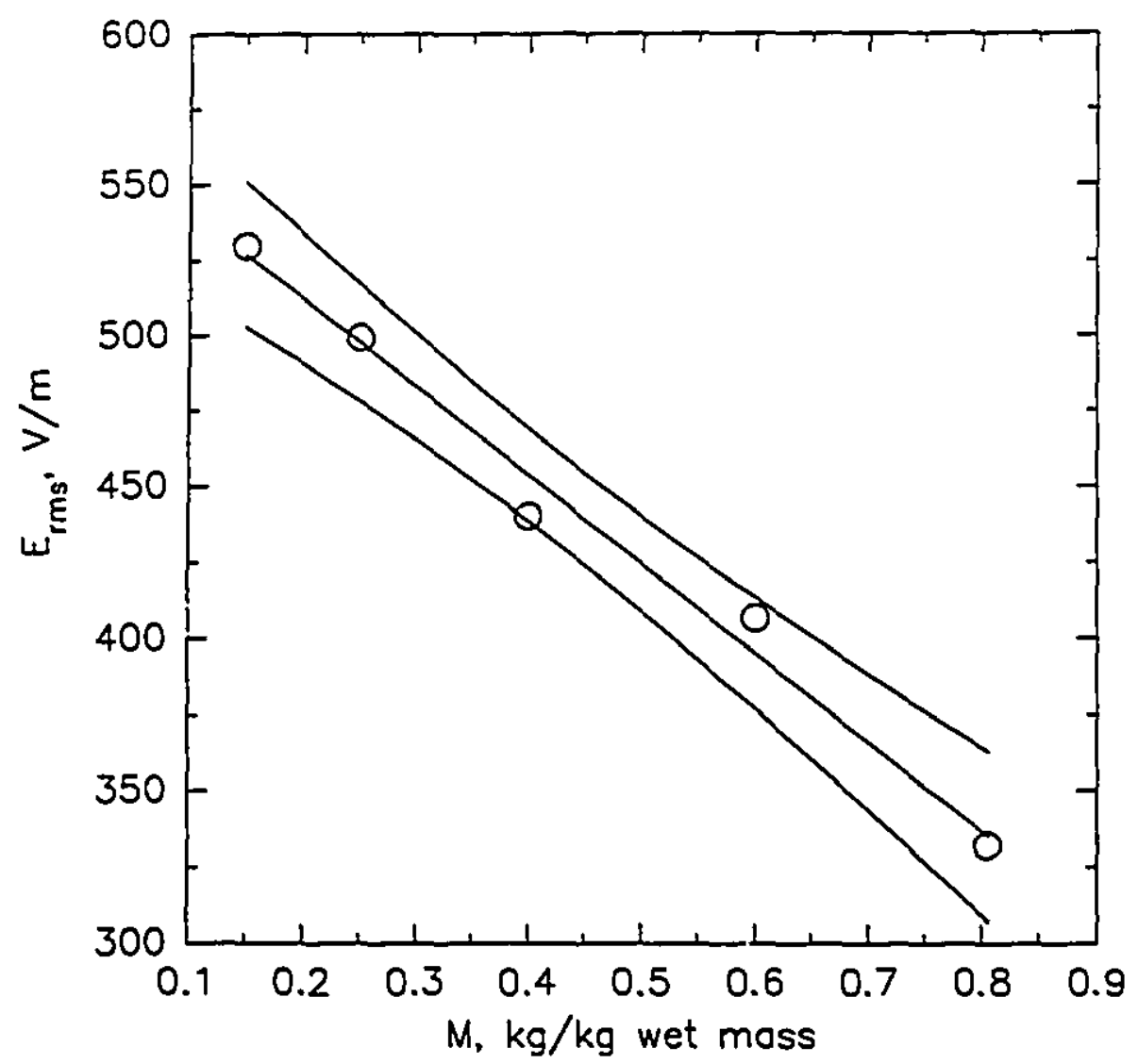

Fig. 5.5. Electric field strength of grapes as a function of in.c. (power density $0.1 \mathrm{~W} / \mathrm{g}$ ) at $2450 \mathrm{MHz}$ ( $95 \%$ confidence interval bands are also shown). 
trend of loss factor with the decreasing moisture content is reflected in higher values $E_{\mathrm{rms}}$ values. However the values of $\mathrm{E}_{\mathrm{rms}}$ observed in this study appear to be smaller and this is due to a very low incident power applied on the material. As the power density increased, the $\mathrm{E}_{\mathrm{rms}}$ values also increased (Table 5.4). As reported earlier, the temperature measurement was on only one particle. It was assumed that the power absorption was uniform in all the particles. However it could be argued that if the power absorption is not uniform in all the particles then the error associated with the computation of $\mathrm{E}_{\mathrm{rms}}$ could be larger. This factor was verified by conducting similar calorimetric studies with crushed grapes in the cavity. Grapes were crushed into juice (without addition of water) and the liquid material, of equal mass corresponding to whole grapes in the previous case, was used. $\mathrm{E}_{\mathrm{rma}}$ values determined for crushed grapes compared well with the corresponding $\mathrm{E}_{\max }$ for whole grapes, thus validating the procedure used.

\subsection{Density $\left(\rho_{m}\right)$}

The density of grapes/raisins as a function of moisture content was experimentally determined. The volume of grapes/raisins at a given m.c. was determined using the toluene displacement method at ambient temperature (Mohsenin, 1986). Mass per unit volume was expressed as density at a given m.c. A linear relationship between density and m.c. was observed for raisins and the linear regression yielded the following equation:

$$
\rho_{\mathrm{m}}=1.408-0.428 \mathrm{M}
$$

where, $\rho_{m}=$ density $g / m L$ and $M=$ m.c. of grapes $/$ raisins (w.b.), $\mathrm{kg} / \mathrm{kg}$ wet material. An $\mathrm{R}^{2}$ value of 0.947 indicated a high degree of correlation for the linear relationship and the results are shown in Fig. 5.6.

\subsection{Specific Heat $\left(c_{m}\right)$}

Specific heat of raisins was computed using the method of distribution 


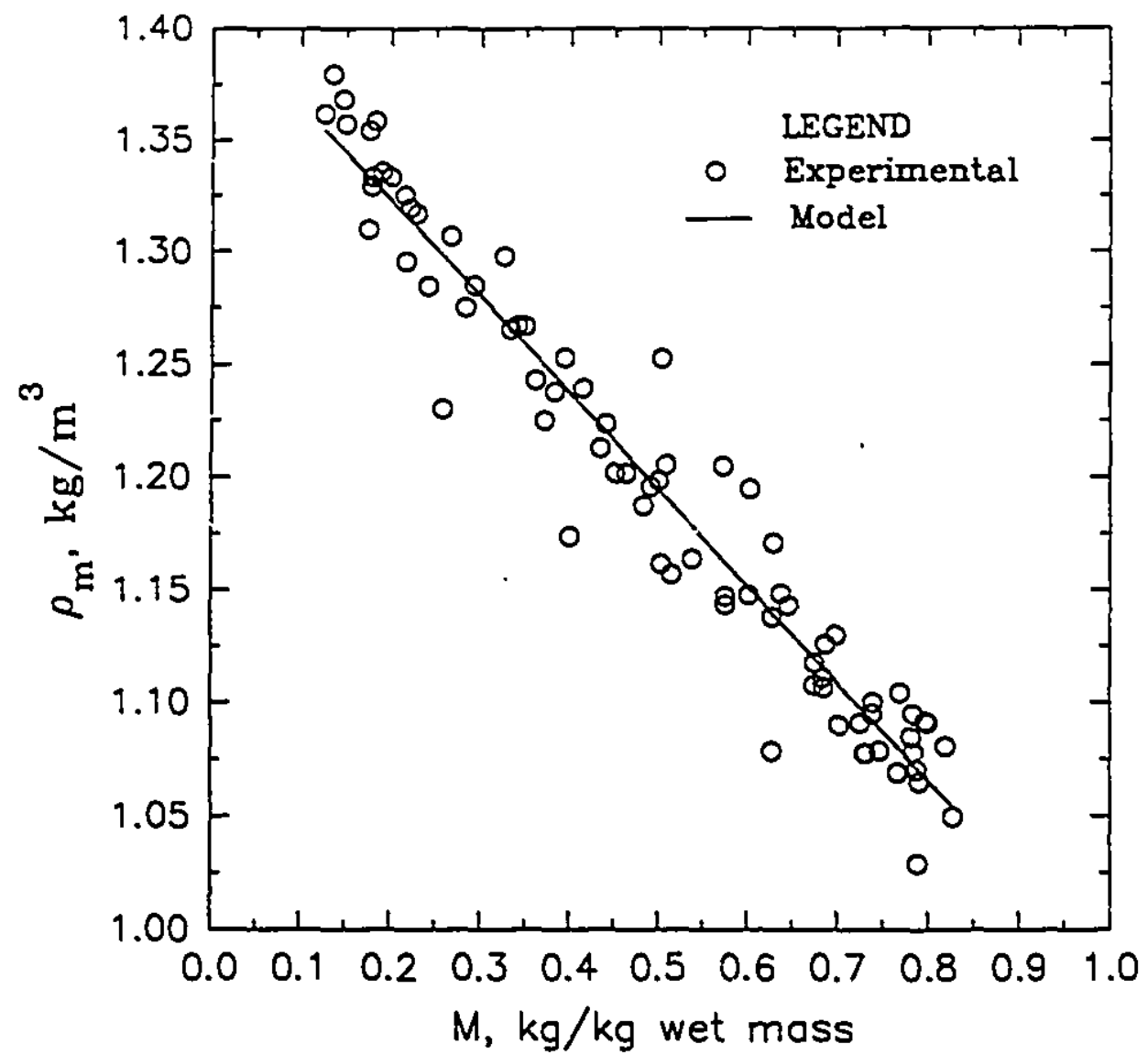

Fig. 5.6. Density of grapes/raisins as a function of m.c. 
(Buffler, 1993). The major components of the material, viz., water, total sugars, proteins and total ash (minerals) were considered to compute the specific heat value using the equation given below (Buffler, 1993):

$$
c_{m}=4190 \mathrm{M}+1420 \mathrm{C}+950 \mathrm{~A}+1780 \mathrm{P}
$$

where,

$\mathrm{c}_{\mathrm{m}} \quad=$ specific heat, $\mathrm{J} / \mathrm{kg} \mathrm{K}$

$\mathrm{M}$ = water content, expressed as a decimal

C = total sugars, expressed as a decimal

$P \quad=$ proteins (nitrogen), expressed as a decimal

A $\quad$ ash content, expressed as a decimal

The composition of grapes/raisins was obtained from published work (Miller, 1963). During drying, the water content of raisins reduces and is associated with a proportionate increase in the other constituents. The specific heat values were computed for 10 different moisture contents by applying Eq. 5.13. The computed values are plotted in Fig. 5.7. The relationship between $c_{m}$ and m.c. was linear with a high degree of correlation $\left(R^{2}=0.999\right)$. The resulting relationship is given below:

$$
c_{m}=(0.361+0.6384 \mathrm{M}) \times 4184
$$

where, $c_{m}=$ specific heat, $\mathrm{J} / \mathrm{kg}{ }^{\circ} \mathrm{C}$ and $\mathrm{M}=$ moisture content in raisins, $\mathrm{kg} / \mathrm{kg}$ of wet material. The resulting values of $c_{m}$ with the use of Eq. 5.14 was in good agreement with the reported values of $c_{m}$ for fresh grapes of $81 \%$ m.c. and raisins of 15\% m.c. (Mohsenin, 1986); however it was not possible to verify the results for the other m.c. for the lack of reported values in the literature. The variation of $c_{m}$ with temperature was assumed to be negligible and Eq. 5.13 was used to obtain $c_{m}$ values at a given moisture content. 


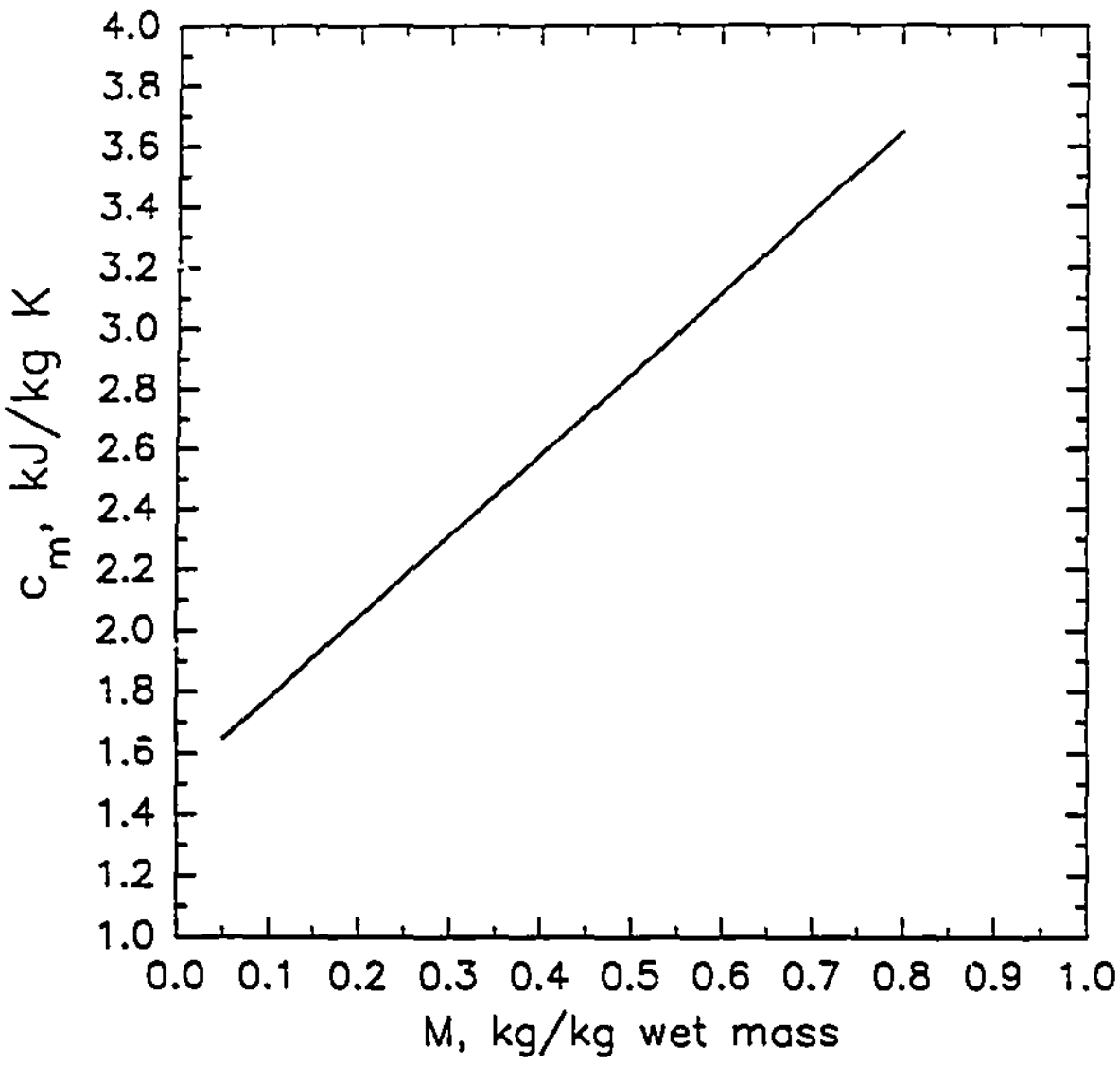

Fig. 5.7. Specific heat of grapes/raisins as a function of m.c. 


\subsection{Mass Transfer Coefficients}

An expression to describe interphase overall mass transfer coefficient is given by (Geankoplis, 1993) :

$$
\eta=k_{G} \nabla p
$$

where, $\quad \eta=$ mass flux, $\mathrm{kg} / \mathrm{m}^{2} \mathrm{~s}$

$\mathrm{k}_{\mathrm{c}}=$ overall mass transfer coefficient, $\mathrm{kg} / \mathrm{m}^{2} \mathrm{~s} \mathrm{kPa}$

$\nabla \mathrm{p}=$ partial water vapour pressure difference, $\mathrm{kPa}$

Eq. 5.15 was applied, as shown by Saravacos and Marousis (1988), to estimate $\mathrm{k}_{\mathrm{c}}$ using convective drying data of grapes obtained in the new microwave drying apparatus discussed in Chapter 4 (data to be presented in chapter 7, section 7.3.1.2). The partial vapour pressure difference was evaluated using psychrometric properties of air corresponding to drying conditions. The values of $\mathrm{k}_{\mathrm{G}}$ obtained at air velocity of $2 \mathrm{~m} / \mathrm{s}$ were transformed to represent equivalent values at air velocity of $1 \mathrm{~m} / \mathrm{s}$. The transformation is described below:

$$
\mathbf{k}_{\mathrm{G}, 1 \mathrm{~m} / \mathrm{s}}=\left[\mathrm{k}_{\mathrm{G}, 2 \mathrm{~m} / \mathrm{s}} / \sqrt{2}\right]
$$

$\sqrt{2}$ in the above equation comes from the power relationship between mass transfer coefficient and the Reynolds Number (heat and mass transfer analogy, Bird, et al., 1960).

The calculated values of $k_{c}$ corresponding to air velocities of $2.0 \mathrm{~m} / \mathrm{s}$ and $1 \mathrm{~m} / \mathrm{s}$ at different air temperatures calculated according to Eqs. 5.15 and 5.16 are tabulated in Table 5.6.

Table 5.6. Overall mass transfer coefficients of

\begin{tabular}{|c|c|c|}
\hline \multirow{2}{*}{$\begin{array}{l}\text { Air Temp., }{ }^{\circ} \mathrm{C} \\
\left(\mathrm{T}_{\mathrm{g}}\right)\end{array}$} & \multicolumn{2}{|c|}{$\mathrm{k}_{\mathrm{G}}, \mathrm{kg} / \mathrm{m}^{2} \mathrm{~h} \mathrm{kPa}$} \\
\hline & $\mathrm{V}_{\mathrm{g}}=2.0 \mathrm{~m} / \mathrm{s}$ & $\mathrm{V}_{\mathrm{g}}=1.0 \mathrm{~m} / \mathrm{s}$ \\
\hline 30 & 0.180 & 0.127 \\
\hline 40 & 0.180 & 0.127 \\
\hline 50 & 0.163 & 0.116 \\
\hline 60 & 0.129 & 0.094 \\
\hline
\end{tabular}
pretreated grapes under convective drying conditions 


\subsection{Connecting Statement to Chapter 6}

The relations obtained in chapter 5 were necessiry inputs to the development of a semi-theoretical model of microwave drying. The modei will be discussed in detail and its validity will be tested in chapter 6 . In chapter 7 , this model will be further used in describing the MW drying kinetics of grapes. 


\section{CHAPTER VI}

\section{MODELLING OF MICROWAVE DRYING OF GRAPES}

\subsection{Introduction}

The volumetric nature of $M W$ heating leads to a rapid transfer of energy throughout the body of the wet material (grapes). Unlike pure convective heating, during which the temperatures in the grape are limited to that of the flowing air, NiW heating can induce an internal temperature greater than that of the ventilating air and thus accentuate internal heat and moisture transport (Perkin, 1990). However, in the microwave drying situation, forced convection is also necessary since it is the process by which water vapour driven from the grape by the absorbed MW energy is then carried away from the immediate drying environment. In order to prevent condensation of the driven moisture onto the surface of the grape, it is necessary that the convective airflow be heated so as to improve its moisture-carrying capacity. Since both the microwave and convective energies are initiated sinultaneously, there is a short period which one may refer to as combined convective and MW heating. Clearly, this period lasts until the surface temperature of the grape reaches that of the convecting air. Thereafter, one may refer simply to microwave heating, since no convective heat transfer towards the interior of the body is possible, and the convective energy is understood to be used entirely for moisture transfer away from the surface.

In this chapter, a model describing all major aspects of this "combined" drying process is formulated. It is aimed at describing the moisture content of the grape at any given time during heating and is more fundamentally aimed at taking into account shrinkage (as occurs drastically in grapes) as well as the changes in dielectric properties that occur throughout the process due to changes in moisture content and temperature. The model is based on the 
continuum approach and includes terms describing internal heat generation, convective heat transfer and evaporation (Turner and Jolly, 1991; Perkin, 1990; Ptasznik et al., 1990).

The MW energy source term was developed from the data obtained in the experiments on the dielectric properties of grapes, during which measurements were made at many combinations of moisture content and temperature (Chapter 5), and measurements of electric field strength. The influence of the geometry of the product on internal moisture diffusion is accounted for by considering a moving coordinate system based on invariate dry solids following shrinkage using the concept presented by Crapiste et al. (1988b) and incorporating the relationships between volume and moisture content deduced during the shrinkage studies (Chapter 5). The model predicts the drying history of the grape and is also capable of simulating temperature and moisture profiles. The general scheme of the model is depicted in Fig. 6.1.

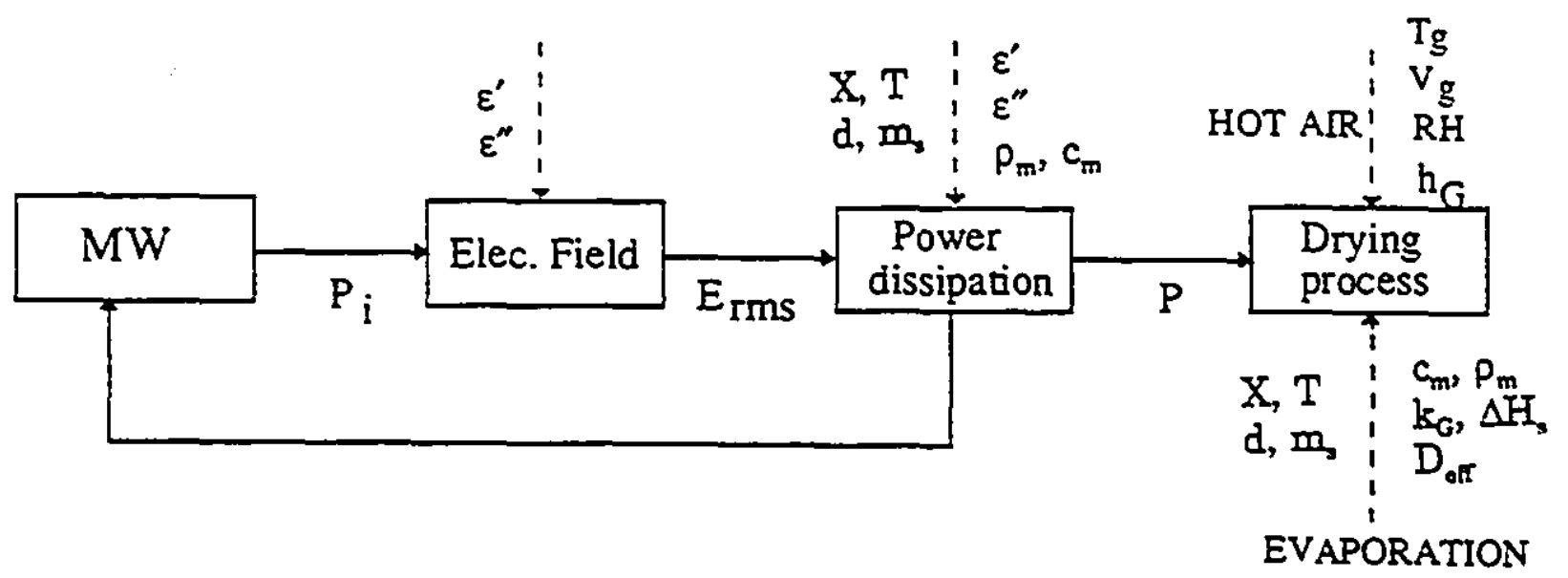

Fig. 6.1. General scheme of the numerical model. 


\subsection{Physical model, Model Formulation and Procedures}

Assumptions

The following assumptions have been made in formulating the model:

a) Each grape berry (particle) is assumed to be spherical, homogeneous and isotropic with initially uniform temperature $\left(T_{m 0}\right)$ and moisture distributions $\left(\mathrm{X}_{0}\right)$.

b) An air stream of constant temperature $T_{8}$ and relative humidity $\mathrm{RH}$ passes over the particle at a constant velocity, $\mathrm{V}_{\mathrm{g}}$.

c) The particle is exposed to $\mathrm{MW}$ radiation at $2450 \mathrm{MHz}$ and the absorption is assumed to be uniform throughout the body ${ }^{3}$.

d) The dielectric properties depend only on the moisture content and temperature of the material.

e) Moisture migration is one-dimensional (radial), from the centre towards the surface where the evaporation is occurring.

f) The vapour pressure of water in the solid is described by sorption equilibrium expressions.

g) Shrinkage of the particle during drying is taker as uniform and proportional to the average moisture content.

h) The combined effect of diffusion and internal pressure on water migration within the particle is expressed through a Fick's type equation with an effective diffusivity parameter.

i) The temperature difference between the centre and the surface is small when compared to the temperature difference between the surface and the bulk gas stream.

\subsubsection{Mass Transfer Equation}

The model formulation begins with the mass transfer equation for a fixed coordinate system as given by Crank (1975):

\footnotetext{
This assumption is closely related to assumption (a); however, attenuation of mierowave energy with dopth in the grape (which is typically of diameters of less than $3 \mathrm{~cm}$ ) is not accounted for.
} 


$$
\frac{\partial \mathrm{X} \cdot}{\partial \mathrm{t}}=\frac{11 \partial}{C_{s} r^{2} \partial r}\left(D_{e \pi}^{\prime} r^{2} \frac{\partial C}{\partial r}\right)
$$

However, since grapes shrink noticeably during drying, the mass transfer equation has been modified to (Crapiste et al., 1988b):

$$
\frac{\partial \mathrm{X}^{\bullet}}{\partial \mathrm{t}}-\dot{\gamma} \frac{\partial \mathrm{X}^{\bullet}}{\partial r}=\frac{11 \partial \partial}{C_{s} r^{2} \partial r}\left(D_{e \pi}^{\prime} r^{2} \frac{\partial C}{\partial r}\right)
$$

where, $\xi=$ velocity of shrinkage, $\mathrm{m} / \mathrm{s}$.

The derivation of this equation is presented in Appendix B (Eq. 10). This equation represents drying in a shrinking particle and is different from the equations normally used in the literature due to the term $-i \partial X^{*} / \partial \mathrm{r}$. To handle the problem of shrinkage, a moving coordinate that follows the shrinkage during drying was defined (Appendix B). In this moving coordinate system, the equation for mass transfer becomes (Eq. 21 in Appendix B):

$$
\frac{\partial \mathrm{X}^{\bullet}}{\partial \mathrm{t}}=\frac{1}{1} \frac{1}{R_{0}^{2} \Lambda^{2} \partial \Lambda}\left(D_{\mathrm{eff}} \Lambda^{2} \frac{\partial X^{\bullet}}{\partial \Lambda}\right)
$$

where, $\Lambda$ represents the dimensionless moving coordinate as given by:

$$
d \Lambda=1 / S^{*}\left(r^{2} / \Lambda^{2}\right) d r / R_{0}^{3}
$$

where, $S^{*}=v / v_{0}$ (local shrinkage coefficient).

In Eq. 6.3 $\mathrm{D}_{\text {or }}$ is a function of temperature, shrinkage, water content and geometry of the product. Eq. 6.3 is similar to the equation for drying of a sphere without shrinkage (Eq. 6.1), with the difference of being written in terms of moving coordinates.

Boundary conditions:

$$
\begin{array}{ll}
\Lambda=0 & \partial X / \partial \Lambda=0 \\
\Lambda=1 & \eta_{w}=-\left(C / R_{0}\right) D_{\text {eff }} \partial X / \partial \Lambda=k_{G} \Delta p
\end{array}
$$

Initial condition:

$$
t=0 \quad X^{*}=X_{0}
$$


Effective Moisture Diffusivity

Crank (1975) derived an analytical solution for the general diffusion equation in a non-shrinking sphere (Eq. 6.1) for the boundary conditions discussed above. The solution for the total amount of diffusing substance ( $\left.\mathrm{M}_{\imath}\right)$ entering or leaving the elemental sphere is (Crank, 1975):

$$
\frac{M_{l}}{M_{-}}=1-\sum_{0} \frac{6 L^{2}}{\beta_{n}^{2}\left[\left(\beta_{n}^{2}+L(L-1)\right]\right.} \exp \left(-\frac{\beta_{n}^{2}}{R^{2}} D_{<\infty t} t\right)
$$

For large drying times, only the first term of the above series solution is of significance (Crank, 1975). Eq. 6.7 thus simplifies to:

$$
\frac{M_{1}}{M_{-}}=1-\frac{6 L^{2}}{\beta_{1}^{2}\left[\left(\beta_{1}^{2}+L(L-1)\right]\right.} \exp \left(-\frac{\beta_{1}^{2}}{R^{2}} D_{\text {aff }} t\right)
$$

where $\beta_{1}$ is the root of the equation:

$$
\beta_{1} \cot \beta_{1}+L-1=0
$$

In Eq. 6.9, I represents the mass transfer Biot number which is a function of air velocity amongst the other variables. The total amount of diffusing substance related to that at an infinite time can be expressed as:

$$
\frac{\mathrm{M}_{\mathrm{e}}}{\mathrm{M}_{-}}=\frac{X_{0}-X}{X_{0}-X_{e}}
$$

Eq. 6.8 then becomes:

$$
\frac{\mathrm{X}-\mathrm{X}_{0}}{\mathrm{X}_{0}-\mathrm{X}_{0}}=\frac{6 L^{2}}{\beta_{1}^{2}\left[\left(\beta_{1}^{2}+L(L-1)\right]\right.} \exp \left(-\frac{\beta_{1}^{2}}{R^{2}} D_{\infty} t\right)
$$

The resulting slope $\left(S=\left[B_{1}^{2} D_{\text {eft }} / R^{2}\right]\right)$ of the plot of $\ln \left[\left(X-X_{0}\right) /\left(X_{0}-X_{0}\right)\right]$ against time $t$, yields the value of the effective diffusivity, $D_{\text {orr }}$. The effect of $X_{0}$ in Eq. 6.11 is only important at very low water contents. For example, in a typical drying situation where the initial moisture content is $\mathrm{X}_{0}=3.5 \mathrm{~kg} / \mathrm{kg}$, 
the final moisture content is $\mathrm{X}=0.18 \mathrm{~kg} / \mathrm{kg}$, the drying air temperature and relative humidity are $\mathrm{T}_{\mathrm{z}}=50^{\circ} \mathrm{C}$ and $\mathrm{RH}=12 \%$, respectively, the difference between $\mathrm{X} / \mathrm{X}_{0}$ and $\left(\mathrm{X}-\mathrm{X}_{0}\right) /\left(\mathrm{X}_{0}-\mathrm{X}_{0}\right)$ is only $7.3 \%$. This is the maximum difference that could be expected since the difference (error) is smaller at higher values of $X$. Hence the plot of $\ln X / X_{0}$ would suffice to estimate $D_{\text {orf }}$.

The effective diffusivity is a function of water content, shrinkage and temperature. In the case of microwave drying, the effect of internal pressure is included in the effective diffusivity parameter since it is based on data from whole drying runs. Rough estimates of these relationships are to be established in order to model the actual process.

\subsubsection{Energy Equation}

Sensible heat gain by the material is described by the governing energy equation. A simplified form of the general energy equation applicable to high frequency heating and drying is given by Ptasznik et al. (1990):

$$
\frac{d T}{d t}=E_{1}+E_{2}+E_{3}
$$

In the above equation, the term $E_{1}$ represents the internal energy generation due to $M W$ heating, $E_{2}$ represents convective heat transfer at the surface and the term $E_{3}$ represents energy loss in phase change due to evaporation at the mass transfer surface. The procedure adopted to evaluate these terms are given in the following sections.

\subsubsection{The Internal Heat Generation Term $\left(E_{1}\right)$}

As the MW energy is absorbed, the material's temperature rises at a rate depending on a number of distinct parameters. These parameters are represented in Eq. 5.8. Eq. 5.9 was applied to compure the internal energy term $E_{1}$. Appropriate $E_{\mathrm{rm}}, \varepsilon^{N}, \rho_{m}, c_{m}$ values corresponding to a given $M W$ drying condition were obtained using Eq. 5.11, 5.7, 5.12 and 5.14, respectively. 


\subsubsection{The Convective Heat Transfer Term (E)}

Convective Heat Transfer Coefficients

The convective heat transfer term $\mathrm{E}_{2}$ is given by:

$$
E_{2}=\frac{-h_{G} A\left(T_{s}-T_{R}\right)}{\rho_{m} c_{m} v}
$$

When a single sphere is heated or cooled by forced convection, the following equation can be ured to predict the average heat transfer coefficient $\left(h_{G}\right)$ for Reynolds Number of 1 to 70,000 and Prandtl Number of 0.6 to 400 (Geankoplis, 1993):

$$
\mathrm{Nu}=2.0+0.60 \operatorname{Re}^{0.5} \operatorname{Pr}^{2 / 3}
$$

For a sphere subjected to heating or cooling in air, the above Eq. reduces to:

$$
h_{G}=\frac{K_{g}}{d}\left(2+0.53 R e^{0.5}\right)
$$

The properties of air were obtained from the literature (Geankoplis, 1993) and regression equations were developed to obtain the values at any desired temperature.

\subsubsection{The Evaporation Term (Ey)}

The evaporation term is given by (Ptasznik et al., 1990; Geankoplis, 1993 ):

$$
E_{3}=\frac{-\Delta H_{s} m_{s}}{c_{m} \rho_{m} v} \frac{d \bar{X}}{d t}
$$

Sorptional Equilibrium Properties

The equations that will be used to represent the equilibrium properties e.g. water activity $\left(\mathrm{a}_{\mathrm{w}}\right)$, and heat of sorption $\left(\Delta \mathrm{H}_{2}\right)$ of the grapes are (Cenkowski et al., 1992; Ratti et al., 1989a): 


$$
\begin{gathered}
\ln a_{w}=-d_{1} X^{\alpha_{2}}+q_{1} \operatorname{cop}\left(-q_{2} X\right) X^{q_{3}} \ln p_{w 0} \\
\Delta H_{s}=\left[1+q_{1} \exp \left(-q_{2} X\right) X^{\alpha_{3}} \Delta H_{w}\right.
\end{gathered}
$$

where the constants $d_{1}, d_{2}, q_{1}, q_{2}$ and $q_{3}$ were determined by non-linear regression of experimental sorption data of grapes (Maroulis et al., 1988). The results are given in the following table (Table 6.1):

Table 6.1. Values of co-efficients of Eq. 6.17 and 6.18.

\begin{tabular}{ccccc}
\hline$d_{1}$ & $d_{2}$ & $q_{1}$ & $q_{2}$ & $q_{3}$ \\
\hline 0.015 & -0.936 & 0.0232 & 11.985 & -0.968 \\
\hline
\end{tabular}

The vapour pressure as well as the heat of vaporization of pure water was calculated using the correlations of the subroutine PSYCHRP (Ratti et al., 1989b).

\subsubsection{Effective Diffusivity Parameter}

The combined effect of $M W$ power and air temperature on moisture diffusivity during MW drying was accounted by an effective diffusivity parameter evaluated from experimental data. MW drying data obtained in the new drying apparatus (data to be presented in chapter 7) was used for firding this parameter. The slope of the plot $\ln \left(\mathrm{X} / \mathrm{X}_{0}\right)$ versus $t$ (S = effective diffusivity parameter) was modelled as a function of microwave power density and air temperature using the empirical model given below:

$$
\ln S=P^{C_{1}}\left(C_{2}+\frac{C_{3}}{T_{8}}\right)
$$

where $C_{1}, C_{2}$ and $C_{3}$ are the coefficients which are evaluated using MW drying experimental data. The basis for choosing this specific model in preference to a general model through non-linear regression analysis is described below. 
The analysis of the MW drying data revealed that the functionality of $S$ and $T_{8}$ was of the type:

$$
\ln S=\left(a+b / T_{k}\right)
$$

The above equation is of the Arrehenius type and has been widely used in the literature to explain the dependency of moisture diffusivity on temperature. Using this relationship, $a$ and $b$ values were obtained for each of the power densities $(P)$ that are used in the present drying studies. When $b$ was plotted against $\mathrm{P}$ a power relationship was noticed between the two $\left(b=\mathrm{P}^{\mathrm{c}}\right)$. The intercept $a$ was also found to have a power relation with $P$. The slope $S$ was therefore assumed to have a power law relationship with $\mathrm{P}$. On this basis, the empirical equation (6.19) was used to describe the dependency of $S$ on $T_{z}$ and P. The Levenverg and Marquardt method was used to determine the parameter values that minimised the sum of squares of differences (Sigma Plot, 1992). The coefficients $C_{1}, C_{2}$ and $C_{3}$ in Eq. 6.19 were obtained from the analysis of $\mathrm{MW}$ drying data obtained in the new drying apparatus (data to be presented in chapter 7) and are presented in the following table (Table 6.2 ).

Table 6.2. Values of $C_{1}, C_{2}$ and $C_{3}$ of Eq. 6.19.

\begin{tabular}{ccc}
\hline $\begin{array}{l}\text { Coefficients } \\
\text { of Eq. } 6.19\end{array}$ & $\begin{array}{l}\text { Air Velocity } \\
\mathrm{V}_{\mathrm{g}}=1.0 \mathrm{~m} / \mathrm{s}\end{array}$ & $\begin{array}{c}\text { Air Velocity } \\
\mathrm{V}_{\mathrm{g}}=2.0 \mathrm{~m} / \mathrm{s}\end{array}$ \\
\hline $\mathrm{C}_{1}$ & -1.7070 & -0.898 \\
$\mathrm{C}_{2}$ & +0.1920 & +1.609 \\
$\mathrm{C}_{3}$ & -63.9380 & -542.041 \\
\hline
\end{tabular}

\subsection{Numerical Procedure}

Equations 6.3 and 6.12 were solved simultaneously using the "Method of Lines". This method describes the spatial derivatives by finite differences of the second order. The radius of the sphere was divided into $\mathrm{N}$ spherical slices of thickness $\Delta r$. The resulting vector of temporal derivatives was solved by using the Gear Method (Hindmarsh, 1972, 1974). 


\subsubsection{Simulation}

The model discussed in the preceding sections (Eq. 6.3 and 6.12), was used to simulate the MW drying process with the initial and boundary conditions given as Eqs. 6.4, 6.5 and 6.6. The "Method of Lines" was used to solve the system of differential equations since Eq. 6.3 is a partial differential equation with two independent variables. This numerical method has been applied successfully to simulate drying process (Ratti and Crapiste, 1992; Ratti and Mujumdar, 1993). In applying this method, the partial derivatives on the right side of the differential equation are initially discretized. A central finite difference discretization scheme is used to represent the second order derivative of Eq. 6.3. The discretization scheme has a second order truncation error. The boundary condition on the surface (Eq. 6.5) is represented with backward discretization while the other boundary condition (Eq. 6.4) is represented with forward discretization, both having a second order truncation error. Thus the system of equations is transformed into a vector of $4 *(N+1)$ temporal derivatives $(\mathbb{N}$ is the number of equal steps into which the sphere is radially divided). The Gear package (Hindmarsh, 1972, 1974) was used to solve the resulting vector of temporal derivatives.

The inputs required by the simulation program are:

\begin{tabular}{|c|c|c|c|}
\hline$T G\left(T_{p}\right)$ & $\mathrm{RH}$ & $\mathbf{P}$ & $\mathrm{TSO}\left(\mathrm{T}_{\mathrm{SO}}\right)$ \\
\hline$K G\left(k_{G}\right)$ & Lo $\left(L_{0}\right)$ & & Vo $\left(v_{0}\right)$ \\
\hline $\mathrm{x} 0\left(\mathrm{x}_{0}\right)$ & $\operatorname{MSS}\left(\mathbf{m}_{\mathrm{s}}\right)$ & $X A\left(X_{A}\right)$ & $L_{A}\left(L_{\Lambda}\right)$ \\
\hline$A(A)$ & $\mathrm{B}(B)$ & & \\
\hline$A 1\left(A_{1}\right)$ & $\mathrm{B1}\left(\mathrm{B}_{1}\right)$ & & \\
\hline $\operatorname{VEL}\left(V_{s}\right)$ & & & \\
\hline $\mathrm{Cl}\left(\mathrm{C}_{1}\right)$ & $\mathrm{C} 2\left(\mathrm{C}_{2}\right)$ & $\mathrm{C} 3\left(\mathrm{C}_{3}\right)$ & \\
\hline
\end{tabular}

Based on this input statement, the program solved the differential equations and obtained all the relevant properties $\left(\mathrm{X} \& \mathrm{~T}\right.$ and $\mathrm{E}_{\mathrm{rme}}, \varepsilon^{\prime \prime}, \rho_{\mathrm{m}}, \mathrm{c}_{\mathrm{m}}, \Delta \mathrm{H}_{2}$, etc.,) at a given instant of time (Appendix-B, programs MW.FOR and DIFFUN.FOR).

Symbols given inside the parentheses represent the corresponding nomenclature followed. 


\subsection{Model Validation Procedure}

The solution obtained from the simulation was compared with experimental data from a $4 \times 3 \times 2$ factorial drying experiment on grapes aimed at evaluating the quality and drying time with respect to the process parameters, inlet air temperature $\left(T_{k}\right)$, power density $(P)$ and inlet air velocity $\left(V_{g}\right)$. This experiment is fully described in Chapter 7. The comparison was done according to the procedure presented recently by Weres and Jayas (1994) which they used to validate a numerical structural model for thin layer drying of corn. They first represented their experimental data by the best fitting of a number of empirical equations. The accuracy of the numerical structural model was then determined by comparing data predicted by the structural model to the experimental data as represented by the best fitted empirical equation. The procedure of Weres and Jayas (1994) was applied to test the accuracy of simulation results of MW drying of grapes as described below.

(a) The experimental data was fitted by the modified logarithmic model (Page, 1949) as this model was found to fit the MW drying data of grapes adequately well (Eq. 3.3). The parameters of the equation were obtained for each of the drying conditions using nonlinear regression analysis (SAS, 1989).

(b) Values of the average moisture ratios calculated through Eq. 3.3 were used to estimate the accuracy of predictions by the numerical model (Eq. 6.3 and Eq. 6.12). The following relative errors of approximations were used to perform the comparisons (Weres and Jayas, 1994):

$$
e^{\tau}\left(t_{\tau}\right)=\frac{\left|M R\left(t_{\tau}\right)-M R_{\exp }\left(t_{\tau}\right)\right|}{M R_{\exp }\left(t_{\tau}\right)}
$$




$$
e^{\ell F}=\frac{\left[\sum_{\tau=1}^{N T}\left|M R\left(t_{\tau}\right)-M R_{\exp }\left(t_{\tau}\right)\right|^{2]^{1 / 2}}\right.}{\left[\sum_{\tau=1}^{N T}\left|M R_{\exp }\left(t_{\tau}\right)\right|^{2}\right]^{1 / 2}}
$$

where,

$t=$ time, $h$

$[t]_{t=1}{ }^{N T}=$ set of instants bisecting two consecutive time intervals, (h) $N T=$ number of time intervals

$e^{\tau}=$ local relative error of approximation at time $[t]_{t=1}{ }^{\mathrm{NT}}(\%)$

$e^{\mathrm{kF}}=$ global relative error of approximation throughout the drying period, (\%)

\subsection{Discussion of Model Performance}

The simulation model (Eqs.6.3 and 6.12) was run using the specified initial and boundary conditions (Eqs. 6.4, 6.5 and 6.6). The simulated results for a given set of $\mathrm{MW}$ drying conditions were compared with the experimental data. The average moisture content as a function of time predicted by simulation is compared with the actual observed values in Fig. 6.2. As can be seen the simulation very closely predicted the actual MW drying process throughout the drying period.

The accuracy of the numerical model was tested by adopting the procedure of Weres and Jayas (1994). The average moisture ratio predicted by simulation was compared to the experimental data represented by the modified logarithmic equation (Eq. 3.3). The values of $\mathrm{k}$ and $\mathrm{n}$ of Eq. 3.3 obtained by fitting the drying of MW drying data is presented in Table 6.4 along with the corresponding $\mathrm{R}^{2}$ values. The calculated global relative error of the numericalmodel for the entire drying period is also given in Table 6.4. The details of these MW drying treatments could be found in Chapter 8 (Table 8.1). 


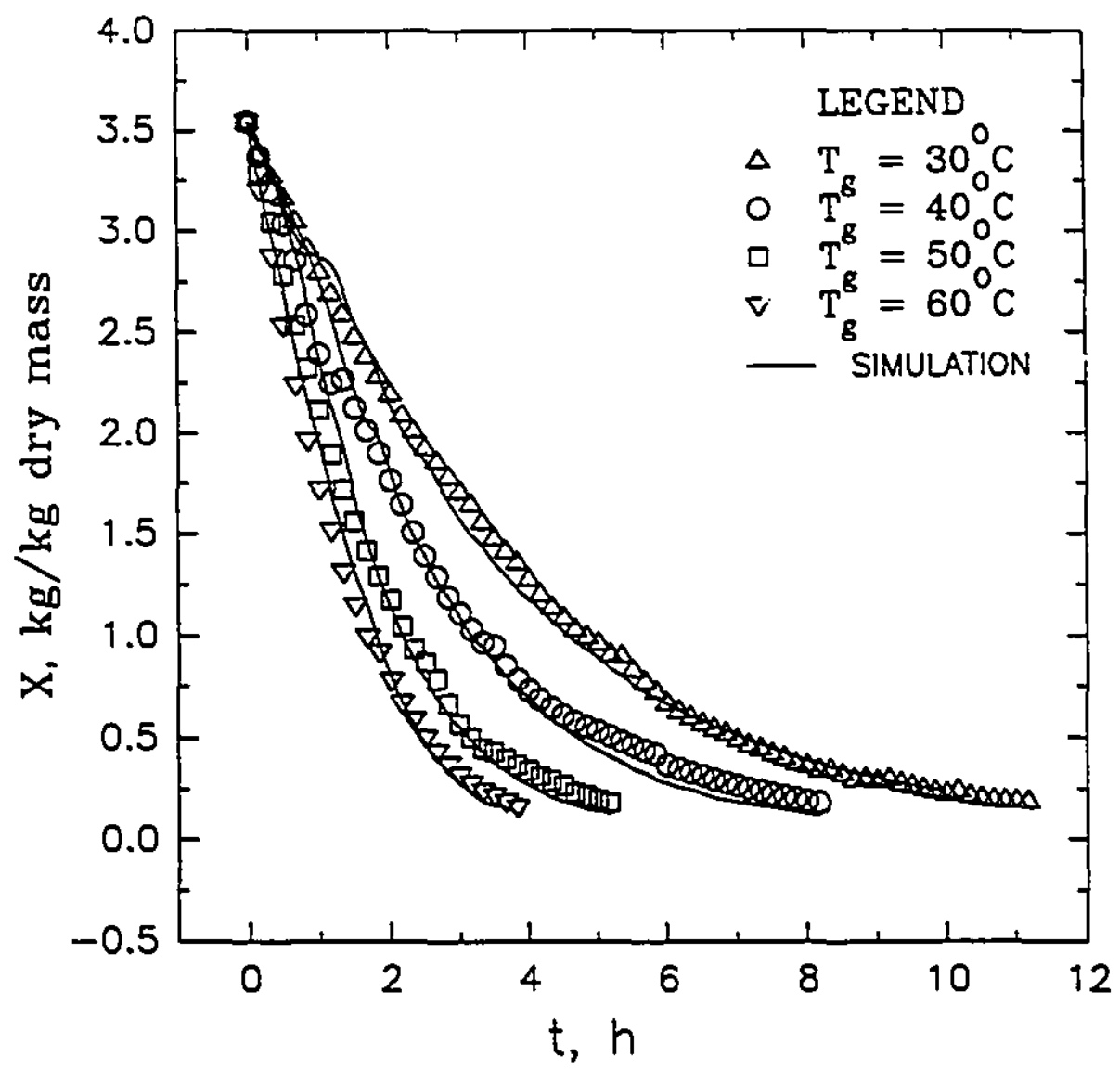

Fig. 6.2. Predicted average m.c. of grapes by the numerical model compared to experimental observations $\left(P=0.1 \mathrm{~W} / \mathrm{g}\right.$ and $\left.V_{g}=2.0 \mathrm{~m} / \mathrm{s}\right)$. 
The modified logarithmic equation (Eq. 3.3) accurately predicted the MW drying of grapes $\left(R^{2}\right.$ values $\left.>0.99\right)$. The fitness of the modified logarithmic equation and the numerical model with the observed data is presented in Fig. 6.3 for MW drying of grapes at an air velocity of $2.0 \mathrm{~m} / \mathrm{s}$, MW power density of $0.1 \mathrm{~W} / \mathrm{g}$ and air temperature of $30^{\circ} \mathrm{C}$. Fig. 6.4 gives the plot of the relative errors of approximation (Eq. 6.21) of experimental data with the numerical model for this case. For this case the global relative exror $\left(e^{2 F}\right)$, calculated through Eq. 6.21, was found to be $3.23 \%$ and which could be considered as an excellent fit. However, the global error noticed in four out of the 24 treatments, listed in Table 6.4, exceeded 10\%, indicating a poorer fit in these cases. A maximum global error of $13 \%$ was noticed in one particular case. Since the actual drying time requirements under MW drying conditions are small, even an error of $13 \%$ would not make a substantial difference from a practical point of view.

\subsection{Summary}

The numerical procedure predicted the MW drying behaviour of grapes adequately well. Although the modified logarithmic model fitted the data very well it lacked in its versatility for applications because of its purely empirical nature. On the other hand, the proposed numerical model is based on semitheoretical approach and therefore lends itself for adaptation to scale-up purposes. Given the nature of a material with its physical and electromagnetic properties, it is possible to predict the $M W$ drying behaviour by applying the numerical procedures elaborated. It is to be noted that this procedure is not restricted in its application to grapes but can be extended to other materials (fruits and vegetables). 
Table 6.4. Parameters of the fitting equation and accuracy of the numerical model on different (global errors) for different MW drying treatments

\begin{tabular}{|c|c|c|c|c|}
\hline $\begin{array}{l}\text { Experiment, } \\
\text { Treatment No. }\end{array}$ & $\mathbf{k}$ & $\mathrm{n}$ & $\mathrm{R}^{2}$ & $\begin{array}{l}\text { Global } \\
\text { Error, \% }\end{array}$ \\
\hline 01 & 0.336 & 1.082 & 0.9967 & 6.49 \\
\hline 02 & 0.440 & 1.265 & 0.9958 & 2.75 \\
\hline 03 & 0.710 & 1.216 & 0.9994 & 4.02 \\
\hline 04 & 0.713 & 1.256 & 0.9990 & 7.35 \\
\hline 05 & 0.565 & 1.232 & 0.9987 & 6.15 \\
\hline 06 & 0.576 & 1.257 & 0.9979 & 5.37 \\
\hline 07 & 0.897 & 1.296 & 0.9992 & 4.75 \\
\hline 08 & 1.009 & 1.137 & 0.9932 & 6.53 \\
\hline 09 & 0.778 & 1.121 & 0.9996 & 8.27 \\
\hline 10 & 0.900 & 1.221 & 0.9986 & 9.98 \\
\hline 11 & 1.060 & 1.286 & 0.9986 & 8.15 \\
\hline 12 & 1.15 & 1.239 & 0.9978 & 7.49 \\
\hline 13 & 0.223 & 1.131 & 0.9991 & 3.23 \\
\hline 14 & 0.355 & 1.051 & 0.9980 & 7.42 \\
\hline 15 & 0.523 & 1.027 & 0.9995 & 11.26 \\
\hline 16 & 0.717 & 1.096 & 0.9998 & 7.053 \\
\hline 17 & 0.449 & 0.987 & 0.9993 & 12.46 \\
\hline 18 & 0.533 & 1.172 & 0.9999 & 6.45 \\
\hline 19 & 0.802 & 1.172 & 0.9978 & 5.83 \\
\hline 20 & 0.794 & 1.235 & 0.9992 & 6.11 \\
\hline 21 & 0.566 & 1.088 & 0.9967 & 8.55 \\
\hline 22 & 0.656 & 1.015 & 0.9993 & 13.07 \\
\hline 23 & 0.879 & 1.042 & 0.9992 & 10.67 \\
\hline 24 & 1.047 & 1.117 & 0.9997 & 6.73 \\
\hline
\end{tabular}




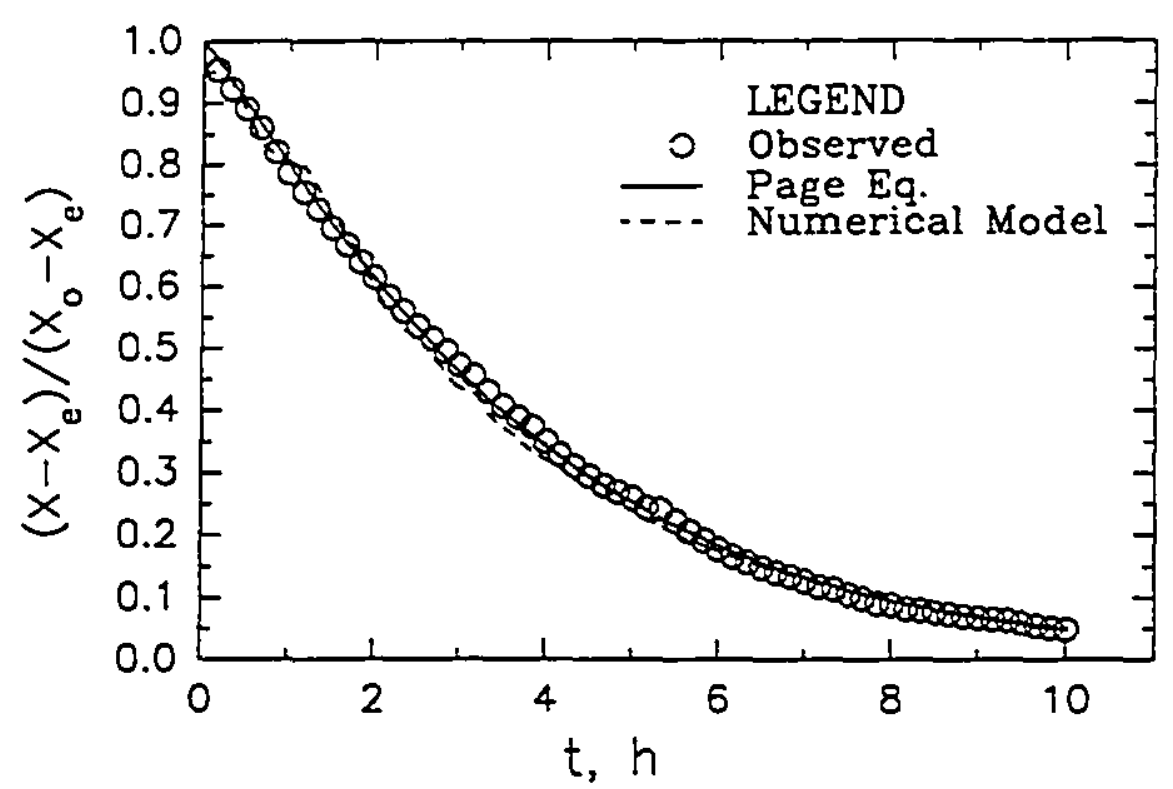

Fig. 6.3. Comporison of observed MR in MW drying of gropes with the MR predicted by the numerical model and the Page's Eq.

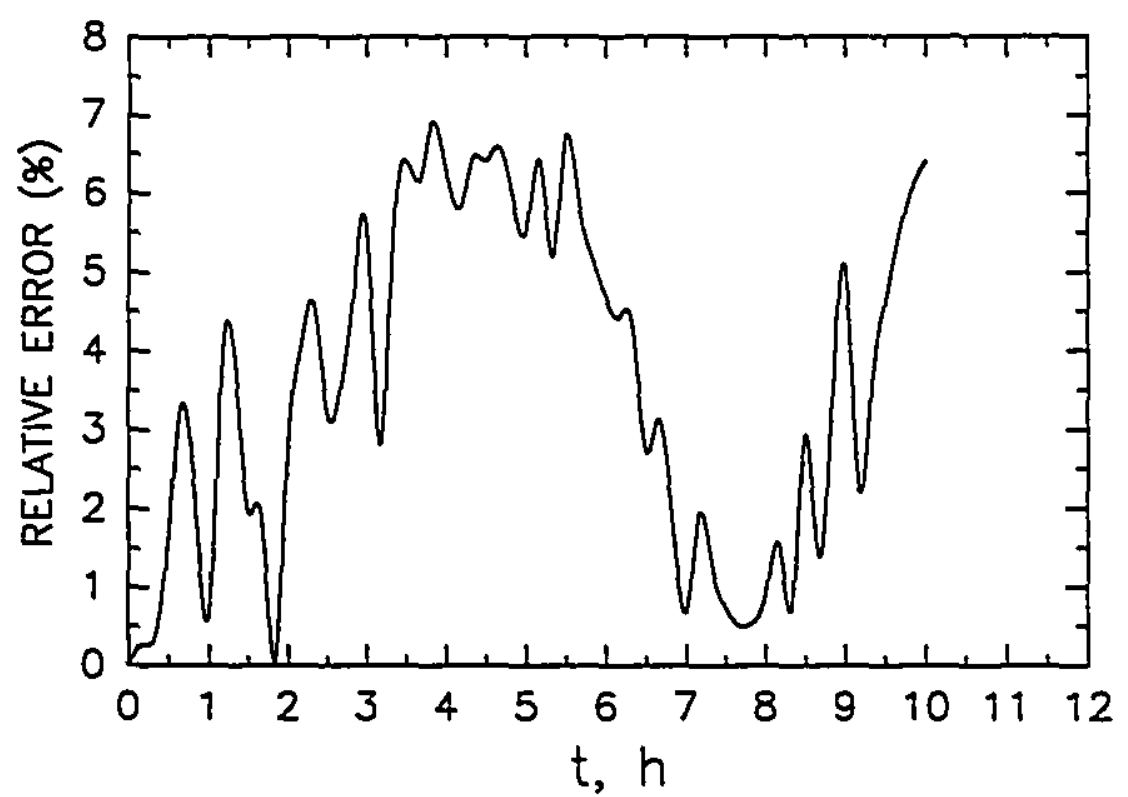

Fig. 6.4. The relative error of opproximation for experimental data represented by Page's equation (Eq. 3.3) compored with numerical model. 


\section{CHAPTER VII}

\section{DRYING BINETICS OF GRAPES}

\subsection{Introduction}

Experiment on drying kinetics of grapes was conducted using the new microwave drying setup developed for the studies (Chapter 4). Drying behaviour of grapes was studied both under pure convective drying conditions and combined convective and $\mathrm{MW}$ drying conditions. Convective drying studies provided basic information on drying kinetics of grapes which were verified with those reported in the literature on hot air drying. Some of this information was required in model building of $\mathrm{MW}$ drying as this technique also involved convective conditions. Effect of drying parameters: a) air temperature, b) microwave power density and c) air velocity on MW drying kinetics of grapes was studied.

The new apparatus had the provision to set the desired incident MW power and it could be operated on a continuous basis. A small power density could be set on incremental basis, in steps, to investigate its effect on drying rates and the associated quality aspects. Also there was a provision for tuning of the applicator by matching the impedance of the circuit with the changing characteristics of the load in the applicator (m.c. in grapes) which provided a control to minimise the reflected power. In situ measurement of mass loss and other process parameters on a continuous basis, with no disturbance in the drying environment, provided accurate data. The data acquisition system was set to collect data at every $5 \mathrm{~min}$. intervals. The other details of the apparatus could be found in chapter 4 . 


\subsection{Materials and Methods}

\subsubsection{Variety of Grapes and other Experimental Procedures}

Thompson seedless grapes were used for the studies as this is the variety generally used for raisins. Grapes are imported to Canada, and therefore fresh fruits were procured from the local market from a single source which received grapes from a known source of origin (California). To ensure uniformity of the test material, grapes having TSS of Brix $20-21^{\circ}$ were selected. Grapes were brought in different lots and stored at $4 \pm 1^{\circ} \mathrm{C}$ and $\mathrm{RH}$ 95\%. Each replicate of the drying study was conducted using grapes from a single lot to maintain uniformity in the test material within that replicate. Initial moisture content was determined as outlined in chapter 3. Samples were prepared for the drying studies by taking out the fruits from the cold store and kept at ambient conditions for about $2 \mathrm{~h}$. Uniform berries of correct size were selected and the stems were hand removed, and the berries taken for pretreatment. The sample size was about $100 \mathrm{~g}$. The pretreatment consisted of dipping the grapes in an alkaline emulsion of $2 \%$ ethyl oleate in $0.5 \%$ sodium hydroxide at $80^{\circ} \mathrm{C}$ for a period of $30 \mathrm{~s}$. These procedures are in accordance with the earlier studies reported in chapter 3 . The other experimental procedures in relation to sample preparation were similar to those reported in chapter 3.

Drying time to reach a desired final moisture content of $0.18 \mathrm{~kg} / \mathrm{kg} \mathrm{dry}$ mass was the response parameter of the study. Drying time is known to be influenced by many factors such as variety, soluble sugars, etc. These factors were assumed to be constant since grapes of same variety and similar Brix reading were used.

\subsubsection{Convective Drying in the New Drying Apparatus}

Grapes were dried into raisins (final m.c about $0.18 \mathrm{~kg} / \mathrm{kg}$ dry mass) under convective drying conditions in the new apparatus, without applying microwaves, in order to obtain information on convective drying behaviour. 
The MW generator was turned off during these tests. The studies were conducted at an air velocity of $2.0 \mathrm{~m} / \mathrm{s}$ and the effect of pretreatment was also analyzed using both normal fruits (untreated) and pre-treated fruits. Normal fruits, i.e, without any pre-treatment, were dried at the high temperatures, 50 and $60^{\circ} \mathrm{C}$, as lower temperatures took very long time to dry. Pretreated grapes were dried at air temperatures of $45,50,55$ and $60^{\circ} \mathrm{C}$.

\subsubsection{Microwave Drying in the New Drying Apparatus}

The drying parameters a) air temperature $\left(\mathrm{T}_{\mathrm{z}}\right), \mathrm{b}$ ) microwave power density $(P)$ and c) air velocity $\left(V_{z}\right)$ were treated as independent variables to find their effect on the response parameter drying time ( $t$ ). To develop an efficient and economical drying process, factors $T_{z}, P$, and $V_{k}$ were chosen at different levels and their individual and interactive effects were analyzed with respect to drying time and product quality.

\section{a) Inlet air temperature $\left(T_{8}\right)$}

Preliminary studies conducted on microwave drying of grapes indicated that air temperatures below $30^{\circ} \mathrm{C}$ were not efficient and drying times at these temperatures were too long. Therefore $30^{\circ} \mathrm{C}$ was fixed as the lower limit for experimentation. Similarly, air temperatures above $60^{\circ} \mathrm{C}$ would result in browning and burning of fruits. This temperature was fixed as the upper limit of $\mathrm{T}_{\mathbf{r}}$. In addition to these lower and upper limits, two more levels of temperatures were chosen at intermediate values: $40^{\circ}$ and $50^{\circ} \mathrm{C}$.

\section{b) Microwave power density $(P)$}

MW drying studies were conducted at different power densities. Heat generation inside the fruit as a result of MW energy absorption may lead to swelling, discolouration, cracking, etc. Based on preliminary studies the three levels considered were $0.1,0.2$ and $0.3 \mathrm{~W} / \mathrm{g}$ on fresh fruit weight basis. 
c) Air velocity $\left(V_{p}\right)$

Drying curves for grapes obtained from preliminary studies clearly indicated that all the drying took place in the falling rate period. Hence it was obvious that external mass transfer was not the controlling mechanism. However the combined effect of microwaves and convective drying may be influenced by air velocity. Also, a cooling effect from the drafted air may influence the microwave drying process. Therefore the effect of air velocity was also included in the study. Two levels of air flow, 1.0 and $2.0 \mathrm{~m} / \mathrm{s}$, were chosen for the studies.

\subsubsection{Experimental Design}

A $4 \times 3 \times 2$ factorial $\left(T_{z}, P, V_{z}\right)$ experiment was laid out in Randomized Complete Block Design (RCBD). This resulted in 24 different combinations of treatments. This experiment was replicated 3 times for a total number of 72 drying runs. The experimental design with various treatment combinations is shown in Table 7.1.

Table 7.1. Experimental factors and their levels in MW drying of grapes.

\begin{tabular}{clcccl}
\hline FACTOR & VARIABLES & \multicolumn{4}{c}{ L E V E L S } \\
& & 1 & 2 & 3 & 4 \\
\hline $\mathrm{T}_{8}$ & Air temperature, ${ }^{\circ} \mathrm{C}$ & 30 & 40 & 50 & 60 \\
$\mathrm{P}$ & $\begin{array}{l}\text { MW power density, } \\
\text { continuous, W/g }\end{array}$ & 0.1 & 0.2 & 0.3 & - \\
$\mathrm{V}_{8}$ & Air velocity, $\mathrm{m} / \mathrm{s}$ & 1.0 & 2.0 & - & - \\
\hline
\end{tabular}

At the end of drying, samples were subjected to m.c. determination and later for quality testing. Quality aspects of drying are discussed in chapter 8. 


\subsection{Results and Discussion}

\subsubsection{Convective Drying}

\subsubsection{Grapes without pre-treatment}

Drying times to reach final m.c of $0.18 \mathrm{~kg} / \mathrm{kg}$ were about $48 \mathrm{~h}$ at $50^{\circ} \mathrm{C}$, and $40 \mathrm{~h}$ at $60^{\circ} \mathrm{C}$. These results are in good agreement with previous observations by Ponting and McBean (1970). $L n \mathrm{X} / \mathrm{X}_{0}$ was plotted against time $(t)$ for air temperatures of 50 and $60^{\circ} \mathrm{C}$. Analysis of the data revealed that these curves could be divided into three different drying zones according to the linearity observed betwe $n \ln \mathrm{X} / \mathrm{X}_{0}$ and $t$. These regions were termed as High, Intermediate and Low moisture zones. As an example, Fig. 7.1 shows the plot of $\ln \mathrm{X} / \mathrm{X}_{0}$ vs. $t$ for an air temperature $50^{\circ} \mathrm{C}$ and air velocity $2.0 \mathrm{~m} / \mathrm{s}$ where the three distinct divisions could be seen. The relationship between $\ln \mathrm{X} / \mathrm{X}_{0}$ and $t$ in each of these zones was explained by:

$$
\ln \left(\frac{X}{X_{0}}\right)=a_{1}+b_{1} t
$$

The values of $a_{1}$ and $b_{1}$ were obtained by linear regression analysis. The computed values of $D_{e}$ (obtained with $R^{2}>0.9$ ) are given in the Table 7.2. As expected, the $D_{0}$ values decreased with a decrease in moisture content.

Table 7.2. Effective moisture diffusivities in convective drying of grapes without pretreatment.

\begin{tabular}{lllll}
\hline Moisture Zone & $\begin{array}{l}\text { Temp. } \\
{ }^{\circ} \mathrm{C} \\
\left(\mathrm{T}_{\mathrm{g}}\right)\end{array}$ & $\begin{array}{l}\text { Av. m.c. } \\
\mathrm{kg} / \mathrm{kg} \mathrm{dry} \\
(\mathrm{X})\end{array}$ & $\begin{array}{l}\text { Av. radius } \\
\mathrm{cm} \\
(\mathrm{R})\end{array}$ & $\begin{array}{l}\mathrm{D}_{\mathrm{g}} \\
\mathrm{m}^{2} / \mathrm{s} \\
\mathrm{x10}^{10}\end{array}$ \\
\hline High moisture & 50 & 2.305 & 0.905 & 2.076 \\
& 60 & 2.180 & 0.910 & 2.798 \\
Inter. moisture & 50 & 0.775 & 0.795 & 1.068 \\
& 60 & 0.745 & 0.785 & 1.467 \\
Low moisture & 50 & 0.280 & 0.695 & 0.679 \\
& 60 & 0.305 & 0.690 & 0.589 \\
\hline
\end{tabular}


These zones indicated the variation in mass transport behaviour as a function of moisture content. Based on the linearity observed within a zone it was assumed that the $D_{\text {off }}$ to be a constant in this region and an average conditions prevailed between the commencement and the end of the zone.

\subsubsection{Grapes with pre-treatment}

Experiments were conducted at air temperatures of $45,50,55$ and $60^{\circ} \mathrm{C}$ and air velocity of $2.0 \mathrm{~m} / \mathrm{s}$ with pretreated grapes. Drying times with pretreatments were $36.2,23.7,19.5,16.8 \mathrm{~h}$ at $45,50,55$, and $60^{\circ} \mathrm{C}$, respectively. The observed drying time at $60^{\circ} \mathrm{C}$ compared well with the reported duration for similarly pretreated grapes (Masi and Riva, 1988; Saravacos and Raouzeos, 1986).

Analysis of $\ln \mathrm{X} \mathrm{X}_{0}$ vs. $t$ showed that linearity existed in three zones similar to the previous case. The zones were divided based upon the linearity exasted in the data (high $\mathrm{R}^{2}$ values). As an example, Fig. 7.2 shows the plot of $\ln \mathrm{XX}_{0}$ vs. $t$ for the air temperature of $50^{\circ} \mathrm{C}$. The relationship between $\ln$ $X X_{0}$ and $t$ in these zones was expressed in the form of Eq. 7.1. The values of constants $a_{1}$ and $b_{1}$ were derived by applying linear regression analysis individually for each of the three drying zones. The resulting $D_{0}$ values (obtained with $\mathrm{R}^{2}$ higher than 0.90 ) are presented in the following Table 7.3.

Diffusivity values increased with moisture content as shown in Fig. 7.3. For instance, at $T_{z}=60^{\circ} \mathrm{C}$ the $D_{0}$ value decreased from $4.97 \times 10^{-10} \mathrm{~m}^{2} / \mathrm{s}$ at a mean m.c. of $2.92 \mathrm{~kg} / \mathrm{kg}$ dry mass to $1.735 \times 10^{-10} \mathrm{~m}^{2} / \mathrm{s}$ at mean m.c. $0.48 \mathrm{~kg} / \mathrm{kg}$ dry mass. Diffusivities calculated in this work compared well with reported values in the literature (Saravacos and Raouzeos, 1986). Diffusivities with pretreatment were higher than the values observed without pretreatment for a similar air temperature. In high moisture zone this increase was about 50\% whereas in the intermediate and low moisture zones it was about 100\%. This demonstrates the effectiveness of dipping pretreatments in enhancing the moisture transport in the grape with the progress of drying. 


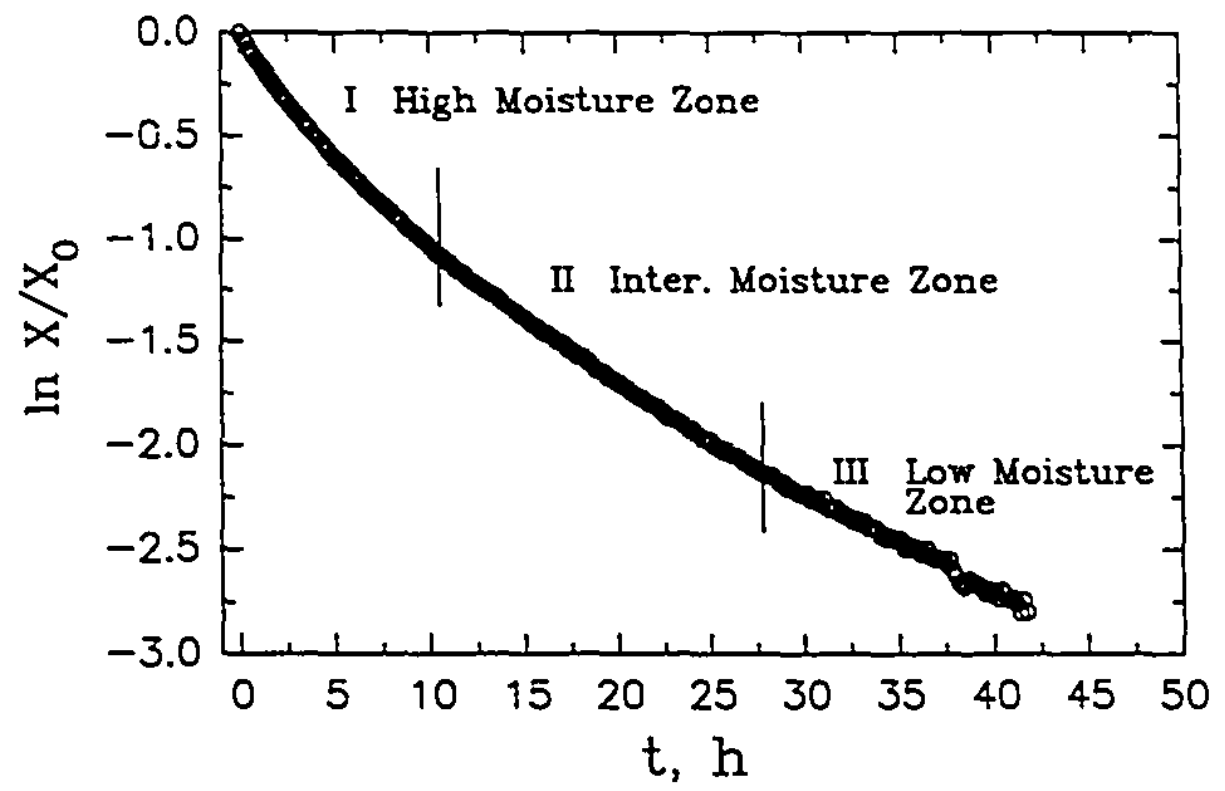

Fig. 7.1. Convective drying of grapes (no pretreatment) showing the three different zones of drying $\left(T_{g}=50 \mathrm{C}, v_{8}=2 \mathrm{~m} / \mathrm{s}\right)$.

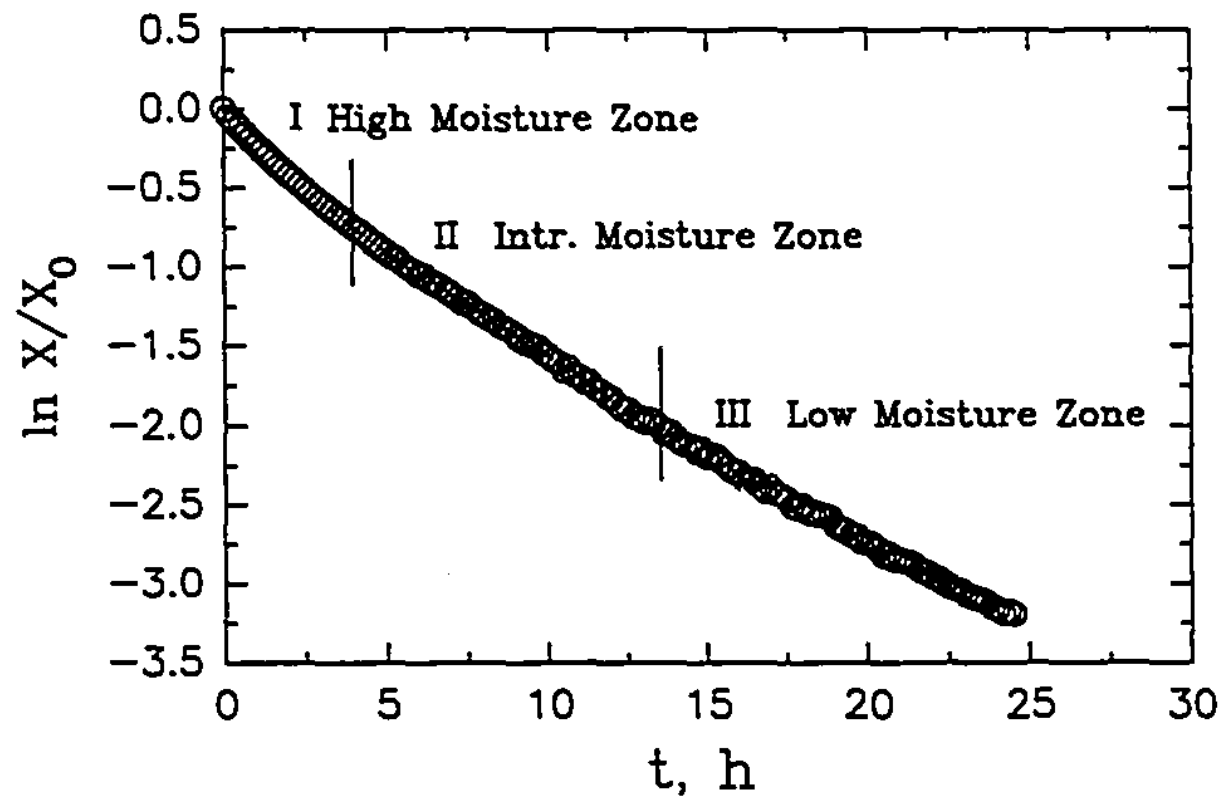

Fig. 7.2. Convective drying of grapes (pretreated) showing the three different zones of drying $\left(T_{g}=50^{\circ} \mathrm{C}, v_{g}=2 \mathrm{~m} / \mathrm{s}\right)$. 
Table 7.3. Effective moisture diffusivities in convective drying of grapes with pretreatment.

\begin{tabular}{|c|c|c|c|c|}
\hline Moisture Zone & $\underset{{ }^{\circ} \mathrm{C}}{\text { Air }}$ Temp. & $\begin{array}{l}\text { Av. m.c. } \\
\mathrm{kg} / \mathrm{kg} \mathrm{dry}\end{array}$ & $\begin{array}{l}\text { Av. radi. } \\
\mathrm{cm}\end{array}$ & $\begin{array}{l}\mathrm{D}_{\mathrm{c}} \times 10^{10} \\
\mathrm{~m}^{2} / \mathrm{s}\end{array}$ \\
\hline High moisture & $\begin{array}{l}45 \\
50 \\
55 \\
60\end{array}$ & $\begin{array}{l}2.77 \\
2.96 \\
3.00 \\
2.92\end{array}$ & $\begin{array}{l}0.815 \\
0.843 \\
0.862 \\
0.856\end{array}$ & $\begin{array}{l}2.806 \\
3.302 \\
4.179 \\
4.967\end{array}$ \\
\hline Inter. moisture & $\begin{array}{l}45 \\
50 \\
55 \\
60\end{array}$ & $\begin{array}{l}1.06 \\
1.08 \\
1.35 \\
1.30\end{array}$ & $\begin{array}{l}0.665 \\
0.680 \\
0.710 \\
0.707\end{array}$ & $\begin{array}{l}1.121 \\
1.944 \\
2.386 \\
2.820\end{array}$ \\
\hline Low moisture & $\begin{array}{l}45 \\
50 \\
55 \\
60\end{array}$ & $\begin{array}{l}0.55 \\
0.40 \\
0.61 \\
0.48\end{array}$ & $\begin{array}{l}0.605 \\
0.590 \\
0.616 \\
0.602\end{array}$ & $\begin{array}{l}0.620 \\
1.212 \\
1.583 \\
1.735\end{array}$ \\
\hline
\end{tabular}

The temperature dependency of diffusivity in the three moisture zones is shown in Fig 7.4. The relationship between $D_{0}$ and $T_{8}$ was represented with an Arrehenius type relationship as follows:

$$
D_{e}=a \exp b\left(\frac{1}{T}\right)
$$

where $T$ is the air temperature expressed in $K$. The values of $a$ and $b$ (Eq. 7.2) obtained with a high degree of correlation $\left(R^{2}>0.9\right)$ for different drying zones are given in the following Table 7.4 and the fitness of Eq. 7.2 is demonstrated in Fig. 7.4. 


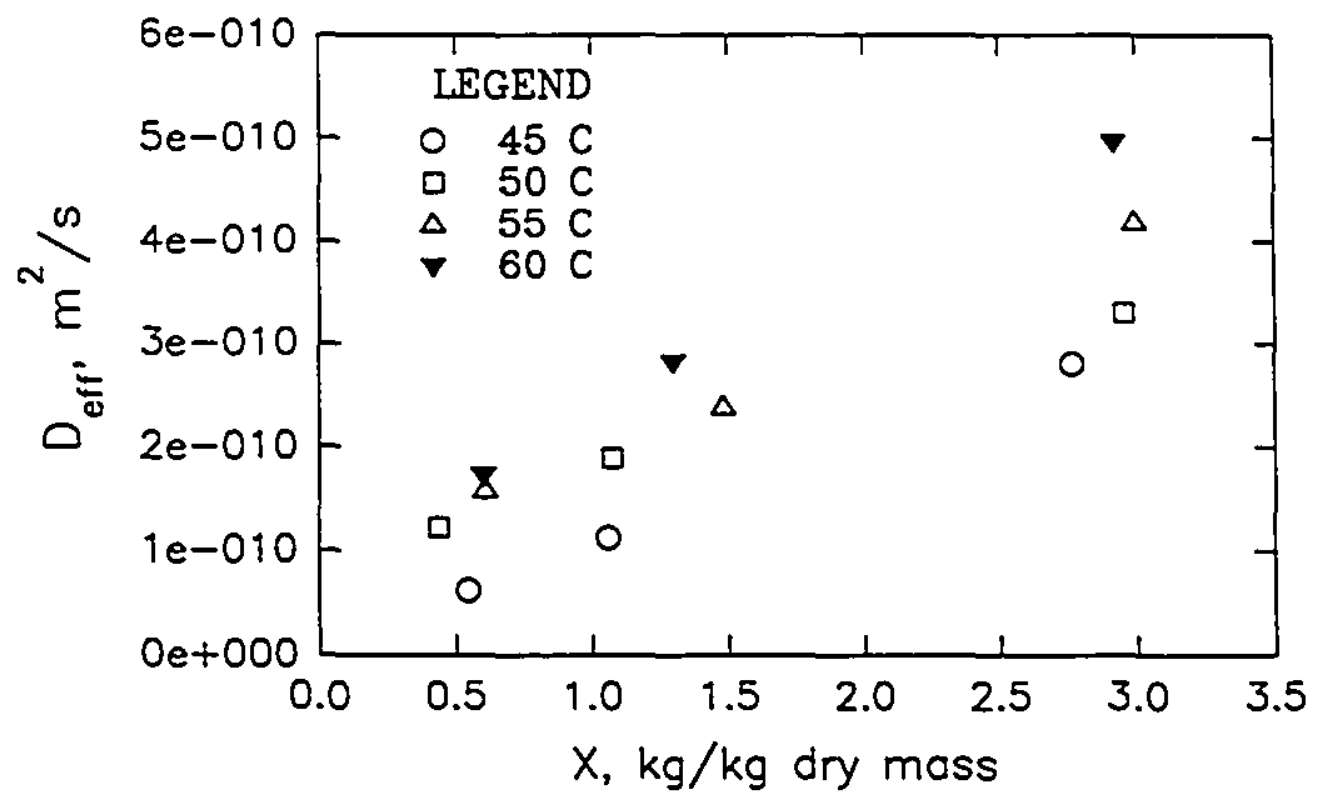

Fig. 7.3. Effective diffusivity in pretreated grapes as a function of m.c. at different air temperatures $\left(V_{k}=2 \mathrm{~m} / \mathrm{s}\right)$.

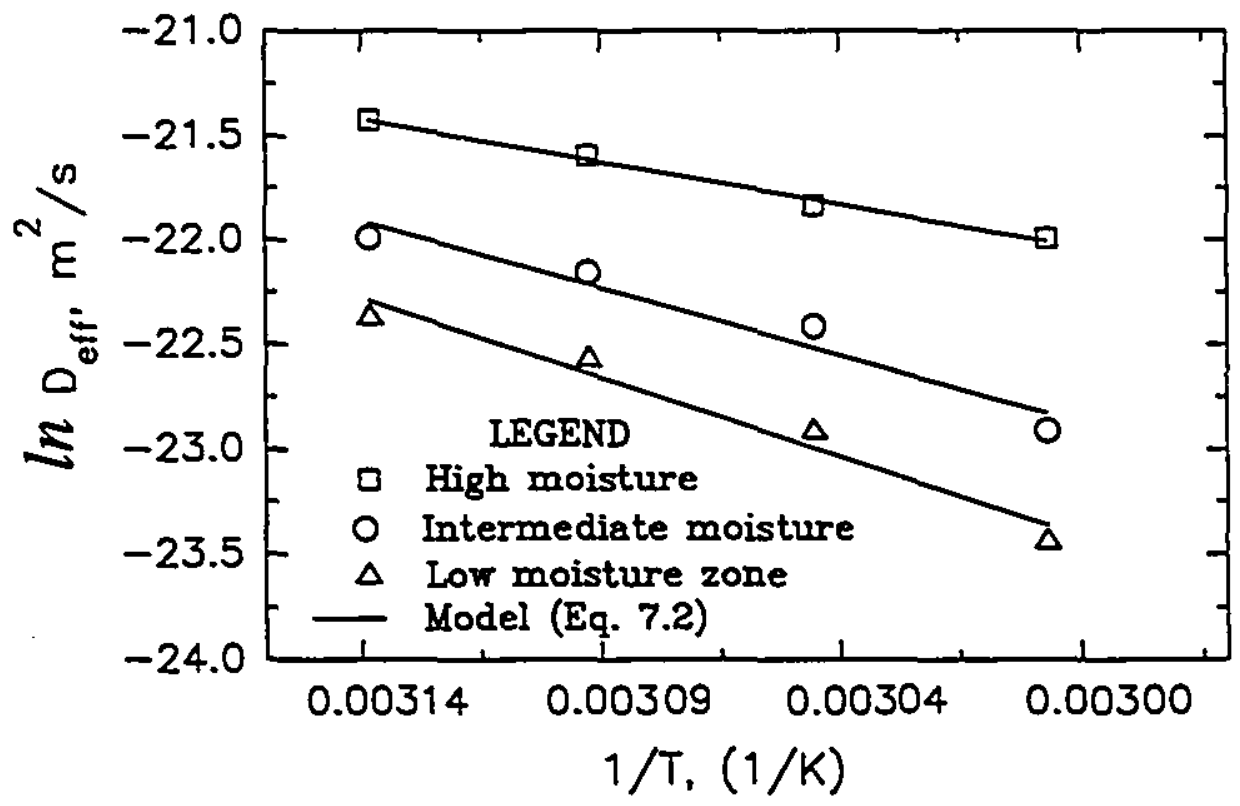

Fig. 7.4. Effective diffusivity in pretreated grapes as a function of air temperature, $v_{z}=2 \mathrm{~m} / \mathrm{s}$. 
Table 7.4. Values of constants $a$ and $b$ of Eq. T.2 describing the dependency of effective moisture diffusivity on air temperature under convective drying conditions in pretreated grapes.

\begin{tabular}{llll}
\hline Drying Zone & $a$ & $b$ & $\mathrm{R}^{2}$ \\
\hline High moisture & 0.00012 & -4129.5 & 0.99 \\
Intermediate moisture & 0.07360 & -6432.1 & 0.95 \\
Low moisture & 1.56000 & -7574.0 & 0.96 \\
\hline
\end{tabular}

\subsubsection{MW Drving Studies}

The drying characteristics of grapes under combined convective and $M W$ drying was studied. The influence of inlet air temperature $\left(T_{8}\right), M W$ power $(P)$ and air velocity $\left(\mathrm{V}_{\mathrm{k}}\right)$ was examined with respect to drying kinetics and quality of raisins. Quality aspects of raisins are discussed in the next chapter.

\subsubsection{Effect of Air Temperature}

Inlet air temperature was found to strongly influence $M W$ drying characteristics. Figs. 7.5 and 7.6 show this effect for air velocities of 1.0 and $2.0 \mathrm{~m} / \mathrm{s}$ respectively at a constant power $0.1 \mathrm{~W} / \mathrm{g}$. The drying time decreased with the increase in air temperature. For example, at $V_{8}=2.0 \mathrm{~m} / \mathrm{s}$ and $\mathrm{P}=0.1$ $\mathrm{W} / \mathrm{g}$, the mean drying times of three replicates for $\mathrm{T}_{\mathrm{z}}=30,40,50$ and $60^{\circ} \mathrm{C}$ were $10.88 \mathrm{~h}, 8.61 \mathrm{~h}, 5.58 \mathrm{~h}$ and $3.86 \mathrm{~h}$, respectively (Fig 7.6). Between 50 and $60^{\circ} \mathrm{C}$ the reduction in drying time was about $30 \%$. A similar corresponding time reduction was noticed in convective drying for which the drying times at these temperatures were 23.7 and $16.8 \mathrm{~h}$, respectively. Average moisture content as a function of time predicted by the numerical model through simulation is shown in Figs. 7.5 and 7.6; a good agreement between the simulated results and the experimental data could be seen.

Variation of fruit temperature $\left(T_{m}\right)$ with progress of drying is plotted in Fig. 7.7a (for the same cases as shown in Fig. 7.6). Time axis was transformed 


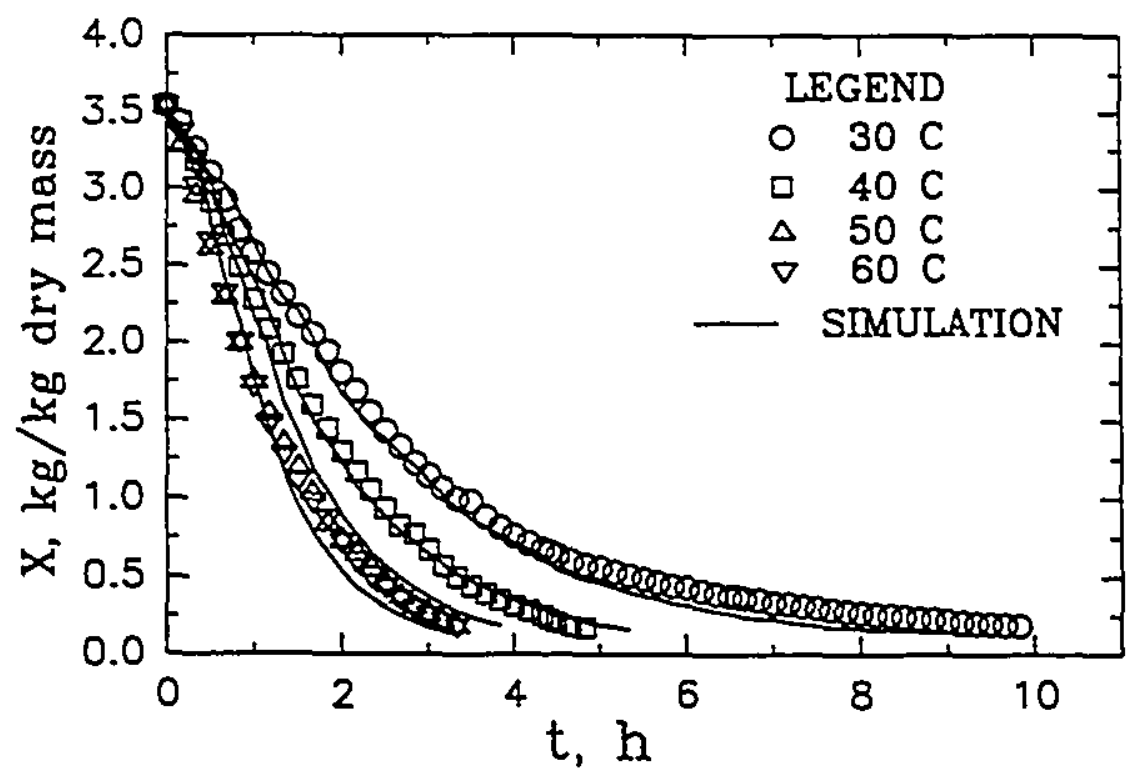

Fig. 7.5. Effect of air temp. on $M W$ drying of grapes $\left(P=0.1 \mathrm{~W} / \mathrm{g}, \mathrm{v}_{\mathrm{g}}=1 \mathrm{~m} / \mathrm{s}\right.$.).

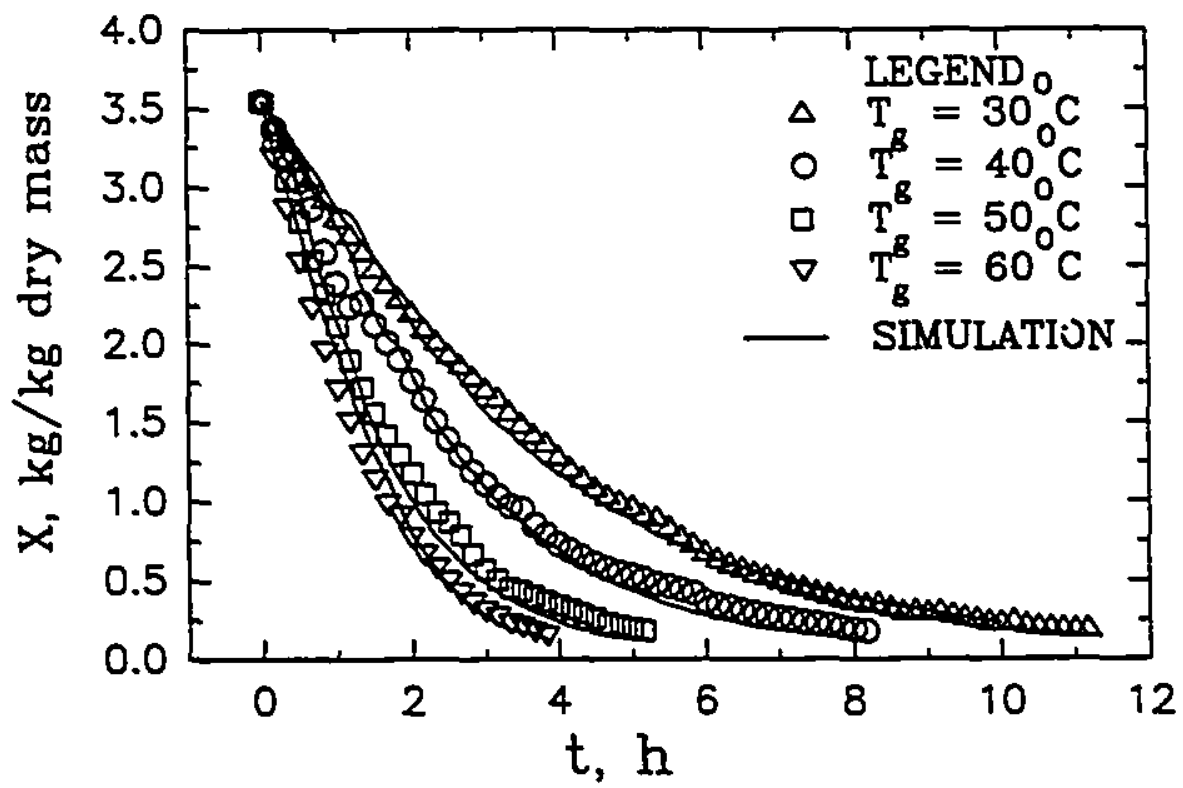

Fig. 7.6. Effect of air temp. on $M W$ drying of grapes $\left(P=0.1 \mathrm{~W} / \mathrm{g}, V_{g}=2 \mathrm{~m} / \mathrm{s}\right)$. 
into corresponding m.c. since $\mathrm{MW}$ absorption and therefore the heating rate is a function of moisture. Temperature variation is well represented in this form and the curves can be easily compared. The temperature peaks which were observed at certain intervals were smoothed while drawing these plots. The high fruit temperatures obtained with MW heating explain the reason for the rapid drying observed when compared to convective drying (up to 4 times faster in some cases).

Mass loss due to evaporation at the surface is a function of partial vapour pressure difference between the surface and the convective air passing over that surface which is the driving force for mass transfer $(\Delta p)$. This mass flux from the surface is therefore a function of wetness of the material and the temperature at the surface. This aspect was examined for the initial phase of drying assuming a water activity $\left(a_{w}\right)$ of 0.95 . The assumption of $a_{w}=0.95$ is in accordance with the moisture sorption isotherms for raisins obtained by Maroulis et al. (1988). Surface temperatures of the fruit were obtained by simulation (Fig. 7.7b). The driving force term $\Delta p$ was then calculated for different drying air temperatures and is presented in the following Table 7.5.

Table 7.5. Partial vapour pressure difference and the surface temperature for different air temperatures during $M W$ drying of grapes at $P=0.1 \mathrm{~W} / \mathrm{g}$ and $V_{8}=2 \mathrm{~m} / \mathrm{s}$.

\begin{tabular}{ccc}
$\begin{array}{l}\text { Air Temp } \\
\mathrm{T}_{\mathrm{g}}{ }^{\circ} \mathrm{C}\end{array}$ & $\begin{array}{l}\text { Surface Temp } \\
\mathrm{T}_{\mathbf{8}}{ }^{\circ} \mathrm{C}\end{array}$ & $\begin{array}{l}\Delta \mathrm{p} \\
\mathrm{kPa}\end{array}$ \\
\hline 30 & 50 & 10.46 \\
40 & 56 & 14.69 \\
50 & 68 & 26.10 \\
60 & 75 & 35.80 \\
\hline
\end{tabular}




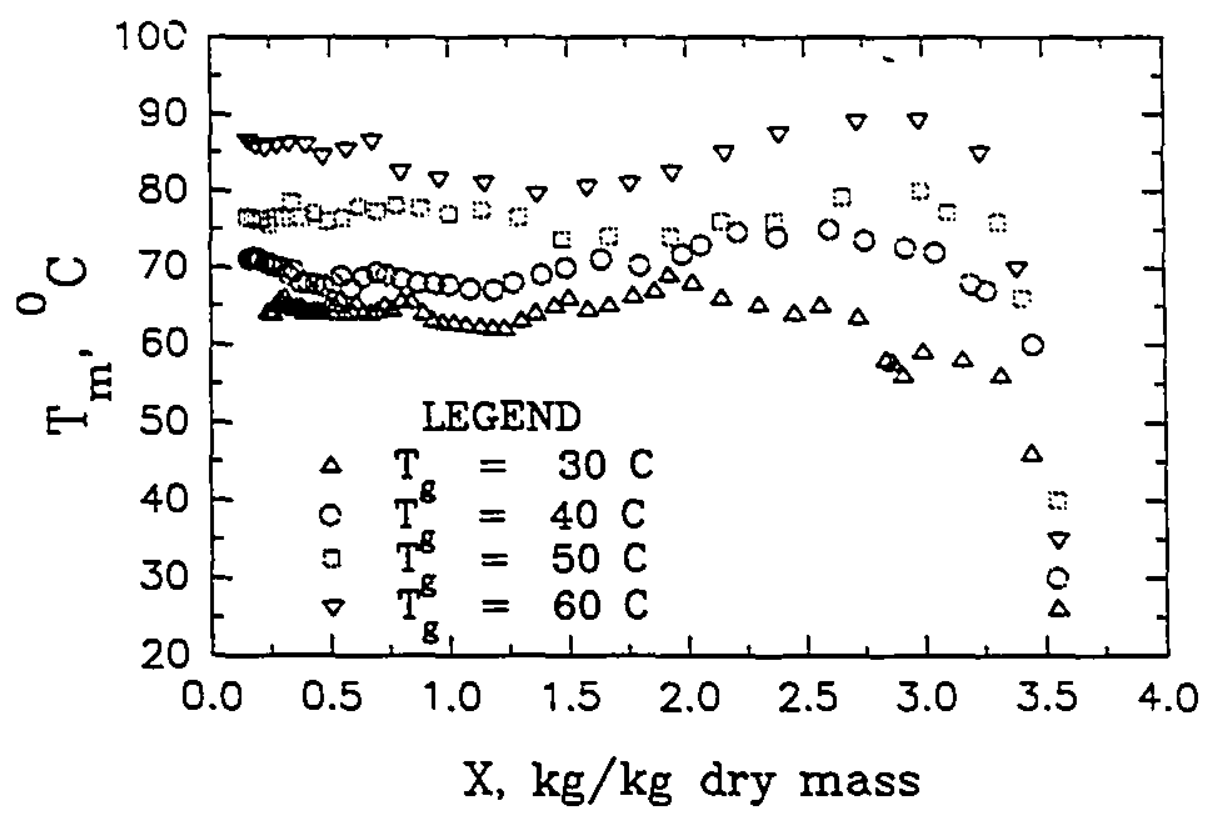

Fig. 7.7a. Effect of air temperature on fruit temperature at $\mathrm{P}=0.1 \mathrm{~W} / \mathrm{g}, \mathrm{V}_{\mathrm{g}}=2 \mathrm{~m} / \mathrm{s}$.

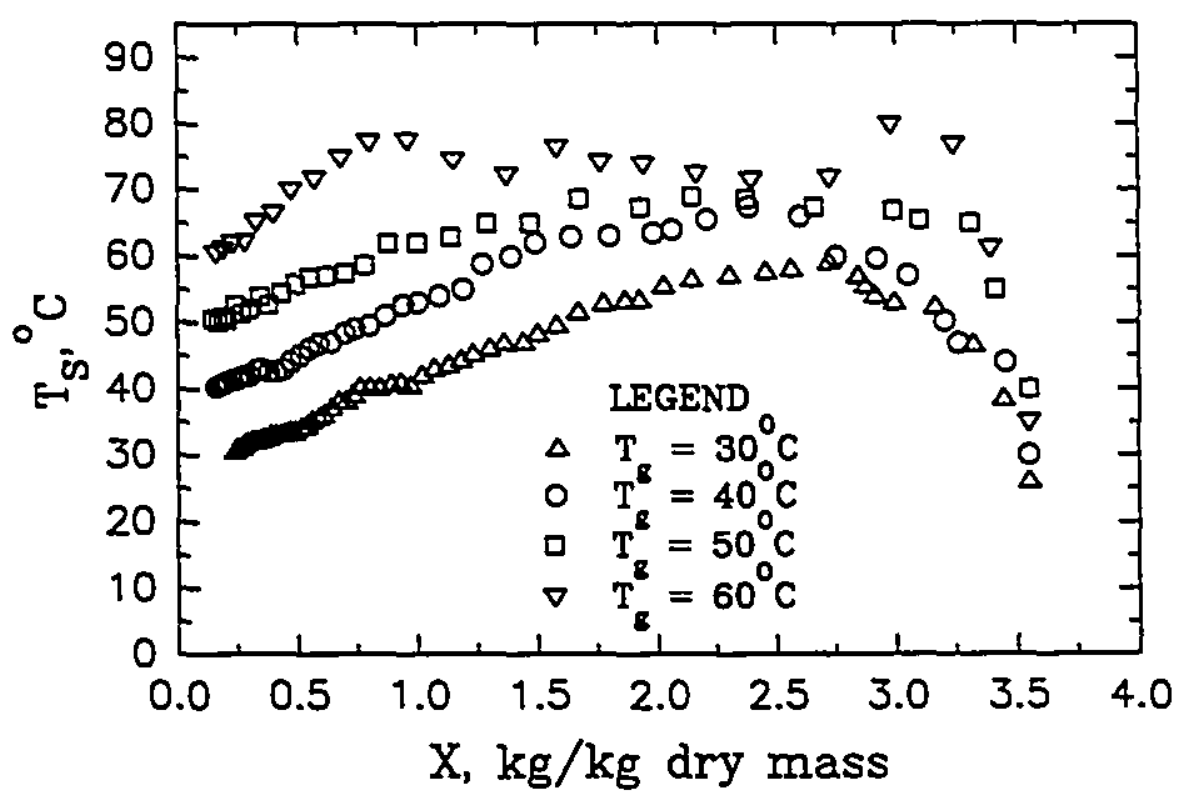

Fig. 7.7b. Effect of air temperature on fruit surface temperature $\left(T_{S}\right)$ at $P=0.1 \mathrm{~W} / \mathrm{g}, V_{\mathrm{B}}=2 \mathrm{~m} / \mathrm{s}$. 
Therefore, the driving force for mass transfer at the surface also increases markedly with $T_{k}$. This increase in $\Delta p$ in addition to the increase in moisture diffusivity due to high $T_{m}$ contributed to faster drying at higher air temperatures.

The temperature variation observed in Fig. 7.7a has followed the well known MW heating pattern in wet materials (Perkin, 1990; Chen and Schmidt, 1990; Turner and Jolly, 1991): the maximum temperature observed near the beginning of heating later dropped to a steady value (Fig. 7.7a). For example in case of $\mathrm{T}_{\mathrm{s}}=50^{\circ} \mathrm{C}$, the fruit temperature at the centre $\left(\mathrm{T}_{\mathrm{m}}\right)$ reached a maximum of about $80^{\circ} \mathrm{C}$ and then dropped to a steady $75^{\circ} \mathrm{C}$. Initially the heating rate is higher because the material absorbs more energy due to its high moisture content. As the drying progresses the dielectric loss factor decreases resulting in less heat generation in the material. A similar trend of $T_{m}$ was observed in the remaining cases also.

Another point to be observed here is that although the MW power level was the same in all the above four cases, the fruit temperature differed depending upon $T_{r}$ The temperature variation in the material is well described by the governing energy equation (Eq. 6.12). The source term $E_{1}$ is larger than convective term $\left(\mathrm{E}_{2}\right)$ or the evaporative term $\left(\mathrm{E}_{3}\right)$. The term $\mathrm{E}_{2}$ (Eq. 6.13) is a negative quantity. As $T_{z}$ increases this term is reduced in absolute value, giving an overall increase in the heating rate. This indicates that higher fruit temperatures can be achieved by increasing $T_{g}$ although the $M W$ power remains the same.

\section{Drying Rates}

The moisture loss expressed as the drying rate $(D R)$ is given by (Treybal, 1980; Geankoplis, 1993):

$$
D R=m / A(d X / d t)
$$

where, $\mathrm{m}_{\mathrm{a}}=$ mass of dry solids, $\mathrm{kg}$ 
$A=$ area of evaporating surface, $\mathrm{m}^{2}$

$\mathrm{DR}=$ drying rate, $\mathrm{kg} \mathrm{H} \mathrm{H}_{2} \mathrm{O} / \mathrm{m}^{2} \mathrm{~h}$.

The $\mathrm{dX} / \mathrm{dt}$ term was derived by numerical differentiation of the observed drying data (Fig. 7.6). A polynomial equation of the 4th order was used to fit the experimental data of moisture loss as a function of time and the resulting equation was differentiated with respect to time to yield $\mathrm{dX} / \mathrm{dt}$. Size variation due to shrinkage has been accounted for computing the surface by using Eq. 5.2. In Fig 7.8 the effect of air temperature on drying rates is illustrated for a case of constant $M W$ power and a constant air velocity $\left(P=0.1 \mathrm{~W} / \mathrm{g} ; V_{R}=2 \mathrm{~m} / \mathrm{s}\right)$. A gradual decrease of $\mathrm{DR}$ with m.c. was observed in all the cases. The rate of drying was found to vary with $T_{p}$; with higher $D R$ at higher temperatures. It was observed in all cases that the drying rates rapidly decreased after the m.c. reached about $1 \mathrm{~kg} / \mathrm{kg}$ dry mass (Fig. 7.8). Low diffusivities observed in the low moisture region (Table 7.3) indicate the possibility of internal control for mass transfer which could be the reason for the rapid drop in DR. Such a behaviour has been observed in the drying of many food materials (Jaros et al., 1992; Karthanos et al., 1990; Saravacos and Raouzeos, 1986). A similar behaviour of $\mathrm{T}_{\mathrm{g}}$ as discussed above was noticed at other combinations of $\mathrm{P}$ and $V_{8}$

\subsubsection{Effect of $M W$ Power Density}

The effect of absorbed MW power (power density) on drying of grapes is shown for a case of $\mathrm{V}_{\mathrm{g}}=2.0 \mathrm{~m} / \mathrm{s}$ and $\mathrm{T}_{\mathrm{g}}=30^{\circ} \mathrm{C}$ in Fig. 7.9. In all the cases the drying times reduced with the increase of $M W$ power density $(P)$. In this cited example the drying times to reach the desired final m.c. of $0.18 \mathrm{~kg} / \mathrm{kg}$ dry mass for MW power densities of $0.1,0.2$ and $0.3 \mathrm{~W} / \mathrm{g}$ were $10.88,7.69$ and $5.72 \mathrm{~h}$, respectively. The amount of $\mathrm{MW}$ energy absorbed by the material is governed by its dielectric properties and the electric field strength as described by Eq. 5.9. It is obvious that higher absorbed power would lead to higher material 


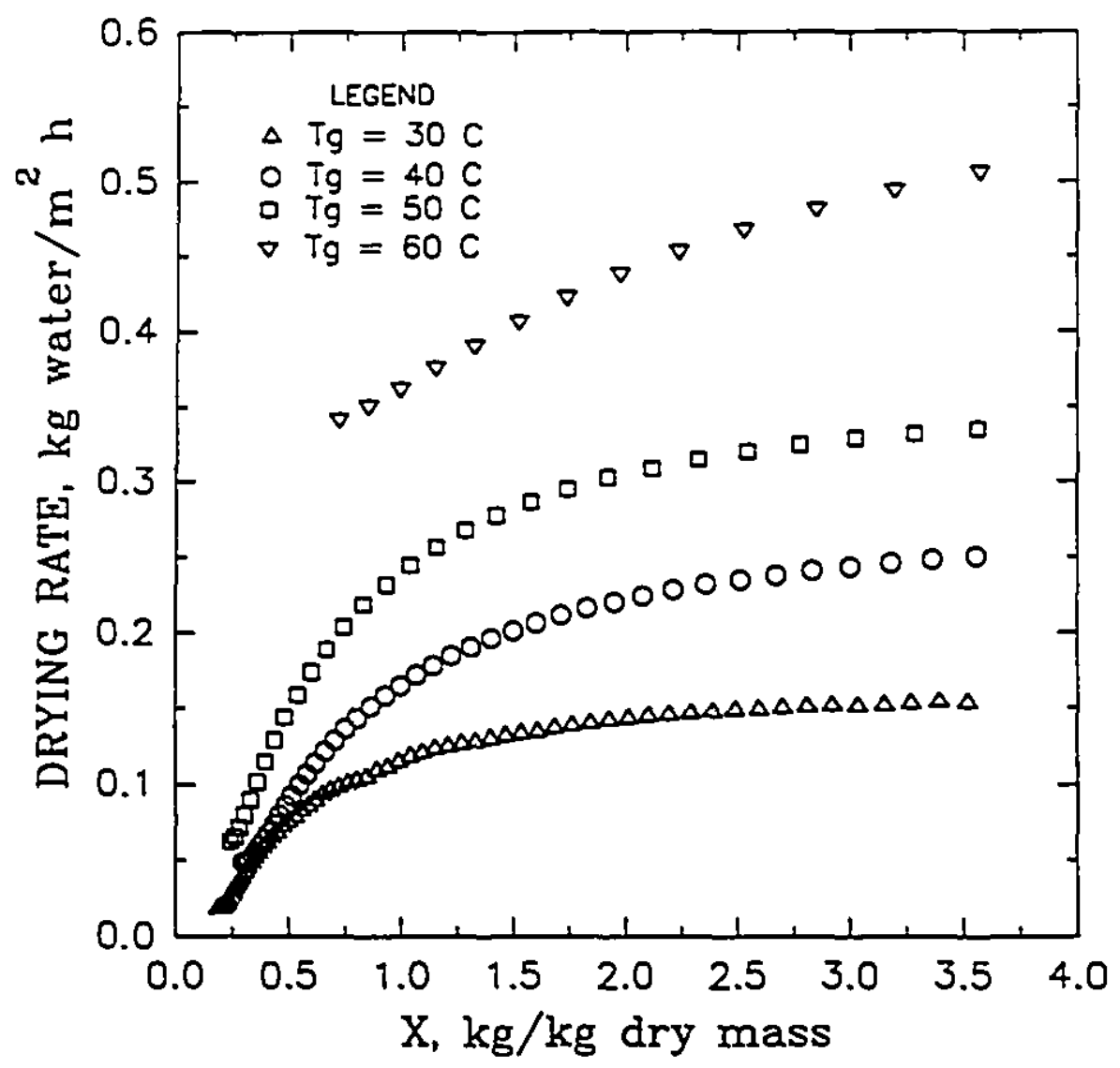

Fig. 7.8. $M W$ drying rate of grapes at different air temperatures at $\mathrm{P}=0.1 \mathrm{~W} / \mathrm{g}, \mathrm{V}_{\mathrm{g}}=2 \mathrm{~m} / \mathrm{s}$. 
temperature, high mass diffusivity and higher mass transfer driving force at the surface and consequently faster drying. All of these trends are evident in the data. Fig. 7.10 shows the smoothed temporal variation in $\mathrm{T}_{\mathrm{m}}$ observed at the centre of the fruit for three power densities at a constant $T_{\mathrm{r}}=30^{\circ} \mathrm{C}$ and a constant $V_{k}=2.0 \mathrm{~m} / \mathrm{s}$. At any given m.c. the material temperature was higher with a higher power density. At $\mathrm{P}=0.1 \mathrm{~W} / \mathrm{g} \mathrm{T}_{\mathrm{m}}$ reached a peak of about $65^{\circ} \mathrm{C}$ whereas at $0.2 \mathrm{~W} / \mathrm{g}$ this peak reached about $80^{\circ} \mathrm{C}$ and it was about $90^{\circ} \mathrm{C}$ at 0.3 W/g (Fig. 7.10). Corresponding drying rate curves plotted in Fig. 7.11 further illustrate the influence of absorbed microwave power. As expected, higher drying rates were obtained with higher $M W$ power densities. The influence of $P$ on drying rate is markedly higher initially when the moisture is higher. The effect of $\mathrm{P}$ on drying rate diminishes as the moisture content reduces. At m.c. less than $1.0 \mathrm{~kg} / \mathrm{kg}$ there is no difference in the drying rates among the different levels of $P$ (Fig. 7.11) indicating the significance of internal resistance to mass transfer at low water content in the material.

The effect of $M W$ power density when the air temperature was increased to higher levels $\left(40\right.$ and $50^{\circ} \mathrm{C}$ ) is illustrated in Figs 7.12 and 7.13 at the same air velocity as before $(2.0 \mathrm{~m} / \mathrm{s})$; decrease of drying times with increase of $P$ is evident in both the cases. An increase of drying rates with an increase of $\mathrm{MW}$ absorption has been noticed in the earlier studies on MW drying (Shivhare et al. 1992; Al-Duri and McIntyre, 1992; Otten and St. John, 1988). In case of drying of heat sensitive products the limit of material temperature is imperative from quality point of view. Higher temperatures would eventually lead to product deterioration because of browning and burning in extreme cases. Though higher drying rates could be achieved with higher power densities, care should be taken to limit the internal heating so as not to damage the product. In certain treatments comprising of higher power densities coupled with higher air temperatures burning and bursting of the fruits was noticed which certainly is a serious limitation for applying of higher 


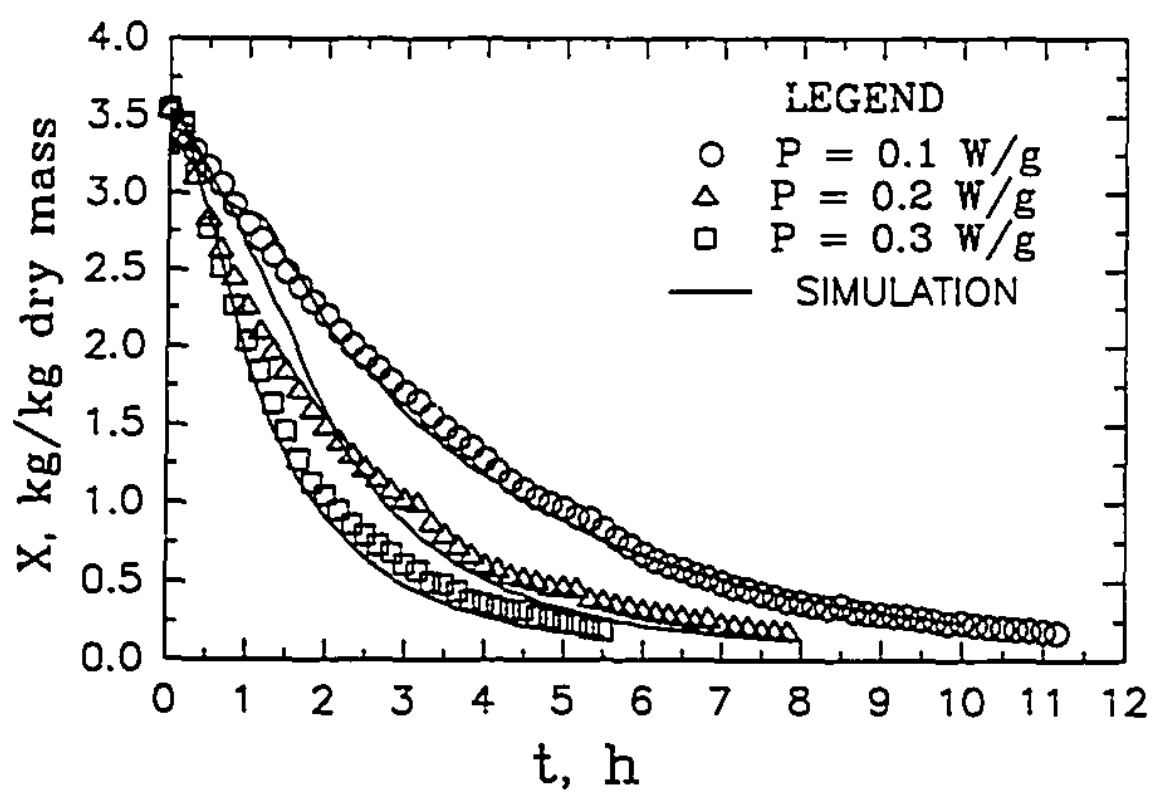

Fig. 7.9. Effect of $M W$ power density on drying of grapes at $T_{g}=30^{\circ} \mathrm{C}$ and $\mathrm{V}_{\mathrm{g}}=2 \mathrm{~m} / \mathrm{s}$.

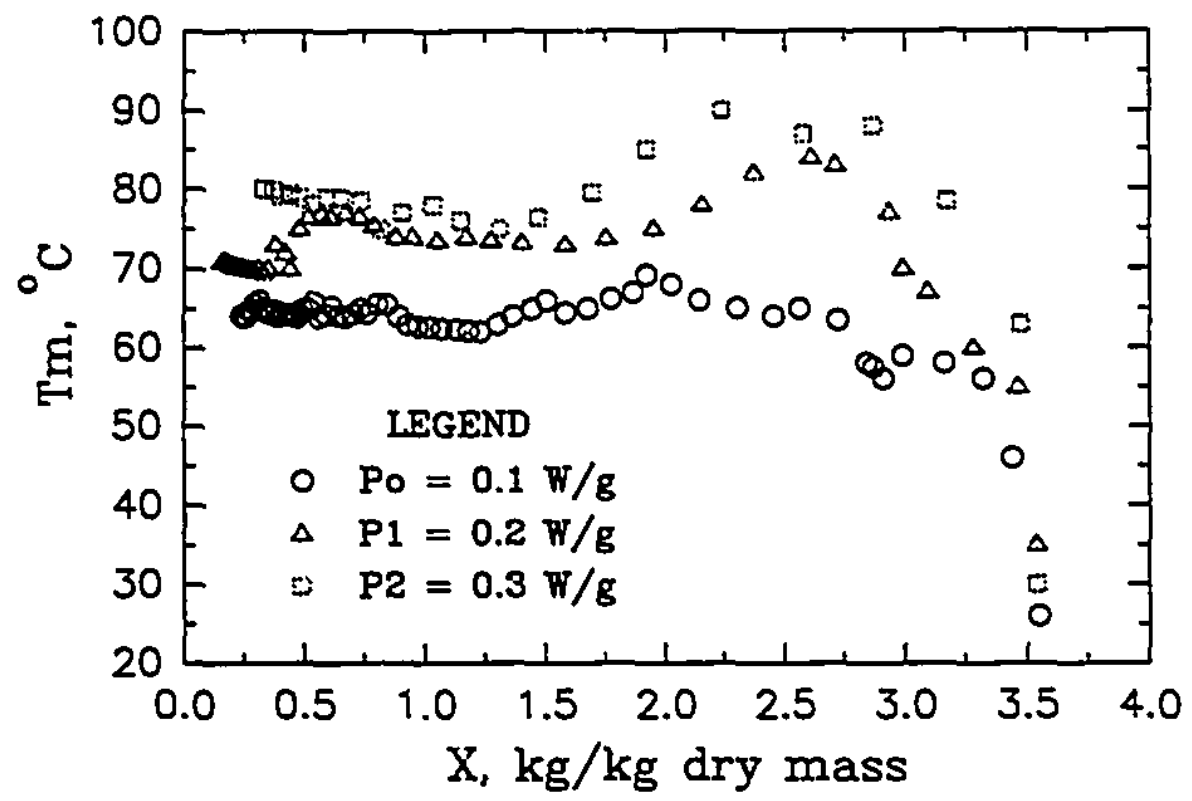

Fig. 7.10. Effect of $\mathrm{NWW}$ power density on fruit temp. $\left(\mathrm{T}_{\mathrm{m}}\right)$ at $\mathrm{T}_{\mathrm{g} .}=30^{\circ} \mathrm{C}, \mathrm{v}_{\mathrm{g}}=2 \mathrm{~m} / \mathrm{s}$. 


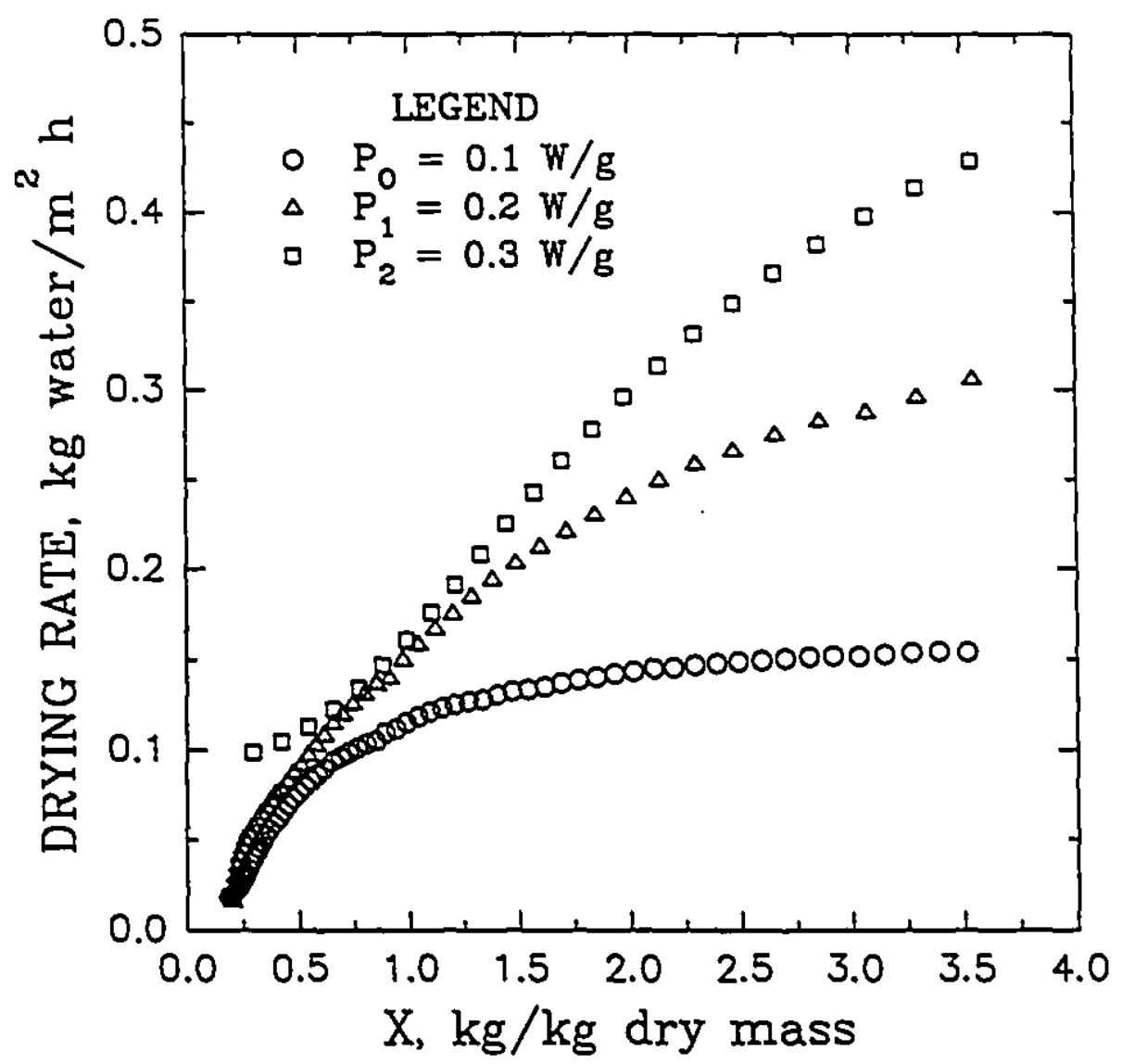

Fig. 7.11. MW drying rate of grapes at different power densities $\left(T_{g}=30^{\circ} \mathrm{C}, V_{B}=2 \mathrm{~m} / \mathrm{s}\right)$. 


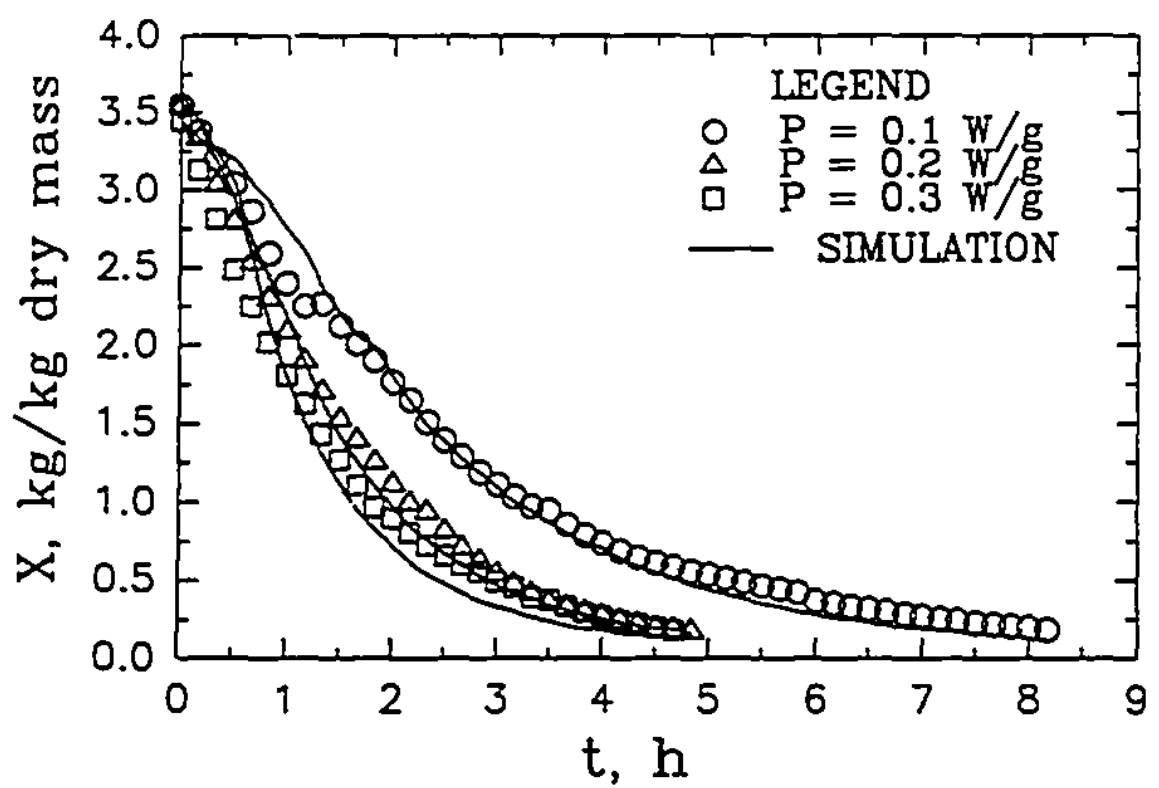

Fig. 7.12. Effect of $\mathrm{MW}$ power density on drying of grapes $\left(\mathrm{T}_{\mathrm{g}}=40^{\circ} \mathrm{C}, \mathrm{V}_{\mathrm{g}}=2 \mathrm{~m} / \mathrm{s}\right)$.

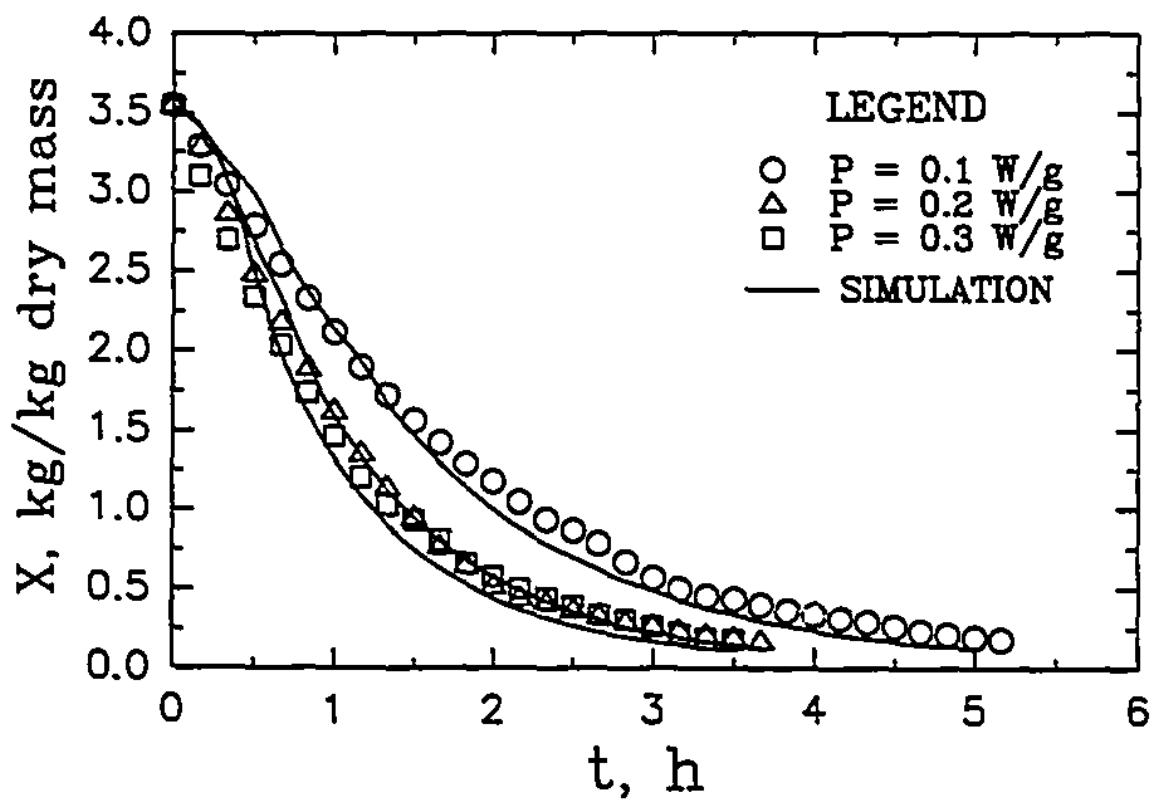

Fig. 7.13. Effect of $M W$ power density on drying of grapes $\left(T_{g}=50^{\circ} \mathrm{C}, v_{8}=2 \mathrm{~m} / \mathrm{s}\right)$. 
power densities. This calls for careful consideration in optimization of process parameters. Quality related aspects of MW drying of grapes are discussed under a separate section.

\subsubsection{Effect of Air Velocity}

Air velocity was found to have a marked effect on $M W$ drying of grapes. In contrast with the behaviour of conventional convective drying, an increase in air velocity during $M W$ drying led to an increase in drying time, (i.e., a lower drying rate). Increase of air velocity in convective drying would normally increase the rate of drying due to the enhancement of mass transfer coefficients at the evaporating surface (Geankoplis, 1993; Treybal, 1980) though this effect would not be substantial during the falling rate regime. However the observations made in the MW drying studies revealed that the air velocity was negatively correlated with drying time. For example, in Fig. 7.14 the effect of air velocity is illustrated $\left(P=0.1 \mathrm{~W} / \mathrm{g}\right.$ and $\left.\mathrm{T}_{\mathrm{z}}=30^{\circ} \mathrm{C}\right)$. The drying time to reach the desired final m.c. was $9.61 \mathrm{~h}$ at $V_{8}=1.0 \mathrm{~m} / \mathrm{s}$ whereas it was 10.89 $h$ at $V_{g}=2.0 \mathrm{~m} / \mathrm{s}$ (an increase of nearly $12 \%$ ). The heat transfer mechanisms in convective drying and MW drying are entirely different. MW absorption generates heat which results in a temperature rise in the material to a level higher than that of the venting air. When a hot material (solid) is subjected to forced convection in a stream of air the heat loss is a function of air velocity (Reynolds Number). Higher air velocities lead to faster cooling thus lowering the material temperature and hence lowering the drying rate. The observed average material temperature $\left(T_{m}\right)$ was lower at higher velocity at all levels of $\mathrm{P}$ and $\mathrm{T}_{\mathrm{z}}$ considered in this study. Fig. 7.15 shows this behaviour together with the resulting effect on drying rates. The drier outlet air temperatures further confirmed this point with higher temperatures recorded for lower air velocities. Fig. 7.16 shows the observed variation in outlet air temperature for the above example. 


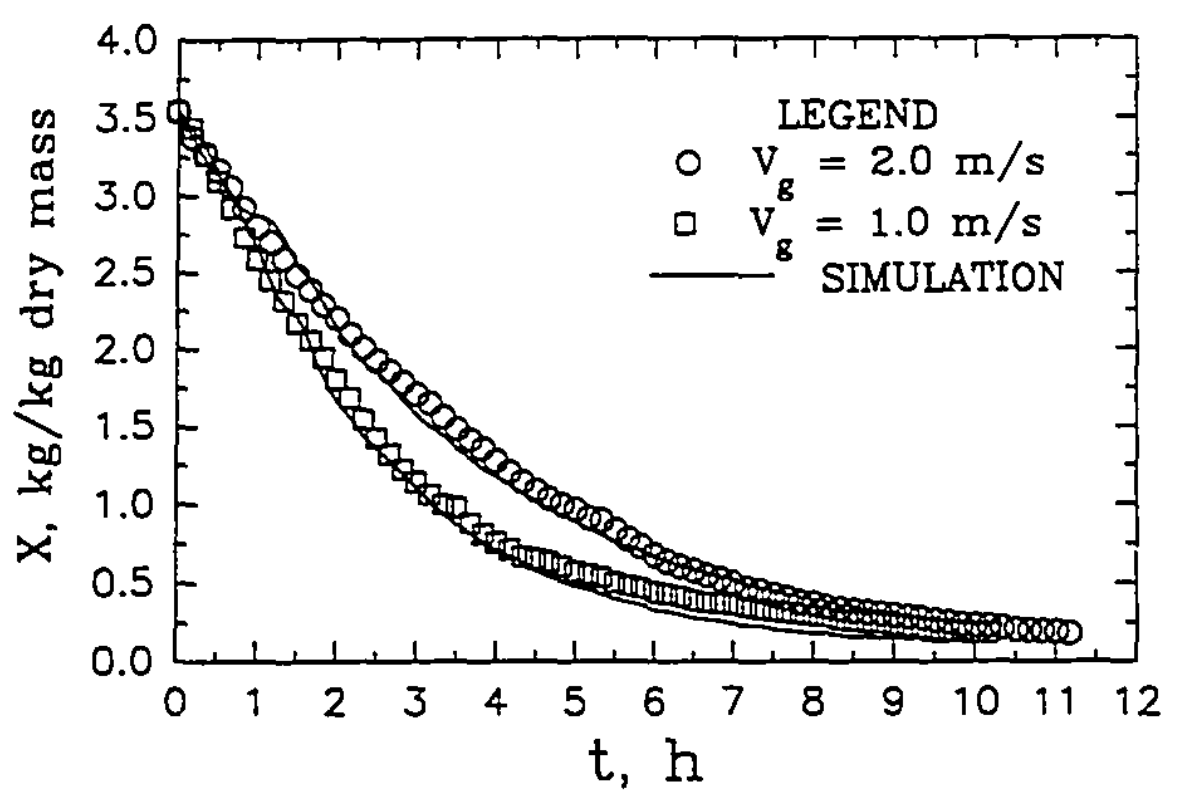

Fig. 7.14. Effect of air velogity on $M W$ drying of grapes $\left(T_{g}=30 \mathrm{C}, P=0.1 \mathrm{~W} / \mathrm{g}\right)$.

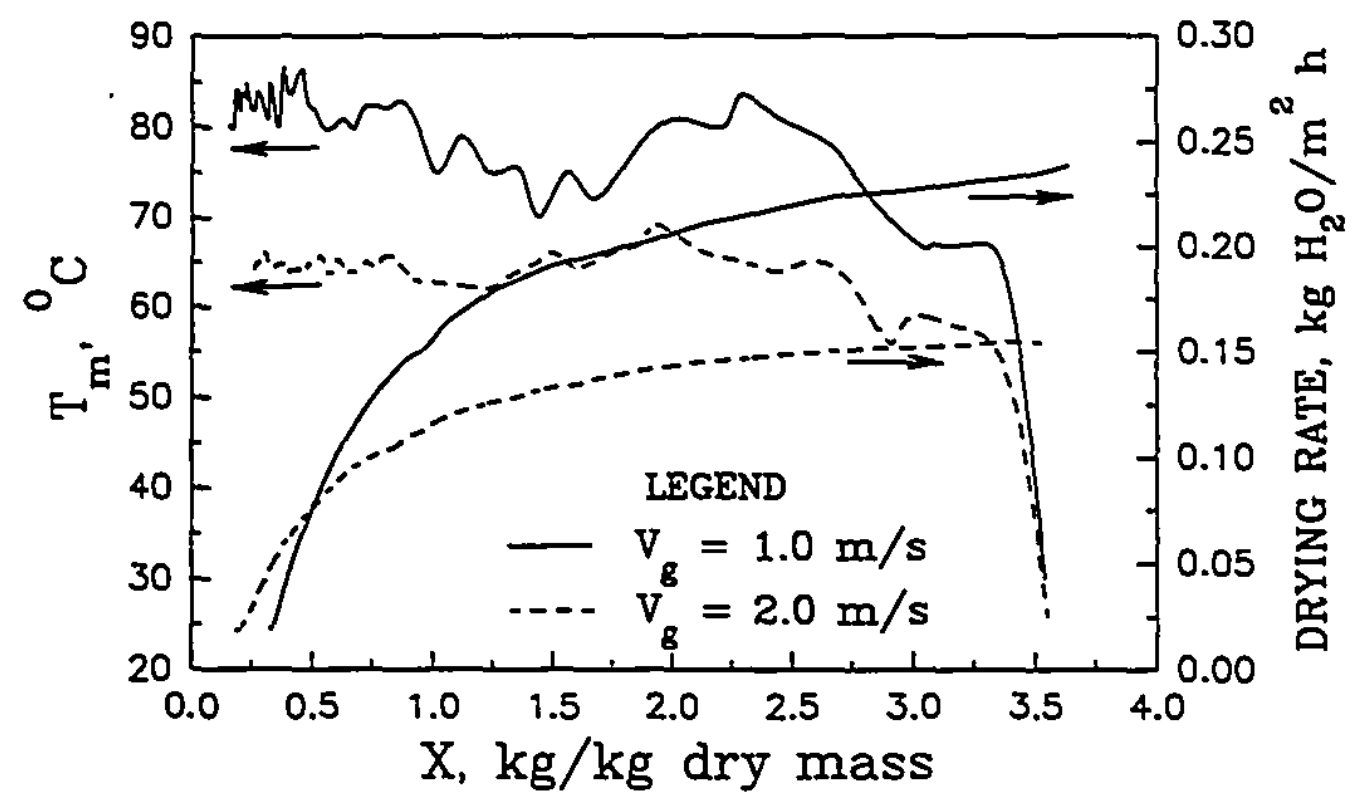

Fig. 7.15. Effect of air velocity on fruit temperature and drying rate in $\mathrm{MW}$ drying of grapes $\left(\mathrm{T}_{\mathrm{g}}=30^{\circ} \mathrm{C}, \mathrm{P}=0.1 \mathrm{~W} / \mathrm{g}\right)$. 
As previously discussed (section 7.3.2.1), drying rates were also greatly affected by air temperature $\left(T_{k}\right)$. This point will be illustrated further for different air velocities. When the air temperature was increased to $40^{\circ} \mathrm{C}$, the observed drying times were 5.02 and $8.61 \mathrm{~h}$ at the two air velocities studied $\left(\mathrm{V}_{\mathrm{g}}\right.$ $=1$ and $2 \mathrm{~m} / \mathrm{s}$ ); an increase of nearly $41.7 \%$ in drying time was noticed at the higher velocity. When the air temperature was further increased to $50^{\circ} \mathrm{C}$, the observed drying times were 3.33 and $5.58 \mathrm{~h}$; with a difference of about $40.3 \%$ higher at the higher air velocity (i.e., at $2 \mathrm{~m} / \mathrm{s}$ ). At any given air temperature, the higher air velocity resulted in longer drying time, i.e., a lesser drying rate. Some interesting observations were noticed with respect to effect of air velocity on drying rates at the low and high air temperatures. Fig. 7.17 shows the drying curves at the said two velocities for drying at a higher air temperature of $50^{\circ} \mathrm{C}(\mathrm{P}=0.1 \mathrm{~W} / \mathrm{g})$; the corresponding drying rate curves are shown in Fig. 7.18 .

At $\mathrm{T}_{8}=30^{\circ} \mathrm{C}$, the drying rates at the final stage of drying were similar for both the velocities (Fig. 7.14 and 7.15) indicating the decaying effect of air velocity at reduced m.c. due to internal resistance to mass transfer. A similar behaviour was noticed when $\mathrm{T}_{\mathrm{g}}=30^{\circ} \mathrm{C}$ at different power densities (Fig. 7.11). In contrast, a different behaviour was observed when $T_{x}$ was increased to the higher levels. At $\mathrm{T}_{\mathrm{g}}=50^{\circ} \mathrm{C}$, the effect of air velocity seemed to be strong till the end of drying (Figs. 7.17 and 7.18) which indicates that at these drying conditions the control of mass transfer is still "combined or mixed" (Strumillo and Kudra, 1986).

\subsubsection{Simulation}

The solution obtained from the simulation was compared with the experimental data of MW drying of grapes. The results are presented together with the experimental data in all the examples discussed in the previous sections. As can be seen the simulation closely predicted the actual drying conditions. Similarly, good agreement between the simulated and the 


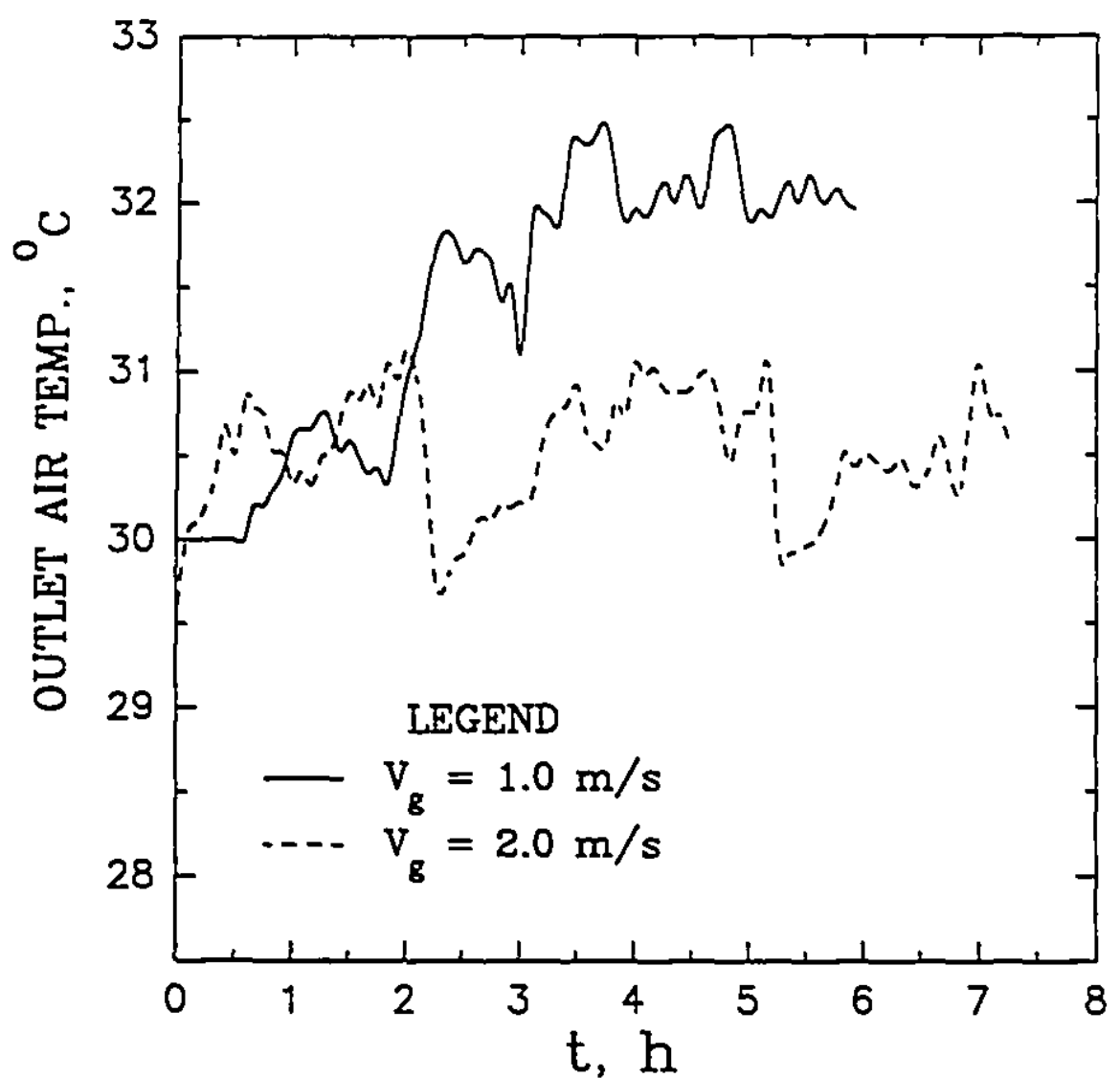

Fig. 7.16. Effect of air velocity on outlet air temperature in $\mathrm{MW}$ drying of grapes $\left(\mathrm{T}_{\mathrm{g}}=30^{\circ} \mathrm{C}, \mathrm{P}=0.1 \mathrm{~W} / \mathrm{g}\right)$. 


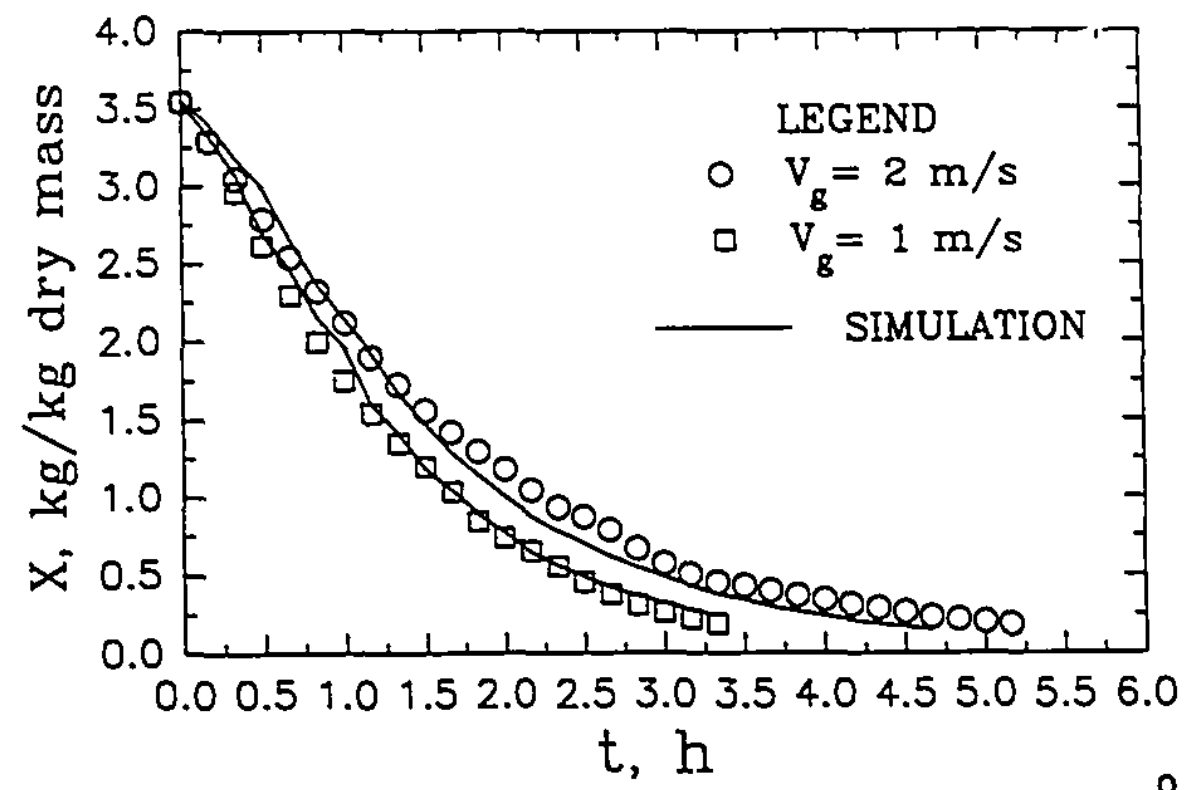

Fig. 7.17. MW drying of grapes at air temp. of $50^{\circ} \mathrm{C}$ at different air velocities $(P=0.1 \mathrm{~W} / \mathrm{g})$.

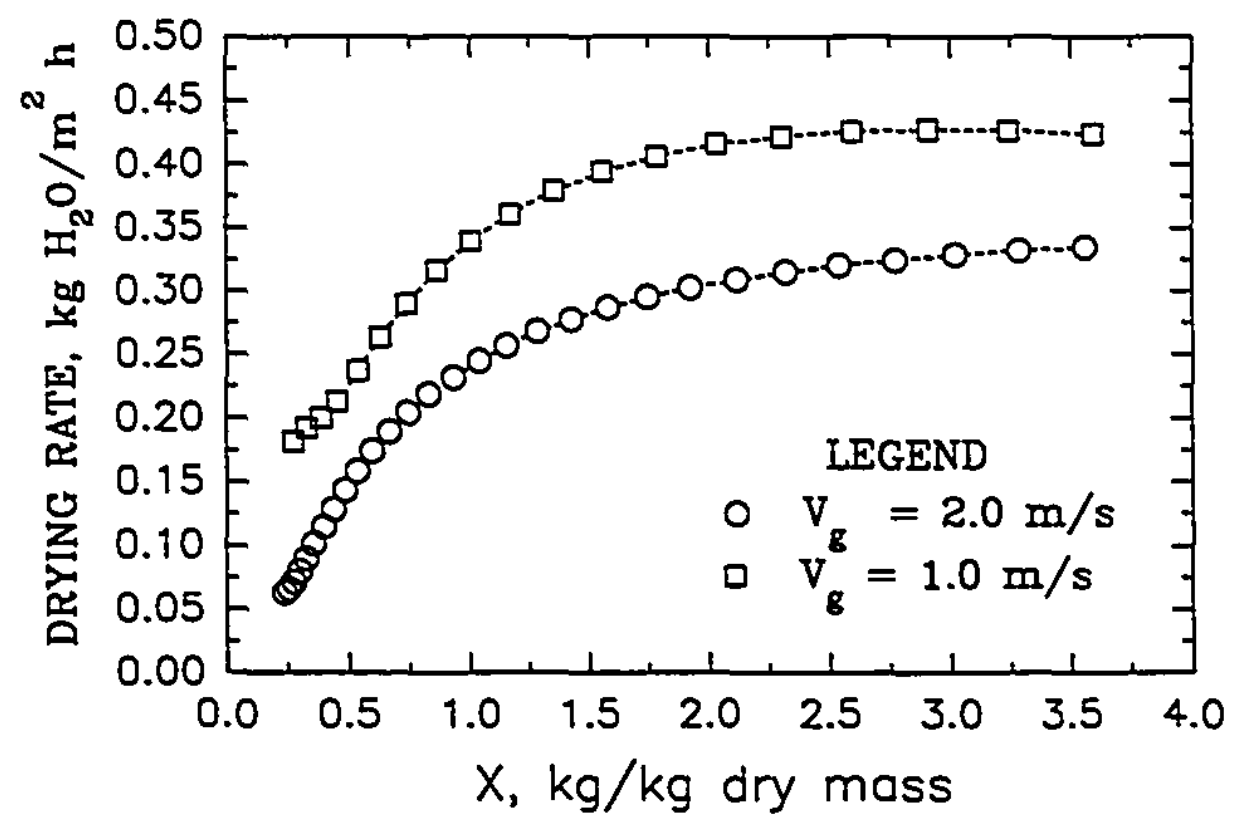

Fig. 7.18. Drying rate at air temp. of $50^{\circ} \mathrm{C}$ at different air velocities $(P=0.1 \mathrm{~W} / \mathrm{g})$. 
experimental results was noticed in the remaining cases also. The accuracy of the model predictions were already discussed in the previous chapter (Table 6.4).

\subsubsection{Moisture Profiles}

Moisture profiles were obtained by simulation and however there is no experimental verification of these results. The internal resistance to moisture diffusion is well indicated by the moisture profiles. Fig. 7.19 shows the moisture profiles in grape during $\mathrm{MW}$ drying at different instants of time $\mathrm{V}_{\mathrm{g}}$ $2.0 \mathrm{~m} / \mathrm{s}, \mathrm{P}=0.1 \mathrm{~W} / \mathrm{g}$ and $\mathrm{T}_{\mathrm{g}}=50^{\circ} \mathrm{C}$ ). The surface gets drier rapidly while the centre is still wet. The steep profiles during the initial part of drying, up-to about $1 \mathrm{~h}$ (Fig. 7.19), indicate a rapid loss of moisture nearer the surface. With the progress of drying the curves got flattened taking longer duration of time and the effect of low moisture on reduced diffusivity is visible. Similarly, Fig. 7.20 show moisture profiles in grape during $\mathrm{MW}$ drying at an air velocity of 1.0 $\mathrm{m} / \mathrm{s}$ and $\mathrm{P}=0.1 \mathrm{~W} / \mathrm{g}$ and $\mathrm{T}_{\mathrm{B}}=30^{\circ} \mathrm{C}$. 


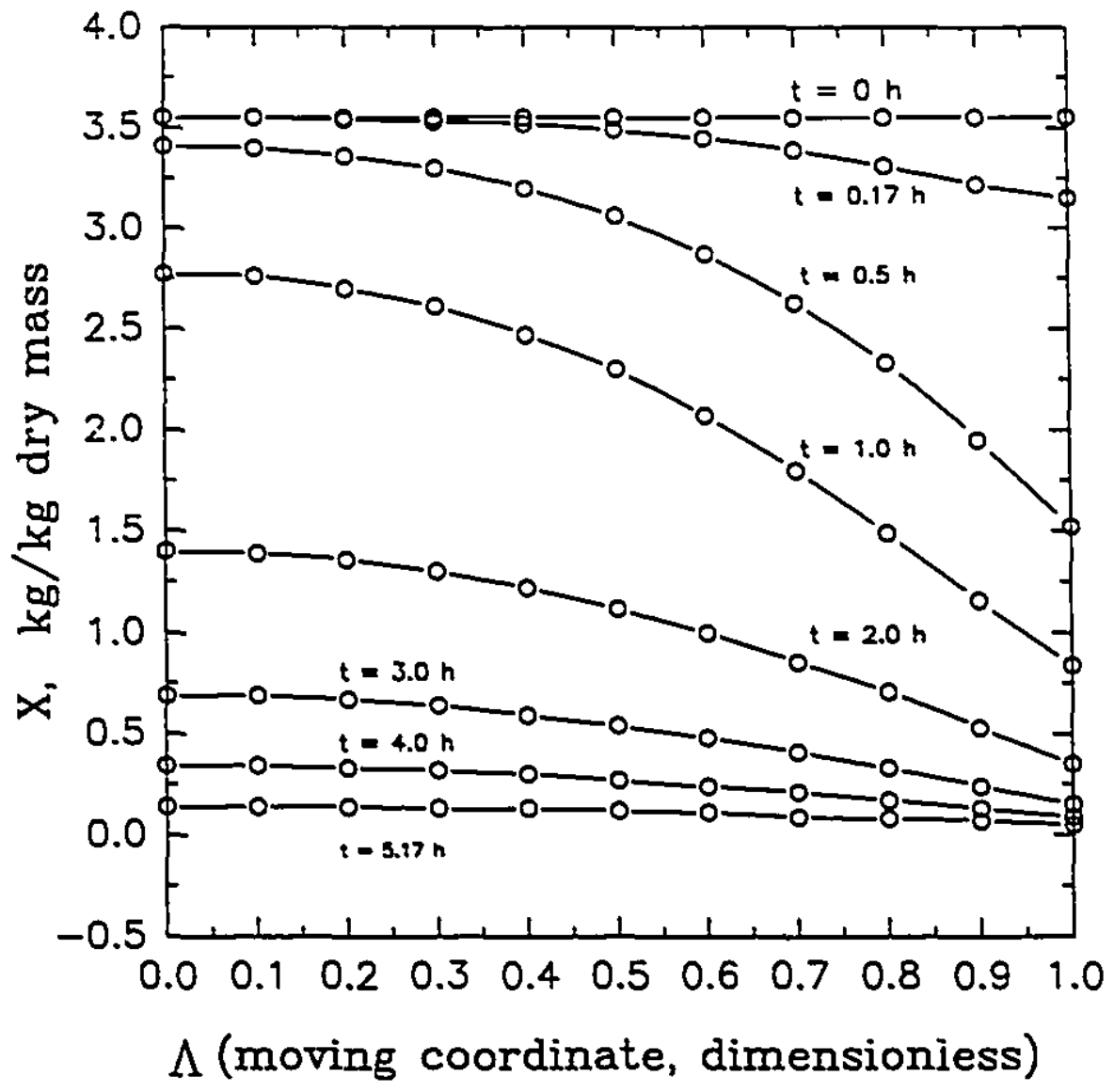

Fig. 7.19. Moisture profiles in grapes during NW drying at different instants of time $\left(P=0.1 \mathrm{~W} / \mathrm{g}, \mathrm{T}_{\mathrm{g}}=50^{\circ} \mathrm{C}, \mathrm{v}_{\mathrm{g}}=2 \mathrm{~m} / \mathrm{s}\right)$. 


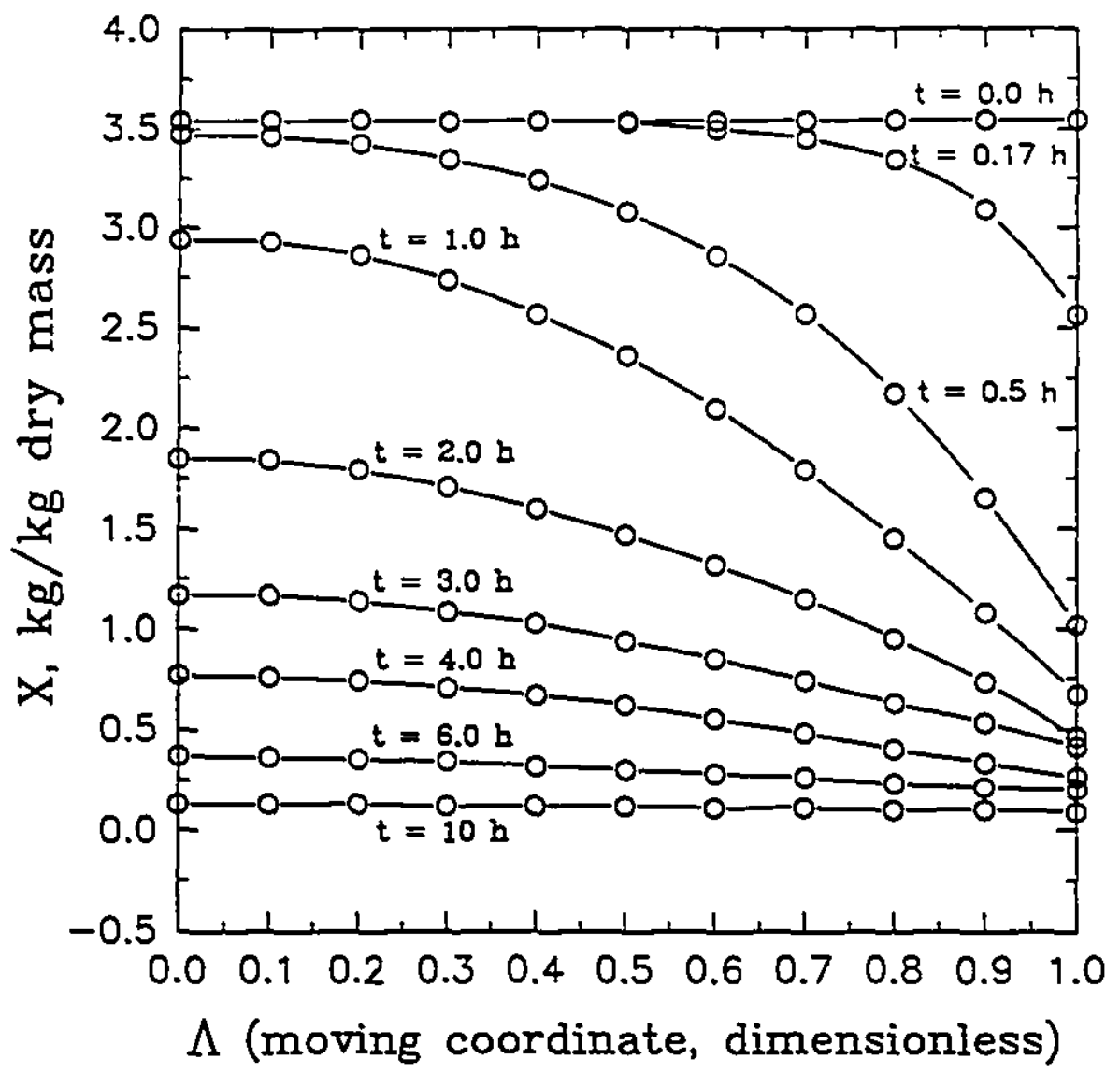

Fig. 7.20. Moisture profiles in grapes during MW drying at different instants of time $\left(P=0.1 \mathrm{~W} / \mathrm{g}, \mathrm{T}_{\mathrm{g}}=30^{\circ} \mathrm{C}, \mathrm{V}_{\mathrm{g}}=1 \mathrm{~m} / \mathrm{s}\right)$. 


\section{CHAPTER VIII}

\section{QUALITY ASPECTS OF MICROWAVE-DRIED GRAPES}

\subsection{Introduction}

Among the criteria used to evaluate the success of the microwave drying process as applied to grapes, the quality of the resulting raisins is of fundamental importance. According to Winkler et al. (1974) and Raouzeos and Saravacos (1986), a raisin is considered to be of good quality if the colour is uniform light yellow with no crystallized sugar. In evaluating a batch of raisins, one must also take into consideration the ratio of good quality raisins to damaged ones. There are both objective and subjective criteria and methods that may be used to evaluate the final quality and in this study both types were considered.

The objective evaluation was based on chromacity measurements and damage counts. In the case of chromacity, a chromometer may be used to determine lightness $L^{*}(L)$, redness $a^{*}(a)$ and yellowness $b^{*}(b)$ (Riva and Peri, 1986; Bolin, 1975). The subjective evaluations were based on sensory evaluations of darkness, stickiness, crystallized sugars and nonuniformity, by a panel of judges. The experimental techniques used to evaluate the quality of microwave-dried grapes and the results obtained are discussed below.

\subsection{Materials and Methods}

The dried samples obtained from different MW drying treatments discussed in the previous chapter were subjected to quality evaluation ${ }^{1}$. These treatments were numbered and coded for easy identification and Table 8.1 gives their description.

\footnotetext{
${ }^{1}$ From here on $\mathrm{V}$ denotes air velocity $\mathrm{V}_{8}$ and $\mathrm{T}$ denotes air temp. $\mathrm{T}_{\boldsymbol{r}}$
} 
Table 8.1 Description of experiments

\begin{tabular}{|c|c|c|c|c|c|c|}
\hline $\begin{array}{l}\text { Treatment } \\
\text { Number } \\
\text { (TRT) }\end{array}$ & $\begin{array}{l}\text { MW } \\
\text { Powe: } \\
\text { (P), म }\end{array}$ & (Code) & $\begin{array}{l}\text { Air } \\
\text { Temp. } \\
\text { (T), }{ }^{\circ} \mathrm{C}\end{array}$ & (Code) & $\begin{array}{l}\text { Air } \\
\text { Velo } \\
\text { (V), }\end{array}$ & \\
\hline 01 & 0.1 & $(0)$ & 30.0 & $(0)$ & 1.0 & $(0)$ \\
\hline 02 & 0.1 & $(0)$ & 40.0 & (1) & 1.0 & $(0)$ \\
\hline 03 & 0.1 & $(0)$ & 50.0 & $(2)$ & 1.0 & $(0)$ \\
\hline 04 & 0.1 & $(0)$ & 60.0 & (3) & 1.0 & $(0)$ \\
\hline 05 & 0.2 & (I) & 30.0 & $(0)$ & 1.0 & (0) \\
\hline 06 & 0.2 & (1) & 40.0 & (I) & 1.0 & $(0)$ \\
\hline 07 & 0.2 & (1) & 50.0 & (2) & 1.0 & $(0)$ \\
\hline 08 & 0.2 & (1) & 60.0 & (3) & 1.0 & $(0)$ \\
\hline 09 & 0.3 & (2) & 30.0 & $(0)$ & 1.0 & $(0)$ \\
\hline 10 & 0.3 & (2) & 40.0 & (1) & 1.0 & $(0)$ \\
\hline 11 & 0.3 & (2) & 50.0 & $(2)$ & 1.0 & $(0)$ \\
\hline 12 & 0.3 & (2) & 60.0 & (3) & 1.0 & $(0)$ \\
\hline 13 & 0.1 & $(0)$ & 30.0 & $(0)$ & 2.0 & (1) \\
\hline 14 & 0.1 & $(0)$ & 40.0 & (1) & 2.0 & (1) \\
\hline 15 & 0.1 & $(0)$ & 50.0 & (2) & 2.0 & (1) \\
\hline 16 & 0.1 & $(0)$ & 60.0 & (3) & 2.0 & (1) \\
\hline 17 & 0.2 & (1) & 30.0 & $(0)$ & 2.0 & (1) \\
\hline 18 & 0.2 & (1) & 40.0 & (1) & 2.0 & (1) \\
\hline 19 & 0.2 & (1) & 50.0 & (2) & 2.0 & (1) \\
\hline 20 & 0.2 & (1) & 60.0 & (3) & 2.0 & (1) \\
\hline 21 & 0.3 & (2) & 30.0 & $(0)$ & 2.0 & (1) \\
\hline 22 & 0.3 & (2) & 40.0 & (1) & 2.0 & (1) \\
\hline 23 & 0.3 & (2) & 50.0 & (2) & 2.0 & (1) \\
\hline 24 & 0.3 & (2) & 60.0 & (2) & 2.0 & (I) \\
\hline
\end{tabular}




\subsubsection{Quality Assessment - Objective Tests}

\subsubsection{Colour Measurements}

The chromaticity of dried samples was measured in $L, a$ and $b$ coordinates using a Chroma Meter (Minolta Chroma Meter, CR-200b, Minolta Camera CO. Ltd., Azuchi-Machi, Chuo-Ku, Osaka 541, Japan). The samples were placed inside a sample holder designed for colorimetric assessment of granular materials (Granular Material Attachment CR-A50, Minolta Camera CO. Ltd., Azuchi-Machi, Chuo-Ku, Osaka 541, Japan). The Chroma Meter was calibrated against a standard calibration plate of a white surface with $L$, a and $\mathrm{b}$ values adjusted to $94.4,0.313$ and 0.320 , respectively, according to the manufacturer's recommendations. The measurements were repeated four times for each sample and the averages for $L$, $a$ and $b$ of each sample were recorded and the ratio $a / b(a / b$ or $A B Y B)$ calculated. The results are presented in the Appendix $\mathrm{C}$ (Table $\mathrm{C} 1$ ). The ratio $\mathrm{a} / \mathrm{b}$ is a convenient way of reducing two colour parameters to one (Francis and Clydesdale, 1975). A higher $a / b$ ratio indicates a darker (more red) product.

\subsubsection{Damage Counts}

The number of visually defective raisins is another attribute which may be objectively evaluated. The number of defective raisins in the dried sample was counted and expressed as damaged raisins (DAMAGE) and recorded as a percent of the total number of raisins in the sample (Appendix $\mathrm{C}$, Table $\mathrm{C} 1$ ).

\subsubsection{Quality Assessment - Subjective Tests}

Quality attributes for which no measurement technique was available, and which could not be quantified by a measurement were: bursting, stickiness, burning and non-uniformity. These attributes were therefore assessed on the basis of sensory evaluation for appearance as described below.

The method of 'scoring' (panel of 10 judges), was adopted to determine the intensity of quality attributes in the samples. The specified quality 
attributes were: (i) darkness (DARK), (ii) crystallised sugars (CRSUGR), (iii) stickiness (STICKY), and (iv) non-uniformity (NONUNI). The ratings assigned by the judges were given numerical values ranging from 0 to 5 points. For example, a value of 0 was attributed to a rating of 'not dark' by the judge whereas a value of 5 was attributed to a rating of 'extremely dark'. Similarly, samples rated 'no stickiness' scored 0 points whereas a rating of 'extremely sticky' scored 5 points, and so on. A sample that scored the highest points in any of the attributes was considered to be the most undesirable while a sample which scored a minimum of 0 points represented the most desirable. The panel members who conducted the tests had the experience of sensory evaluation methods. Samples of dried raisins from each treatment were coded and presented to a panel of 10 judges for evaluation according to the procedure outlined by Larmond (1977). A sample score sheet is provided in Appendix C, Table C2.

\subsubsection{Data Analysis}

The objectives of the data analysis were:

i) to determine how the quality parameters and drying time (which is implicitly related to energy consumption) are related to those parameters which could best serve in the optimization process,

ii) to determine under which operating conditions the best compromise could be made between quality and drying time.

The data were processed with Statistical Analysis System (SAS, 1989) software. The first step was to determine whether differences in quality and drying time could be attributed to the different operating conditions (treatment combinations). This was done using Tukey's honestly significant difference (Steel and Torrie, 1980; SAS, 1989) multiple comparison test.

Response Surface Methodology (RSM) (Box et al., 1978; Henika, 1982; Giovanni, 1983) was adopted as a basis for optimization. The method consists 
of generating regression models of the response variables (quality parameters and time) in terms of the operating parameters (power level $P$, inlet air temperature $T$ and inlet air velocity $V$ ) such that the terms in the model are orthogonal.

Since there were only two levels of inlet air velocity, $V$ could not be used in the model. Therefore models for each of the quality attributes and time were generated at each level of velocity. PROC RSREG (SAS, 1989) was used for this step of the analysis. This procedure was used on all quality attributes. The outputs from PROC RSREG were studied to determine which quality attributes could best be modelled in this way (high $R^{2}$, no lack of fit).

Accordingly, the best models were selected and used to generate data grids for plotting contours on axes of $P$ and $T$. PROC PLOT with the CONTOURS option was used to generate the plots. The plots were then studied to determine under which conditions of $P$ and $T$ various constraints could be satisfied. Although the method is not elegant mathematically, it serves its purpose (Box et al., 1978).

\subsection{Results and Discussion}

The data of chromaticity measurements, and the damage percentages are given in the Appendix C (Table C1). Outputs from PROC RSREG (Response Surface Analysis) are provided in their entirety in Appendix C (Tables C3-C16). The coded regression models for all quality parameters and drying time are given below for both velocity levels. These models are in terms of the coded predictors. Percent damage and the ratio $a / b$ were transformed using the arcsine transformation (Draper and Smith, 1981) and are named DAMT and ABYBT, respectively (DAMT $=\left[2 \sin ^{-1}(\text { DAMAGE) })^{3 / 3}\right.$ and $\mathrm{ABYBT}=\left[2 \sin ^{-1}(\mathrm{ABYB})^{1 / 2}\right]$.

$$
\begin{aligned}
& \text { DAMT }=0.83+0.32 \mathrm{~T}+0.31 \mathrm{P}+0.01 \mathrm{~T}^{2}+0.11 \mathrm{P} T+0.01 \mathrm{P}^{2} \\
& \text { (8) V }=1 \mathrm{~m} / \mathrm{s} \quad \mathrm{R}^{2}=0.920 \quad \mathrm{CV}=12.8 \%
\end{aligned}
$$




$$
\begin{aligned}
& \text { DAMT }=0.64+0.21 \mathrm{~T}+0.39 \mathrm{P}-0.01 \mathrm{~T}^{\circ}+0.05 \mathrm{P} * \mathrm{~T}-0.07 \mathrm{P}^{2} \\
& 0 \quad \mathrm{~V}=2 \mathrm{~m} / \mathrm{s} \quad \mathrm{R}^{2}=0.890 \quad \mathrm{CV}=21.4 \%
\end{aligned}
$$

$$
\begin{aligned}
& \text { ABYBT }=1.32+0.09 \mathrm{~T}+0.06 \mathrm{P}+0.01 \mathrm{~T}^{2}+0.05 \mathrm{P} * \mathrm{~T}+0.01 \mathrm{P}^{2} \\
& \text { (2) } \mathrm{V}=1 \mathrm{~m} / \mathrm{s} \\
& \mathrm{R}^{2}=0.98
\end{aligned}
$$

$$
A B Y B T=1.28+0.07 T+0.07 P+0.03 T^{2}+0.07 P * T-0.00 P^{2}
$$$$
\text { (2) } \mathrm{V}=2 \mathrm{~m} / \mathrm{s} \quad \mathrm{R}^{2}=0.930 \quad \mathrm{CV}=1.9 \%
$$

DARK $=2.19+0.85 \mathrm{~T}+0.73 \mathrm{P}+0.11 \mathrm{~T}^{2}+0.39 \mathrm{P} * \mathrm{~T}-0.08 \mathrm{P}^{2}$

$$
\text { (3) } \mathrm{V}=\mathrm{Im} / \mathrm{s} \quad \mathrm{R}^{2}=0.660 \quad \mathrm{CV}=29.8 \%
$$

DARK $=1.36+0.42 \mathrm{~T}+0.60 \mathrm{P}+0.56 \mathrm{~T}^{2}+0.63 \mathrm{P} * \mathrm{~T}-0.09 \mathrm{P}^{2}$

$$
\text { (2) } \mathrm{V}=2 \mathrm{~m} / \mathrm{s} \quad \mathrm{R}^{2}=0.510 \quad \mathrm{CV}=45.6 \%
$$

$$
\begin{aligned}
& \text { CRSUGR }=1.39+1.01 \mathrm{~T}+0.98 \mathrm{P}-0.16 \mathrm{~T}^{2}+0.65 \mathrm{P} * \mathrm{~T}+0.26 \mathrm{P}^{2} \\
& \text { () } \quad \mathrm{V}=1 \mathrm{~m} / \mathrm{s} \\
& \mathrm{R}^{2}=0.830 \quad \mathrm{CV}=36.3 \%
\end{aligned}
$$

CRSUGR $=0.56+0.59 \mathrm{~T}+0.70 \mathrm{P}+0.18 \mathrm{~T}^{2}+0.57 \mathrm{P} * \mathrm{~T}+0.16 \mathrm{P}^{2}$

$$
\text { (2) } \mathrm{V}=2 \mathrm{~m} / \mathrm{s} \quad \mathrm{R}^{2}=0.690 \quad \mathrm{CV}=71.7 \%
$$

STICKY $=1.96+0.76 \mathrm{~T}+0.98 \mathrm{P}+0.11 \mathrm{~T}^{2}+0.33 \mathrm{P} T-0.11 \mathrm{P}^{2}$

$$
\text { (2) } \mathrm{V}=1 \mathrm{~m} / \mathrm{s} \quad \mathrm{R}^{2}=0.680 \quad \mathrm{CV}=35.6 \%
$$

$$
\begin{aligned}
& \text { STICKY }=1.66+0.49 \mathrm{~T}+1.17 \mathrm{P}+0.08 \mathrm{~T}^{2}+0.33 \mathrm{P} * \mathrm{~T}-0.29 \mathrm{P}^{2} \\
& \text { (2) } \quad \mathrm{V}=2 \mathrm{~m} / \mathrm{s} \quad \mathrm{R}^{2}=0.740 \quad \mathrm{CV}=41.9 \%
\end{aligned}
$$

NONUNI $=2.72+0.98 \mathrm{~T}+0.97 \mathrm{P}-0.01 \mathrm{~T}^{2}+0.42 \mathrm{P} * \mathrm{~T}-0.30 \mathrm{P}^{2}$

$$
\text { ( ) } \mathrm{V}=1 \mathrm{~m} / \mathrm{s} \quad \mathrm{R}^{2}=0.740 \quad \mathrm{CV}=26.6 \%
$$

NONUNI $=1.93+0.30 \mathrm{~T}+0.93 \mathrm{P}+0.37 \mathrm{~T}^{2}+0.43 \mathrm{P} * \mathrm{~T}-0.40 \mathrm{P}^{2}$

$$
\text { (8) } \mathrm{V}=2 \mathrm{~m} / \mathrm{s} \quad \mathrm{R}^{2}=0.690 \quad \mathrm{CV}=36.9 \%
$$

$$
\text { TIME }=2.44-1.54 \mathrm{~T}-1.43 \mathrm{P}+1.07 \mathrm{~T}^{2}+1.11 \mathrm{P} * \mathrm{~T}+0.86 \mathrm{P}^{2}
$$

$$
\text { (2) } \mathrm{V}=1 \mathrm{~m} / \mathrm{s}, \quad \mathrm{R}^{2}=0.884 \quad \mathrm{CV}=18.9 \%
$$

$$
\begin{aligned}
& \text { TIME }=4.50-2.40 \mathrm{~T}-1.53 \mathrm{P}+0.65 \mathrm{~T}^{2}+1.08 \mathrm{P} * \mathrm{~T}+0.85 \mathrm{P}^{2} \\
& \text { (1) } \mathrm{V}=2 \mathrm{~m} / \mathrm{s} \quad \mathrm{R}^{2}=0.980 \quad \mathrm{CV}=6.6 \%
\end{aligned}
$$

All the models (Eq. 8.1 - 8.14) were significant at the 0.01 level, however, not all coefficients are signficantly different from $\mathbf{0}$ (details in Appendix $\mathbf{C}$, Tables C3 to $\mathrm{C16}$ ). 
In general all quality attributes are positively related with $\mathrm{T}$ and $\mathrm{P}$ at both velocity levels. However, since higher values are associated with lower quality, increases in both $T$ and $P$ lead to lower quality, the reason being that the product suffers from overheating (chapter 7). The coefficients of the predictors at the lower velocity level of $1.0 \mathrm{~m} / \mathrm{s}$ were found to be higher than those at velocity $2.0 \mathrm{~m} / \mathrm{s}$. This implies that quality deteriorates more rapidly as either $\mathrm{T}$ or $\mathrm{P}$ (or both) increase, i.e. that the product heats more rapidly at the lower velocity level. A higher air velocity tends to remove heat and moisture more rapidly and results in low product temperature which lead to a better quality. However, the drying times were longer with higher air velocity which indicated a higher energy requirement.

Of the quality variables, DAMAGE and ABYB have substantially higher $R^{2}(>0.89)$ and lower CV's than the others, i.e. they have better predictability at both levels of velocity. The quality constraints to be imposed in the optimization stage were therefore based on these two parameters.

\section{Discussion on constraining limits for ABYB and DAMAGE}

\subsubsection{Colour (ABYB)}

Darkness in the product is mainly due to browning during drying. Temperature of drying and time of drying are the two important operating parameters that control browning. The higher the temperature and the longer the drying time the greater is the darkness. The colour measurements of a and $b$ expressed as a ratio $a / b(A B Y B$ ) essentially indicated the darkness of the product. Lower values indicated yellowness or lightness or in other words less of redness or darkness in the sample. The results of Tukey's multicomparison test (Steel and Torrie, 1980; SAS, 1989) are presented in Appendix C Tables $\mathrm{C} 17$ and C18, and are discussed below. A commercial sample (25) and a hot air dried sample (26) were also included in the multi comparison test.

Samples 25 (commercial) and 26 (hot air dried) yielded higher values of $A B Y B$ than all of the microwave dried samples indicating that these two were 
the darkest of all the samples analyzed. In other words MW dried samples were lighter than the commercial and the hot air dried samples. A similar result was obtained in the sensory evaluation for DARK and this confirms that MW drying with any level of treatment considered in this study yielded lightercoloured raisins. However the $\mathrm{ABYB}$ of $\mathrm{MW}$ dried samples differed considerably between treatments. Treatment 15 scored a minimum mean of 0.305 and this was followed by treatments 14, 17, 1 and 5 and all these four were not significantly different from each other (Tukey's test; Appendix C Table C17). The next best treatments in terms of light coloured raisins were 21 and 2 which had treatment means of 0.337 and 0.342 . In summary, treatments 15 , $14,17,1,5,21$ and 2 yielded light coloured raisins when compared to other treatments under MW drying. An ABYB value of 0.342 was therefore used as the constraining quality factor in further analysis.

\subsubsection{Damage (DAMAGE)}

Treatment 13 scored zero counts indicating absence of defective raisins in that sample. Treatments 14 and 15 scored damage counts of 1.0 and 1.33\%, respectively. This was followed by treatments 16,1 and 17 which had counts under 5.0\%. Treatments 2 and 5 both scored $6.67 \%$, and treatments $18 \& 3$ scored $8.33 \%$ each. Damage counts in all these treatments were not significantly different (Tukey's test at 0.05 level, Appendix C Table $\mathrm{C18}$ ). The rest of the MW dried samples scored damage counts of more than $11.6 \%$. The damage count observed in commercial sample was 4.67. Stipulations for US grade A or 'US Fancy' limit damage to 2\% (Cruess, 1974). For grades B and C, there is no prescribed limit, it is only stated that these grades could have more than $2 \%$ damaged raisins. A damage count of $10 \%$ was used as a constraint in further analysis to permit adequate resolution of contours in the graphical optimization procedures used (next section). 


\subsection{Process Optimization}

The above models (Eqs 8.1 - 8.14) in coded terms were used to generate data with which to plot contours. During calculation of the grid points, the coded predictors were put back in original terms for convenience in reading the contour plots which were developed using PROC PLOT with the CONTOUR option (SAS, 1989). The variables ABYBT and DAMT were also backtransformed to original terms. The interval for grid calculation was extended to include a power level of 0 , corresponding to a convective drying situation. Figs. $8.1-8.3$ show the resulting contours for $V=1 \mathrm{~m} / \mathrm{s}$ and Figs. $8.3-8.6$ for $\mathrm{V}=2 \mathrm{~m} / \mathrm{s}$.

The effects of $T$ and $P$ on DAMAGE are clearly illustrated by the contours in Fig. $8.1(\mathrm{~V}=1 \mathrm{~m} / \mathrm{s})$. Minimum damage is found at lower power levels combined with lower air temperature. Hot-air drying corresponds to the region of 0 power and $50-60^{\circ} \mathrm{C}$, whereas drying under shaded ambient conditions corresponds to the region of 0 power and about $30-35^{\circ} \mathrm{C}$. Under both of these sets of conditions, percent damage is predicted to be between 0.5 and 5\% which may be reasonable. Fig. 8.3 shows that under hot-air drying, the drying time is of the order of 5.5 hours whereas it is of the order of 13 hours for drying at ambient temperatures. At $\mathrm{V}=2 \mathrm{~m} / \mathrm{s}$, the quality tends to be better but the drying time longer (Figs. 8.4 - 8.6). Under both inlet air velocities, the drying times, as well as the colour indicator ABYB (Fig. 8.2) are under-predicted compared to reality for convective drying.

The colour of the convectively dried samples was found to be darker (ABYB > 0.497). The drying time for convective drying was more than $17 \mathrm{~h}$ at an air temperature of $60^{\circ} \mathrm{C}$ (chapter 7). Grapes dried under sun in ambient conditions ('Naturals' of California) are reported to take drying times of more than a month (Winkler et al., 1974). These natural raisins are very dark in colour, approaching black. ABYB measurement made on commercially procured 'Naturals' (sun dried) resulted a negative value for yellowness (b) indicting extreme darkness in these samples $(b>-2.50)$. These results 


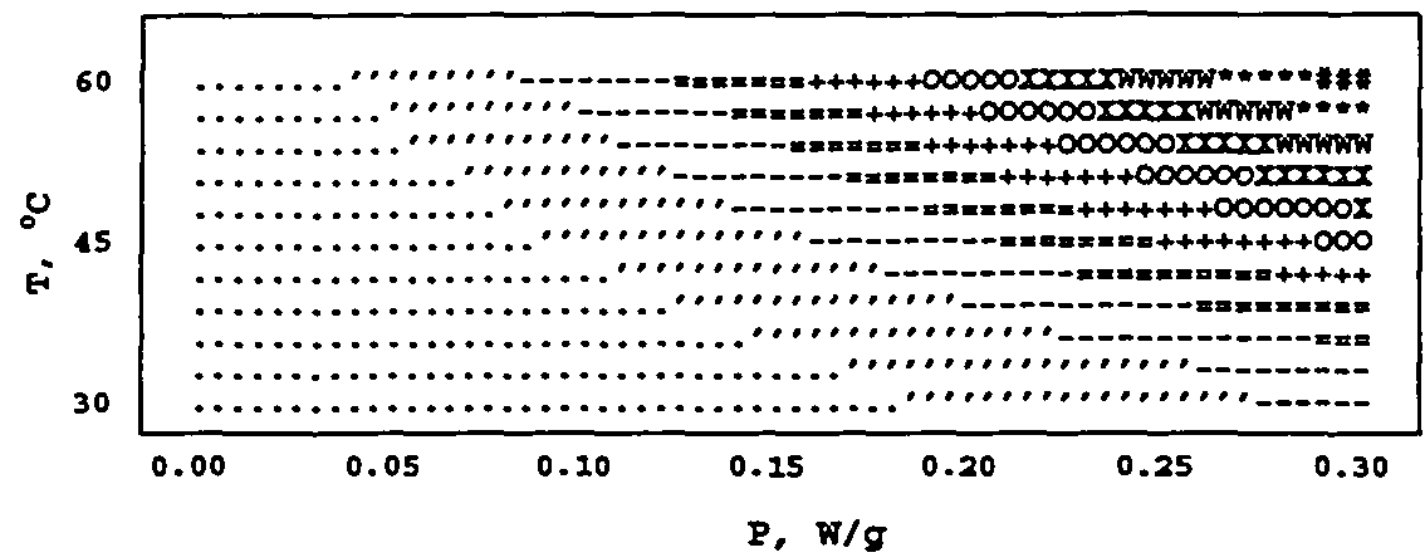

Fig. 8.1. Contour plot of $P x T$ for Damage at $V=1.0 \mathrm{~m} / \mathrm{s}$.

symbol parace *, (x 100)

$\begin{array}{ll}\because \ldots \ldots & 0.00553-0.05544 \\ \because \because \because \quad & 0.05544-0.10536 \\ =--- & 0.10536-0.15527 \\ z=== & 0.15527-0.20518 \\ +++++ & 0.20518-0.25509\end{array}$

Symbol DAMGE *, $\left(x_{100)}\right.$

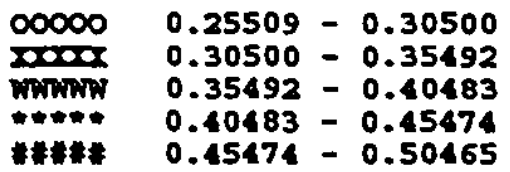

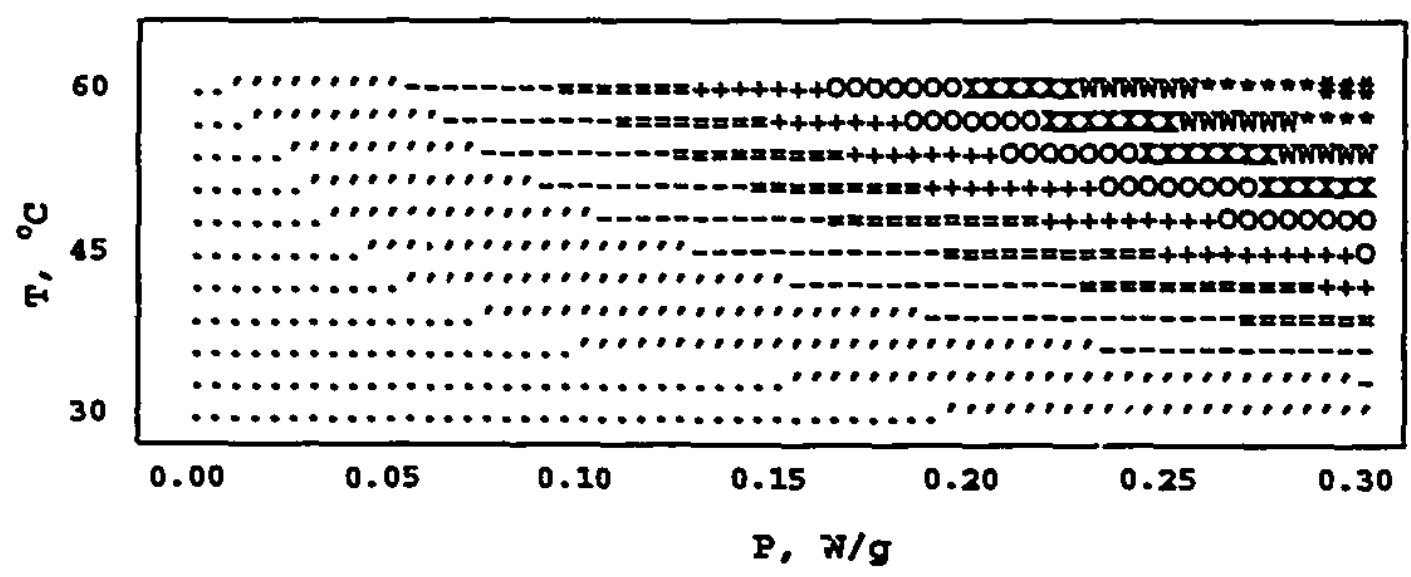

Fig. 8.2. Contour Plot of $P x$ for ABYB at $V=1.0 \mathrm{~m} / \mathrm{s}$.

Symbol

ABYB

$\because: \because: \because$

-ー-ー-

$t+t+t$

$0.31667-0.33333$
$0.33333-0.35000$
$0.35000=0.36667$
$0.36667=0.38333$
$0.38333=0.40000$

symbol

ABYB

\begin{tabular}{|c|c|}
\hline $\operatorname{limin}_{\substack{\infty \\
\lim _{n}}}^{\infty}$ & $\begin{array}{l}0.40000 \\
0.41667 \\
0.43333 \\
0.45000 \\
0.46667\end{array}$ \\
\hline
\end{tabular}




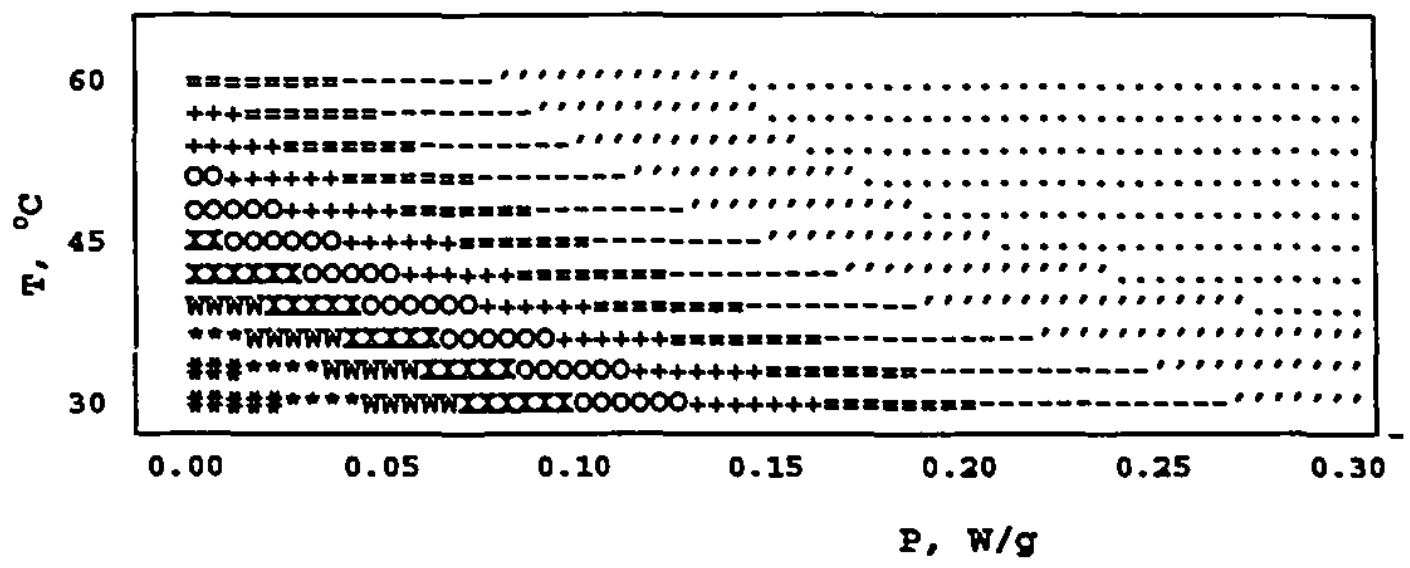

Fig. 8.3. Contour Plot of $P \times T$ for Time at $V=1.0 \mathrm{~m} / \mathrm{s}$.

\begin{tabular}{|c|c|c|c|c|c|c|c|}
\hline symbol & Tras & E, h & Symbol & & TIIE, & symbol & TINe, $\mathbf{b}$ \\
\hline$=$ & $\begin{array}{l}1.25 \\
2.50 \\
3.75 \\
5.00\end{array}$ & $\begin{array}{l}2.50 \\
-\quad 3.75 \\
-\quad 5.00 \\
-\quad 6.25\end{array}$ & $\begin{array}{c}+++++ \\
00000 \\
\text { mece } \\
\text { Nimin }\end{array}$ & $\begin{array}{r}6.25 \\
7.50 \\
8.75 \\
10.00\end{array}$ & $\begin{array}{r}7.50 \\
-\quad 8.75 \\
-\quad 10.00 \\
-11.25\end{array}$ & 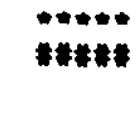 & $\begin{array}{l}11.25=12.50 \\
12.50=13.75\end{array}$ \\
\hline
\end{tabular}

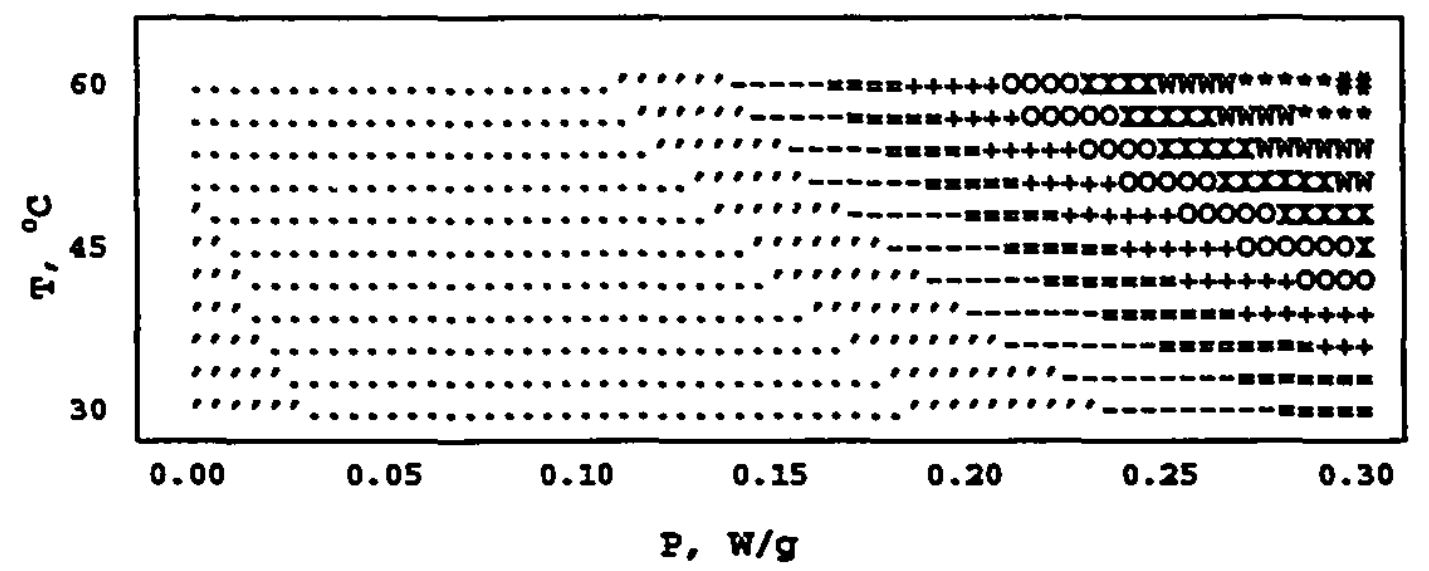

Fig. 8.4. Contour Plot of $P \times T$ for Damage at $V=2.0 \mathrm{~m} / \mathrm{s}$.

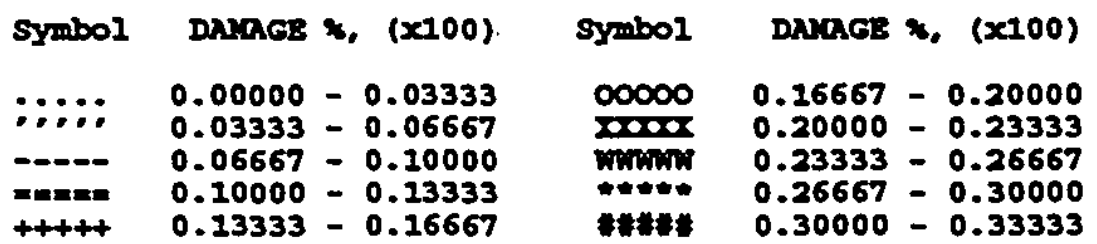




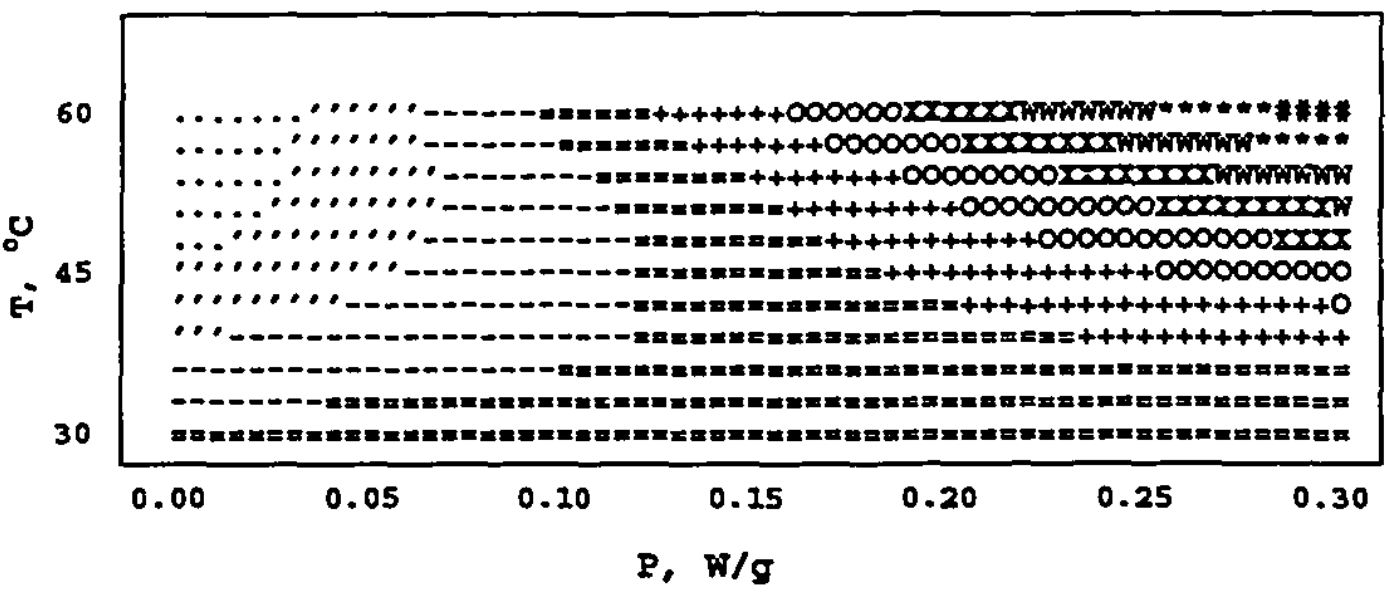

Fig. 8.5. Contour Plot of ABYB at $\mathrm{V}=2.0 \mathrm{~m} / \mathrm{s}$.

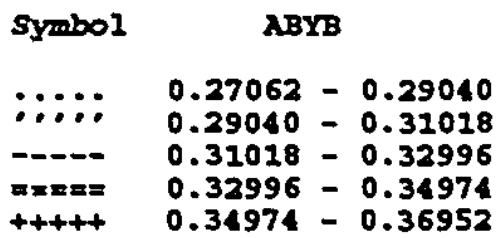

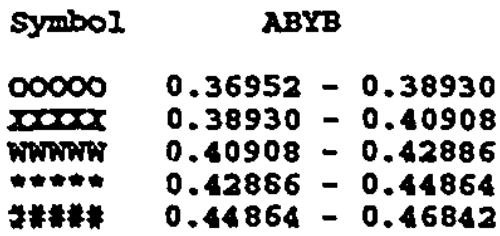

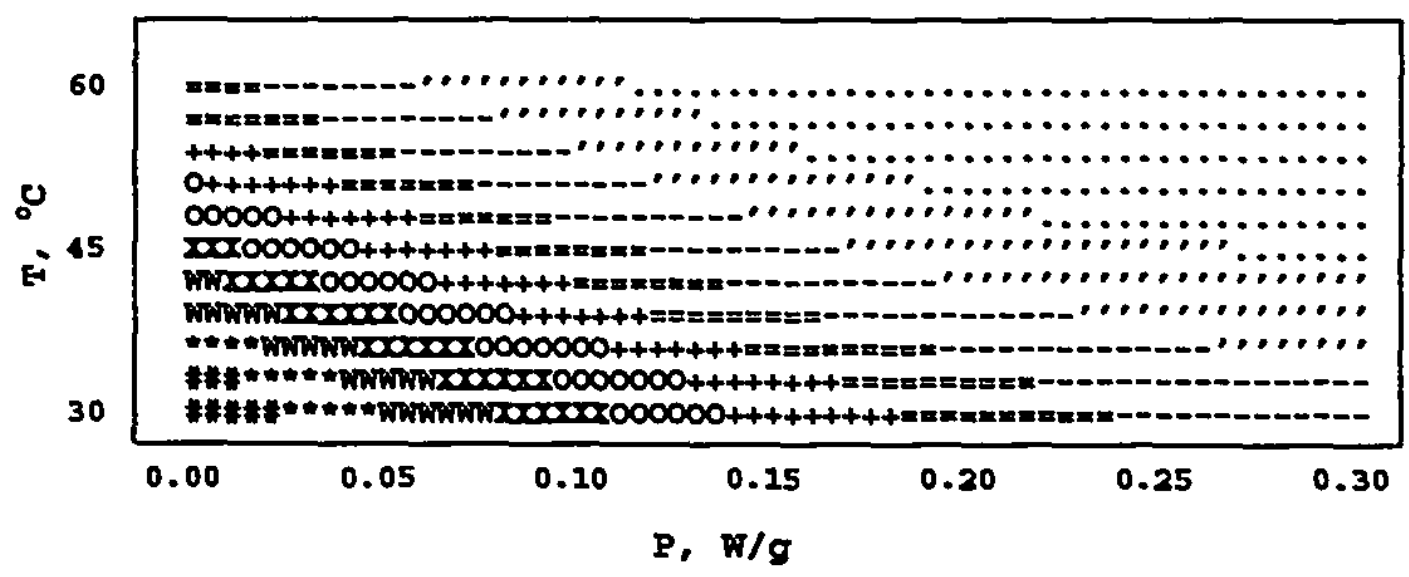

Fig. 8.6. Contour Plot of $P \times T$ for Trus at $V=2.0 \mathrm{~m} / \mathrm{s}$.

\begin{tabular}{|c|c|c|c|c|c|}
\hline 5ymbol & & PIIB & symbol & & TIME \\
\hline$\because: \because:$ & $\begin{array}{l}2.689 \\
1.035 \\
5.381 \\
6.728 \\
8.074\end{array}$ & $\begin{array}{l}-4.035 \\
=\quad 5.381 \\
=\quad 6.728 \\
=\quad 8.074 \\
=\quad 9.420\end{array}$ & 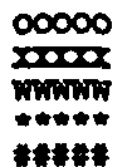 & $\begin{array}{r}9.420 \\
10.766 \\
12.112 \\
13.459 \\
14.805\end{array}$ & $\begin{array}{l}=10.766 \\
-12.112 \\
=13.459 \\
=14.805 \\
-16.151\end{array}$ \\
\hline
\end{tabular}


indicate that convective drying and microwave drying are fundamentally different and that the models should therefore not be extrapolated to include convective drying conditions.

For visual convenience, the contours were redrawn using the restrictions that DAMAGE should be $\leq 10 \%$ and ABYB should be $\leq 0.342$ (Figs. 8.7-8.12). The program written to generate these contours is given in the Apeendix $\mathrm{C}$ (Table C19). These figures clearly indicate the conditions under which the quality constraints are satisfied, as well as the lower limits to microwave drying time possible with the given constraints (a minimum of $3-4 \mathrm{~b}$ drying time is required, depending on power, inlet air temperature and inlet air velocity). An analysis of total ene:gy requirement is also required for selecting optimum operating parameters ( $\mathrm{T}, \mathrm{P}$ and $\mathrm{V})$ in combination with drying time for a cost effective process.

\subsection{Energy Consumption}

\subsubsection{Specific Energy Consumption for Drying}

Specific Energy Consumption $\left(e_{c}\right)$ is defined as the total energy used to evaporate a unit mass of water in drying of grapes ( $78 \%$ m.c.) into raisins of $15 \% \mathrm{~m} . \mathrm{c}$ wet basis $(0.18 \mathrm{~kg} / \mathrm{kg}$ dry mass). Enthalpy demand $(h)$ required to heat the air from its ambient conditions to the desired $T$ is computed from the psychrometeric properties of the air. Energy demand $\left(e_{1}\right)$ required for heating the air for drying is computed for a given drying condition knowing the actual drying time. An efficiency of $90 \%$ has been assumed for the electrical heaters. An overall efficiency of $70 \%$ has been assumed for the blower and the electric motor while calculating energy supplied to the blower for its drive $\left(e_{2}\right)$; a powerfactor of 0.9 has been assumed for the electric motor. Heat loss in the exhaust air is not considered in the analysis since there was no heat recovery. It should be noted that this energy balance is drawn for the purpose of comparing different treatments in this study. As the apparatus used was a laboratory-scale device the results will hold good for a relative evaluation only. 


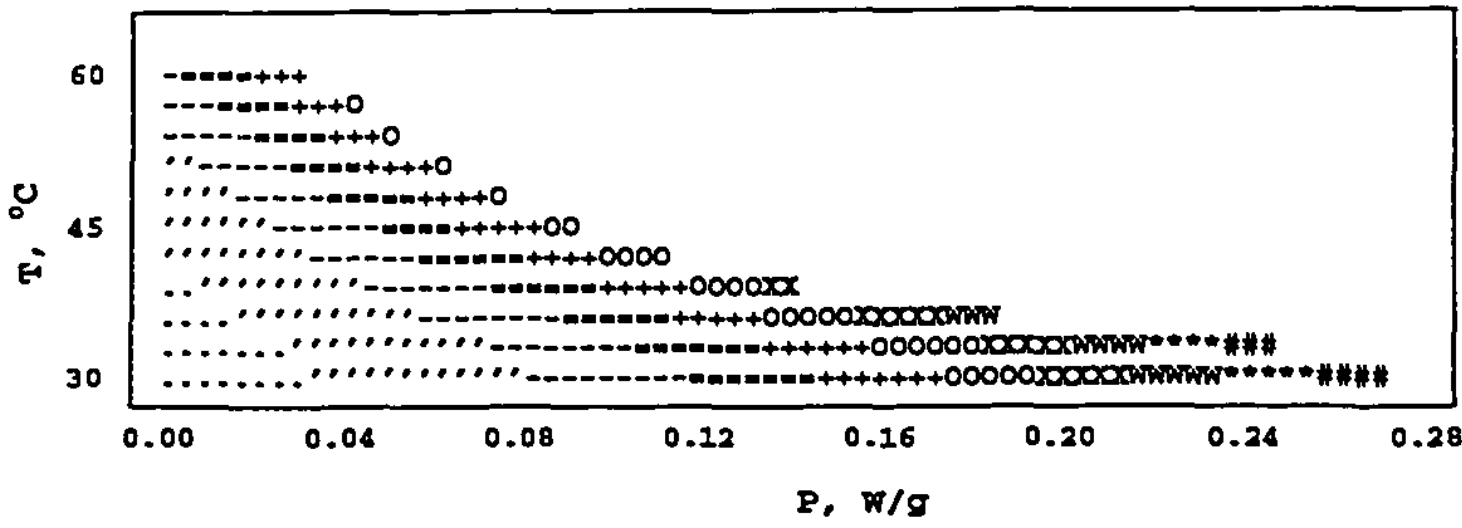

FIg. 8.7. Contour plot of $P \times T$ for DAMAGE with RESTRICTION on DAMAGE at $\leq 10 \%$ and $A B Y B$ at $\leq 0.342$ e $\mathrm{v}=1 \mathrm{~m} / \mathrm{s}$.

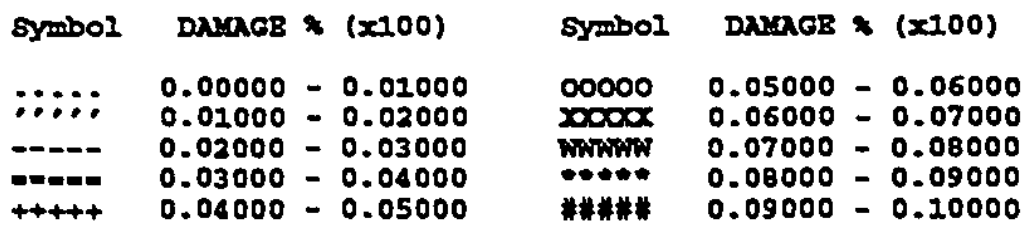

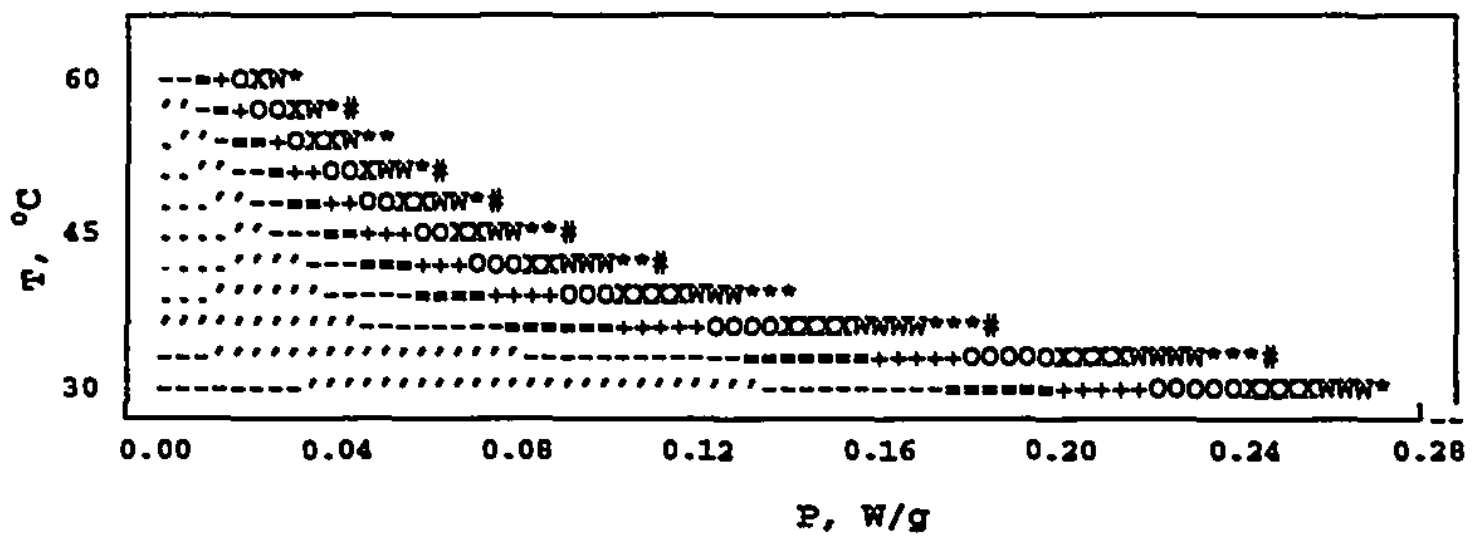

Fig. 8.8. Contour plot of PXT for ABYB with RESIRICTION on DAMGEE at $510 \%$ and $A B Y B$ at $50.342 \mathrm{e} V=1.0 \mathrm{~m} / \mathrm{s}$.

8ymbol

NBYB

$$
\begin{aligned}
& \ldots \ldots 0.32667-0.32833 \\
& \ldots \ldots 00.32833-0.33000 \\
& \text {-..- } 0.33000-0.33167 \\
& =0.33167-0.33333 \\
& ++++0.33333-0.33500
\end{aligned}
$$

Symbol $\mathbf{A B Y B}$

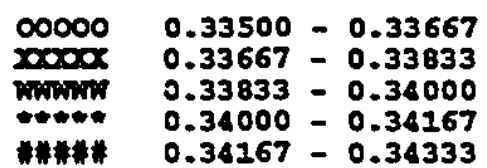




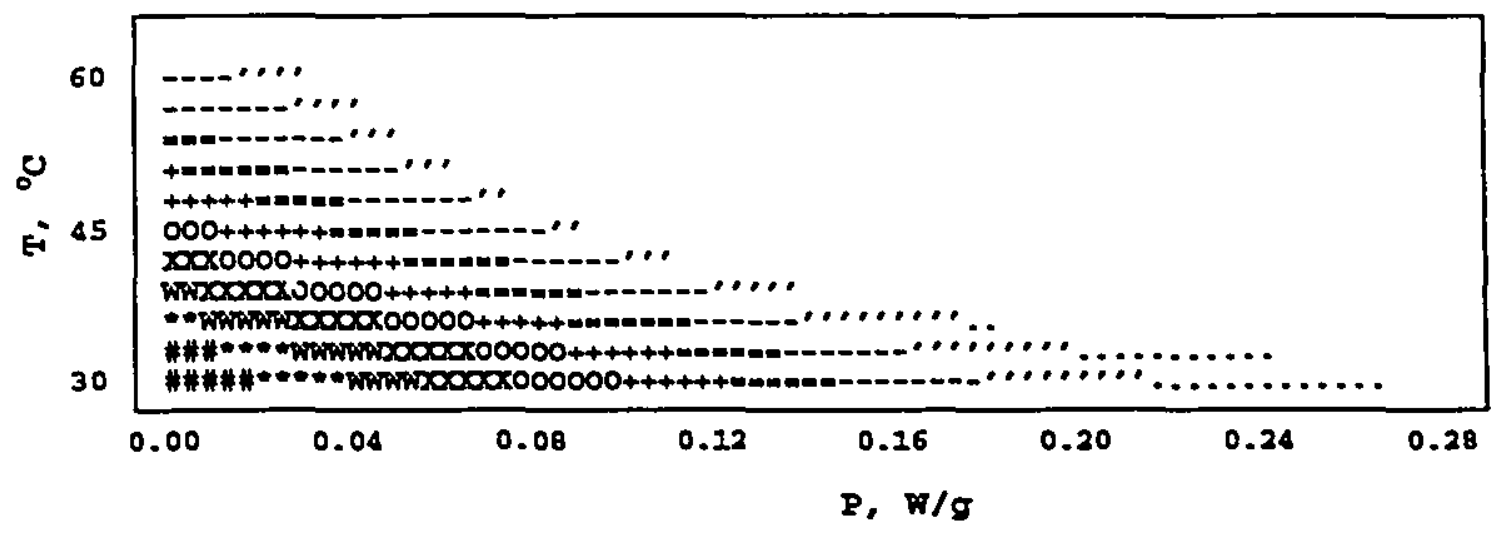

Fig. 8.9. Contour plot of $P \times T$ for TINE with RESTRICTION on on DAMAGE $\leq+10 \%$ and $A B Y B \leq 0.342 \theta v=1.0 \mathrm{~m} / \mathrm{s}$.

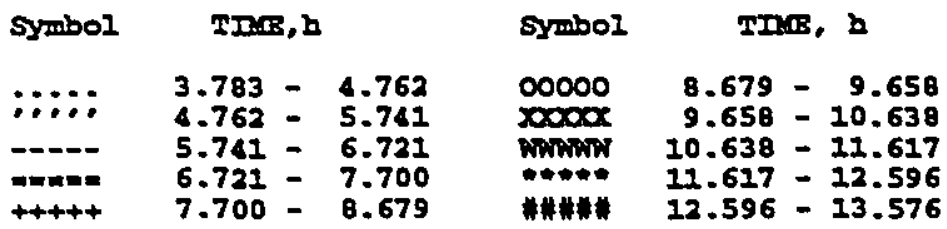

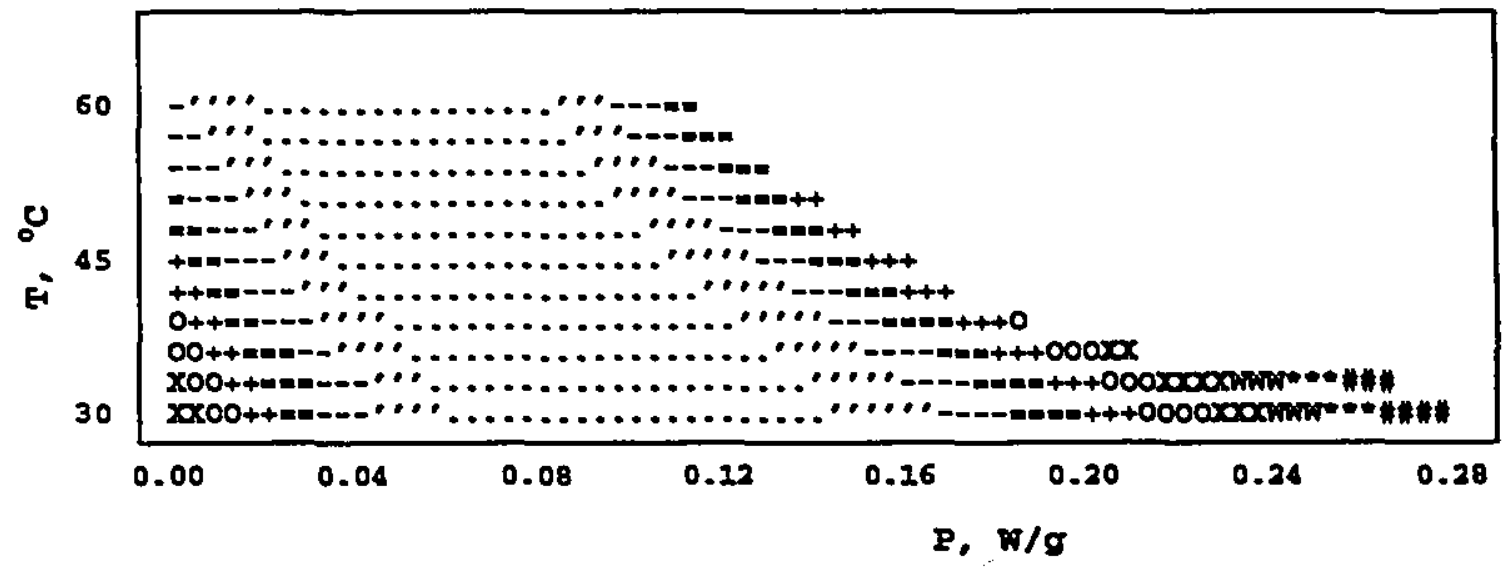

Fig. 8.10. Contour Plot for DAMAGE with constrained restriction on Damage $\leq 10 \%$ and $A B Y B \quad 50.342$ at air velocity of $2 \mathrm{~m} / 8$.

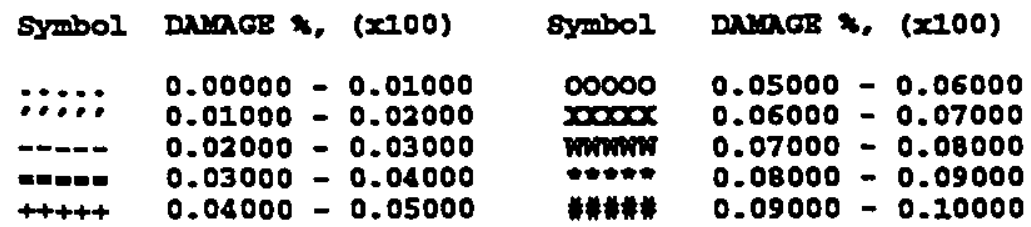




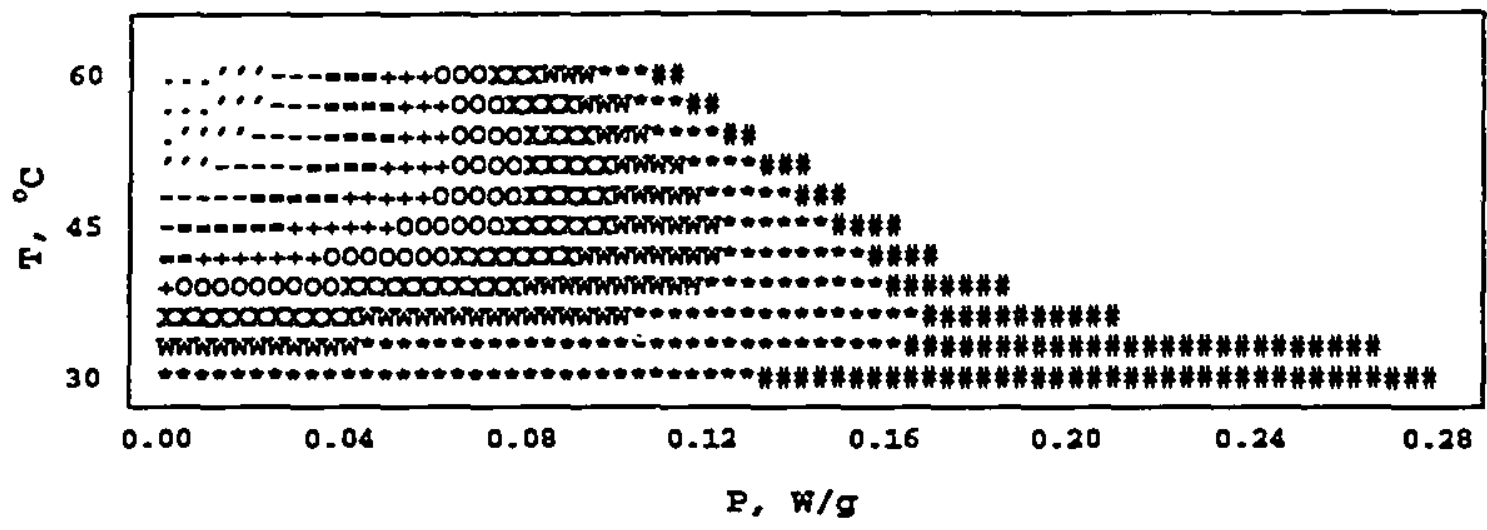

Fig. 8.11. Contour plot for ABYB with constrained restriction on Damage $\leq 10 \%$ and $A B Y B \leq 0.342$ at air velocity of $2 \mathrm{~m} / \mathrm{s}$.

\begin{tabular}{|c|c|c|c|}
\hline Symbol & $\lambda B Y B$ & Symbol & ABYB \\
\hline$\because \because$ & $\begin{array}{l}0.27000-0.27750 \\
0.27750=0.28500 \\
0.28500=0.29250 \\
0.29250-0.30000 \\
0.30000-0.30750\end{array}$ & 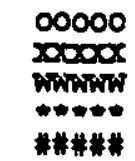 & $\begin{array}{l}0.30750-0.31500 \\
0.31500=0.32250 \\
0.32250=0.33000 \\
0.33000=0.33750 \\
0.33750=0.34500\end{array}$ \\
\hline
\end{tabular}

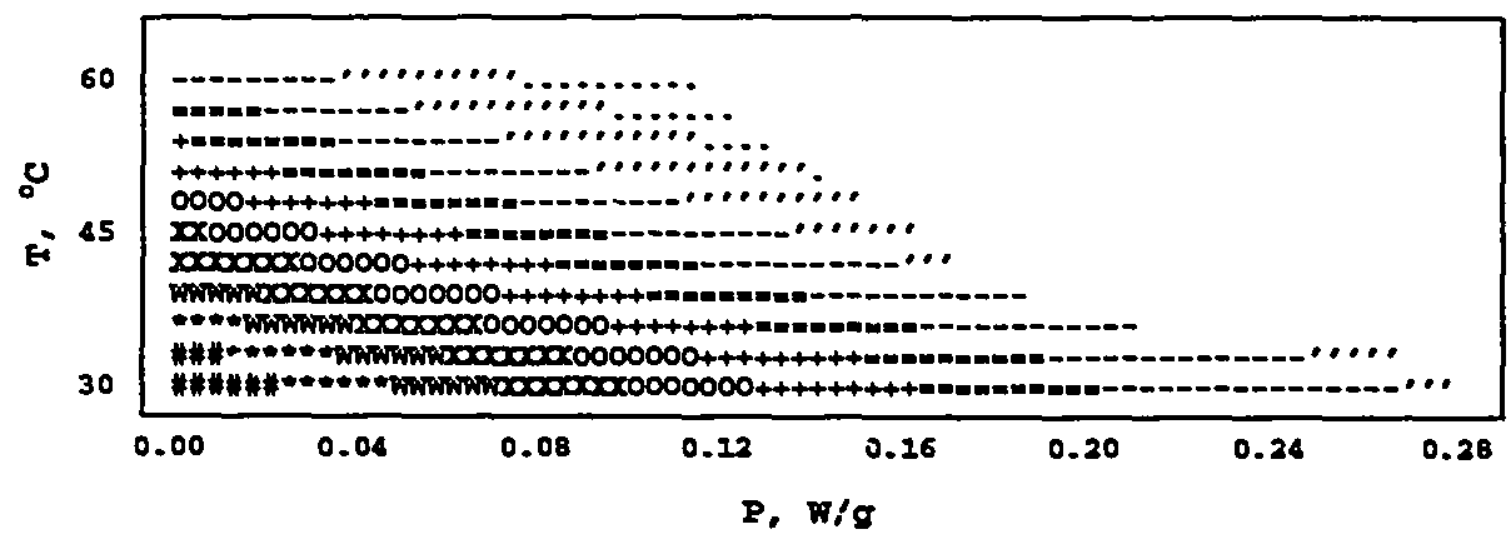

Fig. 8.12. Contour Plot for The with constraived restriction on Damage $\leq 10 \%$ and $A B Y B S 0.342$ at air velocity of $2 \mathrm{~m} / \mathrm{s}$.

\begin{tabular}{|c|c|c|c|c|}
\hline Symbol & & ace,b & 8ymbol & Trane, h \\
\hline$\because \because$ & $\begin{array}{l}3.75 \\
5.00 \\
6.25 \\
7.50\end{array}$ & $\begin{array}{l}-5.00 \\
-\quad 6.25 \\
-\quad 7.50 \\
-\quad 8.75\end{array}$ & $\begin{array}{l}++++4 \\
00000 \\
\text { mocec } \\
\text { Nownin }\end{array}$ & $\begin{array}{r}8.75=10 \\
10.00-1 \\
11.25-12 \\
12.50-13\end{array}$ \\
\hline
\end{tabular}

Symbol Tragh

H4* $13.75-15.00$

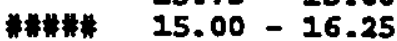




\subsubsection{Specific Energy Consumption in Convactive Drying}

Table 8.2 compares specific energy consuraption in convective drying of pre-treated grapes at two air temperatures, 50 and $60^{\circ} \mathrm{C}$. Drying at $60^{\circ} \mathrm{C}$ was found to be more energy efficient with an $11 \%$ lower specific energy consumption compared to $\mathrm{T}=50^{\circ} \mathrm{C}$. These figures are on the high side compared to reported values for grain drying (4500-6200 kJ/kg water). However, grapes have a much higher moisture load for drying than grain and the drying behaviour of grapes could be entirely different than that of grains. Another factor explaining the higher specific consumption could be the equipment size. The apparatus used was a laboratory-scale device which was designed to be functional for experimentation rather than optimal for drying operations.

\subsubsection{Specific Energy Consumption in MW Drying}

Total energy demand (e) under $M W$ drying is the sum of energy demand for heating the air $\left(e_{1}\right)$, energy supplied to the blower $\left(e_{2}\right)$ and the energy demand through MW power application $\left(e_{3}\right)$. It is assumed that $M W$ systems are only $50 \%$ efficient in converting line power to microwave power (Metaxas and Meredith, 1983,; Buffler, 1990). For electrical usage calculations it is further considered that actual power consumed is double the calculated microwave power (Buffler, 1990). Therefore $e_{3}$ represents double the actual

Table 8.2. Specific energy consumption per $\mathrm{kg} \mathrm{H}_{2} \mathrm{O}$ in convective drying of grapes.

\begin{tabular}{|c|c|c|c|c|c|c|c|}
\hline $\begin{array}{c}\text { Air } \\
\text { Temp. } \\
\\
T \\
{ }^{\circ} \mathrm{C}\end{array}$ & $\begin{array}{c}\text { Air } \\
\text { flow } \\
\text { rate } \\
\text { G } \\
\mathrm{kg} / \mathrm{s}\end{array}$ & $\begin{array}{c}\text { Enthalpy } \\
\text { demand } \\
\text { (air) } \\
h \\
\mathrm{~kJ} / \mathrm{h}\end{array}$ & $\begin{array}{c}\text { Drying } \\
\text { time } \\
t \\
\mathbf{t}\end{array}$ & $\begin{array}{c}\text { Energy } \\
\text { demand } \\
\text { (air) } \\
e_{1} \\
k J\end{array}$ & $\begin{array}{c}\text { Energy } \\
\text { demand } \\
\text { (blower) } \\
e_{2} \\
\text { kJ }\end{array}$ & $\begin{array}{c}\text { Total } \\
\text { energy } \\
\text { e } \\
\text { MJ }\end{array}$ & $\begin{array}{c}\text { Specific } \\
\text { energy } \\
\text { consumpt. } \\
\mathrm{e}_{\mathrm{c}} \\
\mathrm{MJ} / \mathrm{k}_{\mathrm{E}} \mathrm{H}_{2} \mathrm{O}\end{array}$ \\
\hline 50 & 0.0210 & 2399.86 & 23.66 & 56781.0 & 10075.1 & 6.686 & 90.35 \\
\hline 60 & 0.0204 & 3159.19 & 16.75 & 52916.0 & 7132.6 & 6.005 & 81.15 \\
\hline
\end{tabular}


microwave power applied on the material. As only a fraction of the total capacity of the generator was utilized in the present work, the generator was under utilized and therefore the comparison of different methods has been based on the actual MW energy applied on the material. Table 8.3 shows a typical energy balance for MW drying of grapes. As can be seen the amount of energy supplied through $\mathrm{MW}\left(e_{3}\right)$ is a very small quantity compared to $e_{1}$. On comparing the results of energy analysis in convective and MW drying some interesting features were observed. For example the $e_{c}$ for convective drying (at $\mathrm{T}=60^{\circ} \mathrm{C}$ ) was $81.15 \mathrm{MJ} / \mathrm{kg}$. This is nearly 4 times higher than the highest $e_{c}$ under $M W$ drying. At all $M W$ drying conditions the energy consumption was found to be more efficient with lower $e_{c}$ compared to convective drying conditions. The main reason is the saving in $e_{1}$ because of the short drying times achieved in MW drying. As both the convective and MW drying studies are conducted in the same apparatus under similar unditions this comparison is valid.

\subsubsection{Optimization of energy consumption in MW drying}

A considerable variation in the values of $e_{c}$ was observed for different MW drying conditions. The values of $e_{c}$ reduced as $t$ reduced. As aiscussed in the earlier sections increase of $T$ and $P$, individually or in combination, reduced $t$. The combined effect of increasing $T$ and $P$ is well reflected in low values of $e_{c}$ in such cases.

Air velocity showed a bigger effect on $e_{c}$ in $M W$ drying because of two reasons: 1) low air velocity leads to shorter drying iimes and hence the energy demands of $e_{1}, e_{2}$, and $e_{3}$ were small, 2) low air velocity resulted in low air flow rate $(G)$ and hence the enthalpy input $(h)$ in the air heaters was small. For example, at $\mathrm{V}=1.0 \mathrm{~m} / \mathrm{s}$ the reduction in specific energy consumption was nearly $61 \%$ when compared to a higher air velocity of $2.0 \mathrm{~m} / \mathrm{s}$ (Tables 8.3 and 8.4). At other air temperatures reduction in $e_{c}$ at $V=1.0 \mathrm{~m} / \mathrm{s}$ was found to be $177 \%, 186 \%$ and $131 \%$ at 40,50 and $60^{\circ} \mathrm{C}$, respectively. 
Table 8.3. Specific energy consumption per $\mathrm{kg} \mathrm{H}_{2} \mathrm{O}$ in $\mathrm{MW}$ drying of grapes at $\mathrm{V}=2.0 \mathrm{~m} / \mathrm{s}, \mathrm{P}=0.1 \mathrm{~W} / \mathrm{g}$.

\begin{tabular}{|c|c|c|c|c|c|c|c|c|}
\hline $\begin{array}{c}\text { Air } \\
\text { Temp. } \\
{ }^{\mathbf{T}} \\
{ }^{\circ} \mathrm{C}\end{array}$ & $\begin{array}{c}\text { Air flow } \\
\text { rate } \\
\mathbf{G} \\
\mathrm{kg} / \mathrm{s}\end{array}$ & $\begin{array}{c}\text { Enthalpy } \\
\text { demand } \\
\text { (air) } \\
h \\
\mathrm{~kJ} / \mathrm{h}\end{array}$ & $\begin{array}{c}\text { Drying } \\
\text { time } \\
\text { t } \\
\text { h }\end{array}$ & $\begin{array}{c}\text { Energy } \\
\text { demand } \\
\text { (air) } \\
e_{1} \\
k J\end{array}$ & $\begin{array}{c}\text { Energy } \\
\text { demand } \\
\text { (blower) } \\
e_{2} \\
\text { kJ }\end{array}$ & $\begin{array}{c}\text { Energy } \\
\text { demand } \\
\text { (MW) } \\
e_{9} \\
k_{e} J\end{array}$ & $\begin{array}{c}\text { Total } \\
\text { Energy } \\
\text { demand } \\
\text { e } \\
\text { MJ }\end{array}$ & $\begin{array}{c}\text { Specific } \\
\text { energy con- } \\
\text { sumption } \\
\text { e }_{\text {e }} \\
\text { MJ/kg water }\end{array}$ \\
\hline 30 & 0.0224 & 730.91 & 10.89 & 7958.9 & 4636.8 & 784.0 & 1.338 & 18.08 \\
\hline 40 & 0.0217 & 1592.03 & 8.61 & 13709.0 & 3666.8 & 620.0 & 1.800 & 24.32 \\
\hline 60 & 0.0210 & 2399.86 & 5.58 & 13398.4 & 2377.4 & 401.9 & 1.618 & 21.86 \\
\hline 60 & 0.0204 & 3159.19 & 3.86 & 12197.6 & 1644.1 & 278.0 & 1.412 & 19.08 \\
\hline
\end{tabular}

Table 8.4. Specific energy consumption per $\mathrm{kg} \mathrm{H}_{2} \mathrm{O}$ in $\mathrm{MW}$ drying of grapes at $V=1.0 \mathrm{~m} / \mathrm{s}, P=0.1 \mathrm{~W} / \mathrm{g}$.

\begin{tabular}{|c|c|c|c|c|c|c|c|c|}
\hline $\begin{array}{c}\text { Air Temp. } \\
\qquad \begin{array}{c}\mathbf{T} \\
{ }^{\circ} \mathbf{C}\end{array}\end{array}$ & $\begin{array}{c}\text { Air flow } \\
\text { rate } \\
\text { G } \\
\mathrm{kg} / \mathrm{s}\end{array}$ & $\begin{array}{c}\text { Enthalpy } \\
\text { demand } \\
\text { (air) } \\
h \\
\mathrm{~kJ} / \mathrm{h}\end{array}$ & $\begin{array}{c}\text { Drying } \\
\text { time } \\
\text { t } \\
\text { h }\end{array}$ & $\begin{array}{c}\text { Energy } \\
\text { demand } \\
\text { (air) } \\
e_{1} \\
k J\end{array}$ & $\begin{array}{c}\text { Energy } \\
\text { demand } \\
\text { (blower) } \\
e_{2} \\
\text { kJ }\end{array}$ & $\begin{array}{c}\text { Energy } \\
\text { demand } \\
\text { (MW) } \\
e_{3} \\
\text { kJ }\end{array}$ & $\begin{array}{c}\text { Total } \\
\text { energy } \\
\text { e } \\
\text { MJ }\end{array}$ & $\begin{array}{c}\text { Specific } \\
\text { energy con- } \\
\text { sumption } \\
\text { e }_{c} \\
\mathrm{MJ} / \mathrm{kg} \text { water }\end{array}$ \\
\hline 30 & 0.0112 & 328.91 & 9.61 & 3160.8 & 4092.2 & 691.9 & 0.794 & 10.74 \\
\hline 40 & 0.0108 & 716.41 & 5.03 & 3602.1 & 2141.1 & 362.0 & 0.611 & 8.25 \\
\hline 60 & 0.0105 & 1079.94 & 3.33 & 3599.4 & 1419.3 & 239.9 & 0.526 & 7.11 \\
\hline 60 & 0.0102 & 1421.64 & 3.18 & 4520.8 & 1354.1 & 228.9 & 0.610 & 8.25 \\
\hline
\end{tabular}


A similar behaviour prevailed at other power densities. It is therefore concluded that low air velocities are advantageous because of their associated low specific energy consumption.

Quality of raisins is a very important consideration in drying of grapes and as seen in earlier sections air velocity had a significant effect on all the quality attributes. In general, an air velocity of $\mathrm{V}=1.0 \mathrm{~m} / \mathrm{s}$ leads to more quality deterioration than $2.0 \mathrm{~m} / \mathrm{s}$ because the material overheats. In addition to air velocity and air temperature, the $\mathrm{MW}$ power density also affect quality of raisins. Therefore quality aspects are to be carefully considered in relation to the individual and interactive effects of these variables on specific energy consumption.

Table 8.5 show the specific energy consumption of some selected MW drying treatments which were considered good because of their low $a / b$ values and low damage counts (sections 8.3.1 and 8.3.2).

Table 8.5. Specific energy consumption of selected MW drying treatments which yielded good quality raisins.

\begin{tabular}{|c|c|c|c|c|}
\hline $\begin{array}{c}\text { Treatment } \\
\text { No. }\end{array}$ & $\begin{array}{c}\text { Air Velocity } \\
\mathrm{V} \\
\mathbf{m} / \mathbf{s}\end{array}$ & $\begin{array}{c}\text { MW Power } \\
\text { P } \\
\text { W/g }\end{array}$ & $\begin{array}{c}\text { Air Temp. } \\
T \\
{ }^{\circ} \mathrm{C}\end{array}$ & $\begin{array}{c}\text { Specific } \\
\text { energy con- } \\
\text { sumption } \\
\mathrm{e}_{\mathrm{e}}, \mathrm{MJ} / \mathrm{kg} \mathrm{H} \mathrm{H}_{2} \mathrm{O}\end{array}$ \\
\hline 15 & 2.0 & 0.1 & 50 & 21.86 \\
\hline 14 & 2.0 & 0.1 & 40 & 24.31 \\
\hline 17 & 2.0 & 0.2 & 30 & 12.77 \\
\hline$I$ & 1.0 & 0.1 & 30 & 10.74 \\
\hline 21 & 2.0 & 0.2 & 30 & 9.51 \\
\hline 16 & 2.0 & 0.1 & 60 & 19.08 \\
\hline 2 & 1.0 & 0.2 & 40 & 8.25 \\
\hline 18 & 2.0 & 0.2 & 40 & 13.26 \\
\hline
\end{tabular}

The lowest $e_{c}$ of $8.25 \mathrm{MJ} / \mathrm{kg}$ was observed in treatment 2 followed by treatment 
21 with its $e_{c}$ at $9.51 \mathrm{MJ} / \mathrm{kg}$. Thus, given the desired quality level in the final product, operating conditions minimizing energy consumption may be chosen.

\subsection{Summaxy}

The quality of raisins was assessed by several attributes like colour, damage, darkmess, crystallized sugar, stickiness and non-uniformity in the finished product. It was found that colour and damage attributes provided more precise predictability when compared to the other quality attributes considered. It was observea that $\mathrm{MW}$ dried raisins were lighter in colour and hence were superior to hot air dried samples. Within MW dried treatments it was observed that darkness and damage in raisins were dependent on MW power density, air temperature and air velocity. Increase in air velocity resulted in better quality raisins whereas the MW power density and air temperaiture had the opposite effect. Optimum selection of $T, P$ and $V$ was found to be critical to achieve an energy efficient process for a quality product. Response surface models in terms of $T$ and $P$ were obtained for each of the quality attributes for air velocities of 1 and $2 \mathrm{~m} / \mathrm{s}$. Process optimization of the operating variables through response surface method was performed by imposing certain constraint levels on quality attributes and contours were developed. With the help of these contours it becomes possible to select suitable levels of $T$ and $P$ to achieve a desired level of quality in the finished product. 


\section{CHAPTER IX}

\section{GENERAL DISCUSSIONS AND CONCLUSIONS}

\subsection{Summary and Conclusions}

This study was directed at the development of a $\mathrm{MW}$ drying process for transforming grapes into raisins. The following conclusions can be drawn:

1. The MW drying technique was found to be suitable for drying grapes into raisins. Light coloured raisins could be obtained without applying the current industrial method of fumigation with sulphur dioxide.

2. The chemical pre-treatments that are used in hot-air drying to shorten drying time and therefore improve quality, also substantially reduce the $M W$ drying time ( $<8.5 \mathrm{~h}$ ). Nevertheless, if necessary, acceptable quality raisins may be obtained by microwave drying without chemical pretreatment.

The studies on the effects of chemical dipping pretreatments on $\mathrm{MW}$ drying rates revealed that an emulsion of $2 \%$ ethyl oleate in $0.5 \%$ sodium hydroxide was quicker and resulted in better quality raisins. It was also found that water rinsing and length of holding time after dipping had no effect on drying time.

4. The volume reduction in a grape due to shrinkage was found to be related linearly to its moisture content. This relationship was independent of the size of the grape and of the method of drying (convective or $\mathrm{MW}$ ).

5. The dielectric properties of grapes, dielectric constant and the loss factor, were found to be influenced by both m.c. and temperature. Regression equations describing these properties as functions of moisture content and temperature were developed from the data. 
6. A new $M W$ drying apparatus was developed. It permitted the application of MW power at controllable levels in either continuous or pulsed mode. A single mode applicator with a movable end-plate was developed for drying of grapes. An instrumentation and data acquisition system was developed for continuous data collection in a MW environment.

7. A mathematical model was developed to describe $\mathrm{NiW}$ drying of grapes based on Fick's diffusion equation. A moving co-ordinate system based on non-variate dry solids was adopted to handle the problem of shrinkage. The model also accounted for the changes in dielectric and physical properties of grapes due to changes in moisture content as drying progressed. The model was solved by the inite difference technique using the "method of lines". Simulated data agreed well with experimental data from the MW drying studies.

8. The effects of air temperature, MW power density and air velocity on drying kineties of grapes and quality of raisins were investigated.

9. Response surface methodology was used to investigate the possibility of optimizing the MW drying process with respect to desired quality of raisins.

10. The specific energy requirement of MW drying was very small compared to that of convective drying.

\subsection{Contribution to Knowledge}

This thesis has made an original contribution to knowledge by providing basic and applied information on various aspects of the drying of grapes using MW energy in combination with forced air convection. The knowledge gained is of practical value. The main contributions are: 
1. The study demonstrates that the use of sulphur dioxide in raisin production can be eliminated and that the use of chemical surfactants can be reduced. Thus the entry of certain chemicals in the food chain can be reduced.

2. The effects of different dipping treatments on MW drying of grapes have been determined.

3. The shrinkage kinetics of grapes are the same under convective and MW drying conditions.

4. The dielectric properties of grapes at different moisture contents and temperatures have been established. Regression equations to predict these properties as functions of moisture and temperature have been contributed.

5. A mathematical model for simulating the MW drying of grapes, was developed, numerically solved and validated against experimental data on grapes.

6. It has been determined that the specific energy consumption for MW drying of grapes is substantially lower than that required for convection drying.

\subsection{Recommendations for Further Studies}

Further studies could be performed using multimode cavity applicators which could offer advantages in simplifying scale-up.

The heat loss in the outlet air is substantial in MW drying. However, since the outlet air is drier and hotter under $\mathrm{MW}$ drying conditions than under convective drying conditions, there is, therefore a greater scope for heat recovery which would substantially reduce the energy requirements. The pulsed mode of power application could also be investigated since it may reduce energy losses.

The effect of vapour pressure on moisture transport was indirectly represented by an effective diffusivity parameter described as a function of air 
temperature and $M W$ power based on experimental data. Since the predictions by simulation were very close to the actual $M W$ drying data, it is clear that the effective diffusivity indirectly accounted for the vapour pressure effect. However, the method lacked completeness. The vapour pressure gradient due to internal heating could be further detailed in order to generalise the model.

A sensitivity analysis of the model should be executed to examine the accuracy of the model in relation to process variables. 


\section{REFERENCES}

Al-Duri, B. and McIntyre, S. 1992. Comparison of drying kinetics of foods using a fan-assisted convection oven, a microwave oven and a combined microwave/convection oven. J. Food Eng. 15(2), 139-155.

Bala, B.K. 1992. Shrinkage of malt bed during drying. Int. Agrophysics. 6 , 115-117.

Becker, H.A. and Sallans, H.R. 1955. A study of internal moisture movement in the drying of wheat kernel. Cereal Chem. 32(3), 212-226.

Bengtsson, N.E. and Risman, P.O. 1971. Dielectric properties of foods. J. Microwave Power. 6(2), 107-123.

Berna, A., Rossello, C., Canellas, J. and Mulet, A. 1991. Drying kinetics of majorcan seedless grape variety. In: Drying '91. (A.S. Mujumdar and I. Filkova, eds.), Elsevier Science Pub., Amsterdam, 455-461.

Bird, R.B., Stewart, W.E. and Lightfoot, E.N. 1960. Transport Phenomena. John Wiley and Sons, Inc., New York, U.S.A.

Boland, F.E. 1984. Fruits and Fruit Products. In: AOAC Official Methods of Analysis. (W. Horwitz, ed.), AOAC, Washington, 413-418.

Bolin, H.R., Petrucci, V. and Fuller, G. 1975. Characteristics of mechanically harvested raisins produced by dehydration and by field drying. J. Food Sci. 40, 1036-1038.

Box, G.E.P., Hunter, W.G. and Hunter, J.S. 1978. Statistics for Experimenters: An Introduction to Design, Data Analysis and Model Building. John Wiley and Sons, New York, U.S.A.

Brooker, D.B., Bakker-Arkema, F.W. and Hall, C.W. 1992. Drying and Storage of Grains and Oilseeds. Van Nostrand Reinhold, New York, U.S.A. 
Bruce, D.M. 1985. Exposed-layer barley drying. J. Agric. Eng. Res. 32(4), 337-347.

Buffler, C.R. 1993. Microwave Cooking and Processing. Van Nostrand Reinhold, New York, U.S.A.

Byler, R.K. 1983. Parameter estimation methodology in selected moisture desorption models. Ph.D. Thesis. Michigan State University, East Lansing, U.S.A.

Caldas, F.P. 1992. Experiment: ' high frequency dryer for granular materiais. Trans. ASAE. 35(4), 1275-1282.

Canellas, C., Rosello, S., Simal, S., Soler, L. and Mulet, A. 1993. Storage conditions affect quality of raisins. J. Food Sci. 58(4), 805-809.

Cenkowski, S., Jayas, D.S. and Hao, D. 1992. Latent heat of vapourization for selected foods and crops. Can. Agric. Eng. 34(3), 281-286.

CFTRI. 1988. Grapes in India: Production, Preservation, and Processing. Central Food Technological Research Institute, Karnataka, India.

Chambers, T.C. and Possingham, J.V. 1963. Studies of the fine structure of the waxy layer of sultana grapes. Aust. J. Biol. Sci. 16, 818-825.

Chen, P. and Schmidt, P.S. 1990. An integral model for drying of hygroscopic and nonhygroscopic materials with dielectric heating. Drying Tech. 8(5), 907-930.

Chittenden, D.H. and Hustrulid, A. 1966. Determining drying constants for shelled corn. Trans. ASAE. 9(1), 52-55.

Chu, S. 1966. A theoretical and experimental study of the effect of size and shape of kernels on the drying rate of shelled corn. Ph.D Thesis. University of Minnesota, St. Paul, U.S.A. 
Chu, S. and Hustrulid, A. 1968. Numerical solutions of diffusion equations. Trans. ASAE. 11(5), 705-708.

Crank, J. 1975. The Mathematics of Diffusion. Oxford University Press, Oxford, U.K

Crapiste, G., Whitaker, S. and Rotstein, E. 1988a. Drying of cellular material I. A mass transfer theory. Chim. Eng. Sci. 43(11), 2919-2928.

Crapiste, G., Whitaker, S. and Rotstein, E. 1988b. Drying of cellular materialII. Experimental and numerical results.Chem. Eng. Sci.43(11), 29292936.

Cruess, W.V. 1958. Commercial Fruit and Vegetable Products. McGraw-Hill Book Co., New York, U.S.A.

Decareau, R.V. and Peterson, R.A. 1986. Microwave Processing and Engineering. Ellis Horwood Pub., Chichester, U.K.

Diamante, L.M. and Munro, P.A. 1991. Mathematical modelling of hot air drying of sweet potato slices. Int. J. Food Sci. \& Tech. 26, 99-109.

Draper, N.R. and Smith, H. 1981. Applied Regression Analysis, 2nd Edn. John Wiley and Sons, New York, U.S.A.

Dudman, W.F. and Grncarevic, M. 1962. Determination of the waxy substances of grapes. J. Sci. Food Agric. 13(4), 221-224.

Eissen, W. 1984. [Grape drying with solar energy], Grundlagen der Landtechnik, 39(7/8), 362-366; as cited in Agric. Eng. Abs., 10(1), 32, Abs. no. 325.

Eissen, W., Muhlbauer, W., Kutzbach, H.D. and Krichner, E. 1985. [Lifluence of drying air temperature, air velocity and chemical pretreatment on the drying behaviour of grapes], Grundlagen der Landtechnil, 35(2), 33-39; as cited in Agric. Eng. Abs. 1985, 10(11), 488, Abs. no. 4958. 
Ezeike, G.O.I. and Otten, L. 1989. Two-component model for drying unshelled egusi (melon) seeds. ASAE Paper No. 89-6102, ASAE, St. Joseph, MI.

FAO, 1990. FAO Year Book of Production. FAO, Rome.

Francis, F.J. and Clydesdale, F.M. 1975. Food Colorimetry: Theory and Practices. AVI Pub., Connecticut., U.S.A.

Fuller, R.J., Schaeche, M.J., Morey, B.G., Hayes, R.J., Gould, I.V. and Goldsmith, C.A. 1990. Improving traditional grape drying technology using solar energy. Agric. Eng. Aust. 19(2), 14-17.

Geankoplis, C.J. 1993. Transport Processes and Unit Operations. Prentice Hall, New Jersey, U.S.A.

Gekas, V. 1992. Transport Phenomena of Foods and Biological Materials. CRC Press Inc., Florida, U.S.A.

Giovanni, M. 1983. Response surface methodology and product optimization. Food Tech. 37(11), 41-45.

Gunasekaran, S. 1990. Drying corn using continuous and pulsed microwave energy. Drying Tech. 8(5), 1039-1047.

Haghighi, K., Irudayaraj, J., Stroshine, R.L. and Sokhnasanj, S. 1990. Grain kernel drying simulation using the finite element method. Trans. ASAE. 33(6), 1957-1965.

Hansen, R.C., Keener, H.M. and ElSohly, H.N. 1993. Thin-layer drying of cultivated taxus clippings. Trans. ASAE. 36(6), 1873-1877.

Henika, R.J. 1982. Use of response-surface methodology in sensory evaluation. Food Tech. 36(11), 96-101. 
Hindmarsh, A.C. 1972. Linear multistep methcds for ordinary differential equations. Method formulations, stability, and the methods of Nordsieck and Gear. UCLR-51186. Rev.1. Lawrence Rivermore Laboratory, Liverniore, U.S.A.

Hindmarsh: A.C. 1974. Gear - Ordinary differential equations system solver. UCID-3001. Rev. 3. Lawrence Rivermore Laboratory, Livermore, U.S.A.

Hussain, A., Chen, C.S. and Clayton, J.T. 1973. Simultaneous heat and mass diffusion in biological materials. J. Agric. Eng. Res. 18(4), 343-354.

Jacob, H. E. 1944. Factors Influencing the Yield, Composition, and Quality of Raisins. Bulletin No. 683, Agricultural Experiment Station, Univ. of California, Berkeley, California, U.S.A.

Jaros, M., Cenkowski, S., Jayas, D.S. and Pabis, S. 1992. A method of determination of the diffusion coefficient based on kernel moisture content and its temperature. Drying Tech. 10(1), 213-222.

Jayas, D.S., Cenkowski, S., Pabis, S. and Muir, W.E. 1991. Review of thinlayer drying and wetting equations. Drying Tech. 9(3), 551-588.

Kalwar, M.I. 1991. Aerodynamics and drying characteristics of grains in twodimensional spouted beds. Ph.D Thesis. McGill University, Montreal, Canada.

Karthanos, V.T., Villalobos, G. and Saravacos, G.D. 1990. Comparison of two methods of effective moisture diffusivity from drying data. J. Food Sci. 55(1), 218-231.

Kudra, T., Raghavan, V., Akyel, C., Bosisio, R. and van de Voort, F. 1992. Electromagnetic properties of milk and its constituents at $2.45 \mathrm{GHz}$. J. Microwave Power and Electromagnetic Energy. 27(4), 199-204.

Larmaid, E. 1977. Laboratory Methods for Sensory Evaluation of Food. Publication No. 1637. Information Ilivision of Canada Department of Agriculture, Ottawa, KIA OC7. 
$\mathrm{Li}, \mathrm{H}$., Moorey, R.V. and Afinrud, M. 1987. Thin-layer drying rates of oilseed sunflower. Trans. ASAE. 30, 1172-1175.

Lozano, J.E., Rotstein, E. and Urbicain, M.J. 1983. Shrinkage, porosity and bulk density of food stuffs at changing moisture contents. J. Food Sci. 48(5), 1497-1502.

Lyons, D.W., Hatcher, J.D. and Sunderland, J.E. 1972. Drying of porous medium with internal heat generation. Int. J. Heat and Mass Transfer. $15,897-904$.

Maroulis, Z.B., Tsami, E. and Marinos-Kouris, D. 1988. Application of the GAB model to the moisture sorption isotherms for dried fruits. J. Food Eng. 7(1), 63-78.

Martin, R.J. and Stott, G.L. 1957. The physical factors involved in the drying of sultana grapes. Aust. J. Agric. Res. 8(5), 444-459.

Masi, P. and Riva, M. 1988. Modelling grape drying kinetics. In: Preconcentration and Drying of Food Materials. (S. Bruin, ed.), Elsevier Science Pub., Amsterdam, 203-214.

Metaxas, A.C. and Meredith, R.J. 1983. Industrial Microwave Heating. Peter Peregrinus Ltd., Herts, England.

Miller, W.M. and Fischer, D. 1959. The need for research in raisin dehydration and other crop protection methods. In: 20 Years of Raisin Research. California Raisin Advisory Board, Fresno, CA, U.S.A., 29-38.

Miller, M.W. 1963. Grapes to Raisins. In: 20 Years of Raisins Research. California Raisin Advisory Board, Fresno, CA, U.S.A., 19-24.

Mohsenin, N.N. 1986. Physical Properties of Plant and Animal Materials. Gordan and Breach Sci. Pub., New York. 
Mudgett, R.E. 1990. Developments in microwave food processing. In: Biotechnology and Food Process Engineering. (H.E. Schwartzherg and M.A. Rao, eds.), Basic Symp. Series, Marcel Dekker, Inc., New York, 359-403.

Nelson, S.O. 1978. Radio frequency and microwave dielectric properties of shelled field corn. J. Microwave Power. 13(2), 213-218.

Nelson, S.O. 1982. Dielectric properties of some fresh fruits and vegetables at frequencies of 2450 to $22 \mathrm{GHz}$. ASAE Paper No. 82-3053, ASAE, St. Joseph, MI.

Nelson, S.O. and Kraszewski, A.W. 1990. Dielectric properties of materials and measurement techniques. Drying Tech. 8(5), 1123-1142.

Ctten, L. and Brown, R.B. 1982. Low-temperature and combination corn drying in Ontario. Can. Agric. Eng. 24(1), 51-55.

Otten, L. and St. John, C. 1988. Thin-layer microwave drying of peanuts, CSAE Paper No. 88-502. CSAE, Saskatoon, SK

Otten, L., Brown, R.B. and Vogel, KF. 1989. Thin-layer drying of canola, ASAE Paper No. 89-6100, ASAE, St. Joseph, MI.

Pabis, S. and Henderson, S.M. 1962. Grain drying theory. II. A critical analysis of the drying curve for shelled maize. J. Agric. Eng. Res. 6(4), 272-277.

Pachner, J. 1984. Handbook of Numerical Analysis Applications. McGrawHill Book Co., New York.

Page, G.E. 1949. Factors influencing the maximum rates of air drying shelled corn in thin layers. M.Sc. Thesis. Purdue University, U.S.A.

Parti, M. 1990. A theoretical model for thin-layer grain drying. Drying Tech. 8(1), 101-122. 
Parti, M. and Dugmanics, I. 1990. Diffusion coefficient for corn drying. Trans. ASAE. 33(5), 1652-1656.

Patil, R.T., Sokhansanj, S., Arinze, E.A. and Schoenau, G.J. 1993. Methods of expediting drying rates of chopped Alfalfa. Trans. ASAE. 36(6), 17991803.

Perkin, R.M. 1979. Prospects of drying with RF and MW electromagnetic fields. J. Seprration Process Tech. 1(2), 14-23.

Perkin, R.M. 1990. Simplified modelling for the drying of a non-hygroscopic capillary porus body using combination of dielectric and convective heating. Drying Tech. 8(5), 931-951.

Perry, R.H. and Green, D. 1984. Perry's Chemical Engineers Handbook, 6th Edn., McGraw-Hill Company, New York, 20.13-20.14.

Ponting, J.D. and McBean, D.M. 1970. Temperature and dipping treatment effects on drying times of grapes, prunes and other waxy fruits. Food Tech. 24(12), 85-88.

Pozar, D. M. 1990. Microwave Engineering. Addison-Wesley Pub., Massachusetts, U.S.A.

Ptaszoik, W., Zygmunt, S. and Kudra, T. 1990. Simulation of RF- assisted convective drying for seed quality broad bean. Drying Tech. 8(5), 977992.

Raouzeos, G.S. and Saravacos, G.D. 1986. Solar drying of raisins. Drying Tech. 4(4), 633-649.

Ratti, C., Crapiste, G.H. and Rotstein, E. 1989a. A new water sorption equilibrium expression for solid foods based on thermodynamic considerations. J. Food Sci. 54(3), 738-742.

Ratti, C., Crapiste, G.H. and Rotstein, E. 1989b. PSYCHR:A computer program to calculate psychrometric properties. Drying Tech. 7(3), 575-580. 
Ratti, C. and Mujumdar, 1993. Fixed-bed batch drying of shrinking particles with time varying drying air conditions. Drying Tech. 11(6), 1311-1335.

Ratti, C. 1994. Shrinkage during drying of food stuffs. J. Food Eng. 23(1), 91-105.

Riva, M. and Peri, C. 1986. Kinetics of sun and air drying of different varieties of seed-less grapes. J. Food Tech. 21(2), 199-208.

Riva, M., Claudio, P. and Lovino, R. 1986. Effects of pretreatments on kinetics of grape drying. In: Food Engineering and Applications, Vol.I. (M. Le Maguer, ed.), Elsevier Applied Science, Amsterdam, 461-472.

Rzepecka, M. and Pereria, R.P. 1974. Permittivity of some dairy products at $2450 \mathrm{MH}$.z. J. Microwave Power and Electromagnetic Energy. 9(4), 277288.

Saravacos, G.D. and Raouzeos, G.S. 1986. Diffusivity of moisture in air-drying of raisins. In: Proceedings of the International Drying Symposium, IDS '86. (A.S. Mujumdar, ed.), Hemisphere Pub. Corp., New York, 487-491.

Saravacos, G.D. and Marousis, S.N. 1988. Effect of ethyl oleate on the rate of air arying of foods. J. Food Eng. 7(4), 263-270.

SAS. 1989. SAS Institute Inc., SAS/STAT User's Guide, Version 6, 4th Edn., Volume 2, Cary, NC.

Schiffmann, R.F. 1987. Microwave and dielectric drying. In: Handbook of Industrial Drying. (A.S. Mujumdar, ed.), Marcel Dekker, Inc., New York, 327-356.

Sharaf-Eldeen, Y.I., Hamdy, M.Y. and Blaisdell, J.L. 1979. Falling rate drying of fully exposed biological materials: A review of mathematical models. ASAE Paper No. 79-6522, ASAE, St. Joseph, MI. 
Shewfelt, R. 1993. Measuring quality and maturity. In: Post Harvest Handling: A Systems Approach. (R. Shewfelt and S.E. Prussia, eds.), Academic Press, Inc., New York, 109-123.

Shivhare, U.S. 1991. Drying characteristics of corn in a microwave field with a surface-wave applicator. Ph.D Thesis. McGill Univ., Montreal, Canada.

Shivhare, U.S., Alvo, P., Raghavan, G.S.V. and van de Voort, F.R. 1992. Application of response surface methods in grain drying research. In: Proceedings of the International Drying Symposium, IDS '92. (A.S. Mujumdar, ed.), Elsevier Applied Science Pub., Amsterdam, 1549-1559.

Shivhare, U.S., Raghavan, G.S.V. and Bosisio, R.G. 1994. Modelling the drying kinetics of maize in microwave environment. J. Agric. Eng. Res. 57(3), 199-205.

Sigmaplot, 1992. Sigmaplot Scientific Graph System: Transforms and Curve Fitting. Jandel Scientific, California, U.S.A.

Steel, R.G.D. and Torrie, J.H. 1980. Principles and Procedures of Statistics. McGraw-Hill Book Co., Inc., New York.

Steffe, J.F. and Singh, R.P. 1980. Liquid diffusivity of rough rice components. Trans. ASAE. 23(3), 767-774,782.

Steffe, J.F. and Singh, R.P. 1982. Diffusion coefficients for predicting rice drying behaviour. J. Agric. Eng. Res. 27(6), 489-493.

Struder, H.E. and Olmo, H.P. 1973. Vine-drying of Thompson seedless grapes. Trans. ASAE. 16, 944-948.

Strumillo, C. and Kudra, T. 1986. Drying: Principles, Applications and Design. Gordon and Breach Science Pub., New York.

Syarief, A.M. Gustafson, R.J. and Morey, R.V. 1987. Moisture diffusion coefficients for yellow-dent corn components. Trans. ASAE. 30(2),528. 
Treybal, R.E. 1980. Mass Transfer Operations. McGraw-Hill Book Company, New York, U.S.A.

Tang, J. and Sokhansanj, S. 1993. Moisture diffusivity in laird lentil seed components. Trans. ASAE. 36(6), 1791-1798.

Tulasidas, T.N., Kidra, T., Raghavan, G.S.V. and Mujumdar, A.S. 1993. Effect of bed height on simultaneous heat and mass transfer in a twodimensional spouted bed dryer. Int. Commun. Heat and Mass Transfer. 20, 79-88.

Turner, IW. and Jolly, P.G. 1991. Combined microwave and convective drying of a porous material. Drying Tech. 9(5), 1209-1269.

Van Arsdel, W.B., Copley, M.J. and Morgan, A.I. 1973. Food Dehydration, Vol. 2. AVI Pub. Co., Westport, Conn., U.S.A.

Eergnaud, J.M. 1992. Drying of Polymeric and Solid Materials - Modelling and Industrial Applications. Springer-Verlag Pub., New York, U.S.A.

Verma, L.R., Velupiliai. L., Wells, J.H. and Ransibrahmanakuln, V. 1991. Microwave-Vacuum processes in rice parboiling. ASAE Paper No. 913531. ASAE, St. Joseph, MI.

Von Hippel, A.R. 1954. Dielectric Materials and Applications. MIT Press, Massachusetts, U.S.A.

Weres, J. and Jayas, D.S. 1994. Thin-layer drying of corn: Experimental validation of a new numerical structural model. Can. Agric. Eng. 36(2), 85-91.

Whitaker, T.B. and Young, J.H. 1972. Simulation of moisture movement in peanut kernels: Evaluation of diffusion equation. Trans. ASAE. 16(1), 163-166.

Winkler, A.J., Cook, J.A., Kliewer, W.M., and Lider, L.A. 1974. General Viticulture. University of California Press, Berkeley, U.S.A. 


\section{APPENDICES}

Appendix A

Fig. A1 Calibration curve for absorbed $M W$ power on water load

164

Fig. A2 Calibration curve for relative humidity of air

Appendix $\mathbf{B}$

B1.

Derivation of the Mass Transfer Equation

165

B2. Program MW.FOR

171

B3. Program DIFFUN.FOR

Appendix $\mathbf{C}$

Table C1 Results of MW drying of grapes 176

Table C2 Score Sheet for Sensory Evaluation of Raisins 177

Table C3 Response surface analysis for quality - DAMT 178

Table C4 Response surface ans!ysis for quality - DAMT 179

Table C5 Response surface analysis for quality - ABYBT 180

Table C6 Response surface analysis for quality - ABYBT 181

Table C7 Response surface analysis for quality - DARK 182

Table C8 Response surface analysis for quality - DARK 183

Table C9 Response surface analysis for quality - CRSUGR 184

Table C10 Response surface analysis for quality - CRSUGR 185

Table C11 Response surface analysis for quality - STICKY 186

Table C12 Response surface analysis for quality - STICKX 187

Table C13 Response surface analysis for quality - NONUNI 188

Table C14 Response surface analysis for quality - NONUNI 189

Table C15 Response surface analysis for quality - TIME 190

Table C16 Response surface analysis for quality - TIME 191

Table C17 Multi-comparison Test for ABYB 192

Table C18 Multi-Comparison Test for DAMAGE 194

Table C19 Computer Program to draw contours against 196

$P$ and $T$ for quality attributes with imposed restrictions on Dmage and ABYB 


\section{APPENDIX A}

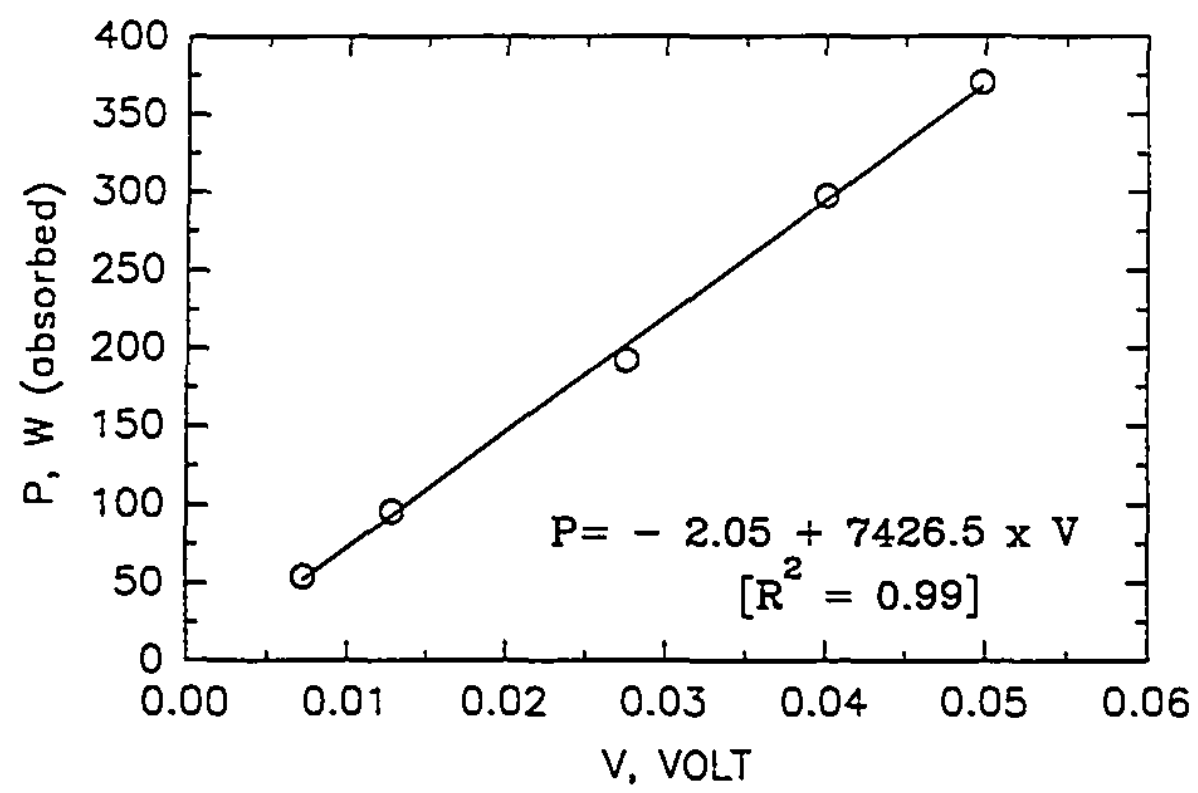

Fig. A1. Calibration curve for absorbed $\mathrm{MW}$ power on water load

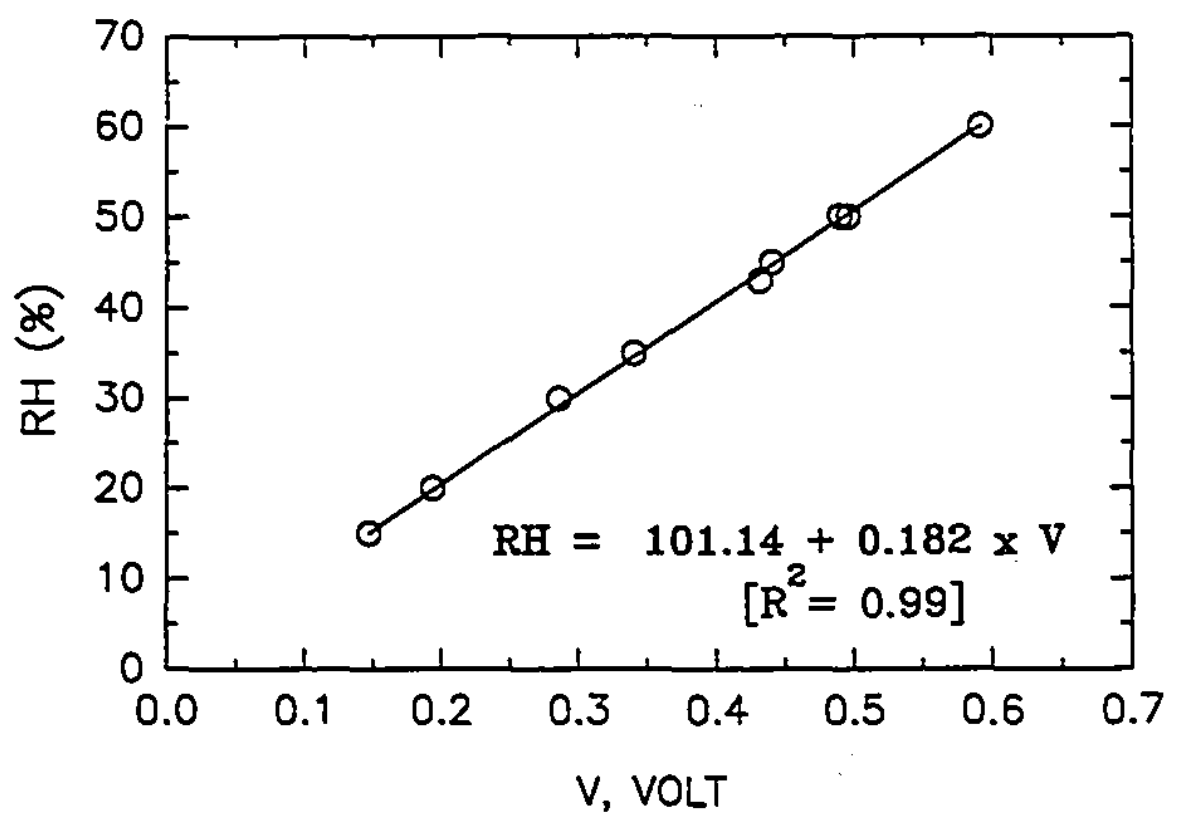

Fig. A.2. Calibration curve for relative humidity of air 


\section{APPENDLX B}

\section{B1. Derivation of the Mass Transfer Equation}

The selected control volume (cv) where the mass balances were written is shown in Fig. B1; r represents the radius in a fixed coordinate system. Note that in the case of drying with volume change there is a movement of solid due to shrinkage that enters and leaves the

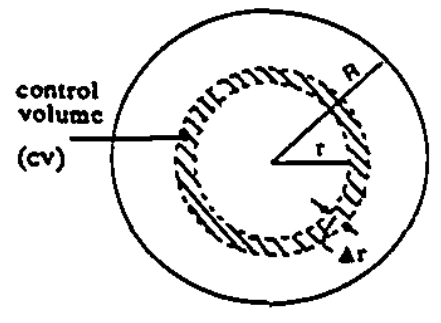

Fig. B1. The control volume. control volume in the opposite direction of the mass transier.

Mass balance equation without shrinkage \{[water migration into $\mathrm{cv}]_{\mathrm{r}}-[\text { wat,er migration out of } \mathrm{cv}]_{\mathrm{r}+\mathrm{dr}}+[$ [water generation]\}

$$
=[\text { water accumulation }]=\partial m_{w} / \partial t=\partial\left[v_{w} C\right] \partial t
$$

Then,

$$
\left[\eta_{w} A_{\tau}\right]_{r}-\left[\eta_{w} A_{\tau}\right]_{r+\Delta r}=\partial\left(C v_{c v}\right) / \partial t
$$

where, $A_{\tau}=4 \pi r^{2}$.

$\eta_{w}$ is the constitutive equation for mass transfer that can be expressed as (Crapiste et al., 1988a, 1988b):

$$
\eta_{w}=-\kappa \partial_{\mu} \partial r
$$

where $\mu$ is the chemical potential. In the case of single phase mass transfer, ie. for moisture inside the solid, $\mu=\mathrm{C}$ and $\mathrm{x}$ gives a measure of an effective coefficient of diffusion (D); then:

$$
\eta_{w}=-\mathrm{D}(\partial \mathrm{C} / \partial \mathrm{r})
$$

The control volume is being given by:

$$
v_{\mathrm{cv}}=4 / 3 \pi(r+\Delta r)^{3}-4 / 3 \pi r^{3}
$$


as $\Delta r$ tends to 0 , the control volume can be approximated by:

$$
v_{v}=4 \pi r^{2} \Delta r
$$

substituting Eqs. (2), (3) and (5) in Eq.(1) and on simplyfying yields:

$$
\partial C / \partial t=\left\{\left[(-D \partial C / \partial r) r^{2}\right]_{r}-\left[(-D \partial C / \partial r) r^{2}\right]_{r+\Delta r}\right] /\left(\Delta r r^{2}\right)
$$

as $\Delta r$ tends to zero,

$$
\partial C / \partial t=1 / r^{2} \partial / \partial r\left(D r^{2} \partial C / \partial r\right)
$$

The initial and boundary conditions are:

$$
\begin{array}{lll}
t=0 & C=C_{O} & \\
t>0 & 1 & \\
& I=R & (-D \partial C / \partial r)_{R}=k_{G} \Delta F \\
r=0 & \partial C / \partial r=0
\end{array}
$$

Mass balance equation with shrinkage

The water mass balance in the control volume is given by:

$$
\left(\eta_{w} A_{r}\right)_{r}-\left(\eta_{w} A_{r}\right)_{r+\Delta r}+\dot{m}_{w} l_{r+\Delta r}-\dot{m}_{w r} l_{r}=\partial\left(C v_{c v}\right) / \partial t
$$

In this case the constitutive mass transfer equation is:

$$
\eta_{w}=-D_{\text {orr }} \partial C / \partial r
$$

$D_{\text {eff }}$ is different from $D$ because it includes the effects of other varaibles. The value $\dot{m}_{w:}$ is the entrance of mass (water) into the control volume due to shrinkage:

$$
\dot{m}_{w e}=\mathrm{CA}_{\mathbf{r}}(\boldsymbol{q})
$$

where, $\gamma$ represents the velocity of shrinkage, the mass balance equation then becomes:

$$
\begin{aligned}
& \left\{\left[\left(-D_{\text {off }} \partial C / \partial r\right) 4 \pi r^{2}\right]_{r}-\left[\left(-D_{\text {off }} \partial C / \partial r\right) 4 \pi r^{2}\right]_{r+\Delta r}+\left[C 4 \pi r^{2} \beta\right]_{r+\Delta r}\right. \\
& -\left[C 4 \pi r^{2} \eta_{r}\right\}=\partial\left(C v_{c u}\right) / \partial t
\end{aligned}
$$

Defining $X$ as a local moisture content and,

$$
\begin{aligned}
& \mathrm{C}=\mathrm{X} \mathrm{C}_{\mathrm{v}} \\
& \mathrm{C} v_{\mathrm{cv}}=\mathrm{X} \mathrm{C}_{\mathrm{s}} 4 \pi \mathrm{r}^{2} \Delta \mathrm{r},
\end{aligned}
$$

Then,

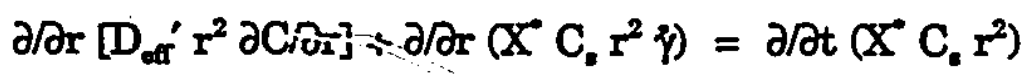


Applying the derivation rules:

$$
\begin{aligned}
& \left.\partial / \partial \mathrm{r}_{\mathrm{efr}} \mathrm{r}^{2} \partial \mathrm{C} / \partial \mathrm{r}\right]+\mathrm{X}^{*} \partial / \partial \mathrm{r}\left(\mathrm{C}, \mathrm{r}^{2} \eta\right)+\mathrm{C}, \mathrm{r}^{2} \gamma \partial \mathrm{X} / \partial \mathrm{r} \\
& =\mathrm{X} \partial / \partial \mathrm{t}\left(\mathrm{C}_{r^{2}}{ }^{2}\right)+\mathrm{C}_{\mathrm{a}} \mathrm{r}^{2} \partial \mathrm{X} / \partial \mathrm{t}
\end{aligned}
$$

On re-arranging the terms, the previous equation becomes:

$$
\begin{aligned}
& C_{2} r^{2}\left[\partial X^{*} \partial t-\gamma \partial X^{*} \partial r\right]+X\left[\partial \partial t\left(C_{2} r^{2}\right)-\partial / \partial r\left(C, r^{2} \xi\right)\right] \\
& =\partial / \partial r\left[\left(D_{o f f} r^{2} \partial C / \partial r\right]\right.
\end{aligned}
$$

Mass balance on the dry solids

$$
\partial \mathrm{m} / \partial \mathrm{t}=\stackrel{\mathfrak{m}_{1}}{\left.\right|_{r+\Delta r}}-\left.\dot{m}_{\mathbf{m}}\right|_{\mathrm{r}}
$$

where,

$$
\mathrm{m}_{2}=\mathrm{C}_{1} 4 \pi \mathrm{r}^{2} \Delta r \text {, and } \dot{m}_{1}=\mathrm{C}_{1} 4 \pi r^{2} \xi
$$

Then,

$$
\partial / \partial t\left(C_{1} r^{2}\right)=\partial / \partial r\left(C, r^{2} \phi\right)
$$

Substituting Eq.(9) in (8) finally results in:

$$
\frac{\partial x^{*}}{\partial t}-q \frac{\partial X^{*}}{\partial r}=\frac{1}{C_{s}} \frac{1}{r^{2}} \frac{\partial}{\partial r}\left[D_{\phi}^{\prime} r^{2} \frac{\partial C}{\partial r}\right]
$$

Eq. 10 is consistant with those presented in Crapiste et al. (1988a, 1988b). This equation represents the drying process of a shrinking particle in a fixed frame coordinate system. As can be seen, it is different from the equations normally used in the literature for describing drying because of the term $[-; \partial \mathrm{X} / \partial \mathrm{r}]$.

Boundary Equations:

$$
\begin{array}{lll}
t \geq 0 & r=0 & \partial X^{\circ} \partial r=0 \\
& r=R(t) & \eta_{w}=k_{c}\left(p_{w}-p_{w}\right) \\
& & -D_{\text {off }}^{\prime}(\partial C / \partial r)_{r w R}=k_{c}\left(p_{w}-p_{w w}\right)
\end{array}
$$

Initial Condition:

$$
t=0 \quad x=x_{0}
$$

Change of the coordinate system 
$R(t)$ is a function of time because of shrinkage. This makes it difficult for finding the solution of Eq. 10. A moving coordinate system that follows the movement of the particle due to shrinkage was selected to undertake this problem. The dry mass of the solid at time $t=0$ is taken as the reference frame. The amount of dry mass that is contained in the control volume at the initial time remains the same during the whole process of drying. Then the relationshp between the fixed and moving coordinates is obtained $\left(\Lambda^{*}\right.$ represent the moving coordinate whereas $r$ represent the fixed coordinate system):

$$
\begin{aligned}
& \mathrm{dm}_{\infty 0}=\mathrm{dm}, \\
& \mathrm{d}\left(\mathrm{C}_{\infty} v_{0}\right)=\mathrm{d}\left(\mathrm{C}_{0} v\right)
\end{aligned}
$$

where $C_{a}$ is the concentration of dry solids and $C_{\infty}$ is its initial value,

$$
\begin{aligned}
& \mathrm{d}\left(\mathrm{C}_{\infty 0} 4 / 3 \pi \Lambda^{* 3}\right)=\mathrm{d}\left(\mathrm{C}_{4} 4 / 3 \pi \mathrm{r}^{3}\right) \\
& \mathrm{d} \Lambda^{*}=\left(\mathrm{C}_{2} / \mathrm{C}_{\infty 0}\right)\left(\mathrm{r}^{2} / \Lambda^{* 2}\right) \mathrm{dr}
\end{aligned}
$$

In Eq. 15, $\mathrm{C} / \mathrm{C}_{w}=[(\mathrm{m} / v)]\left[1 /\left(\mathrm{m}_{\mathbf{}} / v_{0}\right)\right]=1 /\left(v / v_{0}\right)=1 / \mathrm{S}^{*}$

with $S^{*}=v / v_{0}$, local shrinkage coefficient, Eq. 15 becomes,

$$
d \Lambda^{*}=\left(1 / S^{*}\right)\left(r^{2} / \Lambda^{-2}\right) d r
$$

The so called "substantial time derivative" has been defined (Bird et. al., 1960, pp 73). It is the derivative following the motion. This derivative is expressed as:

$$
(\partial \mathrm{C} / \partial \mathrm{t})_{\Lambda^{*}}=\partial \mathrm{C} / \partial \mathrm{t}+\psi_{\mathrm{x}}(\partial \mathrm{C} / \partial \mathrm{x})
$$

in our case $f_{x}=-f$ (negative sign because the movement of shrinkage is in the opposite direction of the radius). Using the previous equation, Eq. 10 can then be rewritten as follows:

$$
(\partial X / \partial t)_{\Lambda^{*}}=\left(1 / C_{\downarrow}\right)\left(1 / r^{2}\right) \partial / \partial r\left[D_{\text {eff }} r^{2} \partial C / \partial r\right]
$$

Eq. 17 with the aid of Eq. 16 becomes:

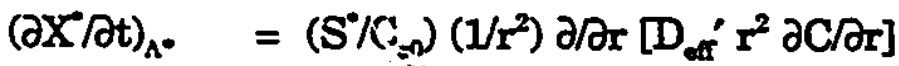

$$
\begin{aligned}
& =\left(1 / C_{\infty} \Lambda^{*}\right) \partial \partial \Lambda^{*}\left[D_{\text {eff }} r^{2} \partial C / \partial X^{*} \partial X / \partial r\right] \\
& =\left(\nu \mathrm{C}_{\infty} \Lambda^{*}\right) \partial / \partial \Lambda^{*}\left[\mathrm{D}_{\text {off }} \mathrm{r}^{2}(\partial \mathrm{C} / \partial \mathrm{X}) \partial \mathrm{X}^{*} / \partial \Lambda^{*} \mathrm{r}^{2} / \mathrm{S}^{*} \Lambda^{*}\right]
\end{aligned}
$$




$$
=\left(1 / C_{\infty 0} \Lambda^{* 2}\right) \partial \partial \Lambda^{*}\left[D_{\text {off }} r^{4} / \Lambda^{* 4}\left(\partial C / \partial X^{*}\right) 1 / S^{*} \Lambda^{* 2} \partial X^{*} \partial \Lambda^{*}\right]
$$

Defining,

$$
D_{\text {or }}=D_{\text {off }}\left(r / \Lambda^{*}\right)^{4}\left(1 / S^{*}\right)(\partial C / \partial X) / C_{\infty 0}
$$

Substituting the previous equation in Eq. 18:

$$
(\partial X / \partial t) \Lambda^{*}=1 / \Lambda^{-2} \partial / \partial \Lambda^{*}\left[D_{\text {ofr }} \Lambda^{-2} \partial X / \partial \Lambda^{*}\right]
$$

In Eq. $20 \mathrm{D}_{\mathrm{eff}}$ is a function of temperature, shrinkage, water content and geometry of the product.

By expressing $\Lambda^{*}$ in dimensionless form, dividing by the value of $\Lambda^{*}$ at $t=0$, the value can be obtained by integrating Eq. 16 to find:

$$
\begin{aligned}
& \Lambda^{*} I_{L=0}=R_{0} \quad \text { (initial radius), and } \\
& \Lambda=\Lambda^{*} / R_{0} \text {, and Eq. } 20 \text { becomes, } \\
& \qquad \frac{\partial X^{*}}{\partial t}=\left(\frac{1}{R_{0}^{2}}\right)\left(\frac{1}{\Lambda^{2}}\right) \frac{\partial}{\partial \Lambda}\left[D_{\odot \infty} \Lambda^{2} \frac{\partial X^{*}}{\partial \Lambda}\right]
\end{aligned}
$$

As can be seen Eq. 21 is similar to the equation established for drying of a sphere (Eq. 10) but with the difference of being written in moving coordinates. Eq. 21 is the defining equation with the following conditions:

Boundary conditios:

$$
\begin{array}{ll}
\Lambda=0 & \partial X^{*} / \partial \Lambda=0 \\
\Lambda=1 & \eta_{*}=-\left(C_{\sigma} / R_{0}\right) D_{\text {ext }} \partial X / \partial \Lambda=k_{G} \Delta p
\end{array}
$$

Initial condition:

$$
t=0 \quad X=X_{0}
$$

Total Water Content:

$$
\begin{aligned}
& m_{w_{w}}=\int_{0}^{m} d m_{w}, \text { where mass of water is } m_{w} \text { and is } \\
& m_{w}=v \rho=v \rho_{s} X=4 / 3 \pi r^{3} \rho_{s} X, \\
& d m_{w}=4 \pi r^{2} \rho_{s} X d r,
\end{aligned}
$$

and therefore total mass of water is given by, 


$$
m_{T w}=\int_{0}^{R}\left(4 \pi r^{2} \rho_{a} X^{*}\right) d r
$$

Total Mass of Dry Solid:

$$
\mathrm{m}_{\mathrm{Tz}}=\left(\rho_{\mathrm{s}}\right)_{\mathrm{O}} v_{0}=\left(\rho_{\mathrm{s}}\right)_{0} 4 / 3 \pi \mathrm{R}^{3}
$$

where $m_{T_{k}}$ is the total mass of dry solids and the moisture content is defined as,

$$
\begin{aligned}
& X=m_{N} / m_{T_{*}} \\
& X=3 \int_{0}^{R}\left[\rho_{0} r^{2} X d r\right] /\left[\left(\rho_{*}\right)_{0} R^{3}\right]
\end{aligned}
$$

This expression for $\mathrm{X}$ is consistant with that derived in Crapiste et al., 1988b for a sphere. 


\section{Appendix B}

B2. Program MW.FOR

PROGRAM MW

C

IMPLICIT REAL*8 (A-H,O-Z)

REAL*8 KG, L0, MSS, LA

DIMENSION YO(1000)

COMOMON NN, TG, RH, KG, X0, LO, MSS, V0, C1, C2, C3,

C

* $\quad$ P, A, B, XA, XM, LA, TSO, A1, B1, VEL

C

C

C

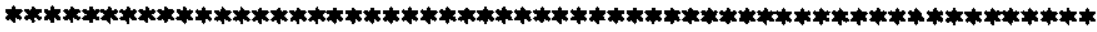

INPUT OF DATA

C

OPEN (UNIT = 3, FILE = 'DATA.DAT', STATUS = 'OLD', ACCESS

C

* = 'SEQUENTIAL', FORM = 'FORMATTED')

READ (3,*) TG,RH,P,TSO

$\operatorname{READ}(3, *) \mathrm{KG}, \mathrm{LO}$,VO

READ $(3, *)$ XO,MSS,XA,LA

$\operatorname{READ}(3, *)$ A,B

$\operatorname{READ}(3, *) \mathrm{Al}, \mathrm{B1}$

$\operatorname{READ}(3, *)$ VEL

$\operatorname{READ}(3, *) \mathrm{C} 1, \mathrm{C} 2, \mathrm{C} 3$

C

CLOSE (UNIT $=3$ )

C

C

$* * * * * * * * * * * * * * * * * * * * * * * * * * * * * * * * * * * * * * * * * * * * * * * * * * * * * * * * * * *$

C INPUT OF DATA FOR DRIVE SUBROUTINE

$\mathrm{C} \quad * * * * * * * * * * * * * * * * * * * * * * * * * * * * * * * * * * * * * * * * * * * * * * * * * * * * * * * * * * * * * *$

C

$\mathrm{NN}=10$

TOUT $=0.166667$

$\mathrm{N}=\mathrm{NN}+2$

$\mathrm{TO}=0$.

$\mathrm{H} 0=1 . \mathrm{D}-10$

C

DO $1 \mathrm{I}=1, \mathrm{NN}+1$

$\mathrm{YO}(\mathrm{I})=\mathrm{XO}$

1 CONTINUE

C

C

$\mathrm{YO}(\mathrm{NN}+2)=\mathrm{TSO}$

EPS $=0.00001$

$M=22$

INDEX $=1$ 


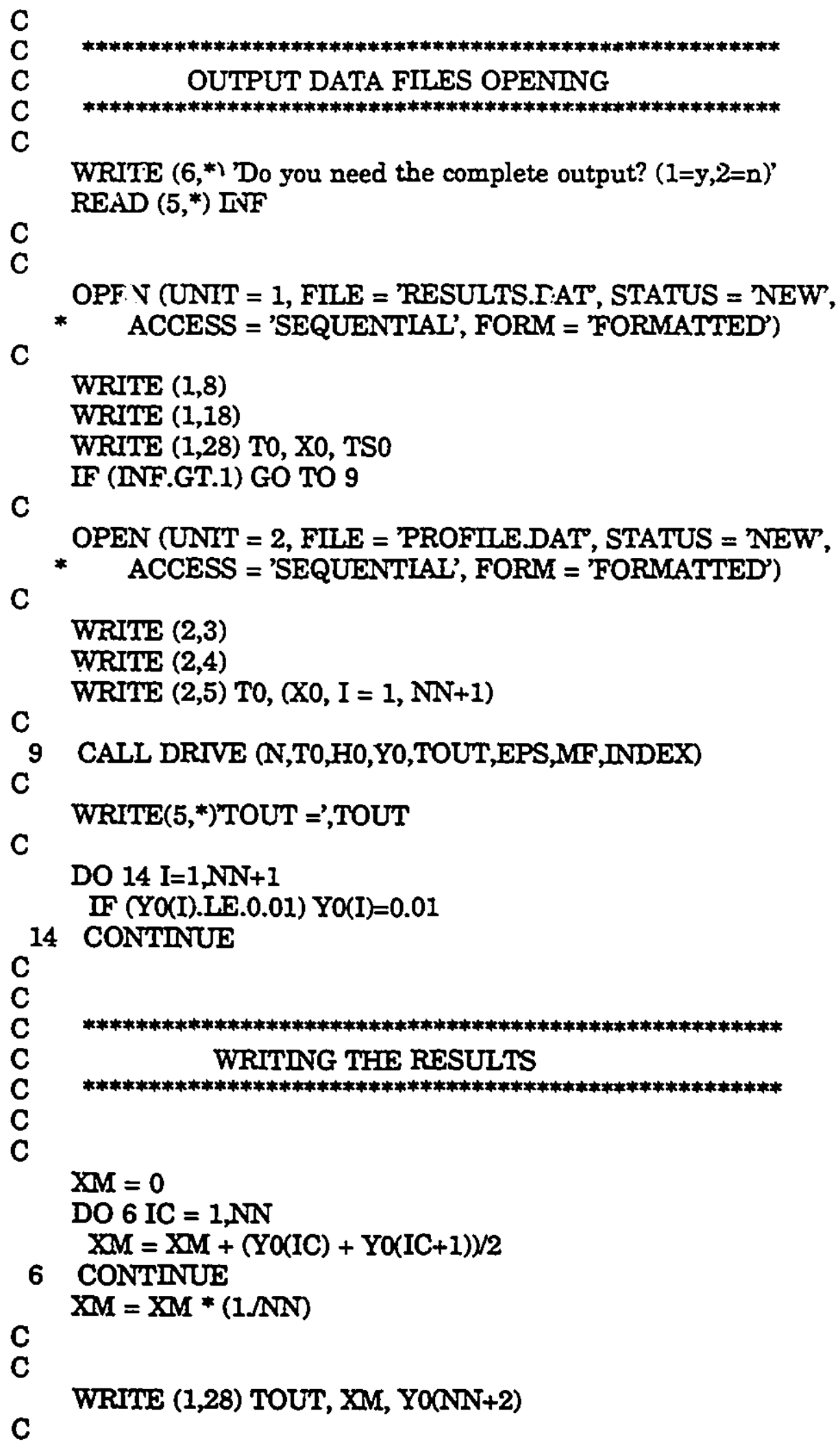




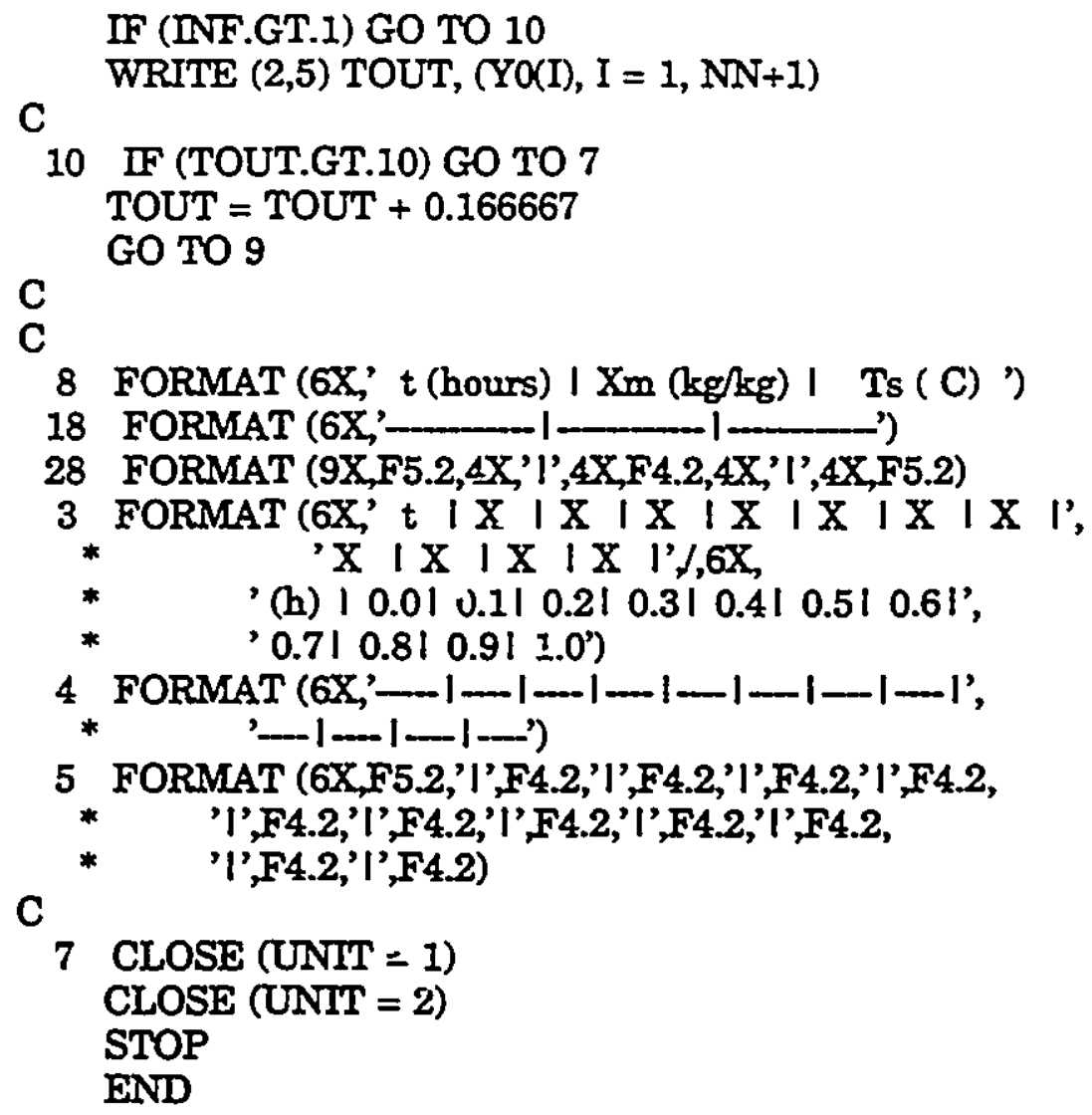

B3. Program DIFFUN.FOR

C

SUBROUTINE DIFFUN (N,T,Y,YDOT)

IMPLICIT REAL*8 (A-H,O-Z)

REAL*8 KG, L0, MSS, LA, M, LOSS, K, MUG

DIMENSION Y(1000),YDOT(1000)

COMMON NN, TG, RH, KG, X0, LO, MSS, V0, C1, C2, C3,

C

* P, A, B, XA, XM, LA, TSO, AI, BI, VEL

C

DO $3 \mathrm{I}=1, \mathrm{NN}+1$

IF (Y(I).LE.0.01) Y(I) $=0.01$

3 CONTINUE

C

$$
M=Y(N N+1)(1+Y(N N+1))
$$

C

C

$$
\mathbf{E}=\mathrm{A} 1+\mathrm{BI} * \mathbf{M}
$$




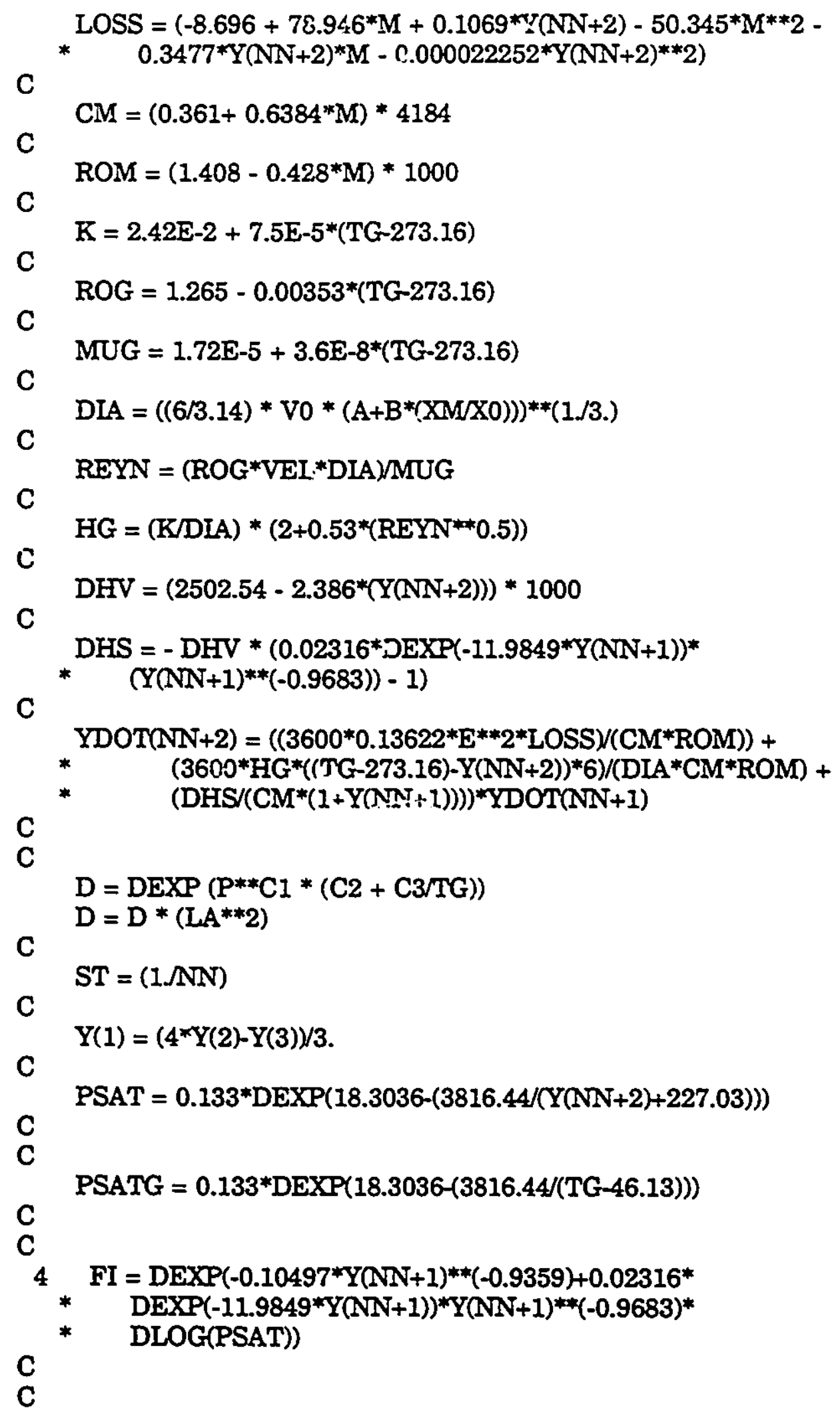




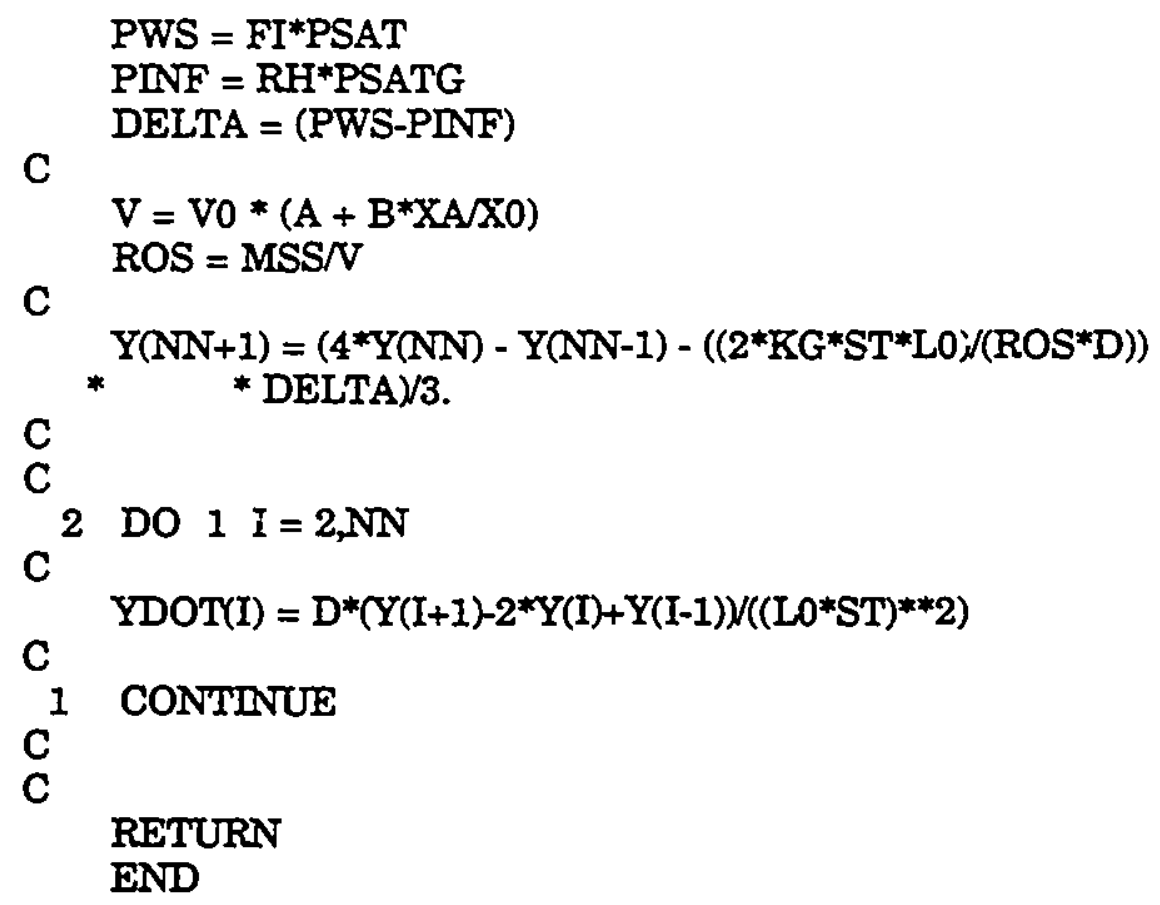


Table C1. Results of MW drying of grapes.

\begin{tabular}{|c|c|c|c|c|c|c|c|c|c|}
\hline $\begin{array}{l}\text { TRT } \\
\text { No. }\end{array}$ & $\begin{array}{l}\text { REP } \\
\text { No. }\end{array}$ & $\begin{array}{l}\lambda B Y B \\
(a / b)\end{array}$ & $\begin{array}{c}\text { DAMGE } \\
(*)\end{array}$ & $\begin{array}{c}\text { TIRE } \\
\text { b }\end{array}$ & $\begin{array}{l}\text { TRT } \\
\text { No. }\end{array}$ & $\begin{array}{l}\text { REP } \\
\text { No. }\end{array}$ & $\begin{array}{l}\text { ABYB } \\
(a / b)\end{array}$ & $\begin{array}{c}\text { DANACE } \\
\text { (*) }\end{array}$ & $\frac{1}{\text { TER }}$ \\
\hline 01 & 1 & 0.325 & 0.00 & 9.250 & 13 & 1 & 0.339 & 0.00 & 10.583 \\
\hline 01 & 2 & 0.323 & 5.00 & 9.917 & 13 & 2 & 0.370 & 0.00 & 11.167 \\
\hline 01 & 3 & c. 327 & 5.00 & 5.667 & 13 & 3 & 0.340 & 0.00 & 10.917 \\
\hline 02 & 1 & 0.351 & 5.00 & 4.917 & 14 & 1 & 0.320 & 1.00 & 8.583 \\
\hline 02 & 2 & 0.346 & 5.00 & 4.917 & 14 & 2 & 0.320 & 1.00 & 8.583 \\
\hline 02 & 3 & 0.330 & 10.00 & 5.250 & 14 & 3 & 0.322 & 1.00 & 8.667 \\
\hline 03 & 1 & 0.364 & 10.00 & 3.250 & 15 & 1 & 0.306 & 2.00 & 5.667 \\
\hline 03 & 2 & 0.363 & 5.00 & 3.333 & 15 & 2 & 0.309 & 1.00 & 5.250 \\
\hline 03 & 3 & 0.362 & 20.00 & 3.417 & 15 & 3 & 0.301 & 1.00 & 5.833 \\
\hline 04 & 1 & 0.370 & 25.00 & 3.167 & 26 & 1 & 0.349 & 0.00 & 3.667 \\
\hline 04 & 2 & 0.368 & 10.00 & 3.417 & 16 & 2 & 0.350 & 5.00 & 3.750 \\
\hline 04 & 3 & 0.368 & 15.00 & 3.417 & 16 & 3 & 0.349 & 5.00 & 4.167 \\
\hline OS & 1 & 0.330 & 5.00 & 3.667 & 17 & 1 & 0.321 & 0.00 & 7.667 \\
\hline 05 & 2 & 0.333 & 5.00 & 3.667 & 27 & 2 & 0.323 & 10.00 & 7.833 \\
\hline 05 & 3 & 0.332 & 10.00 & 3.833 & 17 & 3 & 0.320 & 5.00 & 7.583 \\
\hline 06 & 1 & 0.363 & 15.00 & 3.333 & 18 & 1 & 0.360 & 10.00 & 4.667 \\
\hline 06 & 2 & 0.365 & 25.00 & 3.417 & 18 & 2 & 0.365 & 10.00 & 4.833 \\
\hline 06 & 3 & 0.365 & 10.00 & 3.417 & 18 & 3 & 0.358 & 5.00 & 4.583 \\
\hline 07 & 1 & 0.390 & 15.00 & 2.500 & 19 & 1 & 0.381 & 15.00 & 3.750 \\
\hline 07 & 2 & 0.391 & 20.00 & 2.500 & 19 & 2 & 0.380 & 15.00 & 3.667 \\
\hline 07 & 3 & 0.389 & 20.00 & 2.500 & 19 & 3 & 0.379 & 7.00 & 3.917 \\
\hline 08 & 1 & 0.421 & 35.00 & 2.500 & 20 & 1 & 0.400 & 20.00 & 3.250 \\
\hline 08 & 2 & 0.424 & 30.00 & 2.500 & 20 & 2 & 0.396 & 15.00 & 3.167 \\
\hline 08 & 3 & 0.423 & 30.00 & 2.583 & 20 & 3 & 0.397 & 20.00 & 3.427 \\
\hline 09 & 1 & 0.353 & 20.00 & 3.500 & 21 & 1 & 0.339 & 15.00 & 5.750 \\
\hline 09 & 2 & 0.352 & 10.00 & 3.500 & 21 & 2 & 0.336 & 15.00 & 5.583 \\
\hline 09 & 3 & 0.351 & 15.00 & 3.583 & 21 & 3 & 0.337 & 10.00 & 5.833 \\
\hline 10 & 1 & 0.380 & 30.00 & 2.583 & 22 & 1 & 0.373 & 15.00 & 4.583 \\
\hline 10 & 2 & 0.379 & 25.00 & 2.583 & 22 & 2 & 0.371 & 20.00 & 4.667 \\
\hline 10 & 3 & 0.378 & 25.00 & 2.583 & 22 & 3 & 0.373 & 20.00 & 4.583 \\
\hline 11 & 1 & 0.424 & 35.00 & 1.833 & 23 & 1 & 0.412 & 25.00 & 3.500 \\
\hline 11 & 2 & 0.425 & 30.00 & 2.083 & 23 & 2 & 0.409 & 20.00 & 3.500 \\
\hline 11 & 3 & 0.422 & 31.00 & 2.000 & 23 & 3 & 0.411 & 20.00 & 3.667 \\
\hline 12 & 1 & 0.493 & 60.00 & 1.833 & 24 & 2 & 0.468 & 40.00 & 2.833 \\
\hline 12 & 2 & 0.492 & 50.00 & 1.833 & 24 & 2 & 0.462 & 30.00 & 2.750 \\
\hline 12 & 3 & 0.489 & 45.00 & 1.750 & 24 & 3 & 0.465 & 30.00 & 2.917 \\
\hline
\end{tabular}

NOTE: TRT $=$ Treatment Number and REP $=$ Replication Number 


\section{Table C2. Score Sheet for Sensory Evaluation of Raisins}

Name:

Date..............

Please evaluate these samples of raisins for Appearance. Indicate the amount of Appearance (darkness, crystallized sugars on the surface, stickiness and non-uniformity) in each sample on the scoring scale (0 - 5 points) as indicated (for eg. an extreemly non-uniform sample would get a highest score of 5 points):

\section{Sample No............}

(sample code..........)

\begin{tabular}{llll}
\hline Darkness & Crystallized Sugars & Stickiness & Non-Uniformity \\
\hline not dark (0) & no cr. sugar (0) & not sticky (0) & Uniform (0) \\
trace of dark(1) & tr. of cr. sugar (1) & tr. of sticky (1) & tr.of non-uniform (1) \\
slightly dark (2) & slight cr. sugar (2) & slight sticky (2) & slight non-uniform(2) \\
dark (3) & cr. sugars (3) & sticky (3) & non-uniform (3) \\
very dark (4) & very much cr. sugar (4) & very sticky (4) & very non-uniform (4) \\
extremely dark(5) & extr. high cr.sugars(5) & extr. sticky (5) & extr. non-uniform (5)
\end{tabular}


Table C3. Response ourface analysis for quality - DAMP

voDArT

$$
\text { Quality - DNMT - 01-12 Treatments at v0 = } 1 \mathrm{~m} / \mathrm{s}
$$

coding Coefflctents for the Independent Vartables

Pactor subtracted off Divided by

$\begin{array}{lrr}T & 15.000000 & 15.000000\end{array}$

Responee surface for Varlable DAMT

$\begin{array}{lr}\text { Regponse Koan } & 0.838611 \\ \text { Root MSE } & 0.107626 \\ \text { R-Square } & 0.9158 \\ \text { Coef. of Varlation } & 12.8339\end{array}$

\begin{tabular}{|c|c|c|c|c|c|}
\hline Regression & $\begin{array}{l}\text { Degrees } \\
\text { of } \\
\text { Preedom }\end{array}$ & $\begin{array}{l}\text { Type I sum } \\
\text { of Squares }\end{array}$ & R-Square & P-Ret10 & Prob $>F$ \\
\hline $\begin{array}{l}\text { Ilnear } \\
\text { Quadratlc } \\
\text { Croseproduct } \\
\text { Total Regress }\end{array}$ & $\begin{array}{l}2 \\
2 \\
1 \\
5\end{array}$ & $\begin{array}{r}43.034355 \\
0.008305 \\
1.581954 \\
44.624613\end{array}$ & $\begin{array}{l}0.8832 \\
0.0002 \\
0.0325 \\
0.9158\end{array}$ & $\begin{array}{r}1857.6 \\
0.358 \\
136.6 \\
770.5\end{array}$ & $\begin{array}{l}0.0000 \\
0.6990 \\
0.0000 \\
0.0000\end{array}$ \\
\hline \multicolumn{2}{|c|}{ Resldual } & $\begin{array}{l}\text { Degrees } \\
\text { of } \\
\text { Preedom }\end{array}$ & $\begin{array}{l}\text { Sum of } \\
\text { squares }\end{array}$ & Yean Squar & \\
\hline Total & Brrox & 354 & 4.100532 & 0.01158 & \\
\hline arameter & $\begin{array}{l}\text { Degrees } \\
\text { of } \\
\text { Preedom }\end{array}$ & $\begin{array}{l}\text { Parameter } \\
\text { Betimate }\end{array}$ & $\begin{array}{l}\text { Standard } \\
\text { Brror }\end{array}$ & $\begin{array}{c}\text { T for HO: } \\
\text { Parameter=0 }\end{array}$ & Prob $>|T|$ \\
\hline $\begin{array}{l}\mathrm{PNTERCEPT} \\
T \\
P \\
T \bullet T \\
P \bullet T \\
P \bullet P\end{array}$ & $\begin{array}{l}1 \\
1 \\
1 \\
1 \\
1 \\
1\end{array}$ & $\begin{array}{r}0.010461 \\
0.003481 \\
-0.463167 \\
0.000037778 \\
0.072617 \\
0.629167\end{array}$ & $\begin{array}{r}0.130761 \\
0.005279 \\
0.560966 \\
0.000056724 \\
0.006214 \\
1.203299\end{array}$ & $\begin{array}{r}0.0800 \\
0.659 \\
-0.826 \\
0.666 \\
11.686 \\
0.523\end{array}$ & $\begin{array}{l}0.9363 \\
0.5100 \\
0.4096 \\
0.5058 \\
0.0000 \\
0.6014\end{array}$ \\
\hline
\end{tabular}

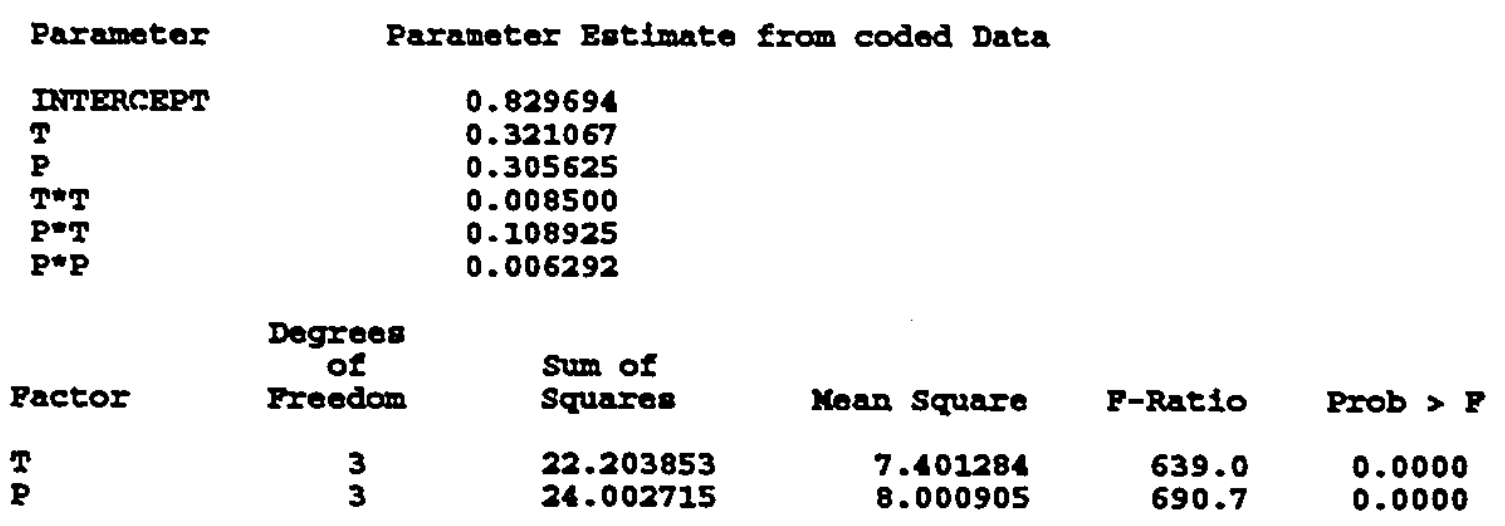


Table C4. Response surface analysis for quality - Dusm

Vidnuer

Guality - Dxir - 13 - 24 Treatmonte at $v_{1}=2 \mathrm{~m} / \mathrm{s}$

Coding Coefficlente for the Independent Vartables

$\begin{array}{lrr}\text { Factor } & \text { subtractod off } & \text { Divided by } \\ \text { T } & 45.000000 & 15.000000 \\ \text { P } & 0.200000 & 0.100000\end{array}$

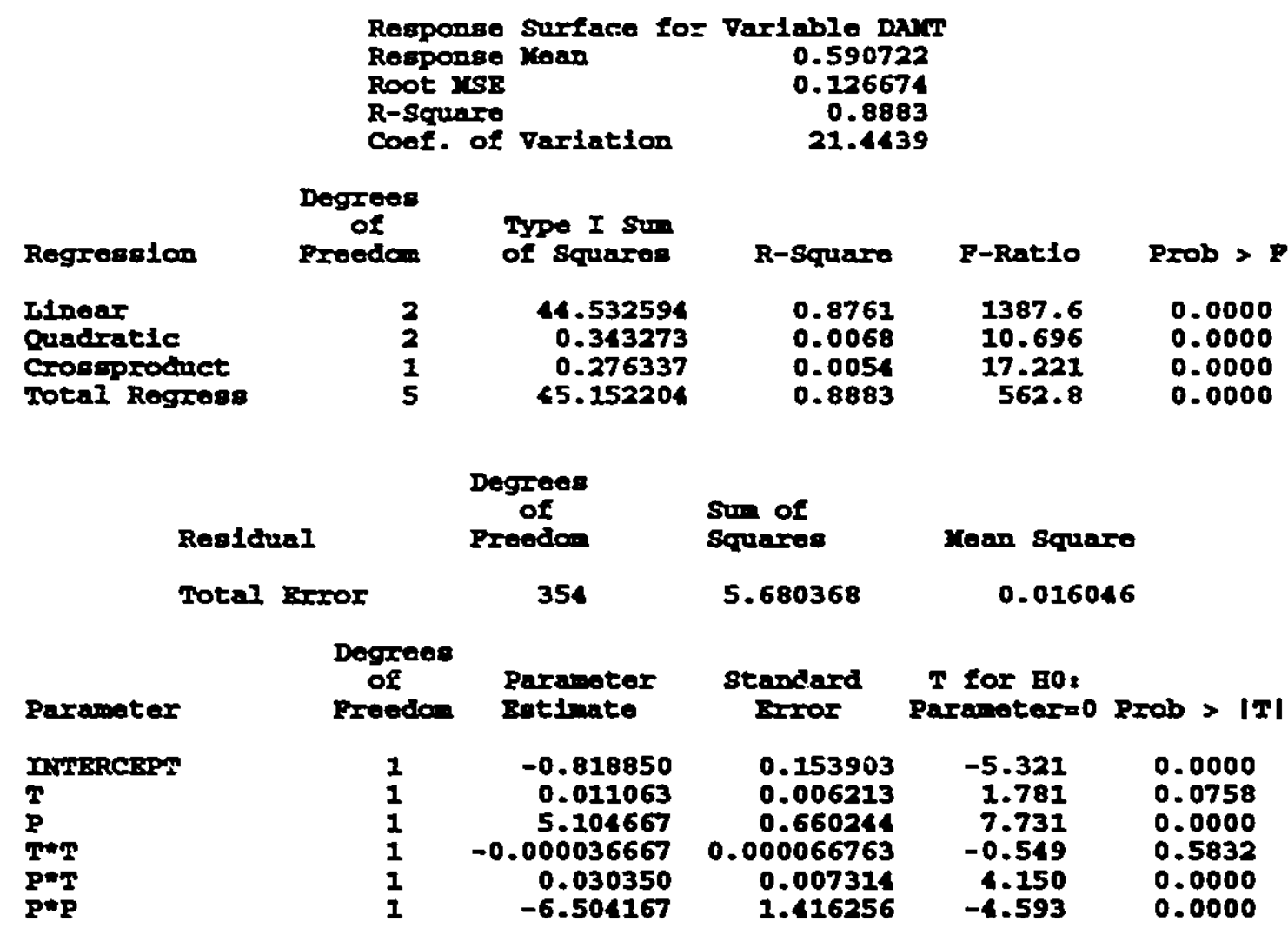

Paraneter

IFIERCKPY

$\mathbf{P}$

$T \oplus T$

$P \backsim T$

$P \backsim \boldsymbol{R}$

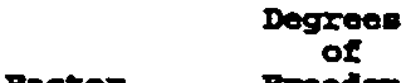

Factor

$\mathbf{T}$

Freedom
Paraneter kstinate from coded Deta

$$
\begin{array}{r}
0.638667 \\
0.207500 \\
0.386875 \\
-0.008250 \\
0.045525 \\
-0.065042
\end{array}
$$

$\begin{array}{lr}3 & 8.892427 \\ 3 & 36.536114\end{array}$

sin of squares 36.536114 yean square

2.964142 12.178705

$\begin{array}{rr}\text { P-Ratio } & \text { Prob }>\text { P } \\ 184.7 & 0.0000 \\ 759.0 & 0.0000\end{array}$


Table C5. Response surface analysis for quality - ABYBT

VOABYBT

Qual1ty - ABYBT - 01-12 Trostments at $\nabla 0=1 \mathrm{~m} / \mathrm{s}$

coding Coefficients for the Indopendent variables

Pactor subtractod off Dlvidod by

$\begin{array}{lrr}T & 45.000000 & 15.000000 \\ P & 0.200000 & 0.100000\end{array}$

Response Surface for Variablo ABYBT

Response Mean

Root XSB

R-Sorare

coes. of variation

Degrees

of

Regression

Preedon

rinear

Gadratic

Croserproduct

Total Regrese

\section{2}

\section{2}

1
Type I sum of squares

$$
\begin{aligned}
& 2.722951 \\
& 0.010582 \\
& 0.290163
\end{aligned}
$$

3.023697

$$
\begin{array}{r}
1.326306 \\
0.013088 \\
0.9803 \\
0.9868
\end{array}
$$

K-square P-Ratio Prob >

\subsection{8 \\ 0.0034 \\ 0.0941 \\ 0.9803}

7947.9

0.0000

30.889

\begin{tabular}{|c|c|c|c|c|c|}
\hline \multicolumn{2}{|c|}{ Rosidual } & $\begin{array}{l}\text { Degreas } \\
\text { of } \\
\text { Preedom }\end{array}$ & $\begin{array}{l}\text { Stm of } \\
\text { squares }\end{array}$ & \multicolumn{2}{|c|}{ Yos sonute } \\
\hline Total & Error & 354 & 0.060640 & $0.0001^{\circ}$ & 71 \\
\hline & $\begin{array}{l}\text { Degrees } \\
\text { of } \\
\text { Preedom }\end{array}$ & $\begin{array}{l}\text { Parameter } \\
\text { Batimate }\end{array}$ & $\begin{array}{c}\text { standard } \\
\text { Brror }\end{array}$ & $\begin{array}{l}\text { T for } \mathrm{E0z} \\
\text { Paramoter=0 }\end{array}$ & ProD $>|T|$ \\
\hline & $\begin{array}{l}1 \\
1 \\
1 \\
1 \\
1 \\
1\end{array}$ & $\begin{array}{r}1.303694 \\
-0.003886 \\
-1.040333 \\
0.000043611 \\
0.031100 \\
0.683333\end{array}$ & $\begin{array}{r}0.015901 \\
0.000642 \\
0.068217 \\
0.000006898 \\
0.000756 \\
0.146330\end{array}$ & $\begin{array}{r}81.986 \\
-6.054 \\
-15.250 \\
6.322 \\
41.157 \\
4.670\end{array}$ & $\begin{array}{l}0.0000 \\
0.0000 \\
0.0000 \\
0.0000 \\
0.0000 \\
0.0000\end{array}$ \\
\hline
\end{tabular}

0.0000

1693.9

3530.3

0.0000

0.0000

Parameter Betimate Irom coded Data
1.316299

\begin{tabular}{|c|c|c|c|c|c|}
\hline Pactor & $\begin{array}{l}\text { Degrees } \\
\text { of } \\
\text { Preedom }\end{array}$ & $\begin{array}{l}\text { sum of } \\
\text { squares }\end{array}$ & Maan scruare & P-Raclo & PIOb $>P$ \\
\hline $\mathbf{T}$ & $\begin{array}{l}3 \\
3\end{array}$ & $\begin{array}{l}2.059826 \\
1.254034\end{array}$ & $\begin{array}{l}0.686609 \\
0.418011\end{array}$ & $\begin{array}{l}1008.2 \\
2440.2\end{array}$ & $\begin{array}{l}0.0000 \\
0.0000\end{array}$ \\
\hline
\end{tabular}
0.093883
0.063250
0.009812
0.046650
0.006833 
rable C6. Response surface analyeis for quality - ABFBI

VIXBXBT

Qual1ty - ABYBT - 13 - 24 Traatients at $V 1=2 \mathrm{~m} / \mathrm{a}$

Coding Coeficients for the Independent Variables

Factor subtracted off Difided by

$\begin{array}{lrr}T & 45.000000 & 15.000000 \\ P & 0.200000 & 0.100000\end{array}$

Responee surface for Varlable ABYBY

$\begin{array}{lr}\text { Response Noas } & 1.294667 \\ \text { Root rSB } & 0.024738 \\ \text { R-Square } & 0.9215 \\ \text { Coef. of varlation } & 1.9108\end{array}$

\begin{tabular}{|c|c|c|c|c|c|}
\hline Regreseion & $\begin{array}{l}\text { Degrees: } \\
\text { of } \\
\text { Froedcas }\end{array}$ & $\begin{array}{l}\text { Type I SW } \\
\text { of squares }\end{array}$ & R-square & P-Ratio & Pxob > E \\
\hline $\begin{array}{l}\text { Inear } \\
\text { Guadratlc } \\
\text { Croesproduct } \\
\text { Total Regrese }\end{array}$ & $\begin{array}{l}2 \\
2 \\
1 \\
5\end{array}$ & $\begin{array}{l}1.997579 \\
0.053041 \\
0.601216 \\
2.651836\end{array}$ & $\begin{array}{l}0.6964 \\
0.0185 \\
0.2096 \\
0.9245\end{array}$ & $\begin{array}{r}1632.0 \\
43.335 \\
982.4 \\
866.6\end{array}$ & $\begin{array}{l}0.0000 \\
0.0000 \\
0.0000 \\
0.0000\end{array}$ \\
\hline \multicolumn{2}{|c|}{ Resldual } & $\begin{array}{l}\text { Degrees } \\
\text { of } \\
\text { Preedon }\end{array}$ & $\begin{array}{l}\text { Swe of } \\
\text { squares }\end{array}$ & \multirow{2}{*}{\multicolumn{2}{|c|}{$\begin{array}{r}\text { Mean Square } \\
0.000612\end{array}$}} \\
\hline Totel & Brror & 354 & 0.216644 & & \\
\hline Parameter & $\begin{array}{c}\text { Degrees } \\
\text { of } \\
\text { Preedom }\end{array}$ & $\begin{array}{l}\text { Parameter } \\
\text { Betinate }\end{array}$ & $\begin{array}{l}\text { standard } \\
\text { Frror }\end{array}$ & $\begin{array}{l}\text { T for } \mathrm{HO}_{3} \\
\text { paraberer=0 }\end{array}$ & Prob $>|T|$ \\
\hline 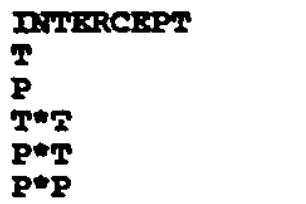 & $\begin{array}{l}1 \\
1 \\
1 \\
1 \\
1 \\
1\end{array}$ & $\begin{array}{r}1.580056 \\
-0.015328 \\
-1.218667 \\
0.000121 \\
0.044767 \\
-0.300000\end{array}$ & $\begin{array}{r}0.030056 \\
0.001213 \\
0.128941 \\
0.000013038 \\
0.001428 \\
0.276584\end{array}$ & $\begin{array}{r}52.570 \\
-12.633 \\
-9.451 \\
9.246 \\
31.343 \\
-1.085\end{array}$ & $\begin{array}{l}0.0000 \\
0.0000 \\
0.0000 \\
0.0000 \\
0.0000 \\
0.2788\end{array}$ \\
\hline
\end{tabular}

Parameter

IIMHARCEPY

$\mathbf{T}$

$\mathbf{P}$

$T+T$

P*T

$\mathbf{P} * \mathbf{P}$

Paraneter Bstinate from coded Data

$$
\begin{array}{r}
1.281597 \\
0.067133 \\
0.067583 \\
0.027125 \\
0.067150 \\
-0.003000
\end{array}
$$

\begin{tabular}{|c|c|c|c|c|c|}
\hline Factor & $\begin{array}{l}\text { Degreen } \\
\text { of } \\
\text { Freedon }\end{array}$ & $\begin{array}{l}\text { swi of } \\
\text { squares }\end{array}$ & Naan Square & P-Ratio & Prob > \\
\hline $\mathbf{T}$ & $\begin{array}{l}3 \\
3\end{array}$ & $\begin{array}{l}1.554914 \\
1.698138\end{array}$ & $\begin{array}{l}0.518305 \\
0.566046\end{array}$ & $\begin{array}{l}846.9 \\
924.9\end{array}$ & $\begin{array}{l}0.0000 \\
0.0000\end{array}$ \\
\hline
\end{tabular}


Table C7. Response surface analysis for quality - DARK

VODARK

Quality - DARK - 01-12 treatments at Vo = $1 \mathrm{~m} / \mathrm{s}$

coding coafictents for the Independent Varlables

Pactor subtractod off Dividod by

T $\quad 45.000000 \quad 15.000000$

P $\quad 0.200000 \quad 0.100000$

Responee Surface for Varlable DARK

Rasponse Mara

Root USB

2.200000

R-Square

0.656139

Coef. of Varlation

0.6595

29.8245

\begin{tabular}{|c|c|c|c|c|c|}
\hline Regression & $\begin{array}{c}\text { fees of } \\
\text { Preedom }\end{array}$ & $\begin{array}{l}\text { Type I sum } \\
\text { of scruarea }\end{array}$ & R-Square & P-Ratio & Exob $>E$ \\
\hline \multirow[t]{2}{*}{$\begin{array}{l}\text { Inear } \\
\text { Cuadratic } \\
\text { Croseproduct } \\
\text { Total Regress }\end{array}$} & $\begin{array}{l}2 \\
2 \\
1 \\
5\end{array}$ & $\begin{array}{r}273.566667 \\
1.350000 \\
20.280000 \\
295.196667\end{array}$ & $\begin{array}{l}0.6122 \\
0.0030 \\
0.0453 \\
0.6595\end{array}$ & $\begin{array}{r}317.7 \\
1.568 \\
47.106 \\
137.1\end{array}$ & $\begin{array}{l}0.0000 \\
0.2099 \\
0.0000 \\
0.0000\end{array}$ \\
\hline & Resldual & $\begin{array}{l}\text { Degrees } \\
\text { of } \\
\text { Proedor }\end{array}$ & $\begin{array}{l}\text { sur of } \\
\text { scuares }\end{array}$ & Mean Squ & are \\
\hline Total & Brror & 354 & 152.403333 & 0.430 & 518 \\
\hline Parameter & $\begin{array}{l}\text { Degreas } \\
\text { of } \\
\text { Preedon }\end{array}$ & $\begin{array}{l}\text { Parameter } \\
\text { Eatimate }\end{array}$ & $\underset{\text { Expor }}{\text { standard }}$ & $\begin{array}{r}\text { T for } \mathbf{1 0} \\
\text { parameter=0 }\end{array}$ & Prob $>|T|$ \\
\hline $\begin{array}{l}\text { INYBRCEPT } \\
T \\
\mathbf{P} \\
T \bullet T \\
P \bullet T \\
P \bullet P\end{array}$ & $\begin{array}{l}1 \\
1 \\
1 \\
1 \\
1 \\
1\end{array}$ & $\begin{array}{r}1.223333 \\
-0.040333 \\
-1.366667 \\
0.000500 \\
0.260000 \\
-7.500000\end{array}$ & $\begin{array}{l}0.797178 \\
0.032181 \\
3.419903 \\
0.000346 \\
0.037882 \\
7.335853\end{array}$ & $\begin{array}{r}1.535 \\
-1.253 \\
-0.400 \\
1.446 \\
6.863 \\
-1.022\end{array}$ & $\begin{array}{l}0.1258 \\
0.2109 \\
0.6897 \\
0.1491 \\
0.0000 \\
0.3073\end{array}$ \\
\hline
\end{tabular}

Parameter Paranoter Estlnate from coded Data

RIMERCEPT 2.187500

T 0.850000

P $\quad 0.733333$

$T=T \quad 0.112500$

P=T $\quad 0.390000$

$P * P \quad-0.075000$

\begin{tabular}{|c|c|c|c|c|c|}
\hline Factor & $\begin{array}{l}\text { Degrees } \\
\text { of } \\
\text { Freedca }\end{array}$ & $\begin{array}{l}\text { Sum of } \\
\text { squares }\end{array}$ & Maan square & P-Ratio & PIOb > P \\
\hline $\begin{array}{c}T \\
P\end{array}$ & $\begin{array}{l}3 \\
3\end{array}$ & $\begin{array}{l}165.680000 \\
149.796667\end{array}$ & $\begin{array}{l}55.226667 \\
49.932222\end{array}$ & $\begin{array}{l}128.3 \\
116.0\end{array}$ & $\begin{array}{l}0.0000 \\
0.0000\end{array}$ \\
\hline
\end{tabular}


Table C8. Response Burface analysis for quality - DARK

VIDARK

quality - DARK - 13- 24 Treatments at $\nabla 1=2 \mathrm{~m} / \mathrm{s}$

coding Coofficionts for the Independent Variables

Factor subtracted off Divided by

$\begin{array}{lrr}T & 45.000000 & 15.000000 \\ P & 0.200000 & 0.100000\end{array}$

Reeponeo Surface for Varlable DNRK

$\begin{array}{lr}\text { Reeponse rean } & 1.616667 \\ \text { Root xSE } & 0.736717 \\ \text { R-Square } & 0.5071 \\ \text { Coef. of Varlation } & 15.5701\end{array}$

Degrees

of Type I sum

Regression

Preedon

of squarea

R-square

P-Ratio

Pxob > P

Inear

Candratic

Croseproduct

$\begin{array}{rr}2 & 245.768333 \\ 2 & 46.225000 \\ 1 & 106.681667\end{array}$

Total Regreas

$5 \quad 398.675000$

0.3126
0.0588
0.1357

0.1357
0.5072

226.4
42.584
196.6

0.0000

146.9

0.0000

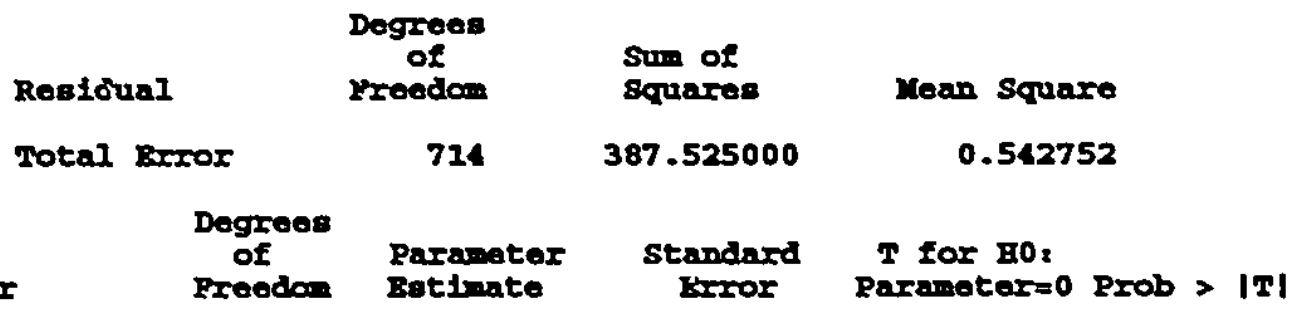

Parameter

DNHERCEPT

$\mathbf{T}$

$\mathbf{P}$

$T \star T$

$P * T$

$\mathbf{P} \bullet \mathbf{P}$

Parameter

TIMERCEPT

I

2

TT*T

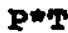

$P=\mathbf{R}$

\section{Degrees}

Pactor

Freedom

$\mathbf{T}$

$\begin{array}{lr}1 & 7.401667 \\ 1 & -0.281333 \\ 1 & -9.433333 \\ 1 & 0.002500 \\ 1 & 0.421667 \\ 1 & -8.750000\end{array}$

0.632915

0.025550

2.715213

0.000275

0.030076

5.824260
11.695
$-11.011$
$-3.474$
9.106
14.020
$-1.502$

0.0000

0.0000

0.0005

0.0000

0.0000

0.1335

Parameter Batiante fron coded Data

$$
\begin{array}{r}
1.362500 \\
0.420000 \\
0.604167 \\
0.562500 \\
0.632500 \\
-0.087500
\end{array}
$$

\section{sum of}

squares

222.241667

283.115000
Iowe square

74.080556

94.371667

$\begin{array}{rr}\text { P-Ratio } & \text { Prob > } \\ 136.5 & 0.0000 \\ 173.9 & 0.0000\end{array}$


Table C9. Response ourface analysis for quality - CRSUGR Qual1ty - CRSUMR - 01-12 treatments at Vo = $1 \mathrm{~m} / \mathrm{s}$

VOCRSUER Coding Coefficients for the Independent Varlablea Pactor subtracted off Divided by

$\begin{array}{lrr}T & 45.000000 & 15.000000 \\ P & 0.200000 & 0.200000\end{array}$

Response surface for Varlable CRSUCR

$\begin{array}{lr}\text { Regponse Koan } & 1.472222 \\ \text { Root ISSE } & 0.533789 \\ \text { R-square } & 0.8307 \\ \text { Coef. of varlation } & 36.2574\end{array}$

\begin{tabular}{|c|c|c|c|c|c|}
\hline Regression & $\begin{array}{l}\text { Degrees } \\
\text { of } \\
\text { Preedom }\end{array}$ & $\begin{array}{l}\text { Type I Sim } \\
\text { of Squares }\end{array}$ & R-Square & P-Rat1o & Prob > P \\
\hline \multirow[t]{2}{*}{$\begin{array}{l}\text { Ilnear } \\
\text { Quadratlc } \\
\text { Croseproduct } \\
\text { Total Rogress }\end{array}$} & $\begin{array}{l}2 \\
2 \\
1 \\
5\end{array}$ & $\begin{array}{r}132.170000 \\
7.216667 \\
55.470000 \\
494.856667\end{array}$ & $\begin{array}{l}0.7255 \\
0.0121 \\
0.0931 \\
0.8307\end{array}$ & $\begin{array}{r}758.4 \\
12.664 \\
194.7 \\
347.4\end{array}$ & $\begin{array}{l}0.0000 \\
0.0000 \\
0.0000 \\
0.0000\end{array}$ \\
\hline & \multicolumn{2}{|l|}{ Degrees } & & & \\
\hline \multicolumn{2}{|c|}{ Residual } & $\begin{array}{l}\text { of } \\
\text { Preedom }\end{array}$ & $\begin{array}{l}\text { sum of } \\
\text { squares }\end{array}$ & Hean Square & re \\
\hline Total & Brror & 354 & 100.865556 & 0.28495 & 31. \\
\hline Parameter & $\begin{array}{l}\text { Degrees } \\
\text { of } \\
\text { Preedon }\end{array}$ & $\begin{array}{l}\text { Paramater } \\
\text { Betimate }\end{array}$ & $\underset{\text { strandard }}{\text { Bryor }}$ & $\begin{array}{l}\text { T for HOs } \\
\text { paraweter=0 }\end{array}$ & Prob > $|T|$ \\
\hline $\begin{array}{l}\text { INTERCEPT } \\
T \\
P \\
T=T \\
P * T \\
P \bullet P\end{array}$ & $\begin{array}{l}1 \\
1 \\
1 \\
1 \\
1 \\
1\end{array}$ & $\begin{array}{r}-0.148889 \\
0.046333 \\
-19.933333 \\
-0.000722 \\
0.430000 \\
25.833333\end{array}$ & $\begin{array}{l}0.618529 \\
0.026180 \\
2.782198 \\
0.000281 \\
0.030818 \\
5.967945\end{array}$ & $\begin{array}{r}-0.230 \\
1.770 \\
-7.165 \\
-2.567 \\
13.953 \\
1.329\end{array}$ & $\begin{array}{l}0.8186 \\
0.0776 \\
0.0000 \\
0.0107 \\
0.0000 \\
0.0000\end{array}$ \\
\hline
\end{tabular}

\begin{tabular}{|c|c|}
\hline Parameter & Parameter Bst \\
\hline 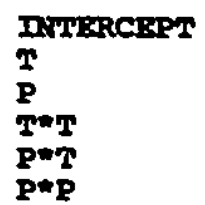 & $\begin{array}{r}1.390278 \\
1.010000 \\
0.975000 \\
-0.162500 \\
0.645000 \\
0.258333\end{array}$ \\
\hline
\end{tabular}

\begin{tabular}{|c|c|c|c|c|c|}
\hline Pactor & $\begin{array}{c}\text { Degrees } \\
\text { of } \\
\text { Preedom }\end{array}$ & $\begin{array}{l}\text { Sur of } \\
\text { Squares }\end{array}$ & Woan square & P-Retio & Prob > $\mathbf{P}$ \\
\hline $\begin{array}{l}\mathbf{x} \\
\mathbf{p}\end{array}$ & $\begin{array}{l}3 \\
3\end{array}$ & $\begin{array}{l}261.367778 \\
288.958889\end{array}$ & $\begin{array}{l}87.122593 \\
96.319630\end{array}$ & $\begin{array}{l}305.8 \\
338.0\end{array}$ & $\begin{array}{l}0.0000 \\
0.0000\end{array}$ \\
\hline
\end{tabular}


Table C10. Response surface analysis for quality - CRSUGR

VICRSUCR Cuality - CRSUGR - 13- Treatwents at $\nabla_{1}=2 \mathrm{~m} / \mathrm{s}$

coding Coefficients for the Independent Variablas

Factor subtractod off Dividod by

$\begin{array}{lrr}T & 45.000000 & 15.000000 \\ P & 0.200000 & 0.100000\end{array}$

Response surface for variable CRSUER

$\begin{array}{lr}\text { Reoposee Woan } & 0.766667 \\ \text { Root uSE } & 0.54949 \\ \text { R-Sguare } & 0.6852 \\ \text { Coef. of varlation } & 71.6738\end{array}$

\begin{tabular}{|c|c|c|c|c|c|}
\hline Regresalon & $\begin{array}{c}\text { Degrees } \\
\text { of } \\
\text { Proodon }\end{array}$ & $\begin{array}{l}\text { Type I Sum } \\
\text { of Squares }\end{array}$ & R-Square & F-Ratio & PIOb > F \\
\hline $\begin{array}{l}\text { Llnear } \\
\text { Cuadratlc } \\
\text { Crospproduct } \\
\text { Total Regress }\end{array}$ & $\begin{array}{l}2 \\
2 \\
1 \\
5\end{array}$ & $\begin{array}{r}373.226111 \\
8.580556 \\
87.401667 \\
469.208333\end{array}$ & $\begin{array}{l}0.5450 \\
0.0125 \\
0.1276 \\
0.6852\end{array}$ & $\begin{array}{r}618.0 \\
14.209 \\
289.5 \\
310.8\end{array}$ & $\begin{array}{l}0.0000 \\
0.0000 \\
0.0000 \\
0.0000\end{array}$ \\
\hline Residus & & $\begin{array}{l}\text { Dogrees } \\
\text { of } \\
\text { Proedon }\end{array}$ & $\begin{array}{l}\text { swe of } \\
\text { squares }\end{array}$ & Moan Squar & \\
\hline Total $\mathrm{I}$ & Error & 714 & 215.591667 & 0.30194 & \\
\hline arameter & $\begin{array}{l}\text { Degrene } \\
\text { Of } \\
\text { Preedom }\end{array}$ & $\begin{array}{l}\text { Parameter } \\
\text { Bstinate }\end{array}$ & $\begin{array}{l}\text { standard } \\
\text { Error }\end{array}$ & $\begin{array}{c}\text { T for } \mathrm{H0z} \\
\text { Parameter=0 }\end{array}$ & Prob > $|T|$ \\
\hline $\begin{array}{l}\text { DNYYERCEPT } \\
T \\
P \\
T=T \\
P * T \\
P \bullet P\end{array}$ & $\begin{array}{l}1 \\
1 \\
1 \\
1 \\
1 \\
1\end{array}$ & $\begin{array}{r}3.049141 \\
-0.106778 \\
-16.716667 \\
0.000778 \\
0.381667 \\
16.250000\end{array}$ & $\begin{array}{l}0.472075 \\
0.019057 \\
2.025210 \\
0.000205 \\
0.022433 \\
4.34171\end{array}$ & $\begin{array}{r}6.460 \\
-5.603 \\
-8.254 \\
3.798 \\
17.013 \\
3.741\end{array}$ & $\begin{array}{l}0.0000 \\
0.0000 \\
0.0000 \\
0.0002 \\
0.0000 \\
0.0002\end{array}$ \\
\hline
\end{tabular}

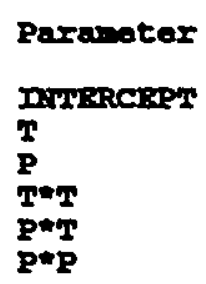

Parametor Betimato fron coded Data

0.561111

0.593333

0.695833

0.175000

0.572500

0.162500

\begin{tabular}{|c|c|c|c|c|c|}
\hline Pactor & $\begin{array}{l}\text { Dogrees } \\
\text { of } \\
\text { preodem }\end{array}$ & $\begin{array}{l}\text { Sum of } \\
\text { Squares }\end{array}$ & Moan squaro & P-Ratio & Rzob $>P$ \\
\hline $\begin{array}{l}\mathbf{T} \\
\mathbf{P}\end{array}$ & $\begin{array}{l}3 \\
3\end{array}$ & $\begin{array}{l}232.575000 \\
324.035000\end{array}$ & $\begin{array}{r}77.525000 \\
108.011667\end{array}$ & $\begin{array}{l}256.7 \\
357.7\end{array}$ & $\begin{array}{l}0.0000 \\
0.0000\end{array}$ \\
\hline
\end{tabular}


Table C11. Responge surface analysis for cuality - STICKY

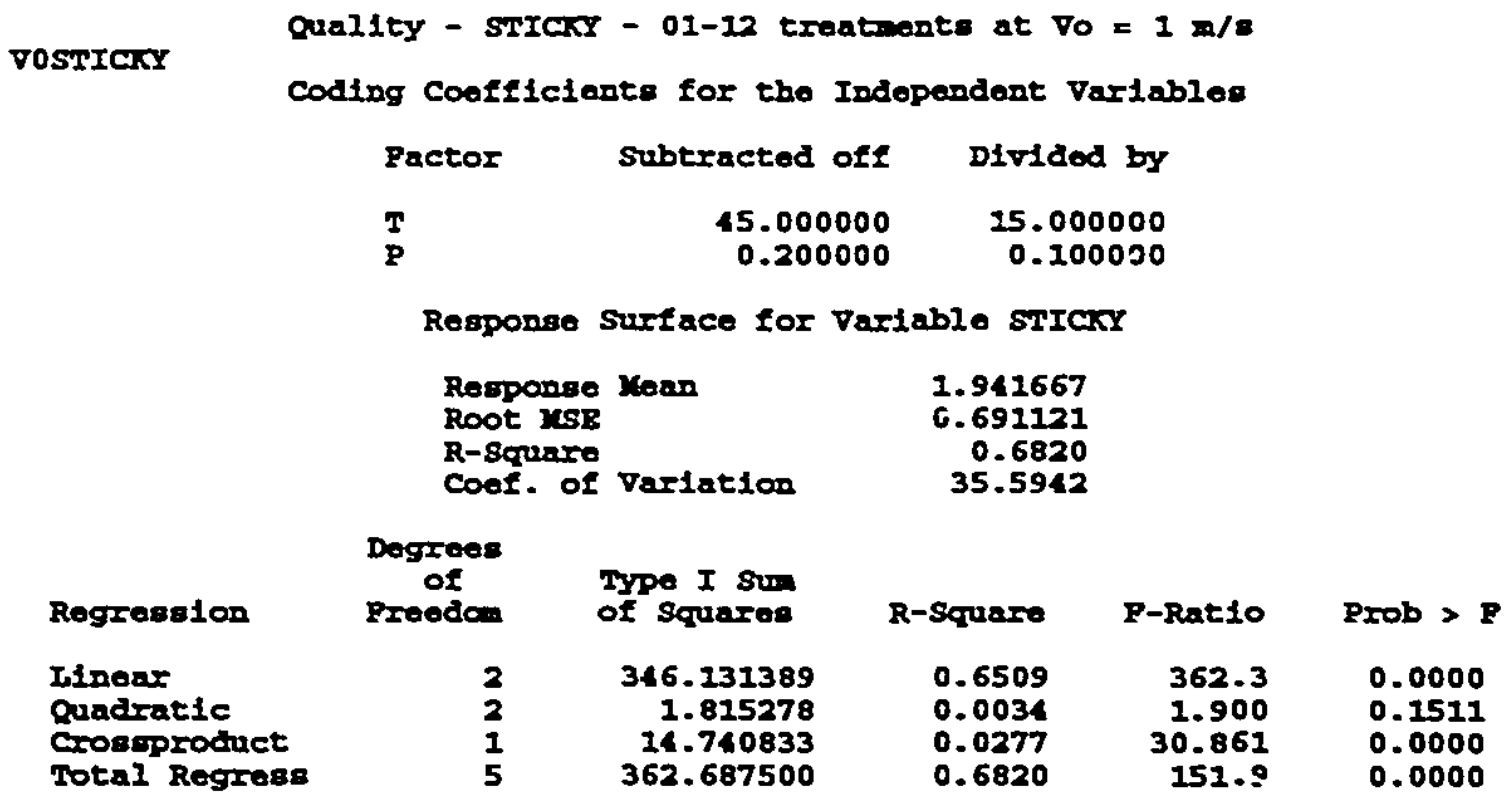

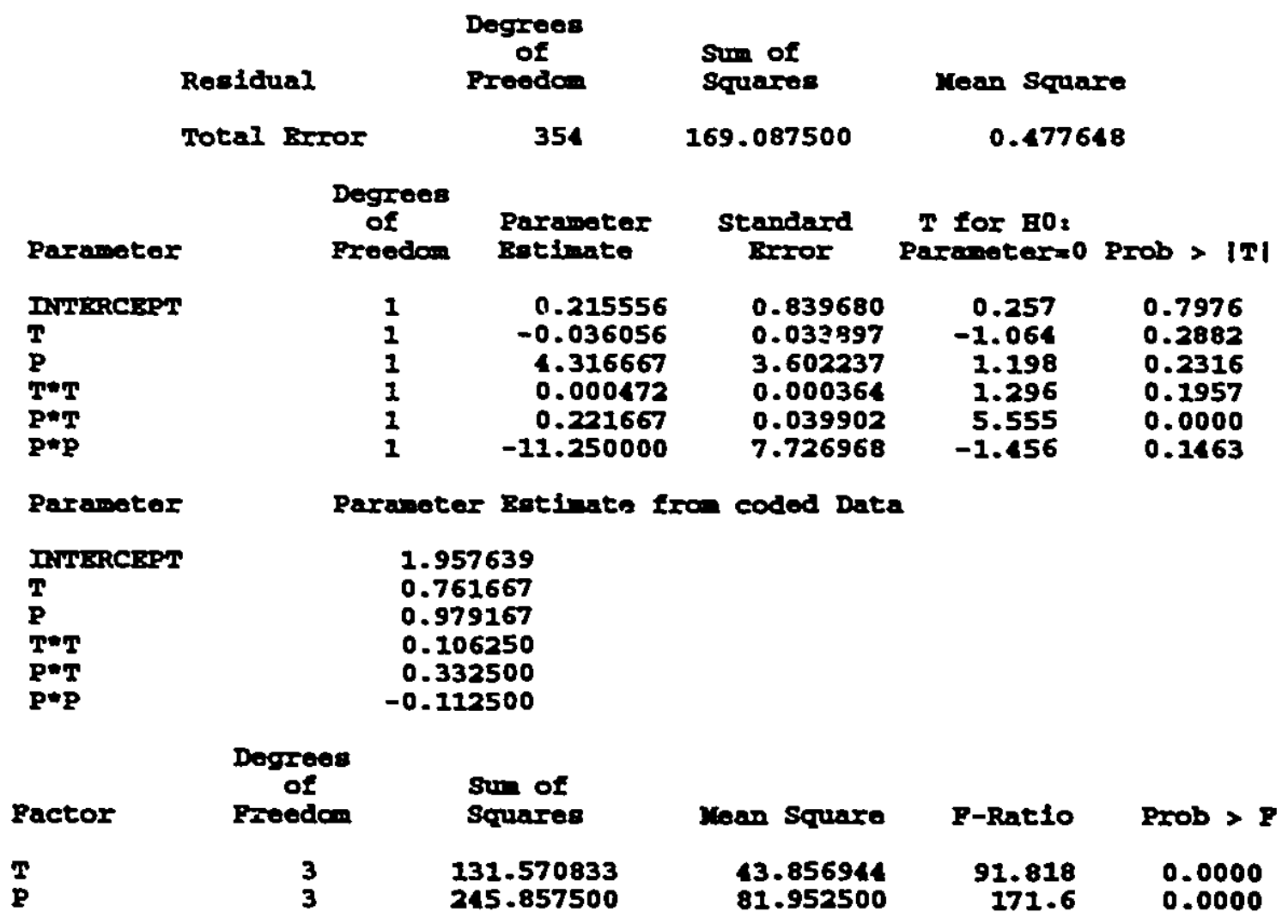




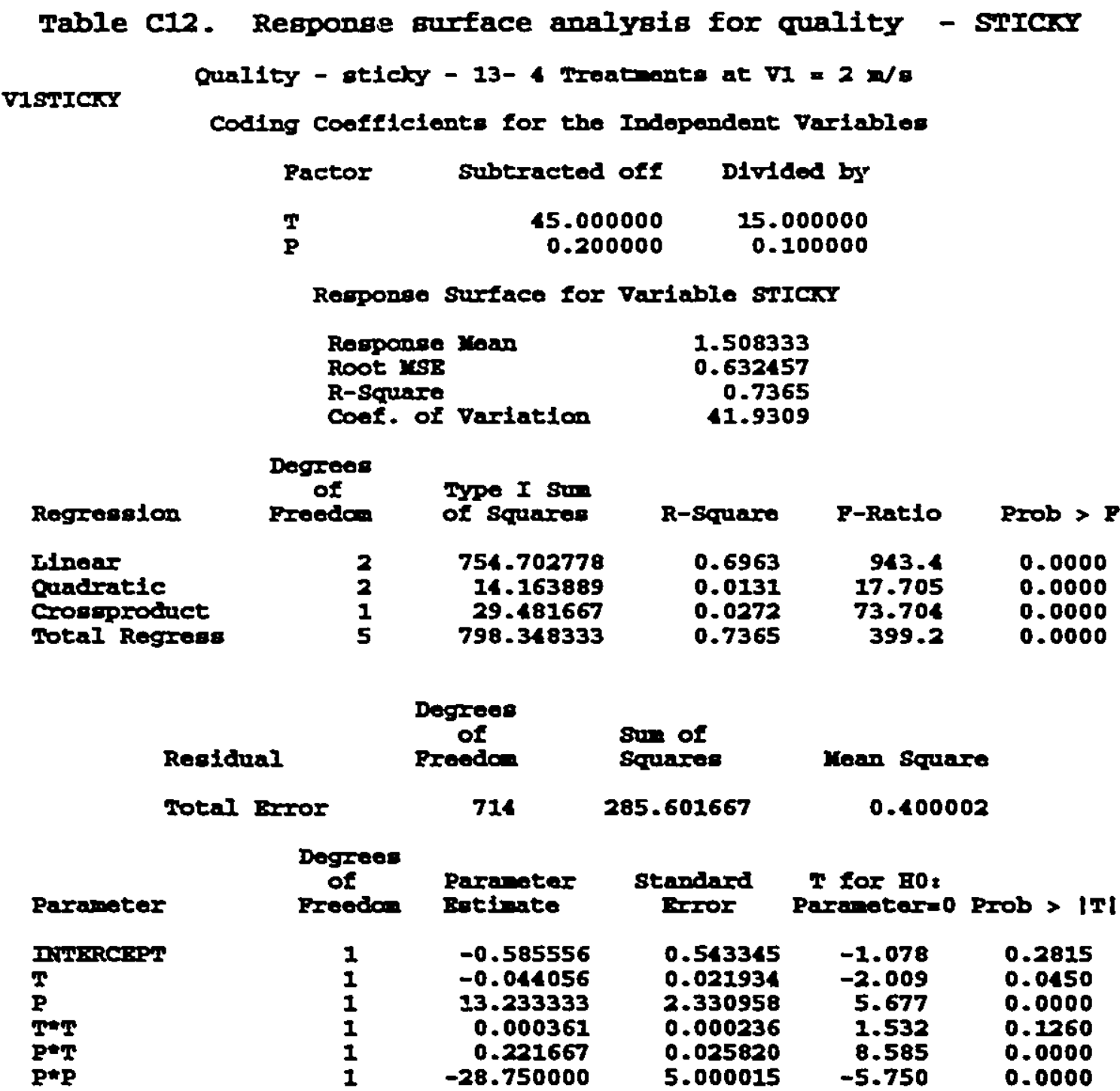

Paramater Retinate fron coded Data

$$
\begin{array}{r}
1.654861 \\
0.491667 \\
1.170833 \\
0.081250 \\
0.332500 \\
-0.287500
\end{array}
$$

\begin{tabular}{|c|c|c|c|c|c|}
\hline Pactor & $\begin{array}{c}\text { Dogrees: } \\
\text { of } \\
\text { Preedom }\end{array}$ & $\begin{array}{l}\text { Sum of } \\
\text { squares }\end{array}$ & Mean Square & P-Rat10 & Prob > P \\
\hline$T$ & $\begin{array}{l}3 \\
3\end{array}$ & $\begin{array}{l}127.115000 \\
700.715000\end{array}$ & $\begin{array}{r}12.371667 \\
233.571667\end{array}$ & $\begin{array}{l}205.9 \\
583.9\end{array}$ & $\begin{array}{l}0.0000 \\
0.0000\end{array}$ \\
\hline
\end{tabular}




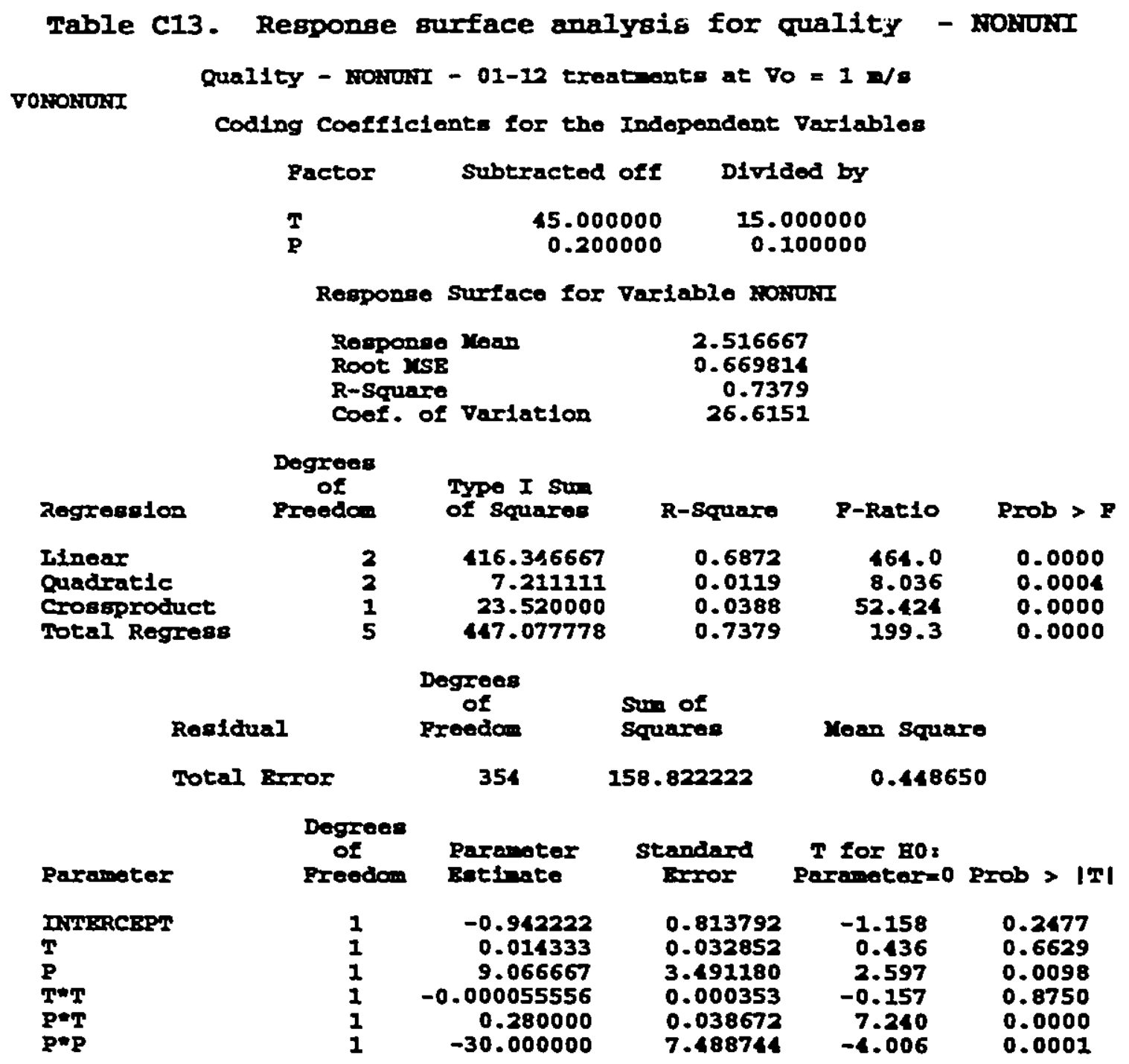

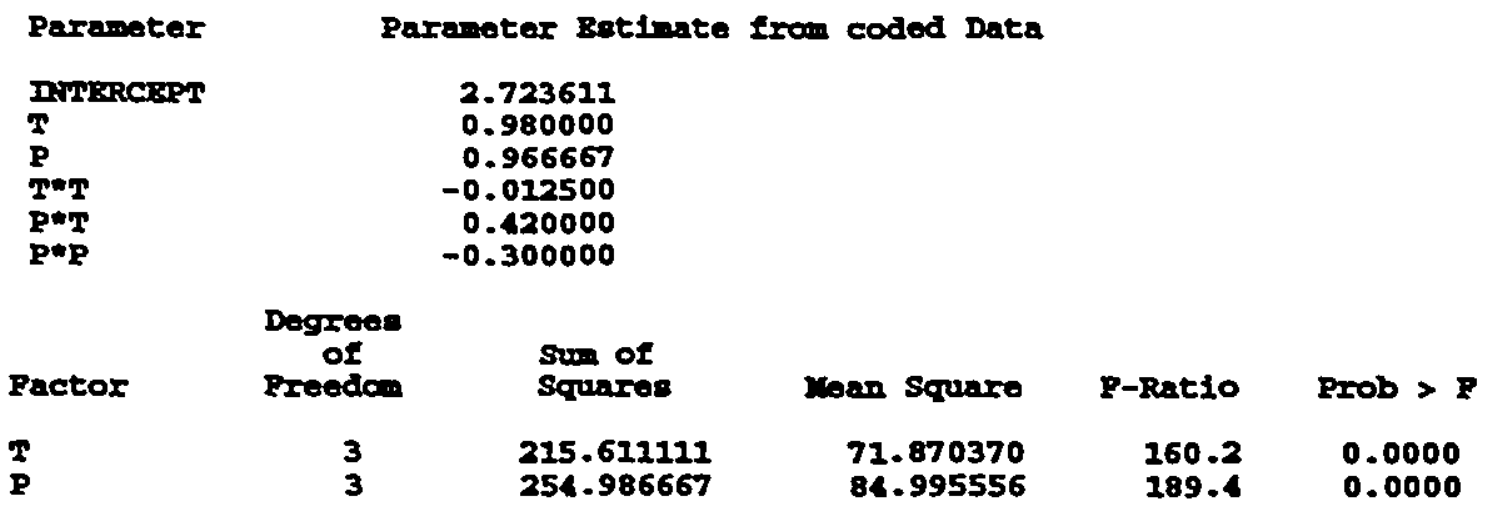




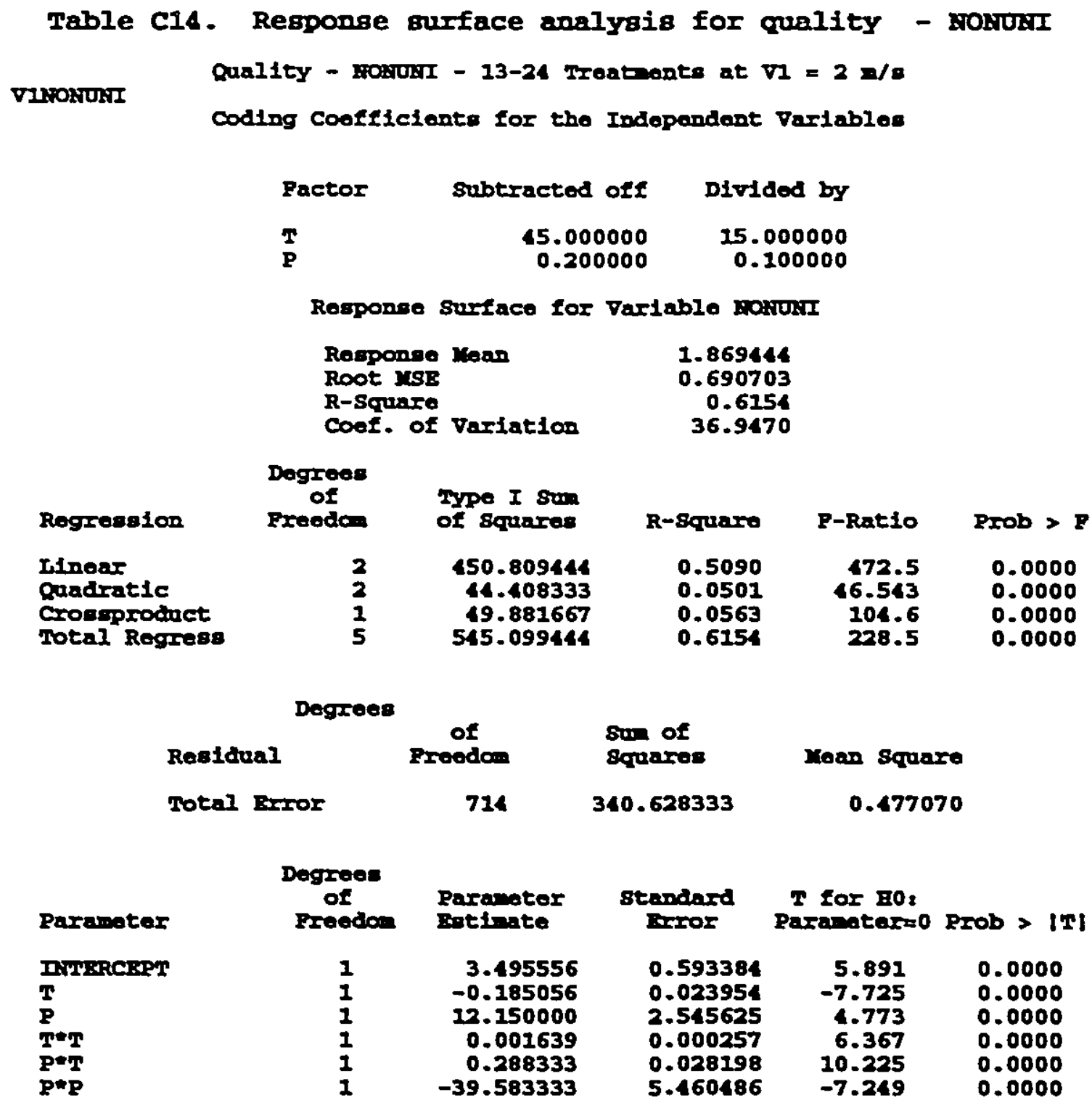

\begin{tabular}{|c|c|}
\hline Parameter & Paranoter Eot \\
\hline 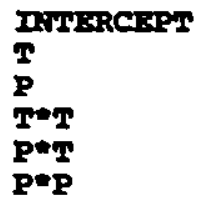 & $\begin{array}{r}1.928472 \\
0.301667 \\
0.929167 \\
0.368750 \\
0.432500 \\
-0.395833\end{array}$ \\
\hline
\end{tabular}

\begin{tabular}{|c|c|c|c|c|c|}
\hline actor & $\begin{array}{c}\text { Degrees } \\
\text { of } \\
\text { Ereedon }\end{array}$ & $\begin{array}{l}\text { Swa of } \\
\text { squares }\end{array}$ & roan square & P-Ratio & Prob > E \\
\hline ? & $\begin{array}{l}3 \\
3\end{array}$ & $\begin{array}{l}105.621667 \\
489.359444\end{array}$ & $\begin{array}{r}35.207222 \\
163.119815\end{array}$ & $\begin{array}{r}73.799 \\
341.9\end{array}$ & $\begin{array}{l}0.0000 \\
0.0000\end{array}$ \\
\hline
\end{tabular}


Table C15. Regponse gurface analysis for quality - TIMB

VoTno:

guality - PIOB - 01-12 Treatments at $\nabla 0=1 \mathrm{~m} / \mathrm{s}$

coding Coofflciente for the Independent Varlables

Pactor subtractod off Dividod by

T $\quad 45.000000 \quad 15.000000$

$P \quad 0.200000 \quad 0.100000$

Responso surface for variablo TIOK

Response Naan

Root MSB

$R$-square

Coof. of Variation

Degrees

of

Regression

Freeda.

Iinear

Gaadratlc

Croseproduct

Total Regrese
Type I su. of Squares

\section{2}

2

1
1267.413289
3.611111

0.685247

0.8841

18.9761

$$
\text { R-square }
$$

0.6714

0.0988

0.1138

0.8841
P-Rat 10

1025.0

150.8

347.5

539.8

\section{Dogrees:}

of

Residual

Total Brox

swe of

squares

354

165.225626

standard

Error

IINTXRCEPW

T

$\mathbf{P}$

TreT

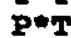

$\mathbf{P} \bullet \mathbf{P}$

Parameter

Dirmatcesp

T

D

TheT

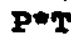

$\mathbf{P} \boldsymbol{P}$ betimate

Degrees of

$1 \quad 29.662539$

$1 \quad-0.679292$

$1 \quad-82.041333$

$1 \quad 0.004769$

$1 \quad 0.737483$

$1 \quad 86.454167$

\subsection{3 \\ 0.033609 \\ 3.571622 \\ 0.000361 \\ 0.039563 \\ 7.661298}

Paraneter Eotinate from coded Data

\subsection{9}

$-1.538933$

$-1.427292$

1.073000

1.106225

0.864542
Leas Square

$$
0.469564
$$

Prob > F

0.0000

0.0000

0.0000

0.0000

T for $\mathrm{EO}:$

Parameter=0 Prob > |TI

\begin{tabular}{|c|c|c|c|c|c|}
\hline Factor & $\begin{array}{c}\text { Degrees } \\
\text { of } \\
\text { Preodan }\end{array}$ & $\begin{array}{l}\text { su of } \\
\text { squares }\end{array}$ & Hoan Squaxe & P-Ratio & Prob > $P$ \\
\hline $\begin{array}{l}\mathbf{T} \\
\mathbf{P}\end{array}$ & $\begin{array}{l}3 \\
3\end{array}$ & $\begin{array}{l}718.699945 \\
711.877844\end{array}$ & $\begin{array}{l}239.566648 \\
237.292615\end{array}$ & $\begin{array}{l}510.2 \\
505.3\end{array}$ & $\begin{array}{l}0.0000 \\
0.0000\end{array}$ \\
\hline
\end{tabular}

$\begin{array}{rr}35.629 & 0.0000 \\ -20.212 & 0.0000 \\ -22.970 & 0.0000 \\ 13.204 & 0.0000 \\ 18.641 & 0.0000 \\ 11.285 & 0.0000\end{array}$


Table C16. Regponse surface analysis for quality - TInB

VITINC

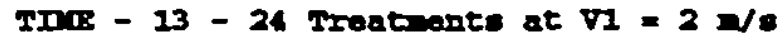

coding coafficients for the Independent Variables

Pactor subtracted off Difided by

$\begin{array}{lrr}T & 45.000000 & 25.000000 \\ P & 0.200000 & 0.100000\end{array}$

Response surface for Varlable rIR

$\begin{array}{lr}\text { Romponse Jean } & 5.425944 \\ \text { Root uSE } & 0.359878 \\ \text { R-square } & 0.9771 \\ \text { Coaf. of Varlation } & 6.6325\end{array}$

\begin{tabular}{|c|c|c|c|c|c|}
\hline ogreseion & $\begin{array}{c}\text { Degrees } \\
\text { of } \\
\text { Proedon }\end{array}$ & $\begin{array}{l}\text { Type I sut } \\
\text { of souaras }\end{array}$ & $R$-Square & P-Ratio & P2ob > $P$ \\
\hline $\begin{array}{l}\text { Inear } \\
\text { Quadratic } \\
\text { Crovaproduct } \\
\text { Total Regrese }\end{array}$ & $\begin{array}{l}2 \\
2 \\
1 \\
5\end{array}$ & $\begin{array}{r}1712.097930 \\
87.079630 \\
155.289685 \\
1954.467246\end{array}$ & $\begin{array}{l}0.8559 \\
0.0635 \\
0.0776 \\
0.9771\end{array}$ & $\begin{array}{r}6609.8 \\
336.2 \\
1199.0 \\
3018.2\end{array}$ & $\begin{array}{l}0.0000 \\
0.0000 \\
0.0000 \\
0.0000\end{array}$ \\
\hline
\end{tabular}

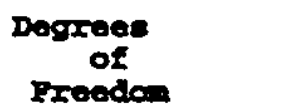

354
Residua:

Total Arer
Sw of squares

45.847353

standard T for $\mathrm{BO}$

Error Peraneter=0 Prob > ITI

\begin{tabular}{|c|c|c|}
\hline Parameter & Freedon & Retdace \\
\hline 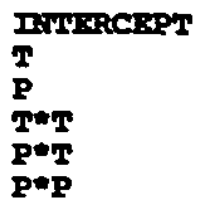 & $\begin{array}{l}1 \\
1 \\
1 \\
1 \\
1 \\
1\end{array}$ & $\begin{array}{r}30.434356 \\
-0.562234 \\
-81.541000 \\
0.002871 \\
0.719467 \\
84.716667\end{array}$ \\
\hline
\end{tabular}

$\begin{array}{lrl}0.437235 & 69.606 & 0.0000 \\ 0.017651 & -31.853 & 0.0000 \\ 1.875744 & -43.471 & 0.0000 \\ 0.000190 & 15.134 & 0.0000 \\ 0.020778 & 34.627 & 0.0000 \\ 4.023560 & 21.055 & 0.0000\end{array}$

Paramater

DAMGRCGPT

T.

$\mathbf{P}$

PmT

$\mathbf{p} \oplus \mathbf{T}$

$\mathbf{P} \approx \mathbf{P}$

Degreas
of
Pactor

T

$\mathbf{P}$

Freeda

3

Paramater Betinate from coded Data

$$
\begin{array}{r}
1.502347 \\
-2.399867 \\
-1.527833 \\
0.615875 \\
1.079200 \\
0.847167
\end{array}
$$

$$
\text { sin of }
$$$$
\text { 8quara: }
$$

1336.826010

772.930921
Mana square
445.608670
257.643640

$\begin{array}{rr}\text { P-Ratio } & \text { Prob }>E \\ 3440.7 & 0.0000 \\ 1989.3 & 0.0000\end{array}$


Appondtx C

Table C17. vulti-comparison Test for ABYB

General Itnea: Modele Procedure

Clase Lovel Inforantion

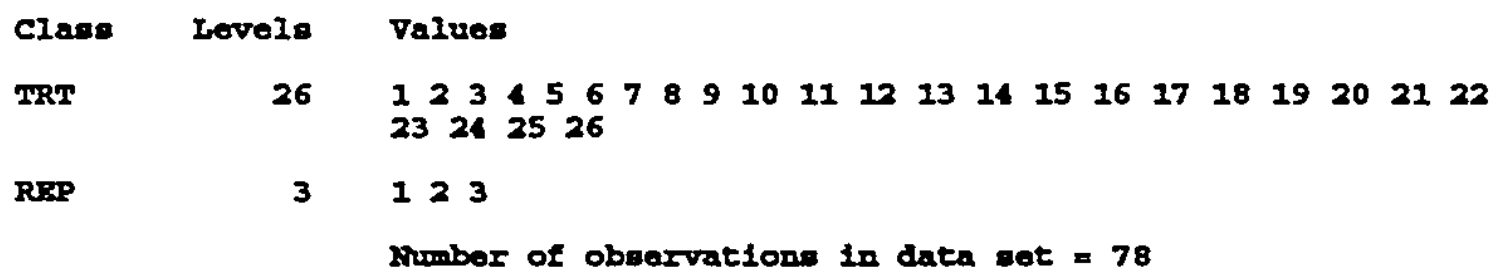

$\begin{array}{rrrrr}25 & 0.23182812 & 0.00927312 & 373.41 & 0.0001 \\ 2 & 0.00007764 & 0.00003882 & 1.56 & 0.2195\end{array}$

Trukey's Studantized Range (ESD) Teat for varlables ABYB NOTB: This test costrols tho type I experimenturise error rate, but generally has a hlgher type II error rate than Rbein.

$\lambda I$ pba $=0.05$ af $=50$ MSE $0.00 n 025$

Crltical value of studentired Range- 5.504

Minim sigenflcant Differencer 0.0158

Means with the sane letter are not elgolftcantly different. Tukey Grouping

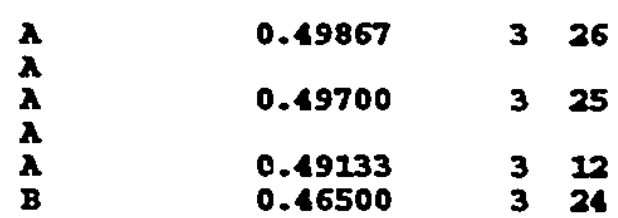




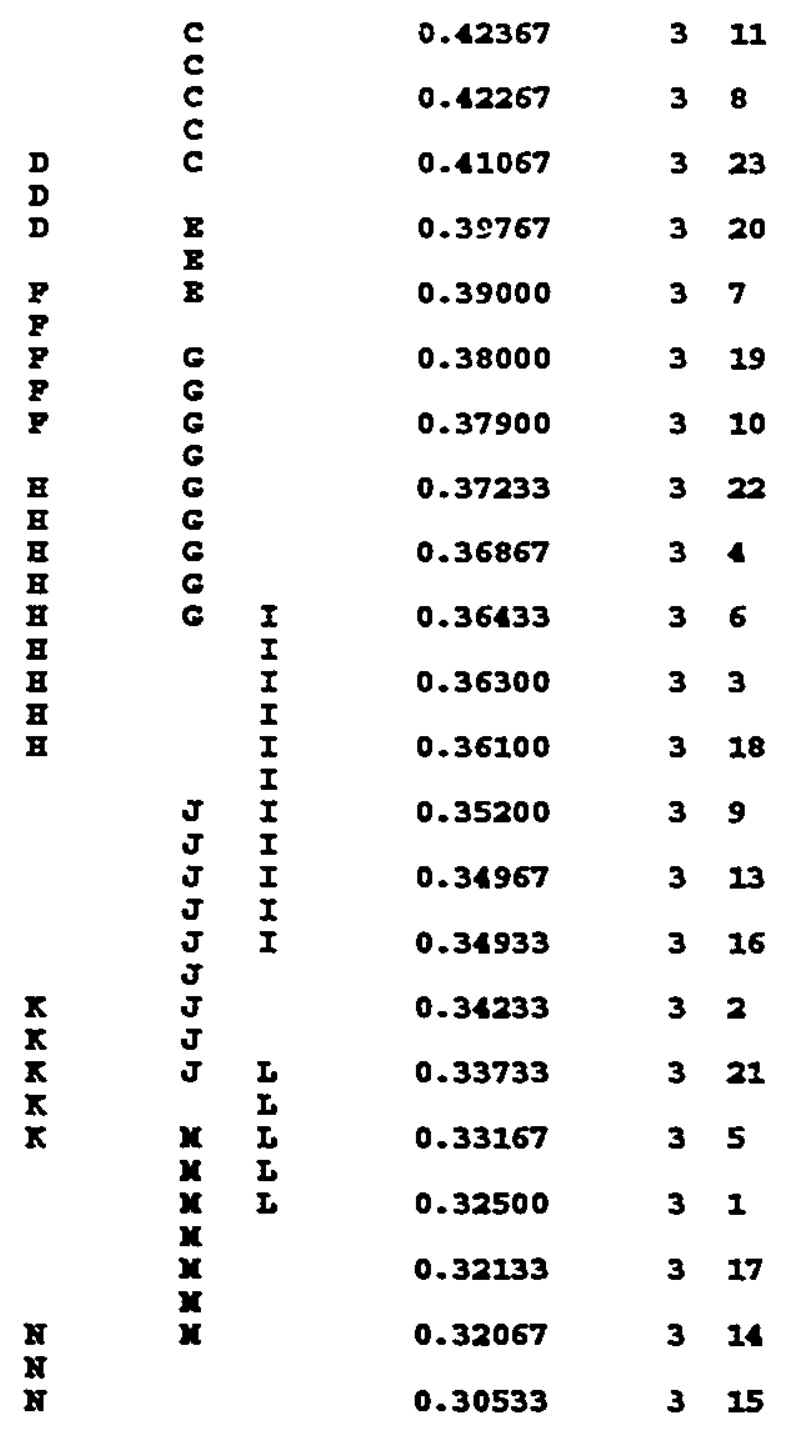

Tukey's Student1xed Range (HSD) Test for variables ABYB

NOIR: This test controls the type I experimentwide erxor rate, bat generally has a higher type II orror rate than REewo.

Alpha 0.05 df $=50$ usE 0.000025

Critical value of studentised Rargo= 3.416

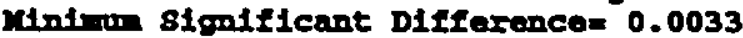

Yoane with the sawe letter are not eignificantly different.

Tukey Groupling

$\mathbf{A}$

$\mathbf{A}$

$\lambda$

$\hat{\mathbf{\lambda}}$
Man $A$ TRT

$\begin{array}{lll}0.38227 & 26 & 2 \\ 0.38219 & 26 & 1 \\ 0.38012 & 26 & 3\end{array}$


Appendix C

Table C18. Nalt1-Comorison Test for DNyGE

Caneral Ithear Modele Procedure

clase tovel Infomintion

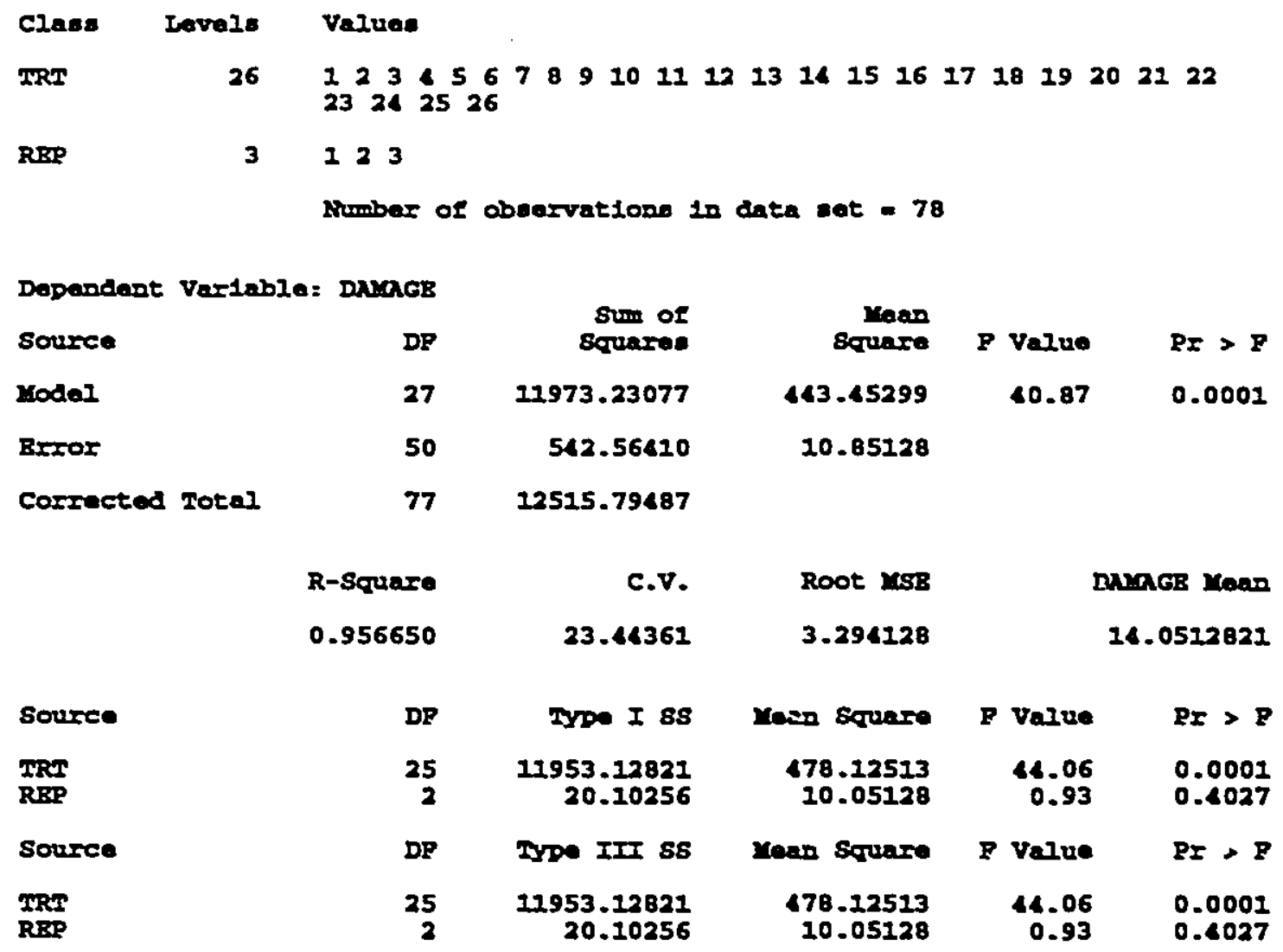

Tukey': studentized Range (BSD) Tast for varlable: DNaGB

NoTB: Thls test controle the type I experdmentwl we error rate, but venerally bas a blgher type II erxor rate than RBGie.

Xlpha $=0.05$ de $50 \mathrm{msBm} 10.85128$

Criticel Value of Btudantized Rangen 5.504

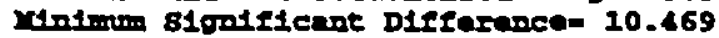

Wase with the ane letter are not aloniflcantly differant.

Tukey Grouplog

$\begin{array}{rll}\text { man } & \text { II } & \text { TRT } \\ 51.667 & 3 & 12 \\ 33.333 & 3 & 24\end{array}$

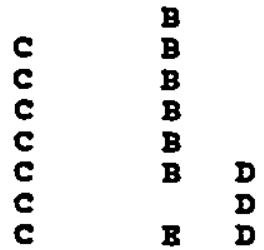

$\begin{array}{lll}32.000 & 3 & 11 \\ 31.667 & 3 & 8 \\ 26.667 & 3 & 10 \\ 21.667 & 3 & 23\end{array}$




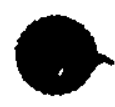

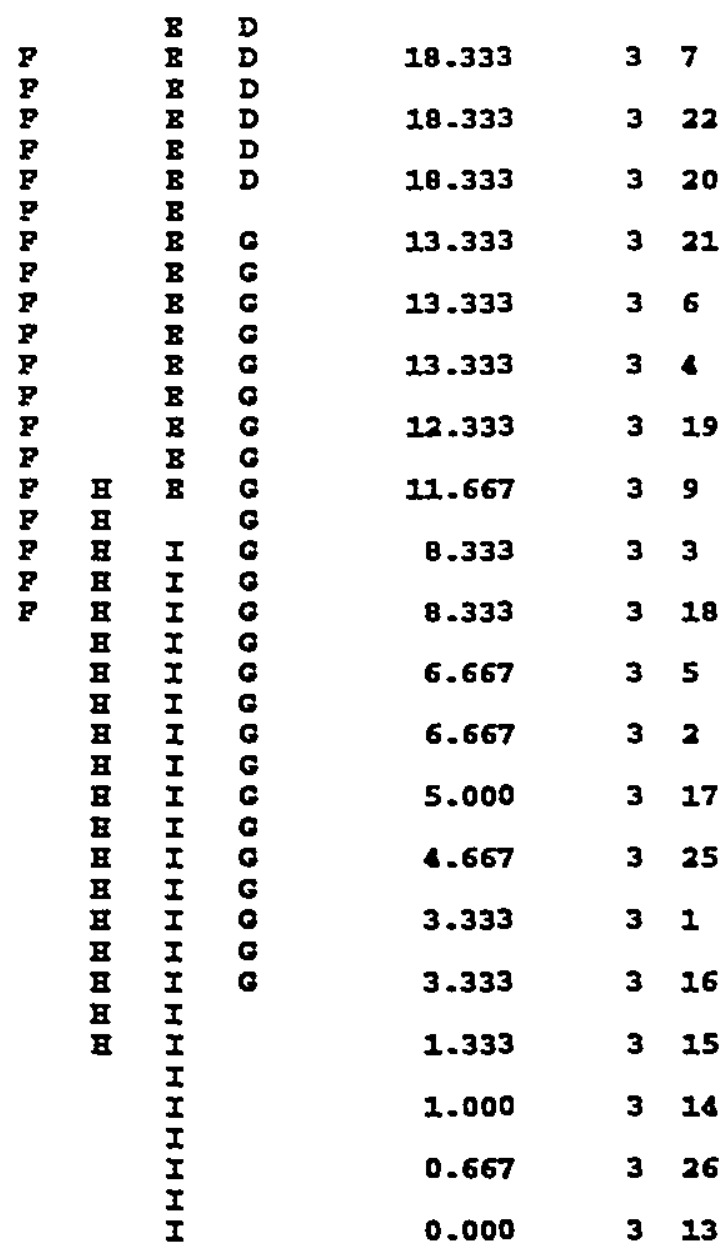

Tukey': student1zed Range (BSD) Teat for varlable: DunGB

NOMB = This teat controls the type I expartmantwdee error rate, but gabarally has a blober type II error rate than RBGiv.

Alphan= 0.05 ar $=50$ msB= 10.85128

Crltical Velue of studantized Range- 3.416

vintmin 81outficant Differance= 2.2069

wane with the same letter are not alopielcantly differant.

Tukey Grouplog

Inan $\mathrm{N}$ MRT

$\begin{array}{llll}\mathbf{\lambda} & 14.769 & 26 & 1 \\ \mathbf{\lambda} & 13.692 & 26 & 2 \\ \mathbf{\lambda} & 13.692 & 26 & 3\end{array}$


Table C19. Computer Program to generate data and draw contours against $P$ and $T$ for quality attributes with imposed restrictions on Dmage and ABYB.

TIILE: 'CP_QUALTY AT VI = 2 MS - DAMAGE, ABYB, TIME WTH RESTRICTION DAMAGE 10\%, ABYB 0.342;

\section{DATA CONTOURS;}

FORMAT DAM 8.5 ABYB 8.5;

DO T $=-1.0$ TO +1.0 BY 0.01;

$D O P=-2$ TO + 1.0 BY 0.01;

$\mathrm{DAM}=0.6387+0.2075^{\circ} \mathrm{T}+0.3869^{\circ} \mathrm{P}-0.0083^{\circ} \mathrm{T} T+0.0455^{\circ} \mathrm{P} T-0.0650^{\circ} \mathrm{P} P$;

DAM = (SIN(DAM/2) $)^{-\infty}$;

$A B Y B=1.2816+0.0671^{\circ} \mathrm{T}+0.0676^{\circ} \mathrm{P}+0.0271^{\circ} \mathrm{T} T+0.0672^{\circ} \mathrm{P}^{\circ} \mathrm{T}-0.0030^{\circ} \mathrm{P}^{\circ} \mathrm{P}$;

$A B Y B=(\operatorname{SIN}(A B Y B / 2))^{\infty} 2 ;$

TIME = 4.5023-2.3999 $T-1.5278^{\circ} \mathrm{P}+0.6459^{\circ} \mathrm{T} T+1.0792^{\circ} \mathrm{P} T+0.8472^{\circ} \mathrm{P} P$;

$\mathrm{P} 1=\mathrm{P}^{0} 0.1+0.2 ; \mathrm{T} 1=\mathrm{T}^{*} 150+45.0 ;$

OUTPUT;

END;

END;

DATA TWO; SET CONTOURS;

IF DAM> $=0.1$ THEN DELETE;

IF $A B Y B>=0.342$ THEN DELETE;

PROC PLOT;

PLOT T1"P1 = DAM / CONTOUR=10; PLOT T1"P1 = ABYB / CONTOUR=10;

PLOT TI"P1 = TIME / CONTOUR=10 ;

RUN; 